\title{
FINITE ELEMENT ANALYSIS AND EXPERIMENTAL VALIDATION OF REINFORCED CONCRETE SINGLE-MAT SLABS SUBJECTED TO BLAST LOADS
}

\author{
A THESIS IN \\ Civil Engineering \\ Submitted to the Faculty of the University of \\ Missouri-Kansas City in partial fulfillment of \\ requirements for the degree of \\ MASTER OF SCIENCE
}

\author{
by \\ Gunjan Ashok Shetye \\ Bachelor of Civil Engineering (B.E.) \\ University of Mumbai - Sardar Patel College of Engineering
}

University of Missouri-Kansas City

2012-13 
Copyright (C) by Gunjan Ashok Shetye

2012-13 


\title{
FINITE ELEMENT ANALYSIS AND EXPERIMENTAL VALIDATION OF REINFORCED \\ CONCRETE SINGLE-MAT SLABS SUBJECTED TO BLAST LOADS
}

\author{
Gunjan Ashok Shetye, Candidate for the Master of Science Degree, \\ University of Missouri- Kansas City
}

\begin{abstract}
The work done in this research is to study the response of reinforced concrete slabs subjected to blast loading as they can be used as protective structures around the main structure. An experimental investigation has been performed in a separate study involving blast-testing of 12 reinforced concrete slabs in a shock tube (Blast Load Simulator). The data from this experimental investigation was made available for performing advanced finite element analysis done in this research to study the behavior of these slabs towards blast loading.

A non-linear transient dynamic finite element analysis program LS-DYNA ${ }^{\circledR}$ is used for this study. The finite element models of these 12 slab panels are developed in LS-DYNA ${ }^{\circledR}$ and blast pressures equivalent to those generated in the experiment are applied to them. These slabs include two material combinations based on their strength namely, the high-strength concrete reinforced with high-strength steel slabs and normal-strength concrete reinforced with normalstrength steel slabs. The primary objective is to study the response of material combinations to blast loading by using two different concrete material models available in LS-DYNA namely, Winfrith Concrete Model and Concrete Damage Model Release 3 and comparing it with the experimental results. Validation of these models with experimental data will provide a
\end{abstract}


numerical analysis procedure which will be less expensive and safer than performing blast testing.

On performing this study, finite element analysis and experimental validation of reinforced concrete single-mat slabs subjected to blast loading it is concluded that the Winfrith Concrete Model predicts a better response in terms of deflection and crack propagation for both normal and high strength concrete. Concrete Damage Model Release 3 needs additional parameters to be defined based on concrete laboratory testing data for it to predict a better response in the normal-strength and high-strength category. These additional parameters have been developed and recommended in this study. 


\section{APPROVAL PAGE}

The faculty listed below, appointed by the Dean of the School of Computing and Engineering have examined a thesis titled "Finite Element Analysis and Experimental Validation of Reinforced Concrete Single-Mat Slabs Subjected to Blast Loads," presented by Gunjan Ashok Shetye, candidate for Master of Science in Civil Engineering, and certify that in their opinion it is worthy of acceptance.

\section{Supervisory Committee}

Ganesh Thiagarajan, Ph.D., P.E., Committee Chair

Departmentof Civil and Mechnical Engineering

Ceki Halmen, Ph.D., P.E.

Departmentof Civil and Mechnical Engineering

ZhiQiang Chen, Ph.D.

Departmentof Civil and Mechnical Engineering 


\section{TABLE OF CONTENTS}

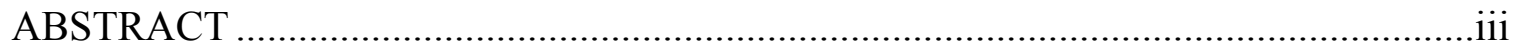

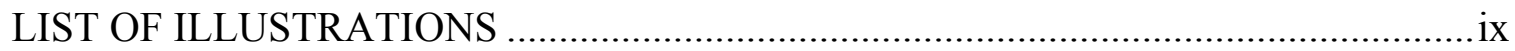

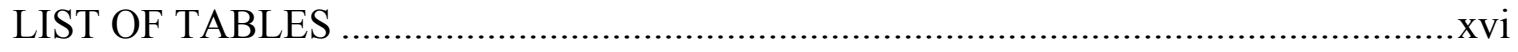

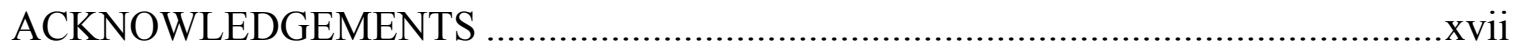

CHAPTER

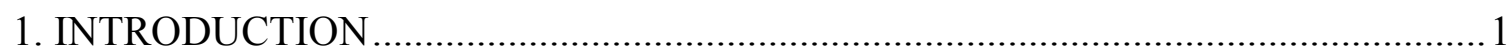

1.1 An Overview on Blast Effects on Structures .............................................. 1

1.2 Significance of Studying Blast Effects on Reinforced Concrete Slabs ............2

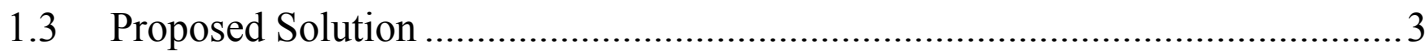

1.4 Thesis Organization ....................................................................................

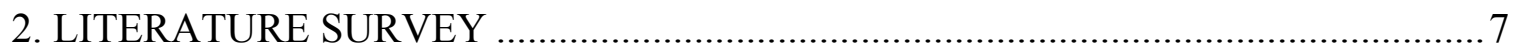

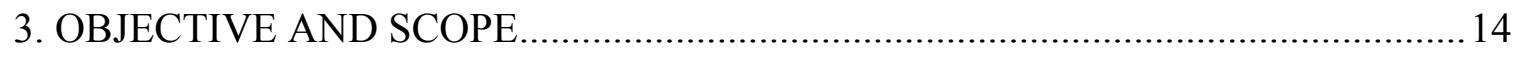

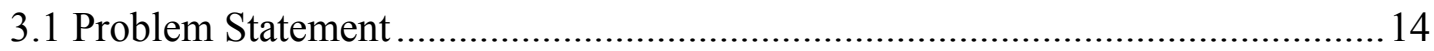

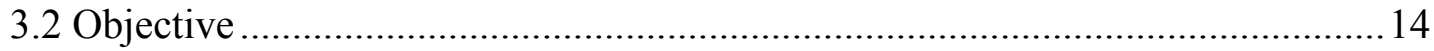

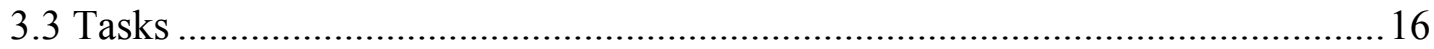

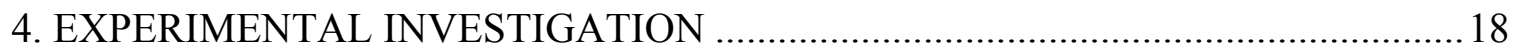

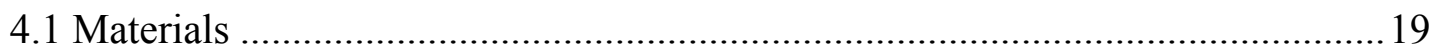

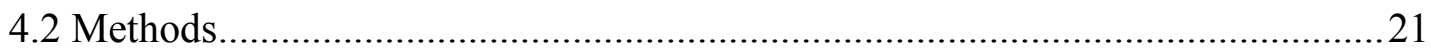

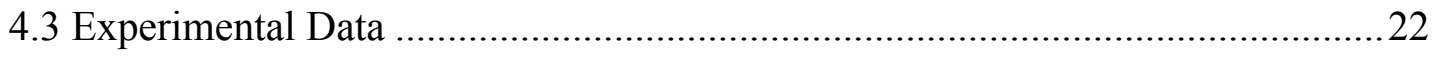


5.1 Significance of Numerical Modeling in LS-DYNA®

5.2 Geometric Models. 25

5.3 Boundary Conditions 32

5.4 Material Models in LS-DYNA® .35

5.5 Blast Load Application in LS-DYNA ${ }^{\circledR}$. 50

6. NUMERICAL analysis RESULTS and comparison with Experiments 52

6.1 Comparison Criterion 1; Peak Deflection for Slab. 52

6.2 Comparison Criterion 2; Crack Propagation Study

7. DISCUSSION OF RESULTS 128

7.1 High-Strength Concrete - Comparison of Model with 1 in. (25.4 mm.) Mesh to $1 / 2$ in. (12.7 mm.) Mesh Model. 128

7.2 High Strength Concrete - Comparison of Winfrith Concrete Model with Concrete Damage Release 3. 129

7.3 Normal Strength Concrete - Comparison of model with 1 in. (25.4 mm.) mesh to $1 / 2$ in. $(12.7 \mathrm{~mm}$.) mesh model. 129

7.4 Normal Strength Concrete - Comparison of Winfrith Concrete Model with Concrete Damage Release 3. 130

7.5 Comparison of High Strength Material with Normal Strength Material. 130

7.6 Comparison of Slabs with 4 in. (101.6 mm.) c/c Longitudinal Steel to 8 in. (203.2 $\mathrm{mm}$.) c/c Longitudinal Steel. 131

7.7 Comparison for validation of numerical analysis by studying damage response 132

8. CONCLUSIONS AND FUTURE WORK 133 
8.1 Future Scope of Work

APPENDIX A - Pressure and Impulse Data for 12 Slabs ......................................... 136

APPENDIX B - Pressure and Impulse Plots for 12 RC Slabs .................................... 137

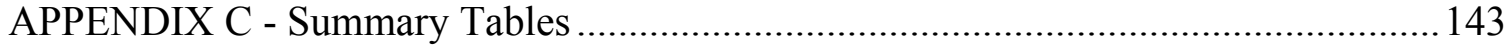

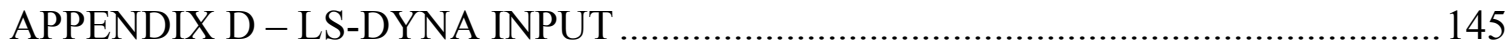

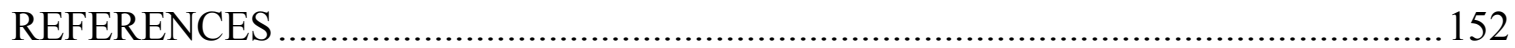

VITA 


\section{LIST OF ILLUSTRATIONS}

Figure

Page

4-1: Reinforced Concrete Slab with 4 in. Type Single Layer of Steel 20

4-2: Reinforced Concrete Slab with 8 in. Type Single Layer of Steel 20

4-3 : Blast Load Simulator (Shock Tube) at US Army ERDC 21

4-4: Post-test damage patterns observed on Slab \# 7 23

5-1: Single-Mat Reinforced Concrete slab model with Solid Elements 1 in. (25.4 mm.) mesh size .27

5-2: Single-Mat Reinforced Concrete slab model with Solid Elements $1 / 2$ in. (12.7 mm.) mesh size. .27

5-3: Single-Mat Reinforced Concrete slab model with Solid Elements 1/4 in. (6.35 mm.) mesh size. .28

5-4: Single layer reinforcement in 4 in. type single-mat RC slab .28

5-5: Single layer reinforcement in 8 in. type single-mat RC slab 29

5-6: Boundary conditions on the front face of slab 33

5-7: Boundary conditions on the back face of the slab 34

5-8: Boundary conditions on the top and bottom face of the slab.

5-9 : Pressure Versus Volumetric Strain Curve for Equation of State Form 8 with compaction for $11.6 \mathrm{ksi}$ concrete. .48

5-10 Pressure Versus Volumetric Strain Curve for Equation of State Form with compaction for 5 Ksi concrete.

6-1: Deflection Comparison between 1 in. $(25.4 \mathrm{~mm}$.) and 1/2 in. (12.7 mm.) mesh sizes for Concrete Damage Model Release 3 and Experimental Deflection for Slab\#1 - HSC-V1-4in.....56 
6-2: Deflection Comparison between 1 in. $(25.4 \mathrm{~mm}$.) and 1/2 in. (12.7 mm.) mesh sizes for Winfrith Concrete Model and Experimental Deflection for Slab\#1 - HSC-V1-4in. .57

6-3: Deflection Comparison between Concrete Damage Model Release 3 and Winfrith Concrete for 1 in. (25.4 mm.) mesh model with Experimental Deflection for Slab\#1 - HSC-V1-4in. ........58

6-4: Deflection Comparison between Concrete Damage Model Release 3 and Winfrith Concrete for 1/2 in. (12.7 mm.) mesh model with Experimental Deflection for Slab\#1 - HSC-V1-4in. ....59

6-5: Deflection Comparison between 1 in. $(25.4 \mathrm{~mm}$.) and 1/2 in. $(12.7 \mathrm{~mm}$.) mesh sizes for Concrete Damage Model Release 3 and Experimental Deflection for Slab\#3 - HSC-V2-4in. ....60

6-6: Deflection Comparison between 1 in. $(25.4 \mathrm{~mm}$.) and 1/2 in. $(12.7 \mathrm{~mm}$.) mesh sizes for Winfrith Concrete Model and Experimental Deflection for Slab\#3 - HSC-V2-4in.

6-7: Deflection Comparison between Concrete Damage Model Release 3 and Winfrith Concrete for 1 in. (25.4 mm.) mesh model with Experimental Deflection for Slab\#3 - HSC-V2-4in.

6-8: Deflection Comparison between Concrete Damage Model Release 3 and Winfrith Concrete for 1/2 in. (12.7 mm.) mesh model with Experimental Deflection for Slab\#3 - HSC-V2-4in. ....63

6-9: Deflection Comparison between Concrete Damage Model Release 3 and Winfrith Concrete for 1 in. (25.4 mm.) mesh model with Experimental Deflection for Slab\#1 - HSC-V1-4in and Slab\#3 - HSC-V2-4in. .63

6-10 : Deflection Comparison between 1 in. $(25.4 \mathrm{~mm}$.) and 1/2 in. (12.7 mm.) mesh sizes for Concrete Damage Model Release 3 and Experimental Deflection for Slab\#5 - HSC-V3-4in. ....65

6-11: Deflection Comparison between 1 in. $(25.4 \mathrm{~mm}$.) and $1 / 2$ in. $(12.7 \mathrm{~mm}$.) mesh sizes for Winfrith Concrete Model and Experimental Deflection for Slab\#5 - HSC-V3-4in. .66

6-12: Deflection Comparison between Concrete Damage Model Release 3 and Winfrith Concrete for 1 in. (25.4 mm.) mesh model with Experimental Deflection for Slab\#5 - HSC-V3-4in. 68

6-13: Deflection Comparison between Concrete Damage Model Release 3 and Winfrith Concrete for 1/2 in. (12.7 mm.) mesh model with Experimental Deflection for Slab\#5 - HSC-V3-4in. ....68

6-14: Deflection Comparison between 1 in. $(25.4 \mathrm{~mm}$.) and 1/2 in. $(12.7 \mathrm{~mm}$.) for mesh sizes for Concrete Damage Model Release 3 and Experimental Deflection for Slab\#7 - HSC-V4-8in. .... 69

6-15: Deflection Comparison between 1 in. $(25.4 \mathrm{~mm}$.) and $1 / 2$ in. $(12.7 \mathrm{~mm}$.) mesh sizes for Winfrith Concrete Model and Experimental Deflection for Slab\#7 - HSC-V4-8in. .70 
6-16: Deflection Comparison between Concrete Damage Model Release 3 and Winfrith Concrete for 1 in. (25.4 mm.) mesh model with Experimental Deflection for Slab\#7 - HSC-V4-8in. ........72

6-17: Deflection Comparison between Concrete Damage Model Release 3 and Winfrith Concrete for 1/2 in. (12.7 mm.) mesh model with Experimental Deflection Slab\#7 - HSC-V4-8in............72

6-18: Deflection Comparison between Concrete Damage Model Release 3 and Winfrith Concrete for 1 in. $(25.4 \mathrm{~mm}$.) mesh model with Experimental Deflection for Slab\#5 - HSC-V3-4in. and Slab\#7 - HSC-V4-8in. .73

6-19: Deflection Comparison between 1 in. $(25.4 \mathrm{~mm}$.) and $1 / 2$ in. $(12.7 \mathrm{~mm}$.) mesh sizes for Concrete Damage Model Release 3 and Experimental Deflection for Slab\#9 - HSC-V5-8in. ....75

6-20: Deflection Comparison between 1 in. $(25.4 \mathrm{~mm}$.) and $1 / 2$ in. $(12.7 \mathrm{~mm}$.) for mesh sizes Winfrith Concrete Model and Experimental Deflection for Slab\#9 - HSC-V5-8in. .76

6-21: Deflection Comparison between Concrete Damage Model Release 3 and Winfrith Concrete for 1 in. (25.4 mm.) mesh model with Experimental Deflection for Slab\#9 - HSC-V5-8in. ........77

6-22: Deflection Comparison between Concrete Damage Model Release 3 and Winfrith Concrete for 1/2 in. (12.7 mm.) mesh model with Experimental Deflection Slab\#9 - HSC-V5-8in .78

6-23: Deflection Comparison between 1 in. $(25.4 \mathrm{~mm}$.$) and 1 / 2$ in. $(12.7 \mathrm{~mm}$.) mesh sizes for Concrete Damage Model Release 3 and Experimental Deflection for Slab\#11-HSC-V6-8in....79

6-24: Deflection Comparison between 1 in. $(25.4 \mathrm{~mm}$.) and $1 / 2$ in. (12.7 mm.) mesh sizes for Winfrith Concrete Model and Experimental Deflection for Slab\#11 - HSC-V6-8in.

6-25: Deflection Comparison between Concrete Damage Model Release 3 and Winfrith Concrete for 1 in. (25.4 mm.) mesh model with Experimental Deflection for Slab\#11 - HSC-V6-8in. .....81

6-26: Deflection Comparison between Concrete Damage Model Release 3 and Winfrith Concrete for 1/2 in. (12.7 mm.) mesh model with Experimental Deflection Slab\#11 - HSC-V6-8in. .82

6-27: Deflection Comparison between Concrete Damage Model Release 3 and Winfrith Concrete for 1 in. (25.4 mm.) mesh model with Experimental Deflection for Slab\#9 - HSC-V5-8in and Slab\#11 - HSC-V6-8in. .82

6-28: Deflection Comparison between 1 in. $(25.4 \mathrm{~mm}$.) and 1/2 in. $(12.7 \mathrm{~mm}$.) mesh sizes for Concrete Damage Model Release 3 and Experimental Deflection for Slab\#2 - RSC-R1-4in. ....85

6-29: Deflection Comparison between 1 in. $(25.4 \mathrm{~mm}$.) and $1 / 2$ in. $(12.7 \mathrm{~mm}$.) mesh sizes for Winfrith Concrete Model and Experimental Deflection for Slab\#2 - RSC-R1-4in. .86 
6-30: Deflection Comparison between Concrete Damage Model Release 3 and Winfrith Concrete for 1 in. (25.4 mm.) mesh model with Experimental Deflection for Slab\#2 - RSC-R1-4in. .88

6-31: Deflection Comparison between Concrete Damage Model Release 3 and Winfrith Concrete for 1/2 in. (12.7 mm.) mesh model with Experimental Deflection Slab\#2- RSC-R1-4in. .88

6-32: Deflection Comparison between 1 in. $(25.4 \mathrm{~mm}$.) and $1 / 2$ in. $(12.7 \mathrm{~mm}$.) mesh sizes for Concrete Damage Model Release 3 and Experimental Deflection for Slab\#4 - RSC-R2-4in. ....89

6-33: Deflection Comparison between 1 in. $(25.4 \mathrm{~mm}$.) and $1 / 2$ in. $(12.7 \mathrm{~mm}$.) mesh sizes for Winfrith Concrete Model and Experimental Deflection for Slab\#4 - RSC-R2-4in. .90

6-34: Deflection Comparison between Concrete Damage Model Release 3 and Winfrith Concrete for 1 in. (25.4 mm.) mesh model with Experimental Deflection for Slab\#4 - RSC-R2-4in. .92

6-35: Deflection Comparison between Concrete Damage Model Release 3 and Winfrith Concrete for 1/2 in. (12.7 mm.) mesh model with Experimental Deflection Slab\#4- RSC-R2-4in.

6-36: Deflection Comparison between Concrete Damage Model Release 3 and Winfrith Concrete for 1 in. $(25.4 \mathrm{~mm}$.) mesh model with Experimental Deflection for Slab\#2 - RSC-R1-4in. and Slab\#4 - RSC-R2-4in. .93

6-37: Deflection Comparison between 1 in. $(25.4 \mathrm{~mm}$.$) and 1 / 2$ in. $(12.7 \mathrm{~mm}$.) for mesh sizes Concrete Damage Model Release 3 and Experimental Deflection for Slab\#6 - RSC-R3-4in. ....95

6-38: Deflection Comparison between 1 in. $(25.4 \mathrm{~mm}$.) and $1 / 2$ in. $(12.7 \mathrm{~mm}$.) mesh sizes for Winfrith Concrete Model and Experimental Deflection for Slab\#6 - RSC-R3-4in. .96

6-39: Deflection Comparison between Concrete Damage Model Release 3 and Winfrith Concrete for $1 \mathrm{in.}$ (25.4 mm.) mesh model with Experimental Deflection for Slab\#6 - RSC-R3-4in. .97

6-40: Deflection Comparison between Concrete Damage Model Release 3 and Winfrith Concrete for 1/2 in. (12.7 mm.) mesh model with Experimental Deflection Slab\#6- RSC-R3-4in. .98

6-41: Deflection Comparison between 1 in. $(25.4 \mathrm{~mm}$.) and 1/2 in. $(12.7 \mathrm{~mm}$.) mesh sizes for Concrete Damage Model Release 3 and Experimental Deflection for Slab\#8 - RSC-R4-8in. ....99

6-42 : Deflection Comparison between 1 in. $(25.4 \mathrm{~mm}$.) and 1/2 in. (12.7 mm.) mesh sizes for Winfrith Concrete Model and Experimental Deflection for Slab\#8 - RSC-R4-8in. 100

6-43: Deflection Comparison between Concrete Damage Model Release 3 and Winfrith Concrete for 1 in. (25.4 mm.) mesh model with Experimental Deflection for Slab\#8 - RSC-R4-8in. 101 
6-44: Deflection Comparison between Concrete Damage Model Release 3 and Winfrith Concrete for 1/2 in. (12.7 mm.) mesh model with Experimental Deflection for Slab\#8 - RSC-R4-8in. .. 102

6-45: Deflection Comparison between 1 in. (25.4 mm.) and 1/2 in. (12.7 mm.) mesh sizes for Concrete Damage Model Release 3 and Experimental Deflection for Slab\#10 - RSC-R5-8in. 103

6-46: Deflection Comparison between 1 in. (25.4 mm.) and 1/2 in. (12.7 mm.) mesh sizes for Winfrith Concrete Model and Experimental Deflection for Slab\#10 - RSC-R5-8in. 104

6-47: Deflection Comparison between Concrete Damage Model Release 3 and Winfrith Concrete for 1 in. (25.4 mm.) mesh model with Experimental Deflection for Slab\#10 - RSC-R5-8in..... 105

6-48: Deflection Comparison between Concrete Damage Model Release 3 and Winfrith Concrete for 1/2 in. (12.7 mm.) mesh model with Experimental Deflection for Slab\#10 - RSC-R5-8in. 106

6-49 : Deflection Comparison between 1 in. (25.4 mm.) and 1/2 in. (12.7 mm.) mesh sizes for Concrete Damage Model Release 3 and Experimental Deflection for Slab\#12 - RSC-R6-8in. 107

6-50: Deflection Comparison between 1 in. (25.4 mm.) and 1/2 in. (12.7 mm.) mesh sizes for Winfrith Concrete Model and Experimental Deflection for Slab\#12 - RSC-R6-8in. 108

6-51: Deflection Comparison between Concrete Damage Model Release 3 and Winfrith Concrete for 1 in. (25.4 mm.) mesh model with Experimental Deflection for Slab\#12 - RSC-R6-8in..... 109

6-52: Deflection Comparison between Concrete Damage Model Release 3 and Winfrith Concrete for 1/2 in. (12.7 mm.) mesh model with Experimental Deflection for Slab\#12 - RSC-R6-8in. 110

6-53: Deflection Comparison between Concrete Damage Model Release 3 and Winfrith Concrete for $1 \mathrm{in}$. (25.4 mm.) mesh model with Experimental Deflection for Slab\#10 - RSC-R5-8in. and Slab\#12 - RSC-R6-8in. 110

6-54: Damage crack patters for Slab \# 1 from (a) Concrete Damage Rel3 Model, (b) Experiment and (c) Winfrith Concrete Model 113

6-55: Damage crack patters for Slab \# 3 from (a) Concrete Damage Rel3 Model, (b) Experiment and (c) Winfrith Concrete Model 114

6-56: Damage crack patters for Slab \# 5 from (a) Concrete Damage Rel3 Model, (b) Experiment and (c) Winfrith Concrete Model 115

6-57: Damage crack patters for Slab \# 7 from (a) Concrete Damage Rel3 Model, (b) Experiment and (c) Winfrith Concrete Model 117 
6-58: Damage crack patters for Slab \# 9 from (a) Concrete Damage Rel3 Model, (b) Experiment and (c) Winfrith Concrete Model

6-59: Damage crack patters for Slab \# 11 from (a) Concrete Damage Rel3 Model, (b) Experiment and (c) Winfrith Concrete Model

6-60: Damage crack patters for Slab \# 2 from (a) Concrete Damage Rel3 Model, (b) Experiment and (c) Winfrith Concrete Model

6-61: Damage crack patters for Slab \# 4 from (a) Concrete Damage Rel3 Model, (b) Experiment and (c) Winfrith Concrete Model 122

6-62: Damage crack patters for Slab \# 6 from (a) Concrete Damage Rel3 Model, (b) Experiment and (c) Winfrith Concrete Model 123

6-63: Damage crack patters for Slab \# 8 from (a) Concrete Damage Rel3 Model, (b) Experiment and (c) Winfrith Concrete Model 125

6-64: Damage crack patters for Slab \# 10 from (a) Concrete Damage Rel3 Model, (b) Experiment and (c) Winfrith Concrete Model 126

6-65: Damage crack patters for Slab \# 12 from (a) Concrete Damage Rel3 Model, (b) Experiment and (c) Winfrith Concrete Model

B-1 : Average Pressure-time History for Slab \# 1.

B-2: Average Pressure-time History for Slab \# 2.

B-3: Average Pressure-time History for Slab \# 3

B-4: Average Pressure-time History for Slab \# 4.

B-5: Average Pressure-time History for Slab \# 5.

B-6: Average Pressure-time History for Slab \# 6.

B-7: Average Pressure-time History for Slab \# 7.

B-8: Average Pressure-time History for Slab \# 8. 140

B-9: Average Pressure-time History for Slab \# 9. 
B-10: Average Pressure-time History for Slab \# 10

B-11: Average Pressure-time History for Slab \# 11.....

B-12: Average Pressure-time History for Slab \# 12

D-1: Input and Output Control Parameters

D-2: Input Parameters for Concrete Damage Model Release 3 for High-Strength Concrete ..... 146

D-3: Input Parameters Generated by Concrete Damage Model Release 3 for High- Strength

Concrete

D-4: Input Parameters for Concrete Damage Model Release 3 for Normal-Strength Concrete .. 148

D-5: Input Parameters Generated by Concrete Damage Model Release 3 for High-Strength Concrete.

D-6: Input Parameters for Winfrith Concrete Model for High-Strength Concrete 150

D-7: Input Parameters for Winfrith Concrete Model for Normal-Strength Concrete 150

D-8: Input Parameters for Plastic-Kinematic Model for High-Strength Concrete. 150

D-9: Input Parameters for Plastic-Kinematic Model for High-Strength Concrete. 150

D-10: Input Parameters for Constrained Lagrange in Solid Formulation 151

D-11: Input Parameters for Mat Add Erosion Model. 


\section{LIST OF TABLES}

Table Page

4 1: Experimental program schedule. .18

4 2: Designations used in Experimental Program....................................................................19

5 1: Input variables provided in *MAT_WINFRITH_CONCRETE required for defining the plasticity model in Winfrith model for two different types of concrete. .40

5 2: Winfrith concrete model generated Volume Compaction curve for $11.6 \mathrm{ksi}$ and $5 \mathrm{ksi}$ concrete.

6 1: Analytical and Experimental Peak Slab Deflection Summary for High Strength

Slabs

6 2: Analytical and Experimental Residual Slab Deflection Summary for High Strength

Slabs

6 3: Analytical and Experimental Peak Slab Deflection Summary for Normal Strength

Slabs.

6 4: Analytical and Experimental Residual Slab Deflection Summary for Normal Strength

Slabs

6 5: Percentage Comparison of Peak Slab Deflections with the Experimental Value for High Strength

Slabs.

6 6: Percentage Change in Peak Slab Deflection when the Mesh Size was Reduced from 1 in. (25.4mm.) to $1 / 2$ in. (12.7 mm.) for High Strength Slabs. .55

6 7: Percentage comparison of deflections with the experimental value for normal strength slabs.

6 8: Percentage change in deflection when the mesh size was reduced from $1 \mathrm{in}$. $(25.4 \mathrm{~mm}$.) to $1 / 2$ in. (12.7 mm.) for normal strength slabs. . .84

C 1: Input Parameters for Winfrith Concrete Model. .143

C 2: Input parameters for Concrete Damage Model Release 3. .144

C 3: Input Parameters for Plastic Kinematic Model for Steel Rebar. 144 


\section{ACKNOWLEDGEMENTS}

It is a pleasure to thank all those who helped me to complete this thesis.

It is with immense gratitude that I acknowledge the guidance and encouragement of my advisor, Dr. Ganesh Thiagarajan throughout the length of my education and research at University of Missouri - Kansas City. His constant support and valuable insights made the completion of thesis possible.

I am grateful to Dr. Ceki Halmen and Dr. Zhiqiang Chen for serving as the members on the supervisory committee providing valuable inputs and suggestions. I am thankful to School of Computing and Engineering for providing necessary facilities to pursue research studies for this thesis.

I like to express my deepest gratitude to my senior lab mates Dr. Yun Kai Lu, Dr. Michael Eilers, Rasekh Rahimzadeh, Anirudha Kadmabi and Jitesh Nalagotla for their inspiring research work which motivated me and developed my interest in doing research and giving me the opportunity to learn from them. I am also thankful to all my wonderful lab mates Kevin Buck, Vidya Sridhar, Pranav Vishnumolakala, Qiwei Cao, Harsh Shah, Bhargav Javvaji, Mayuri Patil, Timothy Hines, Bhavani Ramneedi and Aritra for the fun and memorable moments in the research lab. I owe my sincere thanks to my dear friends Priya and Raghu for their moral support throughout my studies at UMKC.

I also wish to thank all my family members and friends for their support. Most importantly, I owe my loving thanks to my parents Ashok and Vidya Shetye, my brother Ruchir Shetye and my grandparents for their encouragement, patience and understanding throughout my studies abroad. To them I dedicate this thesis. 


\section{CHAPTER 1}

\section{INTRODUCTION}

\subsection{An Overview on Blast Effects on Structures}

The need to design blast resistant civilian structures has arisen due to aggressor attacks on many civilian structures around the world. The April $19^{\text {th }}$, 1995 Oklahoma City bombing incident which destroyed Alfred P. Murrah building and the February 26, 1993 bombing on the North tower building of World Trade Center in New York City are two of the many aggressor attacks from the past two decades [1]. The collapse of the structural elements notwithstanding the blast loading has been the reason behind claiming lives of the building inhabitants. In order to minimize the damage to structural systems in such event, an efficient design approach considering the blast loading design should be adopted. Although military structures have been designed for blast loading in the past, it has become important to develop design guidelines which are feasible for implementing in civilian structures as most of the civilian and Government buildings pose a potential threat of attack. Design guidelines such as DoD Minimum Antiterrorism Standards for Buildings, UFC 4-010-01 have established standards providing minimum levels of protection under terrorist attacks for the Department of Defense buildings [2]. These recommended guidelines are certainly extended to design of military facilities but application of blast-effects mitigation technologies from military to civilian structures should also be made feasible. The National Research Council explains the term blast-effects mitigation as the reduction in the severity of effects of an explosion on a structure resulting from having taken specified blast hardening measures to reduce or eliminate the effects of an explosion [3]. For this reason, it 
is necessary to have an upgrade in the performance of the buildings under blast loadings. Extensive research is carried out in the blast field for finding best alternatives for design of building components such as slabs, beams, columns, wall panels, etc. Such considerations are critical for structures consisting offices, educational institutions, recreational facilities, etc. which house human population in large numbers and thus prone to aggressor attacks.

\subsection{Significance of Studying Blast Effects on Reinforced Concrete Slabs}

An explosion near or within the building can have disastrous effects by damaging the structure's external or internal structural framework, collapsing walls, debris and shutting down of fire-safety and life-safety systems. One solution would be to strengthen the structure itself to resist total failure in case of an explosion near or inside it. Strengthening the structure can make it less economical for its practical application on a wide scale. Mlakar et al, in his report on analysis of blast damage caused to Alfred P. Murrah building during the Oklahoma City Bombing, has evaluated the effect of the blast caused by the truck bomb on the buildings structural frame [1]. Major damage was caused to the column in the vicinity of the blast while the structural bays above and below each floor slabs were filled with blast induced pressures. The upward load that built on each slab because of the pressure difference below and above the slab caused a maximum deflection of $9.3 \mathrm{in}$. in the upward direction which exceeded its ultimate load capacity and thus led to collapse of the slab. Reinforced concrete slabs are an important element of the structural system which requires strengthening against blast loading as they are one of the basic members. Also, protective wall panels around main structures are like reinforced concrete slabs. Hence, studying the behavior of slabs by analyzing its dynamic behavior under short duration and high peak 
value blast loads is the motivation behind this research study. Advanced analysis methods have been employed by structural designers around the world to assess the structural integrity of their design when subjected to blast loading. In order to achieve blast resistant technology advanced analysis procedure should be developed through research to make it easily applicable. This objective of adopting advanced analysis methods for evaluating civilian structures can be achieved through experimental studies, theoretical analyses and advanced numerical simulation approaches for predicting blast loads and the responses of structural systems.

\subsection{Proposed Solution}

Experiments and theory are necessary for prediction of blast effects and quantifying the structural response based on the explosion and its interaction with the structure. The outcome can be utilized in developing computational approaches for estimating structural response to an explosion. Computational approaches are far less expensive than the experiments. Validation of such computational approaches by experiment is necessary to make computational approaches completely reliable. Military organizations have conducted numerous experiments for validating these computer programs over the years but the tests were performed relevant to military structures and their applicability to civilian structures, which can be much more complex, needs further investigation.

This research involves strengthening an important component of a structural system, a reinforced concrete slab by making use of high strength material and comparing it with normal strength material by performing experimental and analytical studies. The effectiveness in resisting blast loading of such a strengthened slab is analyzed using 
computer based Finite Element Method (FEM). In this method, discretization of the problem by dividing it into subdomains called elements, interconnected by nodes is carried out to deal with complex geometries. A non-linear transient dynamic finite element analysis program code LS-DYNA ${ }^{\circledR}$ is used in this research. The LS-DYNA ${ }^{\circledR}$ program has numerous features for analyzing the model by defining pressure-time histories generated in the blast event. The material properties description for the two materials, concrete and steel can be defined using commercially available material models. The concrete material models considered in this study are Concrete Damage Model Release 3 and Winfrith Concrete Model [4]. A plastic kinematic model was used for modeling the steel.

Initially an experimental investigation was carried out on twelve single-mat reinforced concrete RC slab panels at the U.S. Army Engineering Research and Development Center, Vicksburg, MS. The twelve slab panels consisted of two distinct sets of six panels each. One set included High Strength Concrete reinforced with High Strength Steel Reinforcing bars (HSC-V) while the other set included Normal Strength Concrete reinforced with Normal Strength Steel Reinforcing bars (NSC-R). Also each set had two different reinforcement ratios. The first set had \#3 bars spaced at 4 inch $(101.6 \mathrm{~mm}$.) while the second set had \#3 bars spaced at 8 inch $(203.2 \mathrm{~mm}$.). The experimental work involved testing of two sets of reinforced concrete panels by subjecting them to pressure conditions equivalent to those in a blast load. Blast load conditions were generated by a shock tube (Blast Load Simulator) at the U.S. Army Engineering Research \& Development Center, Vicksburg, MS. The experimental data collected for this testing includes pressure versus time history at 6 locations on the slab, displacement at mid-span measured using laser 
deflection gages and accelerometers, strains measured at two locations using strain gages and photos and videos showing damage crack patterns for each slab.

\subsection{Thesis Organization}

This thesis is organized as follows.

1. Chapter 1 introduces the subject of this thesis which is about finite element analysis and experimental validation of reinforced concrete single mat slabs subjected to blast loading.

2. Chapter 2 gives the details of the literature reviewed in this thesis.

3. Chapter 3 defines the objective and scope of thesis.

4. Chapter 4 provides the details for experimental investigation program conducted by Dr. Ganesh Thiagarajan, Principal Investigator for this project at U.S. Army Engineer Research and Development Center at Vicksburg, MS. The experimental investigation was not performed as a part of this thesis and hence the information obtained is discussed in detail. The information on the types of reinforced concrete panels, the equipment used for applying blast pressures and the various types of data collected is presented. The data obtained from this experimental program is used in this research for performing numerical analysis.

5. Chapter 5 discusses the numerical modeling of the reinforced concrete slabs in detail. The significance of the software used for modeling and analysis, the geometry of the finite element models, the various mesh sizes adopted and the material models used for modeling the concrete and steel is addressed in this chapter. 
6. Chapter 6 provides the observations and results of numerical simulations performed using LS-DYNA ${ }^{\circledR}$. The results are provided for different combinations of two different concrete models and three different mesh sizes for the 12 reinforced concrete slab panels.

7. Chapter 7 discusses the results presented in Chapter 6

8. Chapter 8 draws the conclusions based on the analysis of results and gives details on future work. 


\section{CHAPTER 2}

\section{LITERATURE SURVEY}

Improving blast resistance of buildings has been a topic of interest among researchers. The objective has been to design protective technologies which can be easily implemented. The effort has been driven to develop a knowledge base which can be made easily available to structural designers. Crawford and Lan [5] have described technologies which have been evaluated and proven to improve blast resistance of buildings by adopting engineering techniques. Based on their study of blast and impact effects testing and numerical modeling, they recommended the development of high-fidelity physics-based (HFPB) finite element models. These models provide sophisticated representation of the behaviors involved in a blast event and also validation of these models using impacts and blast test is stated to be significant to arrive at the blast resistant solutions. The three key design issues for developing new concepts, identified in their paper, are; ductility and plastic behavior, shock related behaviors, and use of standard materials in a non-standard way. The phenomena of shock related behavior response of reinforced concrete slab systems in which supports must accommodate large loads in short time is addressed by them as the subject of attention.

Hao and Zhongxian [6] performed numerical analysis of dynamic behavior of RC slabs under blast loading. They numerically investigated the influence of slab dimension, concrete strength, and reinforcement ratios on the slab response to blast loading. They concluded that a reasonable increase in slab thickness can improve the blast carrying 
capacity of RC slabs. They have recommended modifications for slab dimensions and reinforcement ratios.

Mosalam and Mosallam [7] developed computational models for reinforced concrete (RC) slabs using finite element method. They carried out non-linear transient analysis for investigating the effects of retrofitting the RC slabs with carbon fiber reinforced polymer (CFRP) as compared to as-built RC slabs to mitigate the effects of blast loading. The computational models were verified using experimental results. The results of non-linear transient analysis using these computational models proved the efficiency of the CFRP composite retrofits in improving the slab behavior under blast loading. The maximum displacement reduced by $40-70 \%$ with the CFRP retrofit compared to the as-built slab.

Agardh [8] presented results of experiments and FE-simulations on fiber reinforced concrete slabs subjected to blast loads. Their study aimed at accurate FE modeling of the behavior of such elements loaded by transient dynamic loads. The results of blast experiments performed in a shock tube on steel fibre and conventionally reinforced concrete slabs were used for validation of codes and material models. LS-DYNA ${ }^{\circledR}$ and ABAQUS®/explicit were the two codes used. Winfrith concrete model for LS-DYNA ${ }^{\circledR}$ and Constitutive model for brittle cracking in ABAQUS $® /$ Explicit were the two models used for this study. The numerical simulations provided accurate results for variables like, displacements for low loads and the ability to predict failure loads. They also recommended the omission of strain rate effects as the distance between the slabs and charge was large causing the strain rate effect to be insignificant.

Kuang [9] modeled only a quarter of the three dimensional solid FE model of the RC slab due to its symmetry and performed numerical simulations by applying blast loading in 
LS-DYNA®. Kuang employed Johnson-Holmquist Concrete (H-J-C) [4] model for concrete to account for damage and strain rate effect. Also, for modeling the spallation process they used erosion technique in LS-DYNA ${ }^{\circledR}$. Comparison of their numerical simulation results with the blast test results have demonstrated the effectiveness of predicting the response of reinforced concrete sections to blast loads by using numerical simulations.

El-Dakhakhni [10] studied the validity of Single-Degree-of-Freedom (SDOF) models for analyzing the response of two-way reinforced concrete panels under blast loading. In their study, a single-degree-of-freedom SDOF model, based on the guidelines of the UFC 3-340-02 is used [2]. RC panels with different dimensions, aspect and reinforcement ratios, and support conditions were considered. Their finite element FE model for concrete utilized the parameter generation capability of *MAT_CONCRETE_DAMAGE_REL3 (mat type 72R3) model whereas the steel was modeled using PLASTIC_KINEMATIC (mat type 003) material model in LS-DYNA® [4]. They validated their FE model with experiments previously reported by Razaqpur (2006). The response predictions were compared to the results of nonlinear explicit finite-element (FE) analyses and significant differences in deflection and shear predictions were observed. The work presented in this paper is expected to contribute to improving the modeling provisions of the two-way RC panels in the future edition of the UFC 3-340-02 by understanding the limitations of SDOF models and overcoming them using advanced FE analysis techniques. The limitations of SDOF model which are suggested to be overcome by adopting FE analysis are the inclusion of accounting for different failure modes i.e. shear, bar slippage, etc., and material strength enhancement due to strain rate effects. 
Over the last few decades significant research has been conducted to account for concrete material properties in finite element models developed for concrete structures. It is essential to have knowledge of behavior of concrete structures to a pre-defined loading condition to replicate the exact behavior in the finite element model. The first step towards this type of study is to conduct laboratory experiments with a definite control over the structural parameters and collection of accurate results of the outcome. The laboratory test results can then be used to calibrate the available computer models. Malvar and Schwer [11] reported an outcome of a similar study which compared well characterized $45.6 \mathrm{MPa}$ unconfined compressive strength concrete parameters obtained in laboratory test with the corresponding material response from the commercial $\mathrm{K} \& \mathrm{C}$ concrete model in LSDYNA ${ }^{\circledR}$ [4]. Recommendations were made on using the model parameter generation capability of Mat72R3 which requires only unconfined compressive strength of concrete to be given as input.

Tanapornaweekit [12] performed blast analysis on $1.19 \mathrm{~m} \mathrm{X} \mathrm{2.19m} \mathrm{X} 0.14 \mathrm{~m} \mathrm{RC}$ panel by conducting a 500kg TNT testing at Woomera, South Australia. In their study the blast properties were predicted by computer programs AIR3D and CONWEP and they were compared to pressures measured by pressure transducers in the test. Similarly, the RC panel was modeled and analyzed in LS-DYNA ${ }^{\circledR}$ and the deflection of the panel was compared to the deflections obtained in the blast tests. To model the concrete material for the panel *MAT_CONCRETE_DAMAGE_REL3 model which considers three failure surface surfaces namely maximum shear failure surface, residual failure surface and initial yield surface is adopted due to its automatic parameter generation capability [4]. A total of eight surface parameters obtained by automatic input data generation based on concrete 
compressive strength of $40 \mathrm{MPa}$ were reported. The three equations which define the three failure surfaces namely maximum failure, residual failure and yield failure surfaces, are discussed in this thesis. The dependability of stress difference at each failure surface on the pressure in a particular element is evident from the parameter values generated for their model. The steel is modeled using *MAT_PLASTIC_KINEMATIC model [4]. A full bond between concrete and steel is assumed by sharing nodes between concrete and steel reinforcement. The FE model reports a maximum and rebound deflections of tested panels as $30 \mathrm{~mm}$ and $4 \mathrm{~mm}$ respectively which corresponds well with the $36 \mathrm{~mm}$ and $5 \mathrm{~mm}$ reported by the experiment thus, showing a difference of $17 \%$ in the maximum deflection in both results. This study demonstrated the capability of the software package to simulate the structural behavior of a RC panel under explosion.

Zhou and Kuznetsov [13] adopted a dynamic plastic damage model of concrete for their study on both ordinary reinforced and high-strength steel fiber reinforced concrete slab. Their concrete material model is developed using derived parameters based on characteristics like strain-rate effect, definition of damage, concrete strength envelope and equation of strength for concrete received from different static and dynamic material testing and material models used by other researchers. Initially they have modeled the detonation and the blast wave propagation in a $2 \mathrm{D}$ simulation. The blast wave model is then applied to the slab model in a 3D numerical simulation as two sequential similar blast events. The numerical results thus obtained for the response of the slabs are compared to the explosive tests conducted by the Weapons Systems Division, Department of Australia. They found that the numerical results compared well with the tests for $\mathrm{t}<2 \mathrm{~ms}$; when $\mathrm{t}>2 \mathrm{~ms}$ the 
numerical results underestimated the ultimate deflection of the slab on both normal RC and the high strength Steel Fiber Reinforced Concrete (SFRC) slabs from the first blast.

Broadhouse [14] in his report on development of Winfrith Concrete Model in LSDYNA ${ }^{\circledR}$ state that a pressure versus volumetric strain curve should be given as input parameter in order to determine the hydrostatic stress state in concrete [4]. This curve is called Volume Compaction Curve and is introduced in the material parameters for Winfrith Model. Similarly, Gebbeken and Ruppert [15] also recommended a necessity to input an equation of state to ensure laws of conservation on which numerical simulations are based. Experimental investigations are however very expensive and require testing apparatus which is not readily available. Therefore, it is essential to develop finite element models which can be used for analysis in accurate prediction of structural response under the constraints of available material parameters; the choice of available material models, exact boundary conditions, and description of reinforcement bonding with concrete. The results obtained from relevant research work have thus been surveyed in this research.

Low and Hao [16] performed a reliability study for analyzing the dynamic behavior of reinforced concrete structural slab subjected to blast loading to account for the various uncertainties involved in accurately predicting the response to blast loading. The need for incorporating the random effects associated with material, geometry and loading into analysis for more realistic estimation was the objective of their research. A slab designed to behave as a flexural member was subjected to blast loading generated by an explosion at some distance above the slab. For simplifying the analysis they assumed uniformly distributed pressure loading. They also accounted for strain rate effect on material strength to account for rapid loading rate. The study was performed by setting up of displacement 
and strain performance functions for an equivalent SDOF system. The SDOF model is verified using finite element analysis performed using Monte Carlo simulations. Parametric studies have been performed on the verified model to identify parameters that have significant impact on the performance of the slab which demonstrated that increasing the thickness of slab and percentage of steel reinforcement and reducing the slab rigidity by changing its support conditions have positive effects on the performance of flexural response of RC slabs subjected to dynamic loading.

The literature reviewed here indicates that the different types of blast mitigation techniques have been performed previously and each of them have been evaluated using either finite element modeling or SDOF system to study the effects of dynamic loading on reinforced concrete slabs. In this thesis a combination of these techniques involving two different strength materials, two different reinforcement ratios, two different mesh sizes, two different material models and a comparison of numerical analysis to the experimental results are performed under one study to validate the numerical approach. 


\section{CHAPTER 3}

\section{OBJECTIVE AND SCOPE}

\subsection{Problem Statement}

Finite element modeling of reinforced concrete slabs to accurately predict their structural response to dynamic loads is a challenging task. In order to capture the rapidly changing material behavior of reinforced concrete slab in a dynamic response it becomes necessary to give exact material description of material parameters given as input to the model. This requires comprehensive material testing to be performed in the laboratory to achieve accurate characteristic material properties which is difficult to achieve. Hence, inherent material model descriptions of commercially available codes have to be utilized to study the behavior and response of FE slab models developed. Validation of these material models by comparison of numerical analysis with experimental results is thus required.

\subsection{Objective}

The goal of this research is to study the effects of blast loading on Reinforced Concrete (RC) one way slabs having single layer of reinforcement by performing Finite Element (FE) simulations and comparing them to experimental data. The goal is achieved as defined by the following objectives.

1. Utilize the data obtained from experimental investigation for performing numerical modeling and analysis in LS-DYNA. The goal here is to utilize the; pressure-time histories, deflection-time histories and damage patterns captured in the post-test photographs. 
2. Create a finite element geometric model of the slab having dimensions 64 in. $x 34$ in. $x$ 4in. (1652 mm. x $863 \mathrm{~mm} . \mathrm{x} 101.6 \mathrm{~mm}$.) in LS-DYNA.

3. Use three uniform mesh sizes of 1 in. $(25.4 \mathrm{~mm})$ having 4 elements through the slab thickness, $1 / 2$ in. $(12.7 \mathrm{~mm}$.) having 8 elements through the slab thickness and $1 / 4$ in. (6.35 mm.) having 16 elements through the slab thickness.

3. To study the effect of reinforcement ratio on the response by looking at two different reinforcement ratios for each slab combination.

4. To consider two types of material combinations based on the concrete strength; high strength concrete reinforced with high strength steel and normal strength concrete reinforced with normal strength steel.

4. Utilize the material models in LS-DYNA namely Winfirth Concrete Model and Concrete Damage Model Release 3 to model the concrete and Plastic Kinematic Model to model the steel. Make use of the Constrained Lagrange in Solid formulation to model the bond between concrete and steel.

5. A comparison is made between the two material models in LS-DYNA® and the experimental results to recommend the best material model for accurate prediction of response of RC slab subjected to equivalent blast pressures as the experiment. Thus, validating the two material models using the results of experiments and provide recommendations on using these material models for analyzing the response of RC slabs to blast loading instead of expensive blast experiments is the goal of this study. 


\subsection{Tasks}

Task 1: To utilize the information from experimental investigation; which was not a part of this thesis. The experimental investigation was carried out on 12 Reinforced Concrete (RC) slab panels having combination of high strength concrete reinforced with high strength steel (HSC-V) and normal strength concrete reinforced with normal strength steel (RSC-R). The slab is a 64 in. (1625 mm.) X 34in. (864 mm.) X 4 in. (101.6 mm.) reinforced concrete panel with single-mat reinforcement. The performance of two types of RC slabs with combinations namely normal strength concrete (5 ksi, 34.47 MPa) with normal strength steel (60 ksi, 413.68 MPa) and high strength concrete $(15 \mathrm{ksi}, 103.42 \mathrm{MPa})$ reinforced with high strength vanadium steel ( $83 \mathrm{ksi}, 572.26 \mathrm{MPa})$ was tested by applying blast pressures in a Shock Tube. The pressure and impulse histories were recorded on six different regions on the slab. The laser deflection gage at the center of the slab recorded the deflection-time history. Accelerometers were also placed at the center of the slab to record acceleration from which deflections were derived. Also, the strain gauges located at quarter points of the unloaded face of the slab recorded the strain history.

Task 2: Reinforced concrete behavior is modeled using three commercially available material models. Winfrith Concrete model and Concrete Damage Model Release 3 is used for concrete while steel is modeled using Plastic Kinematic Model. The effects of mesh density on the response of FE model are also studied. The verification of FE analysis results with experimental results will primarily be based on deflection history observed in the slab when subjected to blast pressures and 
impulses that the experimental specimen were subjected to. The crack patterns developed in two cases will also be compared.

Task 3: The effect of reinforcement ratio on the response is also considered by looking at two different reinforcement ratios for each slab combination. The slabs are spanning one-way in the longitudinal direction. First six slabs are reinforced with \#3 bars spaced at 4in. c/c (101.6 mm.) in the longitudinal direction (reinforcement ratio $=0.68 \%$ ) while the next six slabs are reinforced with $\# 3$ bars spaced at $8 \mathrm{in} . \mathrm{c} / \mathrm{c}$ in the longitudinal direction (reinforcement ratio $=0.46 \%$ ) as main steel while shrinkage steel is \#3 bars spaced at 12in (304.8 mm.) in both the slabs. Therefore, two finite element models are developed in LS-DYNA® for two different reinforcement ratios. They are termed as $4 \mathrm{in}$. model and $8 \mathrm{in}$. model referring to the two different bar spacing.

The results obtained in this study are used for making recommendations on using high strength materials and the two material models in LS-DYNA® for studying the effects of blast loading on RC slabs in future. 


\section{CHAPTER 4}

\section{EXPERIMENTAL INVESTIGATION}

The experimental investigation, done as a part of separate study, was performed on a set of twelve $1 / 3$ scale reinforced concrete (RC) slab panels with clear spans of 58 inch (1473.2 mm.). The testing facility equipped with Blast Load Simulator (Shock tube) at U.S. Army Engineer Research and Development Center at Vicksburg, MS was utilized in this Experimental Program. The slabs were fabricated at the facility and then tested in the blast load simulator. The schedule for the experimental program given in Table 4-1 gives details of the 12 slabs used in the experiments. Designations used for describing the slab type are given in Table 4-2. The date when the experiment was performed on each slab is given along with the driver pressure and the explosion type usedin the shock tube.

Table 4-1 : Experimental program schedule

\begin{tabular}{ccccc}
\hline Slab \# & Slab Type & Date & Driver pressure & Explosion Type \\
\hline $\mathbf{1}$ & HSC - V1 - 4in. & $12 / 13 / 2010$ & $1150 \mathrm{psi}$ & $100 \%$ Air \\
$\mathbf{2}$ & RSC - R1 - 4in. & $12 / 14 / 2010$ & $1150 \mathrm{psi}$ & $100 \%$ Air \\
$\mathbf{3}$ & HSC - V2 - 4in. & $12 / 15 / 2010$ & $1150 \mathrm{psi}$ & $100 \%$ Air \\
$\mathbf{4}$ & RSC - R2 - 4in. & $12 / 16 / 2010$ & $1150 \mathrm{psi}$ & $100 \%$ Air \\
$\mathbf{5}$ & HSC - V3 -4 in. & $12 / 17 / 2010$ & $900 \mathrm{psi}$ & $100 \%$ Air \\
\hline $\mathbf{6}$ & RSC - R3 - 4in. & $02 / 01 / 2011$ & $900 \mathrm{psi}$ & $100 \%$ Air \\
$\mathbf{7}$ & HSC - V4 - 8in. & $02 / 03 / 2011$ & $900 \mathrm{psi}$ & $100 \%$ Air \\
\hline $\mathbf{8}$ & RSC - R4 - 4in. & $02 / 03 / 2011$ & $700 \mathrm{psi}$ & $25 \%$ Helium \\
$\mathbf{9}$ & HSC - V5 - 8in. & $02 / 04 / 2011$ & $700 \mathrm{psi}$ & $25 \%$ Helium \\
\hline $\mathbf{1 0}$ & RSC - R5 - 4in. & $02 / 07 / 2011$ & $750 \mathrm{psi}$ & $25 \%$ Helium \\
\hline $\mathbf{1 1}$ & HSC - V6 - 8in. & $02 / 08 / 2011$ & $800 \mathrm{psi}$ & $25 \%$ Helium \\
\hline $\mathbf{1 2}$ & RSC - R6 - 4in. & $02 / 09 / 2011$ & $725 \mathrm{psi}$ & $25 \%$ Helium \\
\hline
\end{tabular}




\subsection{Materials}

This experimental study was performed by Dr. Ganesh Thiagarajan, Principal Investigator for this project. The experiments investigated the use of high-strength materials for resisting dynamic loads as compared to the normal strength materials. The overall dimensions for the single-mat slab panels tested which are 1/3 scale models are 64 in. (1625 mm.) X 34in. (864 mm.) X 4 in. (101.6 mm.). Two slab combinations based on the material strength namely, high-strength material combination denoted as "HSC-V" and the normalstrength material combination denoted as "RSC-R" were used in this study. The detailed description of slab-designation is given in Table 4.2 below:

Table 4-2: Designations used in Experimental Program

\begin{tabular}{llc}
\hline Designation & Description & Material strength \\
\hline HSC & High-strength concrete & $15 \mathrm{ksi}(103.42 \mathrm{MPa})$ \\
RSC & Normal-strength concrete & $5 \mathrm{ksi}(34.47 \mathrm{MPa})$ \\
$\mathbf{V}$ & Vanadium steel rebar & $83 \mathrm{ksi}(572.26 \mathrm{MPa})$ \\
$\mathbf{R}$ & Grade 60 Conventional rebar & $60 \mathrm{ksi}(413.68 \mathrm{MPa})$ \\
$\mathbf{4}$ in. & Longitudinal bars spacing & - \\
$\mathbf{8}$ in. & Longitudinal bars spacing & - \\
\hline
\end{tabular}

Also, two different reinforcement spacing for longitudinal bars were used. The first set of 6 slabs had \#3 bars spaced at 4 inch $(101.6 \mathrm{~mm}$.) while the next set of 6 slabs had \#3 bars spaced at 8 inch (203.2 mm.) . The detailed layout for the two types of slabs based on the reinforcement spacing can be seen in Figure 4.1 and Figure 4.2. 


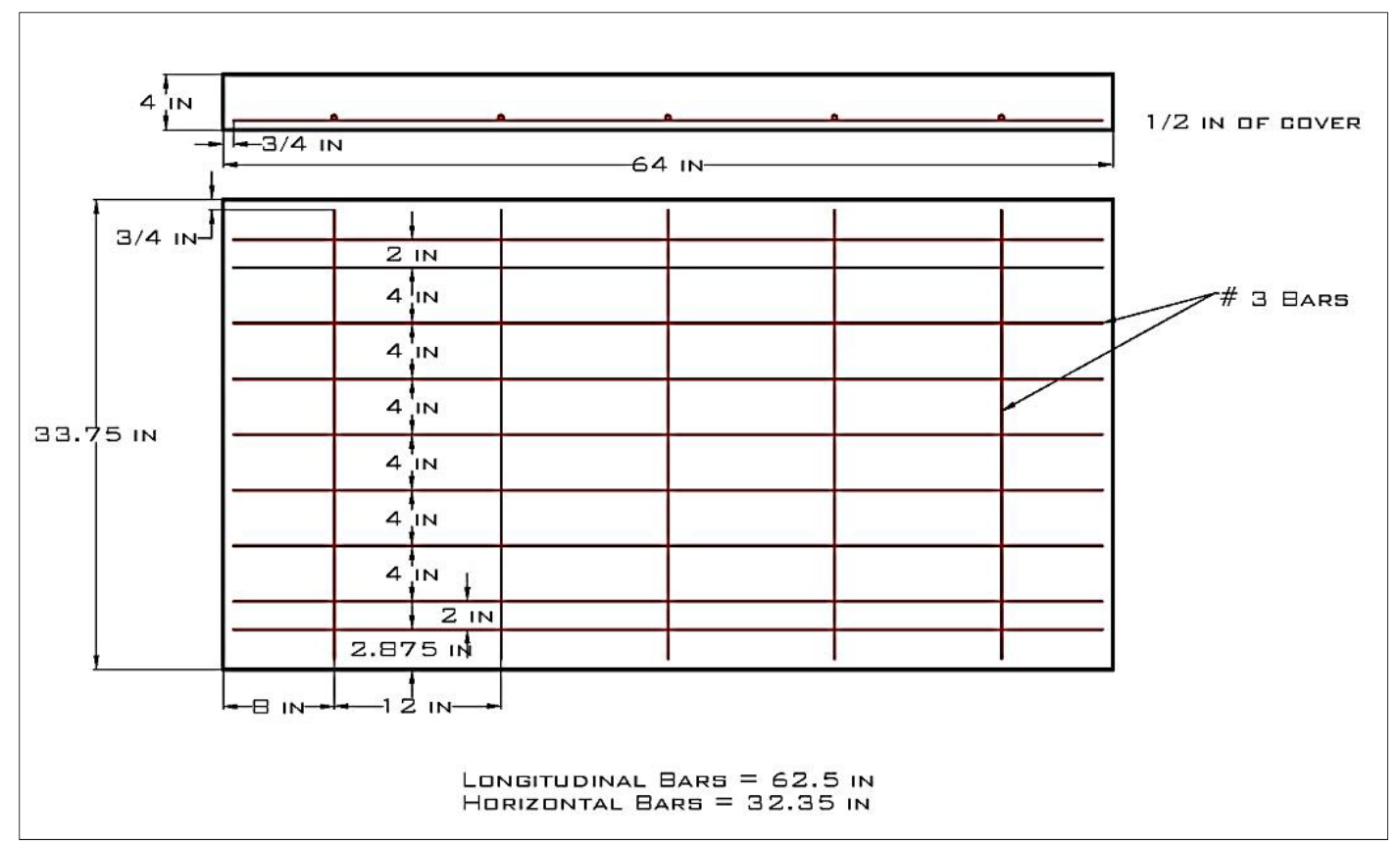

Figure 4-1: Reinforced Concrete Slab with 4 in. Type Single Layer of Steel

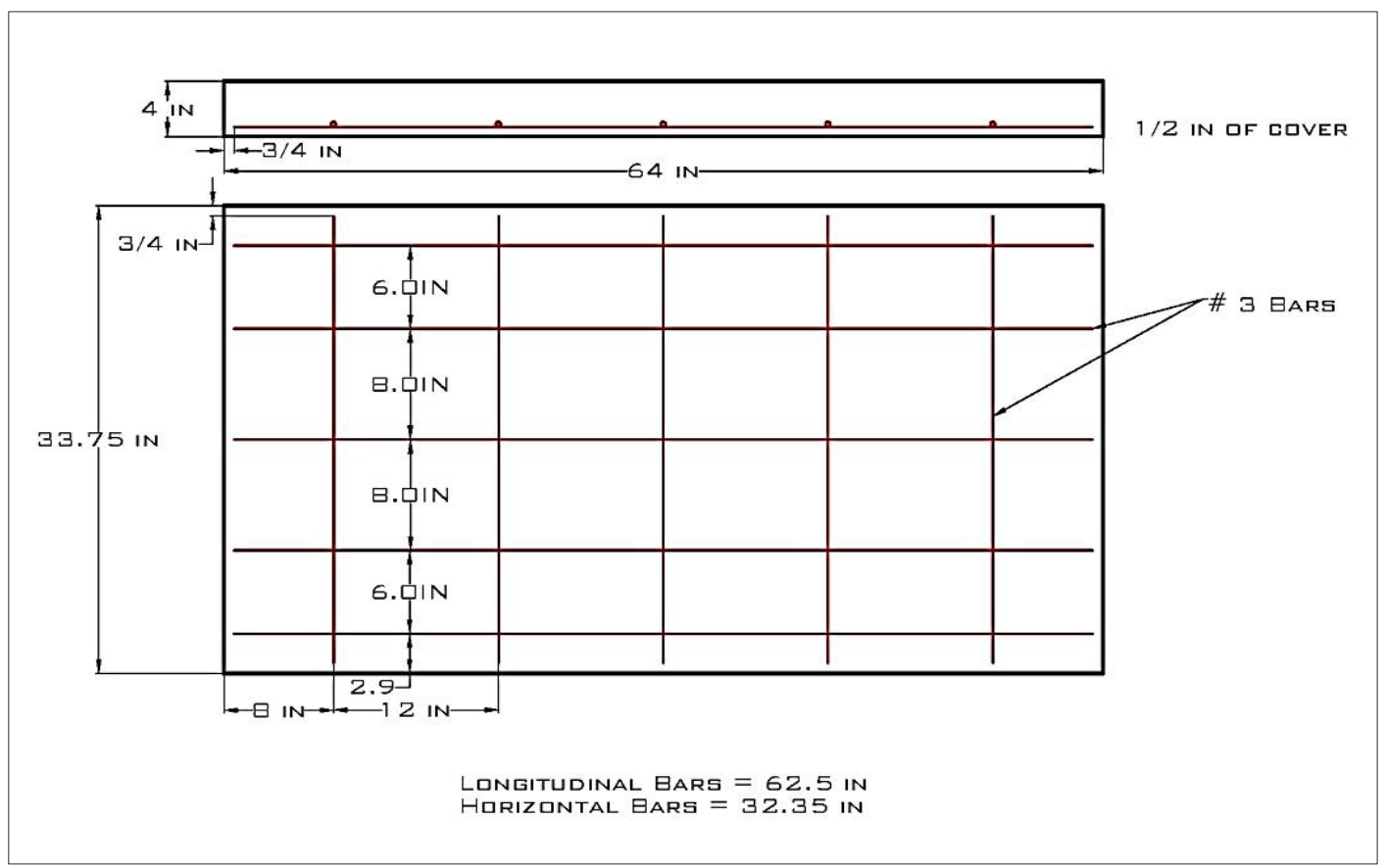

Figure 4-2: Reinforced Concrete Slab with 8 in. Type Single Layer of Steel 


\subsection{Methods}

The two most widely used methods for performing blast tests on structural elements are field tests and shock tubes. Field tests have safety and security issues related to them. Also, the measurements of blast pressures generated in the test have to be predicted using a definite prediction model. In the experimental study, which was not a part of this thesis, the blast load application was performed using a Blast Load Simulator (Shock Tube). Blast Load Simulator provides a controlled generation and uniform application of blast pressures on the face of the slab. The pressure versus time variation in both positive and negative phases can be accurately recorded in the blast load simulator. Pressure data at six different locations namely the four corners and two sides on the slab were recorded in this experiment. The laser deflection measurement device and central accelerometers were used to record the deflection on the back face of the slabs. The response of the slabs was recorded using high speed video cameras. Also the crack patterns developed on the slab are highlighted and recorded in photographs taken after the test for purpose of studying the damage. The raw data captured in this experiment compiled into a usable format was provided which was then used for the finite element modeling in this thesis. The details of the data captured are provided in the next section.

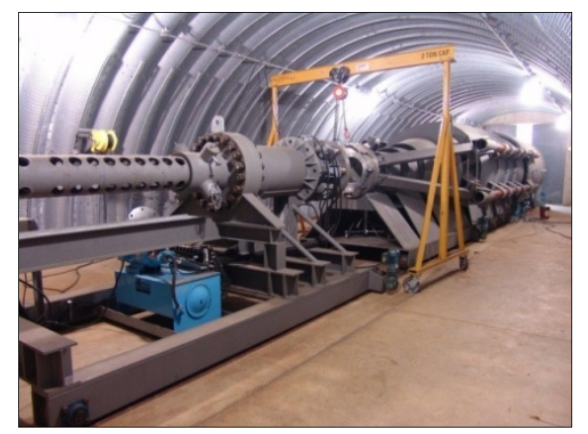

Figure 4-3: Blast Load Simulator (Shock Tube) at US Army ERDC 


\subsection{Experimental Data}

The experimental investigation of twelve $1 / 3$ scale $\mathrm{RC}$ slabs involved the measurement of following four parameters:

1. Pressure at four corners and two sides on the front face of the slab.

2. Mid-span deflections at the center of the back-face.

3. Strains at mid-way top and bottom from the center of the slab on the back-face as can be seen in Figure 4.4.

4. Crack patterns recorded as post-blast photographs.

The pressure vs. time data was recorded at six different locations on the slab. Both the positive and negative phases of the pressure vs. time history were recorded. The pressure vs. time histories were recorded using pressure gages located on the loading frame inside the blast load simulator. The average peak pressures and impulse for all twelve slabs was reported with experimental data (Appendix A). The plots for these pressures vs. time histories for the twelve slabs are provided in Appendix B. The co-ordinates for pressure vs. time plots as obtained from the spreadsheets in comma separated format is used for the purpose numerical simulation. The pressures are applied as uniformly distributed over the entire slab area.

The RC slabs were subjected to pre-determined blast pressures which caused dynamic response to the applied blast loading. This dynamic response was recorded as center-span displacements and strains measured with respect to time for a short duration. The displacement-time history measured using lasers and accelerometers in the experiment were used for the purpose of experimental validation of the numerical models developed in this study. 
The post-test damage patterns observed on the twelve slabs were recorded in the form of digital images taken after each slab was tested as seen in Figure 4.4. The observed cracks were marked with the location details using dimensions denoted by scale. The crack patterns recorded were later used for comparison with the crack patterns developed in the numerical model.

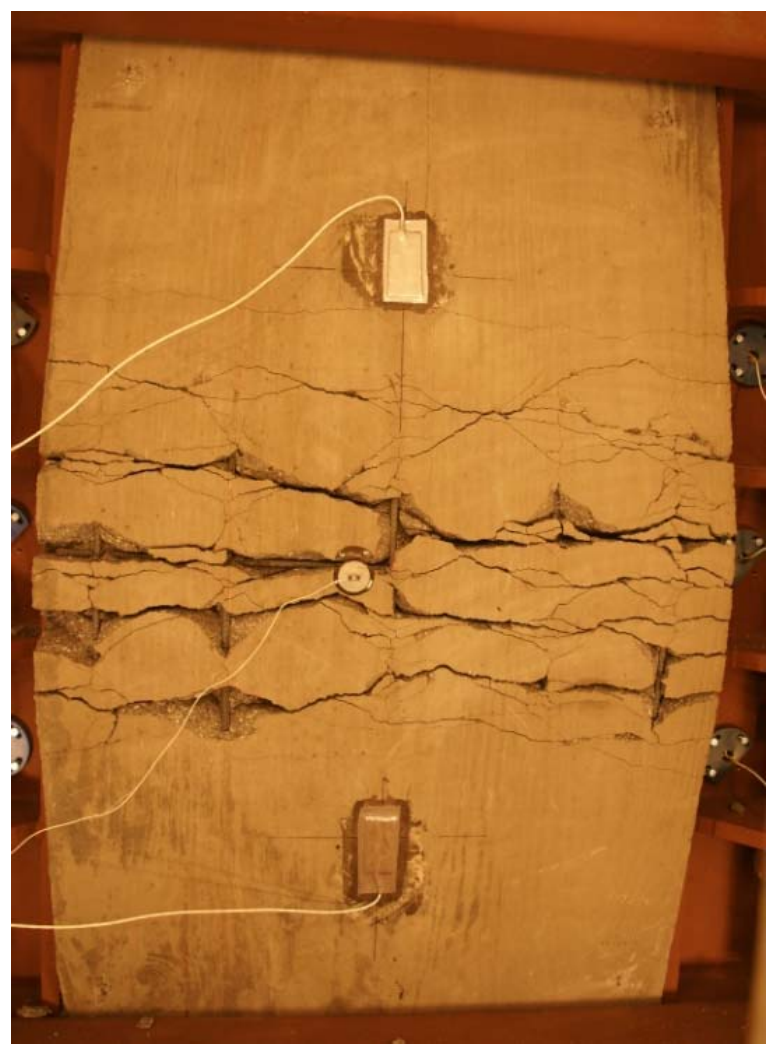

Figure 4-4: Post-test damage patterns observed on Slab \# 7

The experimental investigation program gave information on geometry, loading and response of the 12 single-mat RC Slabs which is utilized in numerical modeling of the 12 slabs for finite element analysis. The pressure data available from the experiments is useful for loading the finite element slab models and the deflection data is useful in comparing with the slab deflections obtained using numerical model. 


\section{CHAPTER 5}

\section{NUMERICAL MODELING IN LS-DYNA®}

The numerical model of the single-mat RC slab was developed and used for studying the response to blast loading. The numerical simulations were performed in LS-DYNA®. The results from the numerical simulation are used for comparison with the results from the experiment to achieve the primary objective of studying the behavior of reinforced singlemat slabs subjected to blast loading. The experimental validation of the two commercial material models was performed using this numerical simulation study. The significance of using LS-DYNA ${ }^{\circledR}$ for simulations, finite element model, boundary conditions, constitutive material models and blast load application is described in detail in this chapter.

\subsection{Significance of Numerical Modeling in LS-DYNA®}

The finite element modeling of the single-mat reinforced concrete slab was performed using LS-DYNA ${ }^{\circledR}$ which is a general purpose finite element program. LSDYNA ${ }^{\circledR}$ is a highly non-linear, transient dynamic finite element analysis program which uses explicit time integration. LS-DYNA ${ }^{\circledR}$ provides numerous material models in its material library and provides various types of element formulations in the element library [4, 17].

The finite element modeling of the reinforced concrete is challenging due to the nonhomogeneity in the material and the composite behavior of concrete and steel. This composite action should be defined in the model to produce good response to the loading applied. The perfect bond between steel and concrete can be modeled by defining the interface between them. LS-DYNA ${ }^{\circledR}$ has pre-defined material models for concrete and steel 
which require basic material properties to define them and are used in this study to model the concrete and steel. Two different element types viz. solid element for concrete and beam elements for steel can be modeled in LS-DYNA ${ }^{\circledR}$ with the concrete bond description given by *CONSTRAINED_LAGRANGE_IN_SOLID keyword and merging the nodes in both elements [4]. Further sections in this chapter present the details of the numerical modeling of the two types of Single-mat RC slabs performed in LS-DYNA ${ }^{\circledR}$ for this study.

\subsection{Geometric Models}

\subsubsection{Meshing for Concrete Model}

The single-mat reinforced concrete slab with two types of reinforcement spacing is modeled using the pre-processor in LS-DYNA ${ }^{\circledR}$. The models consists of two parts namely the rectangular concrete block and the reinforcing steel bars. The rectangular concrete block of dimensions 64 in. $x 34$ in. x 4in. (1652 mm. x $863 \mathrm{~mm} . x 101.6 \mathrm{~mm}$.$) is modeled using$ the eight-noded hexahedron elements with constant stress solid element formulation. Six different slab models consisting of three different mesh sizes modeled for two different reinforced sections were developed for this study. Three uniform mesh sizes of 1 in. (25.4 $\mathrm{mm}$ ) having 4 elements through the slab thickness, $1 / 2$ in. $(12.7 \mathrm{~mm}$.) having 8 elements through the slab thickness and $1 / 4$ in. $(6.35 \mathrm{~mm}$.) having 16 elements through the slab thickness were applied to the concrete block as seen in Figure 5.1, Figure 5.2 and Figure 5.3. The total number of solid elements in the model with 1 in. $(25.4 \mathrm{~mm})$ mesh size is 8,704 solid elements consisting of 11,375 nodes. The total number of solid elements in the model with $1 / 2$ in. (12.7 mm.) mesh size is 69,632 solid elements consisting of 80,109 nodes. The 
total number of solid elements in the model with $1 / 4$ in. $(6.35 \mathrm{~mm}$.) mesh size is 557,056 solid elements consisting of 598,553 nodes.

\subsubsection{Meshing for Steel Model}

The single-mat RC slab has a single layer reinforcement modeled at 1 in. (25.4 mm.) concrete cover spacing from the back face. The steel reinforcement is modeled using the Hughes-Liu beam elements having cross-section integration formulation. Three different mesh sizes of 1 in. $(25.4 \mathrm{~mm}), 1 / 2$ in. $(12.7 \mathrm{~mm}$.) and $1 / 4 \mathrm{in} .(6.35 \mathrm{~mm}$.) are used. The two model types distinguished by the main steel spacing are the one with 4 in. (101.6 mm.) type and 8 in. (203.2 mm.) type. The 4 in. type RC slabs as seen in Figure 5.4 have main steel modeled at 4 in. $(101.6 \mathrm{~mm}$.) spacing on center with the two end bars at 2 in. $(50.8 \mathrm{~mm}$.) spacing and shrinkage steel modeled at 12 in. (304.8 mm.) spacing on center; while the 8 in. type RC slabs as seen in Figure 5.5 have main steel modeled at 8 in. (101.6 mm.) spacing on center with the two end bars at 6 in. (152.4 mm.) spacing and shrinkage steel modeled at 12 in. $(304.8 \mathrm{~mm}$.) spacing on centers. The total number of beam elements for the 4 in. type in the model with 1 in. $(25.4 \mathrm{~mm})$ mesh size is 746 elements; the model with $1 / 2$ in. $(12.7 \mathrm{~mm}$.) mesh size consists of 1492 beam elements while the model with $1 / 4 \mathrm{in}$. (6.35 mm.) mesh size consists of 2983 elements. The total number of beam elements for the 8 in. type in the model with 1 in. $(25.4 \mathrm{~mm})$ mesh size is 490 elements; the model with $1 / 2 \mathrm{in}$. (12.7 mm.) mesh size consists of 980 beam elements while the model with $1 / 4$ in. $(6.35 \mathrm{~mm}$.) mesh size consists of 1958 elements. 


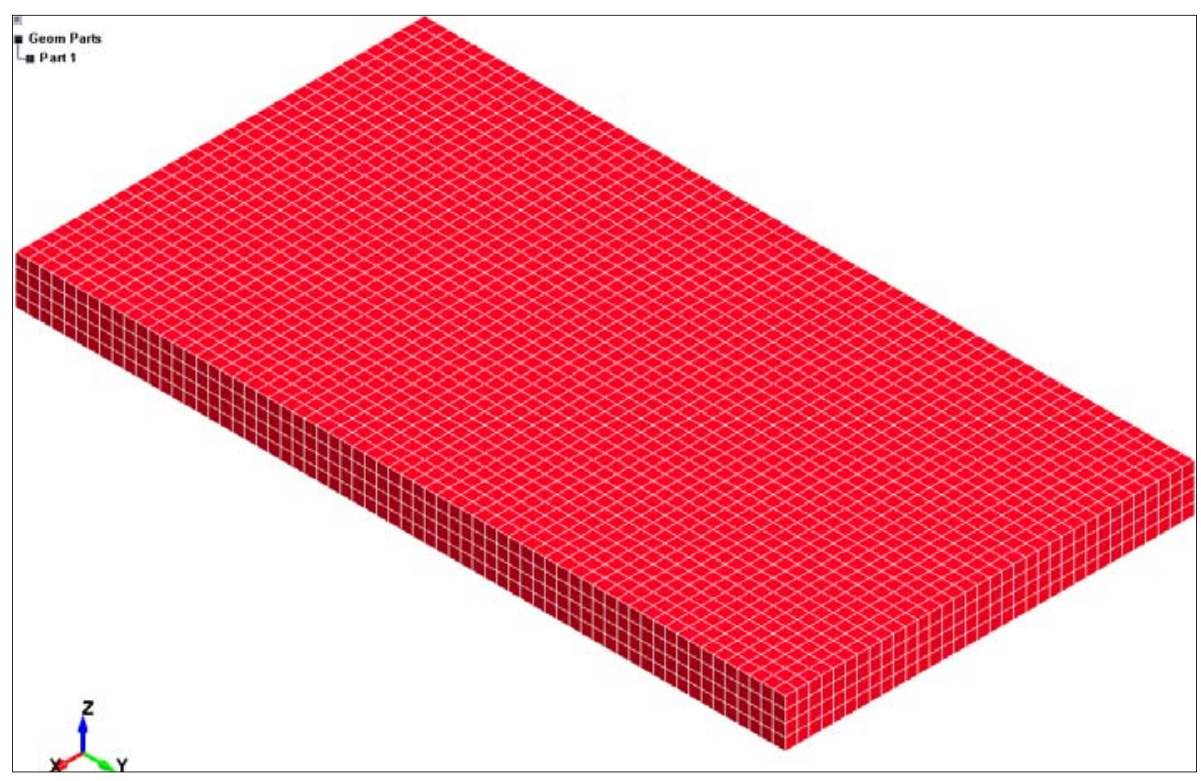

Figure 5-1: Single-Mat Reinforced Concrete slab model with Solid Elements 1 in. (25.4 mm.) mesh size

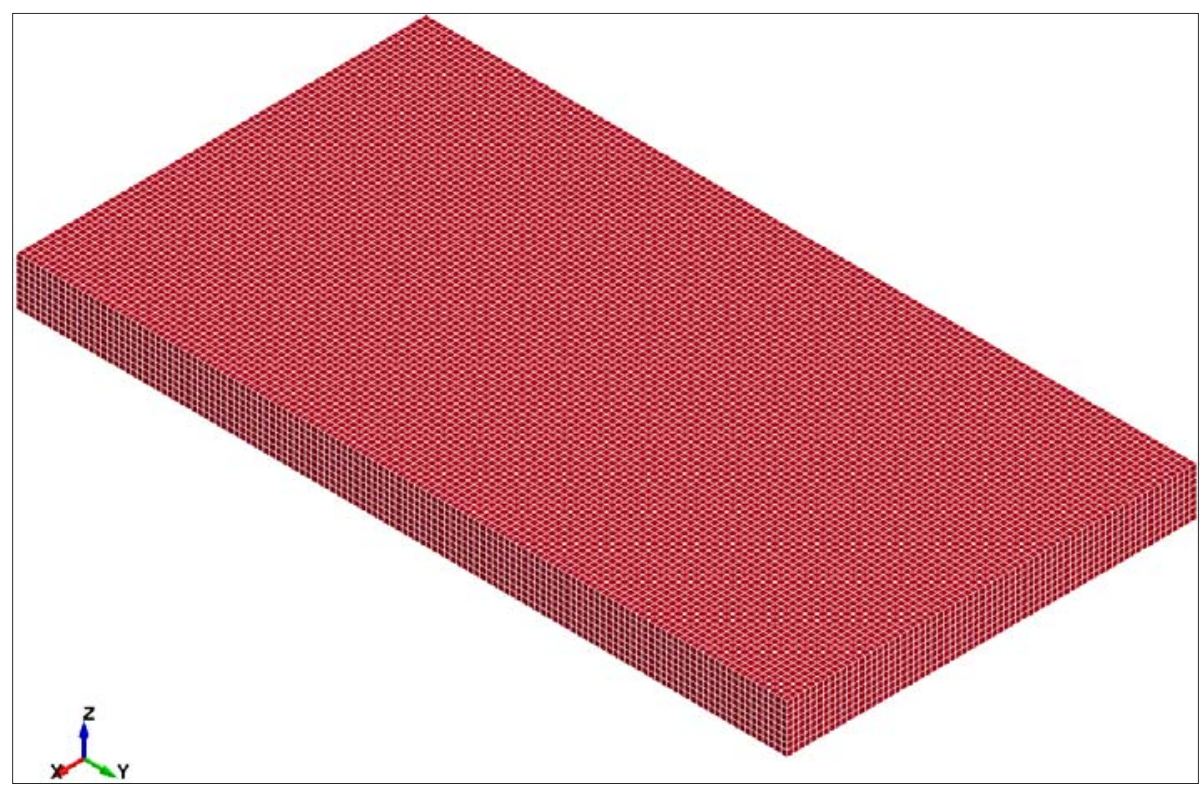

Figure 5-2: Single-Mat Reinforced Concrete slab model with Solid Elements $1 / 2$ in. (12.7 mm.) mesh size. 


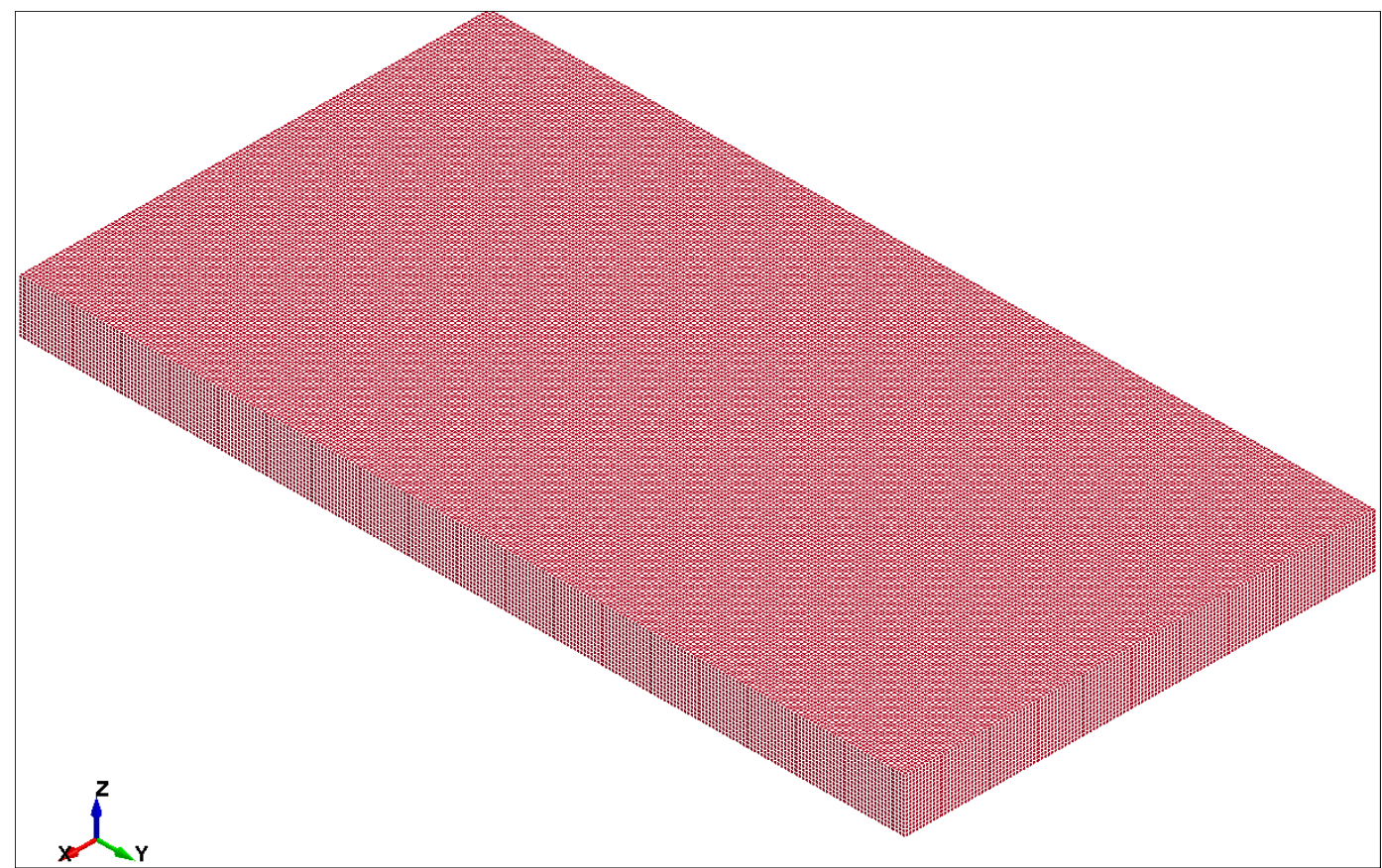

Figure 5-3: Single-Mat Reinforced Concrete slab model with Solid Elements $1 / 4$ in. $(6.35 \mathrm{~mm}$.) mesh size.

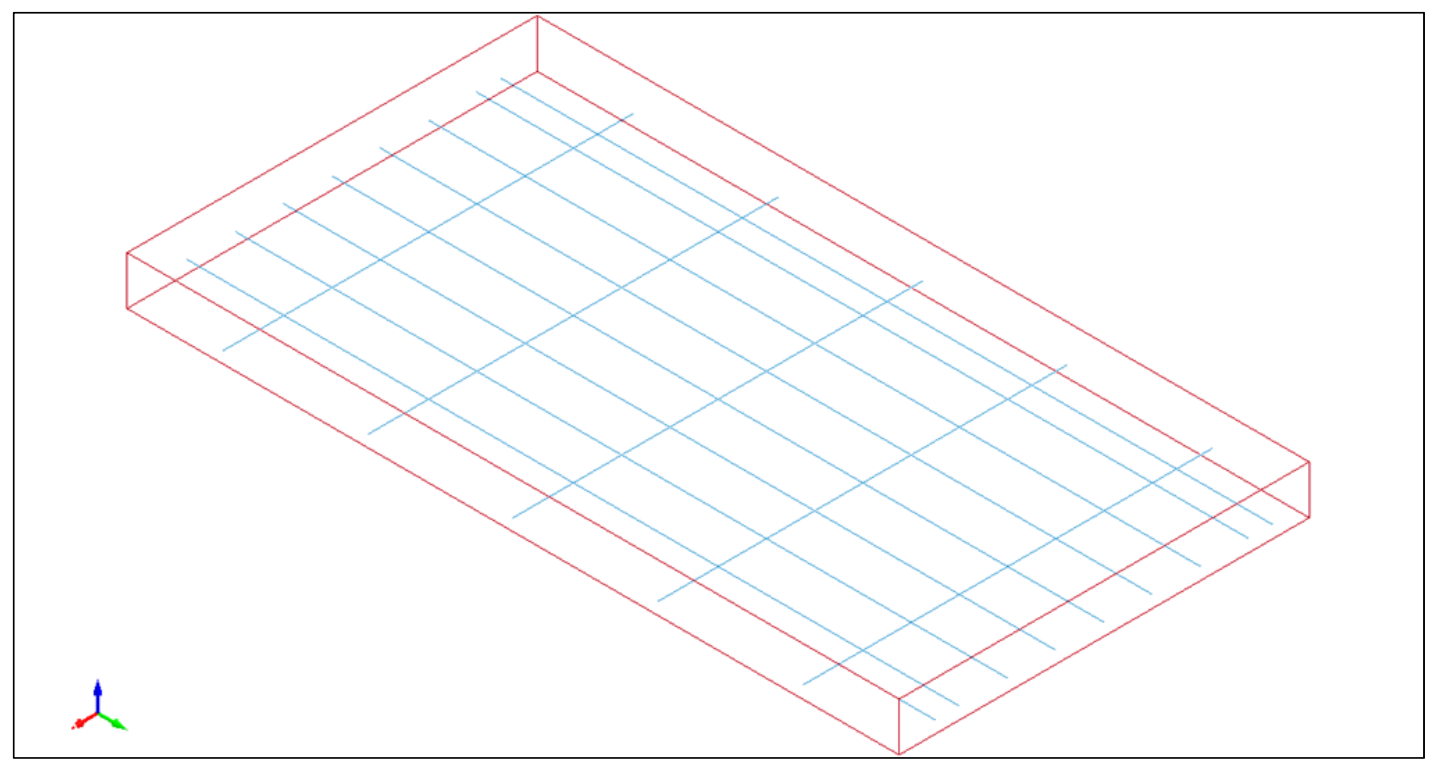

Figure 5-4: Single layer reinforcement in 4 in. type single-mat RC slab 


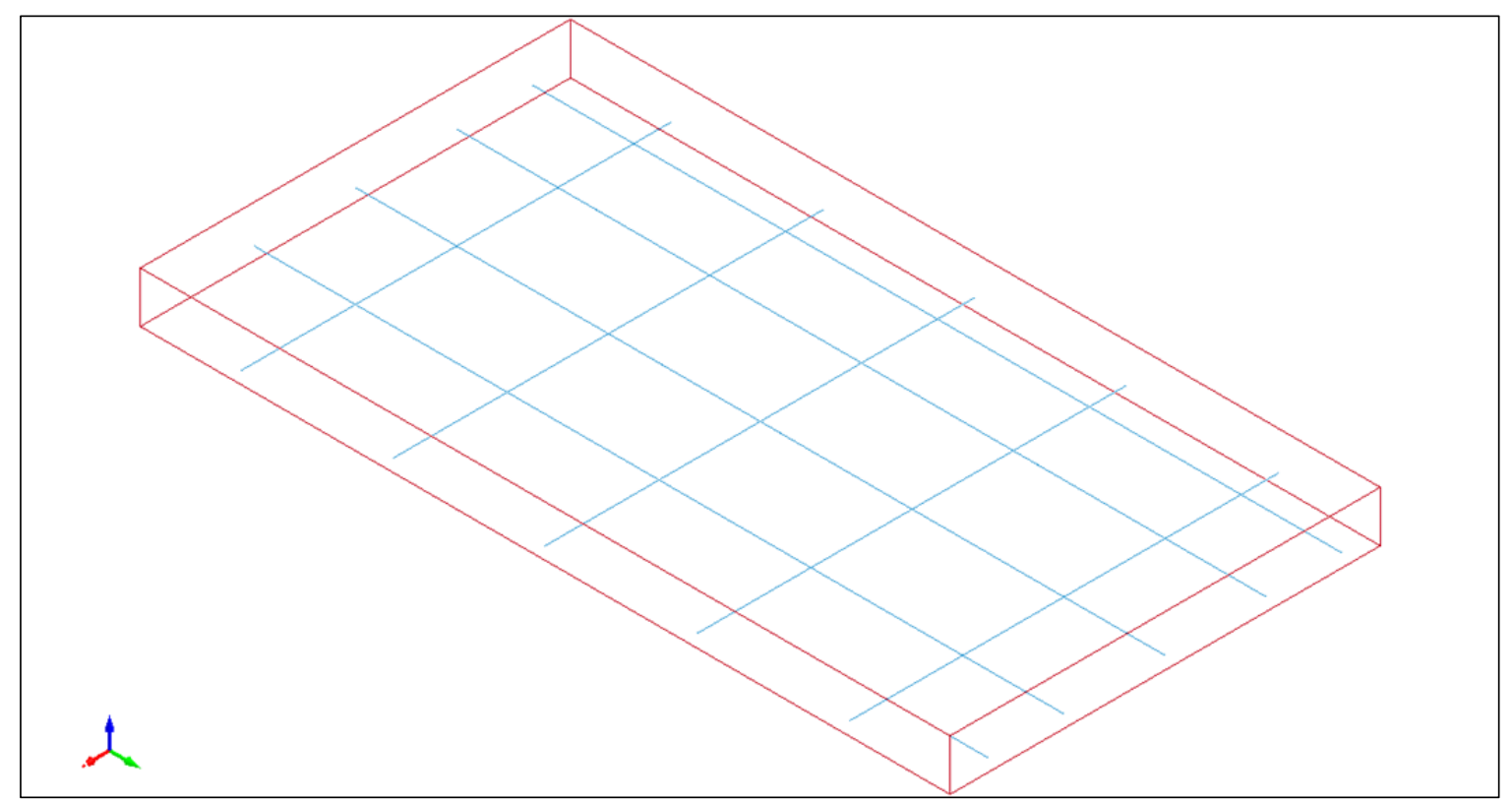

Figure 5-5: Single layer reinforcement in 8 in. type single-mat RC slab

\subsubsection{The Constrained Lagrange in solid formulation}

The interface between concrete and steel which is assumed to be a perfect bond is modeled using the *CONSTRAINED_LAGRANGE_IN_SOLID (CLS) formulation such that the nodes in the steel element are modeled independent of the nodes in the concrete element. A previous study was performed by Vasudevan [18] on the effects of using the CLS formulation for modeling the double-mat reinforced concrete slabs. In this study it was observed that deflection response of the numerical model matched well with the deflection response in the experiment.

\subsubsection{The Constant Stress Solid Element Formulation}

LS-DYNA® element library provides different types of element formulations based on the different types of integration methods. The type of element formulation required is 
specified in the *SECTION keyword under the variable 'ELFORM'. The default formulation used in LS-DYNA $®$ is the constant stress solid formulation which uses reduced integration [19]. This formulation is denoted by ELFORM value of 1 and it is useful in large deformation applications. The constant stress solid element uses the single point integration which reduces the time spent in stress determination. In reduced integration the number of integration points is reduced and thus it is advantageous in decreasing the CPU time and storage requirements [20]. A trial study was first performed to use different types of element formulations for modeling a reinforced concrete slab subjected to blast loads. Trials were carried out for Slab \# 1 with Concrete Damage Model Release 3 material and ONE inch mesh model. The observations made for the two element formulations namely, ELFORM $=1$ which uses reduced integration and ELFORM $=2$ which uses fully integrated S/R solid elements be seen in Figure 5-6 and Figure 5-7 respectively.

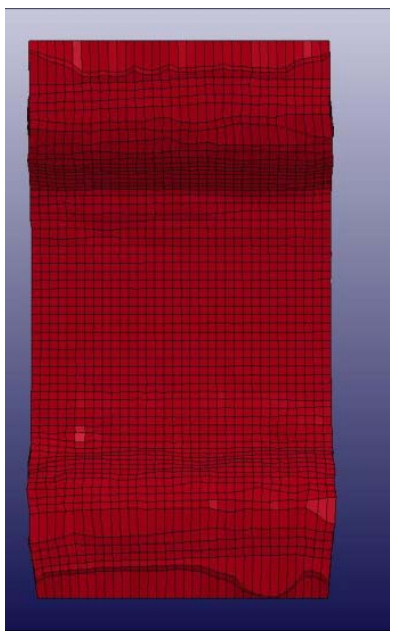

Figure 5-6: Slab response with ELFORM = 1

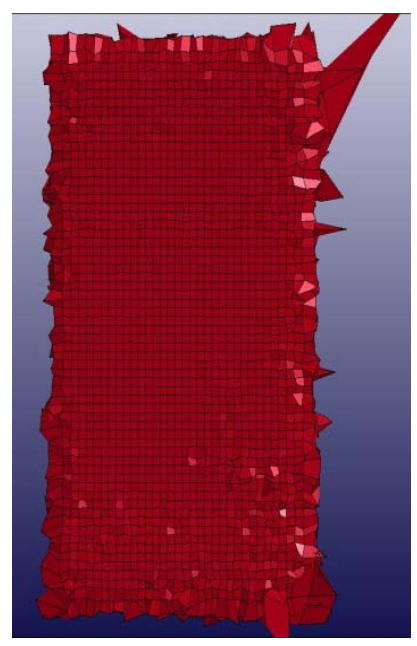

Figure 5-7: Slab response with ELFORM = 2

The total clock time for simulations using the two different element formulation was, 32 minutes with normal termination for ELFORM $=1$ and it was 240 minutes with error 
termination; negative volume in elements for ELFORM $=2$. The use of constant stress solid element reduced the time spent in stress determination by factor of 8 .

The negative volume effect which is dominant in the fully integrated $\mathrm{S} / \mathrm{R}$ solid elements $(E L F O R M=2)$ subjected to large deformation causing instabilities and error terminations can be overcome by using constant stress solid elements[21]. But the reduced integration formulation can cause no straining at the integration points thus leading to deformation modes called zero-energy modes or "hourglass modes". A zero-energy mode starts propagating through the mesh making the element rank-deficient. This phenomenon is termed as "hourglassing" [22]. To avoid such excessive deformations an additional artificial stiffness is added to the element associated with its zero-energy deformation modes. This procedure adopted by many Finite Element Programs is termed as Hourglass Control procedure $[20,22]$.

\subsubsection{Hourglass Control in LS-DYNA®}

LS-DYNA ${ }^{\circledR}$ recommends introduction of viscous damping or small elastic stiffness capable of resisting undesirable hourglassing by stopping the formation of zero energy modes. LS-DYNA ${ }^{\circledR}$ uses the algorithms developed by Kosloff and Frazier and Wilkins [23] [24]. In an eight-node element with one integration point a total of twelve hourglass modes exist. An hourglass-resisting force is implemented in the code represented by force vectors. This force vector includes a user defined constant, $\mathrm{Q}_{\mathrm{HG}}$ which is usually set to a value between 0.05 and 0.15 [20].

In LS-DYNA ${ }^{\circledR}$, hourglass control procedure is implemented using *CONTROL_HOURGLASS keyword option which allows to set the type of hourglass 
viscosity through variable IHQ and the hourglass co-efficient through variable QH [4]. The hourglass viscosity type recommended for stiffness type control is given by IHQ types $4 \&$ 5. The coefficient $\mathrm{QH}$ can take user defined values but values exceeding 0.15 may cause instabilities. However, the work done by hourglass resistance is neglected in the energy equation and may cause loss of energy. The total energy in the structures which remains constant during the analysis has to be analyzed to confirm the accuracy of the simulation. The hourglass energy is related to the non-physical modes of deformation occurring in the under-integrated element formulation such as the constant stress solid element formulation used here. The energy loss due to the dissipation of energy by hourglass forces reacting against the formation of hourglass modes can be reported in output files MATSUM and GLSTAT. The HGEN variable in *CONTROL_ENERGY is set to type 2 for computation of hourglass energy and inclusion in the energy balance [4]. The non-physical hourglass energy should be small relative to the peak internal energy $(<10 \%$ as rule of thumb) for confirming the effectiveness of hourglass control [21]. Remennikov and Kong performed numerical simulation of the response of non-composite steel-concrete-steel sandwich panels where they reported hourglass energy up to $50 \%$ of its peak internal energy when the effects of strain rate were considered in the simulation. They recommended exclusion of strain rate effects to minimize the hourglass energy as that reduced it to $15 \%$ of internal energy [21]. The default hourglass control was used for the FE slab models studied in this thesis and the strain rate effects were turned off.

\subsection{Boundary Conditions}

The boundary restraints applied in the numerical model are described here: 
i. Figure 5.6 shows the front face of the slab which was not restrained and the slab was free to move with the negative pull generated by the negative phase of the blast pressure wave.

ii. A 3 in. restraint in the Z-direction after a distance of 3 in. from the top and bottom edge is applied on the back face of the slab as shown in Figure 5.7.

iii. A single line of nodes in the center of 4 inch thick slab was restrained in Y-direction at both top and bottom faces as seen in the isometric view of the slab in Figure 5.8. These boundary conditions were used in order to be consistent with the experiment and keeping the modeling of boundary restraints simple by restraining the nodes rather than modeling a frame and its interaction with slab.

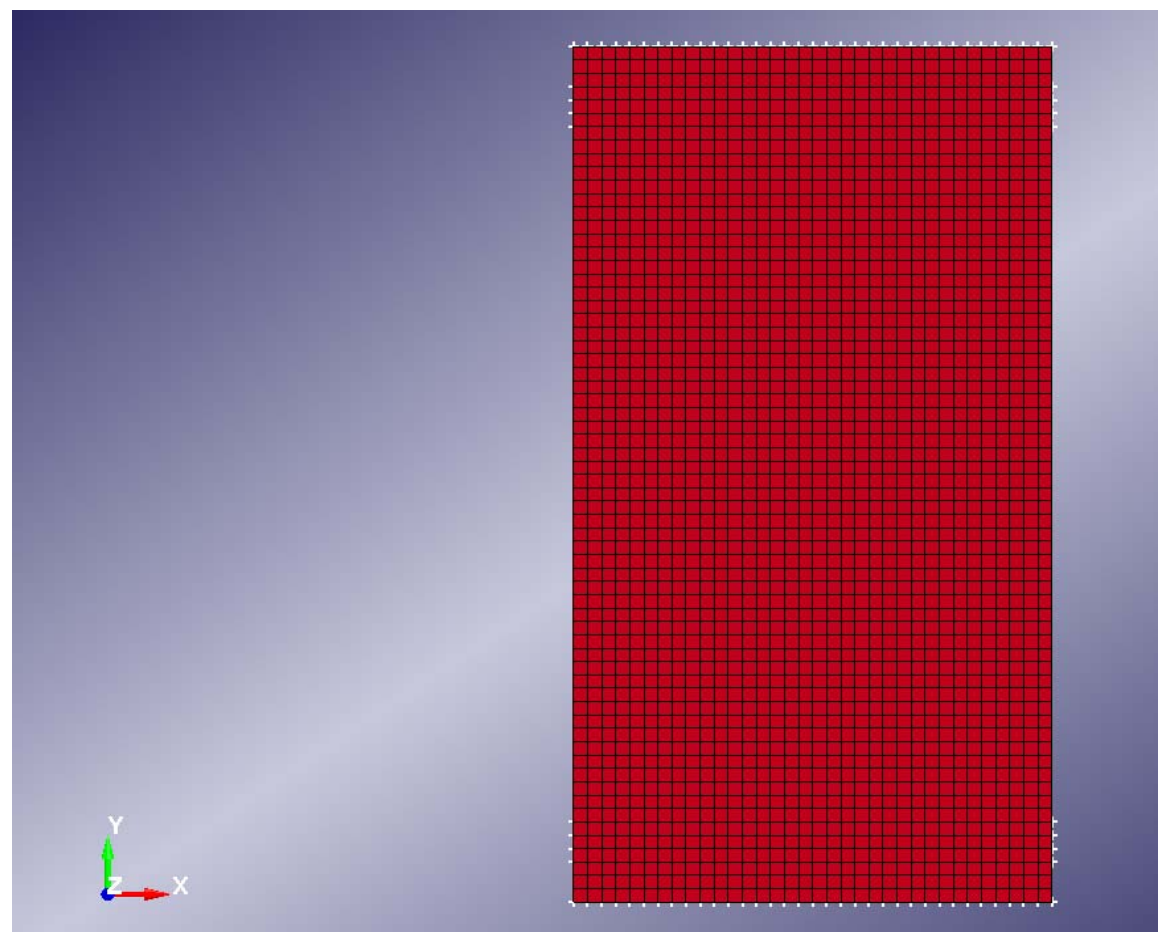

Figure 5-6: Boundary conditions on the front face of slab 


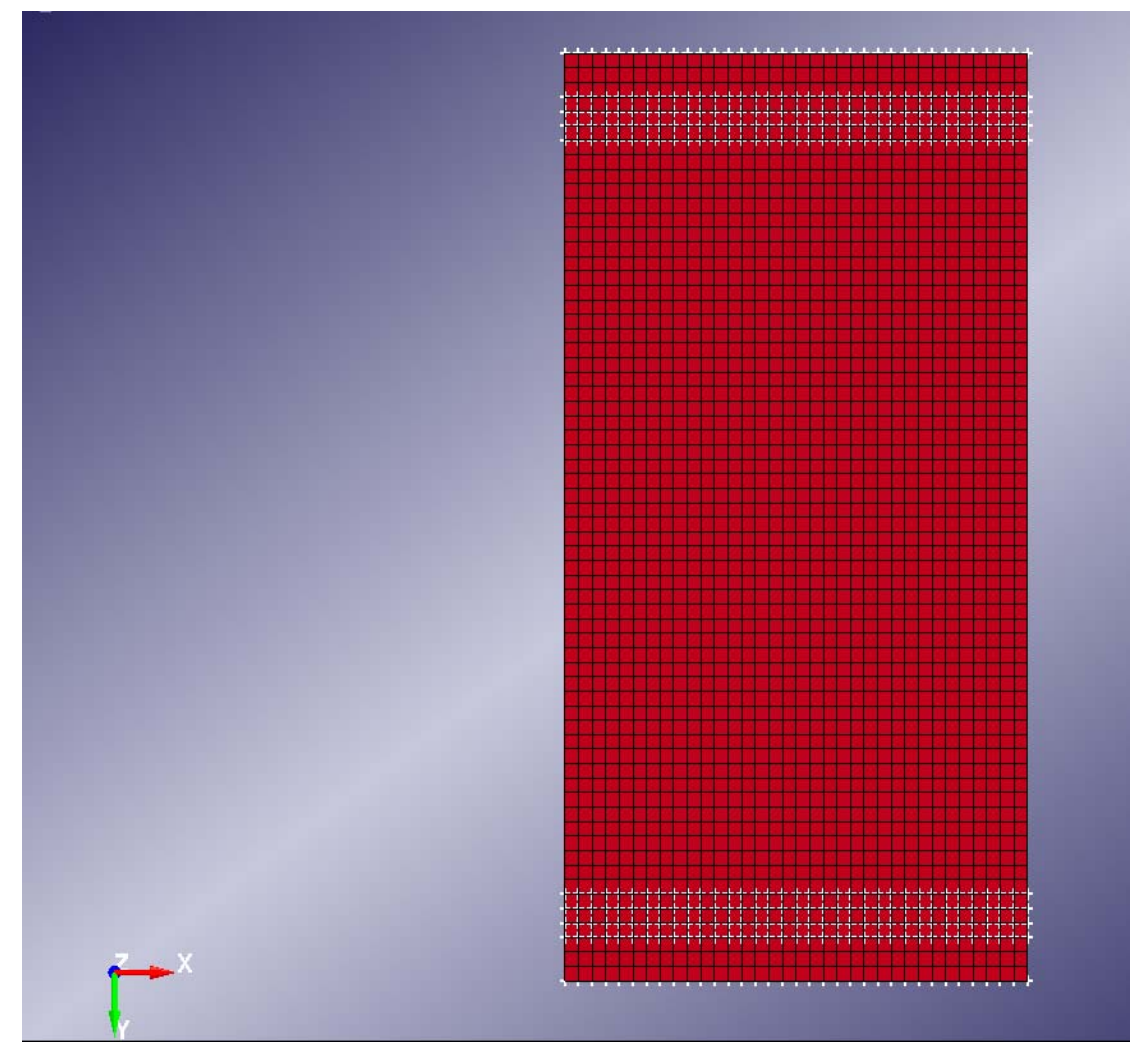

Figure 5-7: Boundary conditions on the back face of the slab

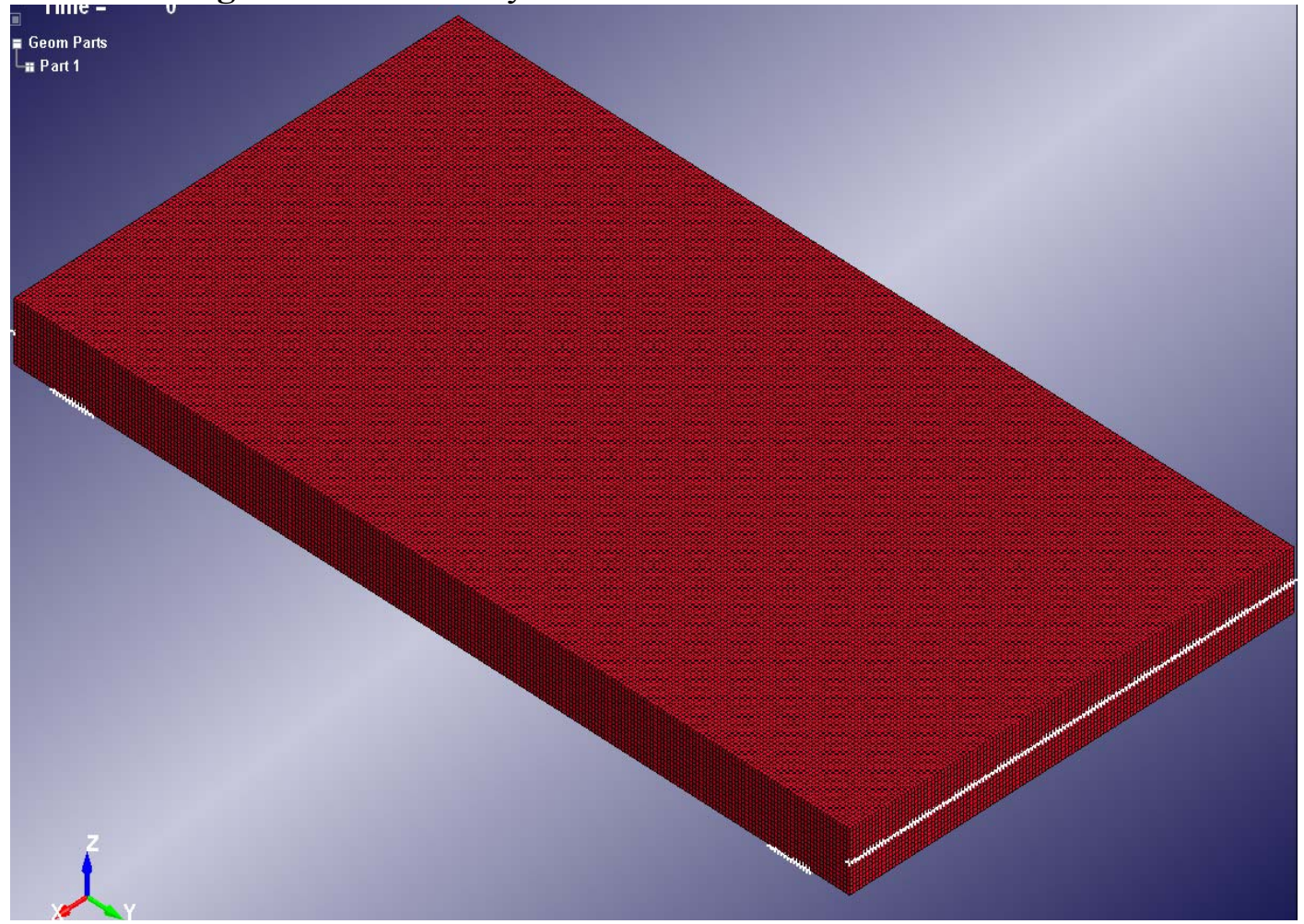

Figure 5-8: Boundary conditions on the top and bottom face of the slab 


\subsection{Material Models in LS-DYNA®}

LS-DYNA ${ }^{\circledR}$ provides 'simple input' concrete models for modeling the behavior of concrete using basic strength test data and thus reducing the burden of performing comprehensive tests on concrete to determine the parameters. The 'simple input' concrete models available in LS-DYNA® are *MAT_WINFRITH_CONCRETE (Mat 084 and Mat 085); *MAT_CONCRETE_DAMAGE_REL3 (Mat 072R3); *MAT_PSEUDO_TENSOR (Mat 016) and *MAT_CSCM_CONCRETE (Mat 159) [19]. In this research the Winfrith Concrete Model and the Concrete Damage Model Release 3 were chosen to model the concrete in the Single-mat RC slabs in order to be consistent with the available parameter input for both high-strength and normal-strength concrete. These parameters are tabulated in Appendix C.

\subsubsection{The Winfrith Concrete Model}

The Winfrith Concrete Model [19] is a smeared crack model (pseudo crack) which is implemented in the 8-node single integration point continuum element. The most important capability of this model is the generation of an additional binary output database giving details of crack location and its dimensions. This constitutive material model for reinforced concrete employs the smeared rebar approach, i.e. the reinforcement stresses are calculated separately from the calculation of concrete stresses and the two components are smeared together according to their relative cross-sectional area to give the total element stress. However, in this research the smeared rebar function in the Winfrith Concrete Model is not utilized. The steel is modeled using a different material model called the *MAT_PLASTIC_KINEMATIC[4] and the detailed discussion is given later in this chapter. 
Also, the interface between steel and concrete is defined using *CONSTRAINED_LAGRANGE_IN_SOLID formulation [4]. This formulation was adapted for Winfrith Concrete model in order to be consistent with the modeling performed using the *MAT_CONCRETE_DAMAGE_REL3 material model which does not provide formulation for defining the rebar within the concrete material model.

In further sections the various parameters required to be given as input in *MAT_WINFRITH_CONCRETE (*MAT084-085) [4] and their significance is discussed in detail.

\subsubsection{Plasticity Model Definition in Winfrith Concrete}

The Winfrith Concrete Model in LS-DYNA ${ }^{\circledR}$ provides a basic plasticity model which has the plasticity portion based upon the shear failure surface as proposed by Ottosen $[25,26]$. The basic plasticity model is referred to as a four parameter model in which the first two parameters denoted by constants ' $a$ ' and ' $b$ ' depend on the ratio of the unconfined tensile strength $\mathrm{f}_{\mathrm{t}}$, to the unconfined compressive strength $\mathrm{f}_{\mathrm{c}}$. The uniaxial compression and uniaxial tension are required input, in *MAT_WINFRITH_CONCRETE (*MAT084-085) [4].

The representation of shear failure surface proposed by Ottosen [25] is a quadratic given as:

$$
\mathrm{F}\left(\mathrm{I}_{1}, \mathrm{~J}_{2}, \cos 3 \theta\right)=\mathrm{a} \frac{\mathrm{J}_{2}}{\left(f_{c}^{\prime}\right)^{2}}+\lambda \frac{\sqrt{\mathrm{J}_{2}}}{f_{c}^{\prime}}+b \frac{I_{1}}{f_{c}^{\prime}}-1
$$

Equation 1

Here, constants a and b control the meridional shape of the shear failure surface, and $\lambda=\lambda(\cos 3 \theta)$ ranging $-1 \leq \cos 3 \theta \leq+1$ for triaxial compression to triaxial extension controls 
the shape of shear failure surface on the $\pi$-plane. The independent parameter $I_{1}$ is the first invariant of the stress tensor. In the Winfrith concrete model the invariants of the stress tensor are calculated first and then the invariants of the deviatoric stress tensor are computed using identities. The stress tensor, $\sigma_{\mathrm{ij}}$ has three scalar invariants (Eigenvalues):

$$
\begin{gathered}
I_{1}=\sigma_{k k} \\
I_{2}=0.5\left(\sigma_{i i} \sigma_{j j}-\sigma_{i j} \sigma_{j i}\right) \\
I_{3}=\operatorname{DET}\left(\sigma_{i j}\right)
\end{gathered}
$$

Equation 2

The deviatoric stress tensor, $\mathrm{S}_{\mathrm{ij}}$ is introduced to separate the mean stress from the shear response:

$$
S_{i j}=\sigma_{i j}-\frac{\sigma_{k k}}{3}
$$

Equation 3

Here, $\sigma_{k k}=I_{1}=3 P$ and $P$ is referred to as the mean stress. The deviatoric stress tensor has three invariants, $J_{2}, J_{3}$ and $\cos 3 \theta$. The first two invariants of the deviatoric stress tensors, $J_{2}$ and $J_{3}$ are related to the stress invariants as given below:

$$
\begin{gathered}
J_{1}=S_{k k}=S_{11}+S_{22}+S_{33}=0 \\
J_{2}=0.5 S_{i j} S_{i j}=\frac{1}{3} I_{1}{ }^{2}-I_{2} \\
J_{3}=\operatorname{DET}\left(S_{i j}\right)=\frac{2}{27} I_{1}{ }^{3}-\frac{1}{3} I_{1} I_{2}+I_{3}
\end{gathered}
$$


The third invariant of the deviatoric stress is represented as an angle in the $\pi$ - plane with limits $0 \leq \theta \leq \pi / 3$ and is defined in terms of deviatoric stress tensor invariants, $J_{2}$ and $J_{3} ;$ and the Lode Angle, $\theta$.

$$
\cos 3 \theta=\frac{3 \sqrt{3}}{2} \frac{J_{3}}{J_{2}{ }^{1.5}}
$$

Equation 3(b)

The meridional shape parameters' a' and 'b' are internally generated based on the data provided for unconfined tensile and compressive strengths and they are considered to be best fitting the shear failure surface of laboratory data. In the Winfrith model the user cannot determine these parameters ' $a$ ' and ' $b$ ' from the available data. Instead the Winfrith model introduces three non-dimensional constants:

$$
\alpha=1.16 ; \quad \beta=0.5907445 ; \quad \gamma=-0.6123724
$$

The meridional shape parameters $\mathrm{a}$ and $\mathrm{b}$ are evaluated by the model using these constants in the following equations:

$$
\begin{gathered}
b=\frac{1+R \alpha \frac{\gamma}{3}-\alpha^{2} \frac{\gamma}{3}-\frac{\alpha}{R}}{\alpha^{2} \frac{\beta}{3}-3 \alpha-R \alpha\left(\frac{\beta}{3}\right)} \\
a=\beta b+\gamma
\end{gathered}
$$

Where $R=\frac{f_{t}^{\prime}}{f_{c}^{\prime}}<1$ is the ratio of the unconfined tensile to compressive strength.

The Octahedral Shape Parameters are the remaining two parameters of the four parameter model and are denoted as $k_{1}$ and $k_{2}$ in Ottosen's notation. These parameters define 
the shape of the shear failure surface in the octahedral $(\pi-$ plane $)$. Two additional constants are defined in the Winfrith Model in terms of constants a and b:

$$
\begin{gathered}
c=\frac{\sqrt{3}}{R}\left(1-b R-R^{2} \frac{a}{3}\right) \\
d=\frac{3+3 b-a}{\sqrt{3}}
\end{gathered}
$$

Equation 5

The two constants $\mathrm{c}$ and $\mathrm{d}$ thus are included in the definition of the $\pi$ - plane shape factors as

$$
\begin{gathered}
k_{2}=\cos \left[3 \tan ^{-1}\left(\frac{1}{\sqrt{3}}-\frac{2 d}{c \sqrt{3}}\right)\right] \\
k_{1}=\frac{c}{\cos \left[\frac{1}{3} \cos ^{-1}\left(k_{2}\right)\right]}
\end{gathered}
$$

Equation 6

Also, the function $\lambda=\lambda(\cos 3 \theta)$ is now defined in terms of the constants $k_{1}$ and $k_{2}$ as defined below:

$$
\begin{gathered}
\lambda=k_{1} \cos \left[\frac{\cos ^{-1}\left(k_{2} \cos 3 \theta\right)}{3}\right] \text { for } \cos 3 \theta \geq 0 \\
\lambda=k_{1} \cos \left[\frac{\pi}{3}-\frac{\cos ^{-1}\left(-k_{2} \cos 3 \theta\right)}{3}\right] \text { for } \cos 3 \theta \leq 0
\end{gathered}
$$

Equation 7

The four parameters $\mathrm{a}, \mathrm{b}, k_{1}$ and $k_{2}$ thus define the shear failure surface in the Winfrith concrete model [26]. The uniaxial compressive strength and the uniaxial tensile strength are provided as input parameters along with mass density, initial tangent modulus of concrete, Poisson's ratio for concrete. Table 5-2 gives the details of the user input variables provided: 
Table 5-1: Input variables provided in *MAT_WINFRITH_CONCRETE required for defining the plasticity model in Winfrith model for two different types of concrete.

\begin{tabular}{llll}
\hline Variable & Description & $\begin{array}{l}\text { Input value for High } \\
\text { strength concrete }\end{array}$ & $\begin{array}{l}\text { Input value for } \\
\text { Normal strength } \\
\text { concrete }\end{array}$ \\
\hline RO & Mass Density & $2.246 \mathrm{E}-04 \mathrm{lb}-\mathrm{s} / \mathrm{in}^{3}$ & $2.246 \mathrm{E}-04 \mathrm{~b}-\mathrm{s} / \mathrm{in}^{3}$ \\
TM & Initial Tangent Modulus of & $3.6 \mathrm{E}+06 \mathrm{psi}$ & $3.6 \mathrm{E}+06 \mathrm{psi}$ \\
& Concrete & & \\
PR & Poisson's Ratio & 0.18 & 0.18 \\
UCS & Uniaxial Compressive Strength & $11600 \mathrm{psi}$ & $5000 \mathrm{psi}$ \\
UTS & Uniaxial Tensile Strength & $928 \mathrm{psi}$ & $460 \mathrm{psi}$ \\
\hline
\end{tabular}

\subsubsection{Volume Compaction curve in Winfrith Model}

The Winfrith concrete model is called the 'flat cap' model [26] because the pressure versus volume strain relation can be represented as a straight line normal to the mean stress

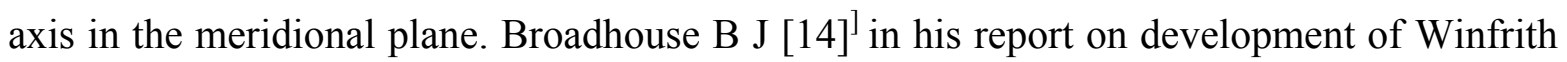
Concrete Model in LS-DYNA® states that a Pressure-v-volumetric strain curve is given as input parameter in order to determine the hydrostatic stress state in concrete. This curve is called Volume Compaction Curve and is introduced in the material parameters for Winfrith Model. Eight pairs of natural volume strains and corresponding pressures can be given as user input but the Winfrith model has the predefined pressure versus volume strain input option. These predefined values are derived strain and pressures occurring at the unconfined compressive strength, $f_{c}^{\prime}$. The pressure values are derived from the mean stress given by $P_{c}=\frac{f_{c}^{\prime}}{3}$ and the volume strain is approximated by $\varepsilon_{c}^{v o l}=\frac{P_{c}}{K}$, the elastic bulk modulus $\mathrm{k}$ is also computed from the elastic modulus and Poisson's ratio given as user input using the relation $=\frac{E}{3(1-2 v)}$. Table5-2 provides the pressure versus volume strain points generated by the Winfrith model for two different strengths of concrete. The tabulated data are given in 
order of increasing compression, with no initial zero point. A scaled curve is automatically used where $P_{c}$ is the pressure at uniaxial compressive failure form:

$$
\begin{aligned}
& P_{c_{11600 p s i}}=\frac{f_{c}^{\prime}}{3}=\frac{11600}{3}=3866.7 \mathrm{psi}=26.66 \mathrm{MPa} \\
& P_{c_{5000 p s i}}=\frac{f_{c}^{\prime}}{3}=\frac{5000}{3}=1666.7 \mathrm{ksi}=11.49 \mathrm{MPa}
\end{aligned}
$$

and $\mathrm{K}$ is the bulk unloading modulus computed as

$$
\mathrm{K}=\frac{\mathrm{Es}}{3(1-2 \mathrm{v})}=\frac{(3.6 \mathrm{e}+6)}{3 *(1-(2 * 0.18))}=1.875 \mathrm{e}+6
$$

Table 5-2: Winfrith concrete model generated Volume Compaction curve for $11.6 \mathrm{ksi}$ and $5 \mathrm{ksi}$ concrete.

\begin{tabular}{cccc}
\hline 11.6 ksi & & & \\
\hline $\begin{array}{c}\text { volumetric } \\
\text { Strain }\end{array}$ & $\begin{array}{c}\text { Pressure } \\
\left(\mathrm{x}^{*} \mathrm{P}_{\mathrm{c}}\right)\end{array}$ & Pressure & Pressure \\
$-\mathrm{P}_{\mathrm{c}} / \mathrm{K}$ & $\mathrm{x}$ & $(\mathrm{Psi})$ & $(\mathrm{Mpa})$ \\
\hline-0.000019 & 1.00 & 3866.7 & 26.66 \\
-0.002 & 1.50 & 5800.0 & 39.99 \\
-0.004 & 3.00 & 11600.1 & 79.98 \\
-0.010 & 4.80 & 18560.1 & 127.97 \\
-0.020 & 6.00 & 23200.2 & 159.96 \\
-0.030 & 7.50 & 29000.2 & 199.95 \\
-0.041 & 9.45 & 36540.3 & 251.93 \\
\hline-0.051 & 11.55 & 44660.4 & 307.92 \\
-0.062 & 14.25 & 55100.5 & 379.91 \\
-0.094 & 25.05 & 96860.8 & 667.83 \\
\hline
\end{tabular}

\begin{tabular}{lccc}
\hline $\mathbf{5}$ ksi & & & \\
\hline $\begin{array}{l}\text { volumetric } \\
\text { Strain }\end{array}$ & $\begin{array}{c}\text { Pressure } \\
\left(\mathrm{x}^{*} \mathrm{P}_{\mathrm{c}}\right)\end{array}$ & Pressure & Pressure \\
$-\mathrm{P}_{\mathrm{c}} / \mathrm{K}$ & $\mathrm{X}$ & $(\mathrm{Psi})$ & $(\mathrm{Mpa})$ \\
\hline-0.000019 & 1.00 & 1666.7 & 11.49 \\
-0.002 & 1.50 & 2500.0 & 17.23 \\
-0.004 & 3.00 & 5000.0 & 34.47 \\
-0.010 & 4.80 & 8000.0 & 55.16 \\
-0.020 & 6.00 & 10000.0 & 68.95 \\
-0.030 & 7.50 & 12500.0 & 86.18 \\
-0.041 & 9.45 & 15750.0 & 108.6 \\
-0.051 & 11.55 & 19250.0 & 132.72 \\
-0.062 & 14.25 & 23750.0 & 163.75 \\
-0.094 & 25.05 & 41750.0 & 287.86 \\
\hline
\end{tabular}

\subsubsection{Strain Rate effects in Winfrith Concrete Model}

Another important parameter in the Winfrith Model is the inclusion of strain rate effect. The Winfrith concrete model in LS-DYNA® offers two strain rate options to include or exclude strain rate effects which are selected via the user input parameter RATE. Two values 0 or 1 are given as input to turn the strain rate effect on or off respectively. The use 
of strain rate option for including strain rate effects i.e. RATE $=0$ is not recommended since many researchers have reported the Winfrith model to give odd results thus doubting the accuracy and reliability of results $[8,26]$. Hence, strain rate effects were not included in this model.

\subsubsection{Crack Analysis Using Winfrith Concrete Model}

The Winfrith Concrete Model provides information on crack propagation in concrete. A user input parameter for tensile cracking, denoted as 'FE' in the LS-DYNA set of input parameters for the Winfrith Concrete Model has to be provided. The definition of parameter 'FE' depends on the RATE parameter [4]. When strain rate effects are turned off the parameter 'FE' defines the crack width at which the tensile stress normal to the crack goes to zero. This crack width denotes the size of the gap formed by a planar tensile crack propagating through the medium. The crack width formulation used in the Winfrith model is a function of the crack opening displacement. As the crack opening displacement increases the crack length also increases and the work done in propagating the crack is utilized in creating a new crack surface. The energy per unit area dissipated in opening the crack is termed as the specific fracture energy [27]. The visual definition of this specific fracture energy in measurable terms is given by Wittman (1988) as the area under the stress-displacement curve [28]. These stress displacement curve is obtained from the force displacement variation data measurements which includes specific fracture energy, crack opening displacement and maximum load for a large number concrete samples. Based on the specific fracture energy and the unconfined tensile strength a strain softening response is developed which is a normalized version of the stress displacement curve and a relation 
between crack width $w$, specific fracture energy $\mathrm{G}_{f}$ and unconfined tensile strength $f_{t}^{\prime}$ is defined in terms of parameter $\mathrm{c}$ is given by [27].

$$
c=w \frac{f_{t}^{\prime}}{\mathrm{G}_{f}}
$$

..Equation 8

This strain softening response is implemented in the Winfrith concrete model in LSDYNA ${ }^{\circledR}[26]$ [27]. For RATE $=0$, with strain rates the cracking form is defined by a linear strain softening response where the relation between crack width $w$, specific fracture energy $\mathrm{G}_{f}$ and unconfined tensile strength $f_{t}^{\prime}$ is given by

$$
w=2 \frac{\mathrm{G}_{f}}{f_{t}^{\prime}}
$$

Equation 9

The Winfrith concrete model for no strain rate form (i.e. RATE=1) this parameter 'FE' denotes the crack width at which the crack-normal tensile stress goes to zero. The value provided here was $0.0002 \mathrm{inch}$. The parameter ASIZE which denotes the aggregate size was given as 0.125 inch.

The database generated for providing the details of crack propagation is implemented at the execution line in LS-DYNA ${ }^{\circledR}$ by giving the input, $q=$ CRACK, where CRACK is the name of the crack database [4]. This database includes the information on crack location, directions and widths. This crack database can be opened in LS-Prepost, which displays the cracks on deformed mesh plots. The visible cracks displayed in LSPrepost are used for basic comparison with the crack pattern recorded for each slab in the experimental analysis. 
The material parameters provided as input in the Winfrith Concrete Material model are tabulated in Table C-1 of Appendix C.

\subsubsection{The Concrete Damage Model Release 3}

The Concrete Damage Model Release 3 is another type of 'simple input' model which is available in LS-DYNA® material model library. The most important capability of this material model is to generate model parameters based on unconfined compressive strength of concrete. This capability is important because it reproduces concrete behavior critical to blast analysis by characterizing most of the concrete properties which include both the elastic and plastic response [29]. This model is termed as the 'Simplified' model as it uses minimum user input (i.e. 1 or 2 Parameters) and it has been simplified for user's use to provide a robust representation of many response characteristics of a complex material, concrete $[11,30]$. This model can also be used with complete user specified inputs although it provides internal parameter generation. If the laboratory test data for various parameters required to be given as input is available then it is recommended to use them as per the study performed by Malvar and Schwer [11] which compared a well characterized 45.6 $\mathrm{MPa}$ unconfined compression strength concrete material parameters obtained in laboratory with the corresponding material response from the $\mathrm{K} \& \mathrm{C}$ Concrete Model. This paper reports mainly two types of test i.e. isotropic (hydrostatic) compression test and tri-axial compression test measuring the pressure versus volume strain compaction response and compressive failure surface respectively for 45.6 Mpa concrete. The comparison for 45.6 Mpa concrete has shown fairly accurate prediction of parameters by the Material type 72R3. For modifying the generated model parameters, the generated parameters for a particular unconfined compressive strength of concrete are 
written to the LS-DYNA® message file. The pressure-volume strain response for the model is also generated in the form 'Tabulated Compaction Equation-of-state' (EOS 8) and its parameters are also written to the LS-DYNA ${ }^{\circledR}$ "messag" file [4]. This model parameters generated in the message file are studied, modified and given as input in the keyword file. The keyword file is then processed in LS-DYNA® and the results are observed using LSPrePost.

\subsubsection{The Three-Shear Failure Surfaces in Concrete Damage Model Release 3}

The *Concrete Damage Model Release 3 (*MAT072R3) is a three invariant model which uses 3-shear failure surfaces namely maximum shear failure surface, residual failure surface and initial yield surface. This model also incorporates damage and strain-rate effects. This Karagozian and Case $(\mathrm{K} \& \mathrm{C})$ - Concrete Damage Model Release III requires a set of seven cards of model input parameters to be defined. An Equation-of-State is also required for the pressure-volume strain response [19].

The three failure surfaces are defined by three sets of parameters; $(\mathrm{a} 0, \mathrm{a} 1, \mathrm{a} 2)$ : maximum shear failure surface, (a0f, a1f, a2f) : residual failure surface and (a0y,a1y,a2y) : yield failure surface. The compressive shear strength measured using a triaxial compression test is represented mostly by plotting the results in which the two axes comprise of stress difference and mean stress. The equation for this graph is represented in the equation (10):

$$
\text { Von mises stress }=(\text { axial stress }- \text { lateral stress })=a 0+\left(\frac{\text { mean stress }}{a 1+(\text { a2*mean stress })}\right)
$$

Thus, a total of eight parameters define the three fixed surfaces, as follows [12, 30]:

$$
\Delta \sigma_{m}=a 0+\frac{p}{a 1+a 2 * \mathrm{p}} \quad \text { (maximum failure surface) }
$$




$$
\begin{aligned}
& \Delta \sigma_{r}=\frac{p}{a_{1 f}+a_{2 f} * \mathrm{p}} \quad \text { (residual failure surface) } \\
& \Delta \sigma_{y}=a_{0 y}+\frac{p}{a_{1 y}+a_{2 y^{*} \mathrm{p}}} \text { (yield failure surface) }
\end{aligned}
$$

Equation 11

Where, $\Delta \sigma$ is the difference in the principal stresses and $\mathrm{p}$ is the pressure in an element.

The maximum shear failure surface parameter value characterized for the particular type of concrete is given as input for the variables a0, a1 and a2. But if laboratory testing results are not available for a particular concrete then the unconfined compressive strength fc' is provided as input instead of a0 with a negative sign to represent compression. This value is used by the Concrete Damage Model Release 3 for automatic parameter generation. However, the surface parameters generated for the model can be read in the "messag" file.

\subsubsection{The tensile strength of concrete}

The next important input parameter which is the tensile strength of concrete can be given as input based upon the unconfined compressive strength using the following relationship which is a standard concrete relations given in CEB-FIP Model Code 1990 as used by Malvar and Schwer [11] :

$$
f_{t}=1.58 *\left(\frac{f c^{\prime 2}}{a_{0}}\right)^{\frac{1}{3}}
$$

for unconfined compressive strength of $11.6 \mathrm{ksi}$ concrete the tensile strength generated is $\quad f_{t}=1.58 *\left(\frac{11.6^{2}}{a_{0}}\right)^{\frac{1}{3}}=7.832 \mathrm{ksi}$ and similarly for unconfined compressive strength of $5 \mathrm{ksi}$ concrete the tensile strength generated is $f_{t}=1.58$ * 
$\left(\frac{5^{2}}{a_{0}}\right)^{\frac{1}{3}}=4.62 \mathrm{ksi}$. The tensile strength generated by Concrete Damage Model Release 3 automatic parameter generation capability also gives the same value as verified in LSDYNA ${ }^{\circledR}$ output messag file.

\subsubsection{Equation of State for Concrete Damage Model Release 3}

An equation-of-state is also used by Concrete Damage Model Release 3 to provide the pressure and volume strains. The default parameters generated for a standard 45.6 MPa concrete as studied by Malvar and Schwer [11] when compared to the laboratory data available to them has shown underestimation of the post elastic bulk modulus. The comparison of slope for both data plots clearly has shown the response of Concrete Damage Model Release 3 lower than the laboratory data for $45.6 \mathrm{MPa}$ concrete. Due to such variability in the volumetric response for concrete (Equation of State) the calibration of this model to specific material characterization data is warranted [29]. It is therefore recommended to use the pressure-volume strain data for the particular concrete of interest if it available. The default parameters generated by Concrete Damage Model Release 3 can be replaced by providing Equation-of-state input keyword and provide the available pressurevolume data. The laboratory data available for $11.6 \mathrm{Ksi}$ and $5 \mathrm{Ksi}$ concrete for the pressure versus volume strain response is shown in Figure 5-9 and Figure 5-10 respectively.

The pressure and volumetric strain values from the curve shown in Figure 5-9 and 510 were given as input in the Equation of state description provided as input in the keyword file. The Equation of state form used here to give the new values as input is the *EOS_TABULATED_COMPACTION. In the *EOS_TABULATED_COMPACTION about 10 points for pressure versus volume data can be given as input. Volumetric strain values are given with negative sign (in compression) while pressure is positive in 
compression. The volume strain data obtained from the laboratory had to be converted to natural strains by using their natural logarithmic values. The details of the EOS form is given in Appendix D as a part of the *PART form. The EOSID input parameter in the *PART card had to be specified as per the EOSID used. In this case for pressure-volume data the EOSID recommended in LS-DYNA ${ }^{\circledR}$ keyword manual was EOSID=8 [20]. The input parameters for the Concrete Damage Model Release3 for two types of concrete are tabulated in Table C-2 in Appendix C.

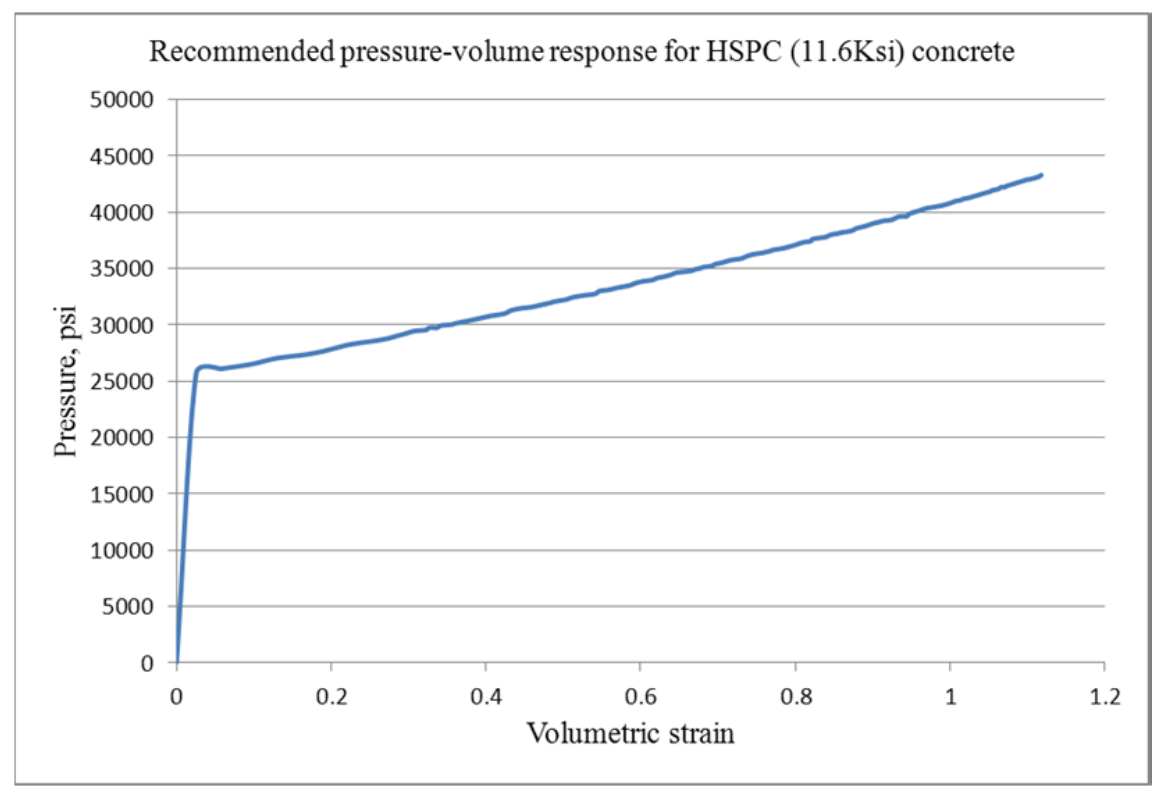

Figure 5-9 : Pressure Versus Volumetric Strain Curve for Equation of State Form 8 with compaction for $11.6 \mathrm{ksi}$ concrete 


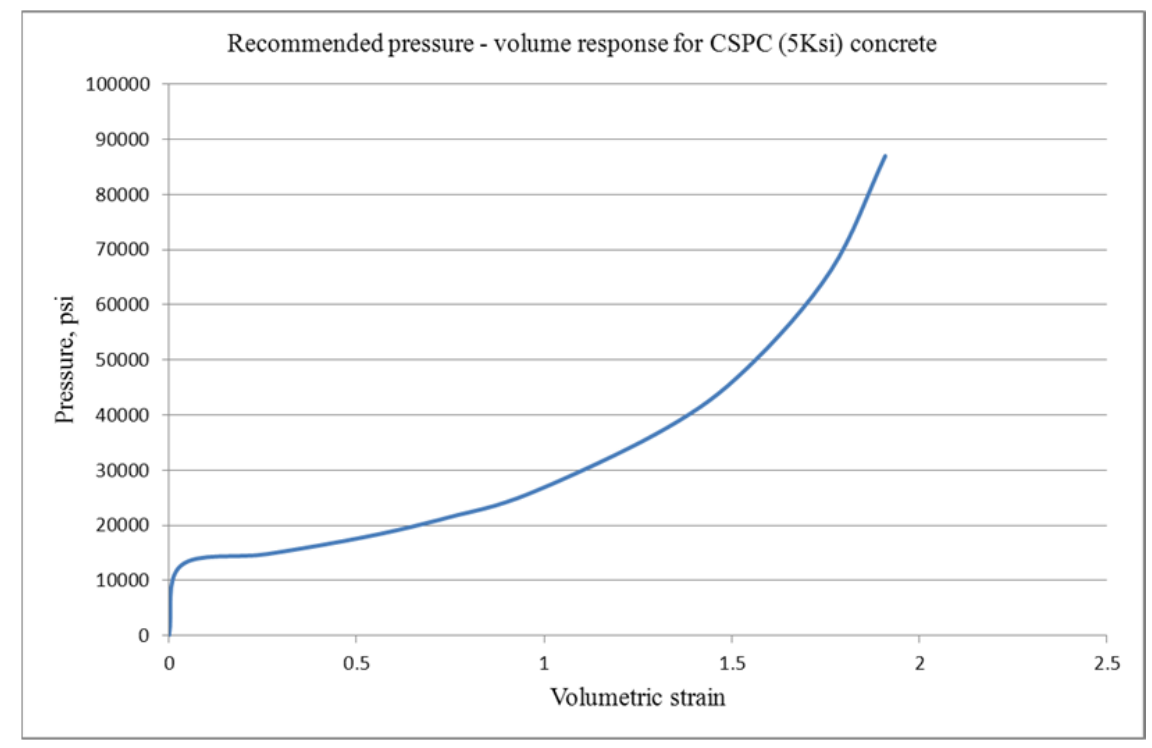

Figure 5-10 Pressure Versus Volumetric Strain Curve for Equation of State Form with compaction for $5 \mathrm{Ksi}$ concrete

\subsubsection{Crack Analysis Using Concrete Damage Model Release 3}

The Concrete Damage Model Release 3 is not capable of generating crack output to simulate the physical crack patterns which develop in FE concrete slab model. In order to generate physical crack patterns an additional keyword needs to be introduced. This additional keyword is a material model called the Mat_Add_Erosion which is used with the constitutive models which do not allow failure and erosion. The Mat_Add_Erosion option provides a way of including failure in such constitutive models. This keyword allows several criteria to be defined independently to model the erosion and failure. The elements get deleted during simulation when one of the criteria is satisfied. [4]

\subsubsection{The Plastic Kinematic Model for Steel}

For modeling of the steel reinforcement, the elastic-plastic Plastic Kinematic material model was adopted. This model formulated by Krieg and Key is a very cost effective model suited to model the isotropic and kinematic hardening plasticity with the 
option of including rate effects [31]. A parameter Beta is varied between values $0<\beta<1$ in order to specify the kinematic, isotropic or a combination of kinematic and isotropic hardening. In this study kinematic hardening was taken into consideration and thus the value of Beta was given as zero. The strain rate effects were not taken into consideration and thus the strain rate parameter was given as zero. The other parameters for specifying the material properties of steel are mass density, Young's modulus, Poisson's ratio, Yield strength and tangent modulus. The input parameters for the Plastic Kinematic model for two types of steel are tabulated in Table C-3 in Appendix C.

\subsection{Blast Load Application in LS-DYNA ${ }^{\circledR}$}

In an explosion phenomenon the most significant feature is the sudden release of energy in the atmosphere causing a change in pressure which is termed as a blast wave. This blast wave propagates outwards from the source in all directions at a very high speed. The magnitude and shape of the blast wave depends on the nature of the explosion and the distance of the point under consideration from the explosion epicenter.

In the blast experiments a shock tube was used to generate pressures equivalent to the pressures generated in the blast wave. The characteristic shape of the blast wave generated is that of the shock wave type. The shock wave consists of a sudden rise in pressure above ambient atmospheric condition to a peak overpressure followed by a gradual fall to ambient pressure resulting in a negative pressure wave.

The parameter's that are used to define a blast wave are peak side-on positive overpressure, $\mathrm{P}_{\mathrm{so}}$ having positive phase duration, $\mathrm{t}_{\mathrm{d}}$ and the corresponding positive impulse, $\mathrm{I}_{0}$; peak side-on negative overpressure, $\mathrm{P}_{\text {so }}{ }^{-}$having negative phase duration, $\mathrm{t}_{\mathrm{d}}{ }^{-}$and the corresponding negative impulse, $\mathrm{I}_{0}^{-}$. It is important to have a definite description of these 
parameters to simulate the blast wave in the finite element analysis to resemble the blast phenomenon inside the shock tube. The pressure vs. time histories with the impulse values is shown in appendix B for all 12 slabs. The load curves as seen in the figures B-1 to B12 are then applied uniformly over the slab front face. The *LOAD_SEGMENT_SET keyword in LS-DYNA is used to define the load curve and slab surface interaction. The pressure vs time co-ordinates are defined using *DEFINE_CURVE while the surface is defined using the *SET_SEGMENT keywords.

The numerical modeling for 12 reinforced concrete single-mat slabs was completed using various functionalities available in LS-DYNA®. The results of the numerical simulation are made available in LS-DYNA post-processor. The results which are important for this thesis were the mid-span deflection-time histories, crack damage patterns in slabs using Winfirth Concrete Model and contours for max-principal strain in slabs using the Concrete Damage Model Release 3. The results from numerical analysis are presented and discussed in detail in the next chapter. 


\section{CHAPTER 6}

\section{NUMERICAL ANALYSIS RESULTS AND COMPARISON WITH EXPERIMENTS}

In this chapter the results obtained from the numerical simulations performed in LSDYNA are compared with the experimental results. The two criteria used for the comparison are peak slab deflections and damage patterns. The numerical simulation comparison with the experiments was done for all 12 slabs which consists of two sets namely the combination of high strength concrete reinforced with high strength steel (HSCV) and normal strength concrete reinforced with normal strength steel (RSC-R).

\subsection{Comparison Criterion 1; Peak Deflection for Slab}

The peak deflections observed in the numerical simulation are compared with the peak deflections of slab observed in the experiment as follows:

1. Two different mesh sizes are compared, namely 1 in. $(25.4 \mathrm{~mm})$ and $1 / 2$ in. (12.7 $\mathrm{mm})$. The two different models are denoted as "One Inch Mesh Model" and "Half Inch Mesh Model". This study is termed as "Mesh Size Effect".

2. Two concrete material models namely, the Winfrith Concrete Model and the Concrete Damage Model Release 3. This study is termed as "Material Model Effect".

The overall deflection results for the simulations and the experiments for all 12 slabs are tabulated in Table 6-1 to Table 6-4. Table 6-1 and Table 6-2 give the peak and residual deflection respectively as observed in all the high strength slabs. Table 6-3 and Table 6-4 give the peak and residual deflection respectively as observed in all the normal strength slabs. 
Table 6-1: Analytical and Experimental Peak Slab Deflection Summary for High Strength Slabs.

\begin{tabular}{|c|c|c|c|c|c|c|}
\hline \multirow[t]{3}{*}{ Slab No. } & \multirow[t]{3}{*}{ Description } & \multicolumn{4}{|c|}{ Deflections } & \multirow{3}{*}{ Experimental } \\
\hline & & \multicolumn{2}{|c|}{1 in.mesh } & \multicolumn{2}{|c|}{0.5 in. mesh } & \\
\hline & & Winfrith & $\begin{array}{l}\text { Damage } \\
\text { Release } 3\end{array}$ & Winfrith & $\begin{array}{l}\text { Damage } \\
\text { Release } 3\end{array}$ & \\
\hline Slab 1 & HSC-V1-4in. & 3.83 & 3.8 & 5.63 & 4.37 & 3.89 \\
\hline Slab 3 & HSC-V2-4in. & 4.77 & 4.28 & 5.11 & 4.31 & 4.53 \\
\hline Slab 5 & HSC-V3-4in. & 2.94 & 3.38 & 3.14 & 3.41 & 2.46 \\
\hline Slab 7 & HSC-V4-8in. & 6.97 & 4.61 & $* *$ & 5.37 & 7.20 \\
\hline Slab 9 & HSC-V5-8in. & 3.25 & 3.49 & 3.71 & $* *$ & 3.40 \\
\hline Slab 11 & HSC-V6-8in. & 3.25 & 3.88 & 4.30 & 4.09 & 3.38 \\
\hline
\end{tabular}

Table 6-2: Analytical and Experimental Residual Slab Deflection Summary for High Strength Slabs.

\begin{tabular}{|c|c|c|c|c|c|c|}
\hline \multirow[t]{3}{*}{ Slab No. } & \multirow[t]{3}{*}{ Description } & \multicolumn{4}{|c|}{ Deflections } & \multirow{3}{*}{ Experimental } \\
\hline & & \multicolumn{2}{|c|}{1 in.mesh } & \multicolumn{2}{|c|}{0.5 in. mesh } & \\
\hline & & Winfrith & $\begin{array}{l}\text { Damage } \\
\text { Release } 3\end{array}$ & Winfrith & $\begin{array}{l}\text { Damage } \\
\text { Release } 3\end{array}$ & \\
\hline Slab 1 & HSC-V1-4in. & 2.18 & 1.99 & 4.22 & 0.82 & 1.98 \\
\hline Slab 3 & HSC-V2-4in. & 3.69 & 2.81 & 4.97 & 1.95 & 3.48 \\
\hline Slab 5 & HSC-V3-4in. & 2.37 & 1.25 & 2.62 & Slab rebounds & 1.30 \\
\hline Slab 7 & HSC-V4-8in. & 4.87 & 1.69 & $* *$ & 1.99 & 5.56 \\
\hline Slab 9 & HSC-V5-8in. & 2.58 & 3.43 & 2.91 & $* *$ & 1.40 \\
\hline Slab 11 & HSC-V6-8in. & 2.55 & 2.04 & 3.86 & Slab rebounds & 1.92 \\
\hline
\end{tabular}

Table 6-3: Analytical and Experimental Peak Slab Deflection Summary for Normal Strength Slabs.

\begin{tabular}{|c|c|c|c|c|c|c|}
\hline \multirow[t]{3}{*}{ Slab No. } & \multirow[t]{3}{*}{ Description } & \multicolumn{4}{|c|}{ Deflections } & \multirow{3}{*}{ Experimental } \\
\hline & & \multicolumn{2}{|c|}{1 in.mesh } & \multicolumn{2}{|c|}{0.5 in. mesh } & \\
\hline & & Winfrith & $\begin{array}{l}\text { Damage } \\
\text { Release } 3\end{array}$ & Winfrith & $\begin{array}{l}\text { Damage } \\
\text { Release } 3\end{array}$ & \\
\hline Slab 2 & RSC-R1-4in. & 3.30 & 4.73 & 3.67 & 5.69 & 4.29 \\
\hline Slab 4 & RSC-R2-4in. & 3.27 & 4.45 & 3.73 & 5.71 & 4.45 \\
\hline Slab 6 & RSC-R3-4in. & 2.13 & 3.47 & 2.45 & $* *$ & 3.17 \\
\hline Slab 8 & RSC-R4-8in. & 2.80 & 3.65 & 2.55 & 4.66 & 3.38 \\
\hline Slab 10 & RSC-R5-8in. & 3.29 & 3.98 & 2.93 & 4.92 & 3.6 \\
\hline Slab 12 & RSC-R6-8in. & 3.01 & 3.42 & 2.75 & 5.23 & 3.17 \\
\hline
\end{tabular}


Table 6-4: Analytical and Experimental Residual Slab Deflection Summary for Normal Strength Slabs.

\begin{tabular}{|c|c|c|c|c|c|c|}
\hline Slab No. & Description & & Defle & tions & & \\
\hline & & & iesh & & mesh & Experimental \\
\hline & & Winfrith & $\begin{array}{l}\text { Damage } \\
\text { Release } 3\end{array}$ & Winfrith & $\begin{array}{l}\text { Damage } \\
\text { Release } 3\end{array}$ & \\
\hline Slab 2 & RSC-R1-4in. & 0.22 & 2.74 & 2.48 & 3.56 & 3.38 \\
\hline Slab 4 & RSC-R2-4in. & 1.15 & 3.2 & 2.29 & 4.46 & 3.34 \\
\hline Slab 6 & RSC-R3-4in. & 1.31 & 0.9 & 1.71 & ** & 1.97 \\
\hline Slab 8 & RSC-R4-8in. & 2.26 & Slab rebounds & 1.53 & Slab rebounds & 1.8 \\
\hline Slab 10 & RSC-R5-8in. & 2.58 & Slab rebounds & 1.77 & Slab rebounds & 1.48 \\
\hline Slab 12 & RSC-R6-8in. & 2.38 & Slab rebounds & 1.63 & Slab rebounds & 2.05 \\
\hline
\end{tabular}




\subsubsection{High Strength Concrete with High Strength Steel Slabs (HSC-V)}

The first set of slabs studied here are the ones having combination of high strength concrete reinforced with high strength steel (HSC-V). The deflection-time histories for each of the 6 slabs are represented in this section. The comparison is made between two mesh sizes i.e. 1 " and 0.5 " for each of the two material models as shown in Table 6-5 and Table 6-6.

Table 6-5: Percentage Comparison of Peak Slab Deflections with the Experimental Value for High Strength Slabs.

\begin{tabular}{|c|c|c|c|c|c|c|}
\hline \multirow[t]{3}{*}{$\begin{array}{l}\text { Slab } \\
\text { No. }\end{array}$} & \multirow[t]{3}{*}{ Description } & \multirow[t]{3}{*}{$\begin{array}{c}\text { Pressure } \\
\text { (psi)/Impulse } \\
\text { (psi-msec) } \\
\end{array}$} & \multicolumn{4}{|c|}{$\begin{array}{c}\text { Percentage Change in Deflections in the } \\
\text { Numerical Model from Experimental } \\
\text { Deflection values. }\end{array}$} \\
\hline & & & \multicolumn{2}{|c|}{1 in.mesh } & \multicolumn{2}{|c|}{0.5 in. mesh } \\
\hline & & & Winfrith & $\begin{array}{l}\text { Damage } \\
\text { Release } 3\end{array}$ & Winfrith & $\begin{array}{l}\text { Damage } \\
\text { Release } 3\end{array}$ \\
\hline 1 & HSC-V1-4in. & $52.82 / 1013.28$ & $\downarrow 1.5 \%$ & $\downarrow 2 \%$ & $\uparrow 44 \%$ & $\uparrow 12 \%$ \\
\hline 3 & HSC-V2-4in. & 49.28/997.62 & $\uparrow 5 \%$ & $\downarrow 5 \%$ & $\uparrow 12 \%$ & $\downarrow 5 \%$ \\
\hline 5 & HSC-V3-4in. & $42.04 / 773.95$ & $\uparrow 19 \%$ & $\uparrow 37 \%$ & $\uparrow 27 \%$ & $\uparrow 38 \%$ \\
\hline 7 & HSC-V4-8in. & $44.42 / 753.56$ & $\downarrow 3 \%$ & $\downarrow 36 \%$ & $* *$ & $\downarrow 25 \%$ \\
\hline 9 & HSC-V5-8in. & $34.01 / 511.77$ & $\downarrow 4 \%$ & $\uparrow 2.5 \%$ & $\uparrow 9 \%$ & $* *$ \\
\hline 11 & HSC-V6-8in. & $37.05 / 576.07$ & $\downarrow 4 \%$ & $\uparrow 14 \%$ & $\uparrow 27 \%$ & $\uparrow 21 \%$ \\
\hline
\end{tabular}

Table 6-6: Percentage Change in Peak Slab Deflection when the Mesh Size was Reduced from 1 in. $(25.4 \mathrm{~mm}$.) to $1 / 2$ in. (12.7 mm.) for High Strength Slabs.

\begin{tabular}{cccc}
\hline Slab No. & Description & \multicolumn{2}{c}{ Deflection Percentage } \\
\hline & & Winfrith & $\begin{array}{l}\text { Damage } \\
\text { Release 3 }\end{array}$ \\
Slab 1 & HSC-V1-4in. & $\uparrow 46 \%$ & $\uparrow 15 \%$ \\
Slab 3 & HSC-V2-4in. & $\uparrow 7 \%$ & $\uparrow 0.7 \%$ \\
Slab 5 & HSC-V3-4in. & $\uparrow 6 \%$ & $\uparrow 0.8 \%$ \\
Slab 7 & HSC-V4-8in. & $* *$ & $\uparrow 16 \%$ \\
Slab 9 & HSC-V5-8in. & $\uparrow 14 \%$ & $* *$ \\
Slab 11 & HSC-V6-8in. & $\uparrow 32 \%$ & $\uparrow 5 \%$ \\
\hline \multicolumn{2}{c}{$*$ Negative volume in elements terminated the analysis. }
\end{tabular}




\subsection{Mesh Size Effect for Slab \# 1 (HSC-V1-4in.)}

The deflection results obtained from numerical simulations for slab \# 1 which is a HSC-V1-4in. is compared for two different mesh sizes. This slab experienced a peak pressure of $52.82 \mathrm{psi}(0.36 \mathrm{MPa})$ and an impulse of 1013.28 psi-msec $(6.98 \mathrm{MPa}-$ msec) in the blast experiment. The blast pressures recorded for this slab are summarized in Appendix A. The average deflection obtained from the experiment was 3.89 in (98.8 mm.) recorded at 28 milliseconds.

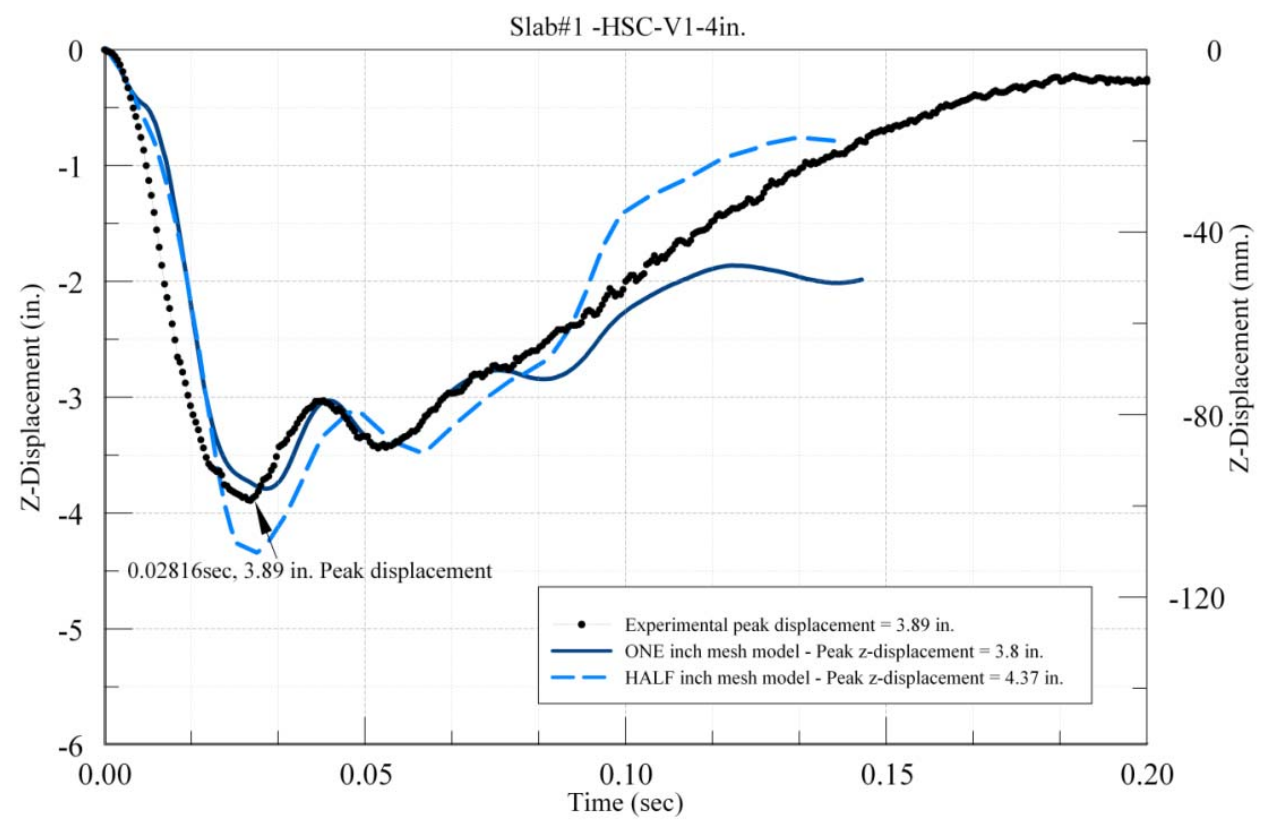

Figure 6-1: Deflection Comparison between 1 in. (25.4 mm.) and 1/2 in. (12.7 mm.) mesh sizes for Concrete Damage Model Release 3 and Experimental Deflection for Slab\#1 HSC-V1-4in.

The deflection results obtained from LS-DYNA® ${ }^{\circledR}$ concrete models with two mesh sizes for Concrete Damage Model Release 3 (CDMR3) are compared with the experimental deflection in Figure 6-1. The peak deflection obtained from the CDMR3 with 1 in. (25.4 mm.) mesh was $3.8 \mathrm{in}(96.52 \mathrm{~mm}$.) recorded at 30.5 milliseconds while for $1 / 2$ in. (12.7 mm.) mesh model it was 4.37 in. (110.98 mm.) recorded at 27.5 milliseconds. The 
deflections obtained from the models for CDMR3 with $1 \mathrm{in}$. $(25.4 \mathrm{~mm})$ mesh size showed a $2 \%$ decrease while for the $1 / 2$ in. (12.7 mm.) model showed a $12 \%$ increase when compared to the experimental values.

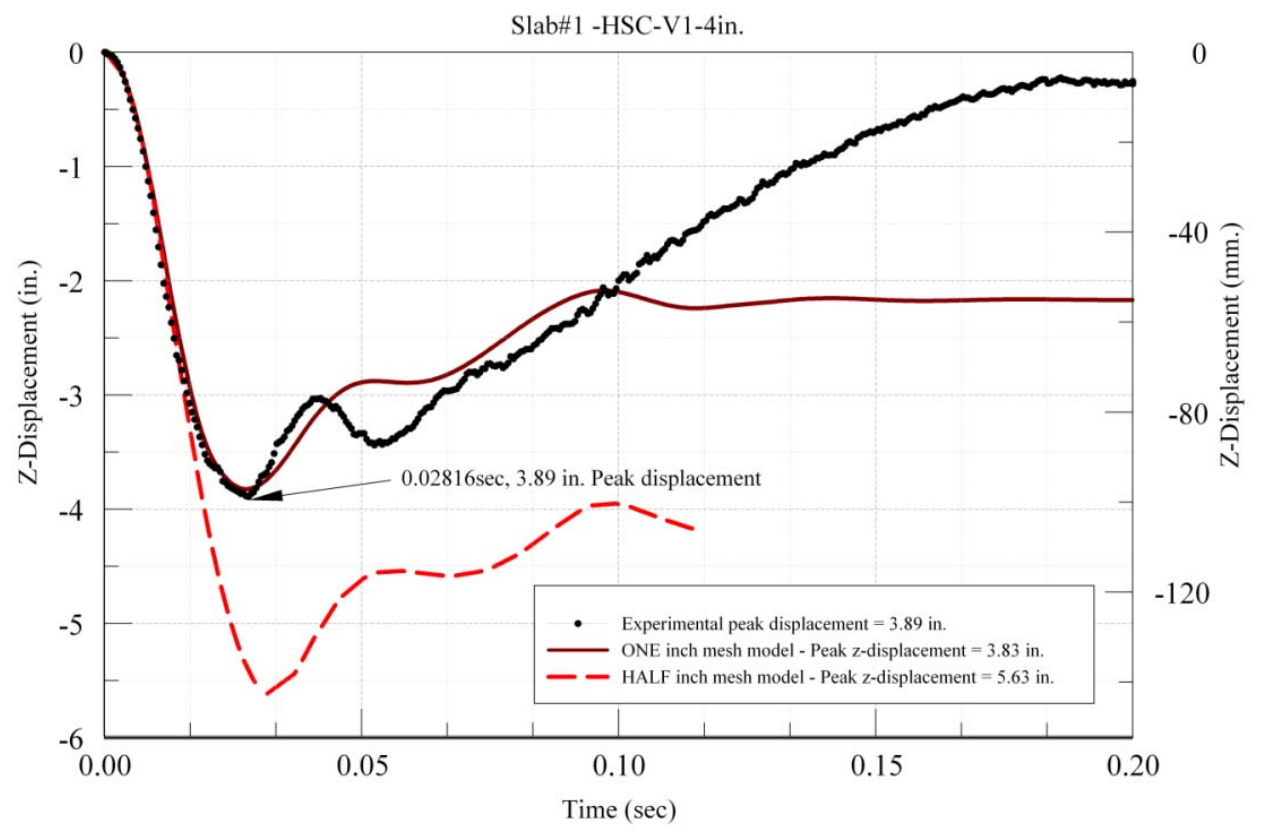

Figure 6-2: Deflection Comparison between 1 in. $(25.4 \mathrm{~mm}$.$) and 1 / 2$ in. $(12.7 \mathrm{~mm}$.) mesh sizes for Winfrith Concrete Model and Experimental Deflection for Slab\#1 - HSC-V1-4in.

The deflection results obtained from LS-DYNA ${ }^{\circledR}$ concrete models with two mesh sizes for Winfrith Concrete Model (WCM) are compared with the experimental deflections in Figure 6-2. The peak deflections obtained from the WCM with 1 in. $(25.4 \mathrm{~mm}$.) mesh was $3.83 \mathrm{in}(97.28 \mathrm{~mm}$.) recorded at 27.5 milliseconds while for $1 / 2 \mathrm{in.}(12.7 \mathrm{~mm}$.) mesh model it was $5.63 \mathrm{in.}(143 \mathrm{~mm}$.) recorded at 32.5 milliseconds. The deflections obtained from the models for WCM with 1 in. $(25.4 \mathrm{~mm})$ mesh size showed a $1.5 \%$ decrease while for the $1 / 2$ in. (12.7 mm.) model showed a $44 \%$ increase when compared to the experiment.

From Figure 6-1 and Figure 6-2 it can be noted that varying the mesh size from 1 in. (25.4 mm.) to $1 / 2$ in. $(12.7 \mathrm{~mm}$.) increased the deflection by 1.8 in. $(45.72 \mathrm{~mm}$.) for the 
WCM and by 0.57 in. (14.48 mm.) for CDMR3 respectively. The $1 \mathrm{in.} \mathrm{mesh}(25.4 \mathrm{~mm})$ can be useful to predict the deflection accurately in both the models in comparison with the experimental deflection.

\subsection{Material Model Effect for Slab \# 1 (HSC-V1-4in.)}

Figure 6-3 and Figure 6-4 compare the deflections between two material models for two mesh sizes. From Figure 6-3 for the 1 in. $(25.4 \mathrm{~mm})$ mesh model the WCM predicted the deflection 0.06 in. $(1.52 \mathrm{~mm}$.) less while the CDMR3 predicted the deflection $0.09 \mathrm{in}$. $(2.28 \mathrm{~mm}$.) less than the experimental value respectively. From Figure $6-4$ for the $1 / 2 \mathrm{in}$. $(12.7 \mathrm{~mm})$ mesh model the CDMR 3 predicted the deflection 0.48 in. $(12.19 \mathrm{~mm}$.) more while the WCM predicted the deflection 1.74 in. $(44.2 \mathrm{~mm}$.) more than the experimental value respectively. The CDMR3 predicted the response better in both mesh size category.

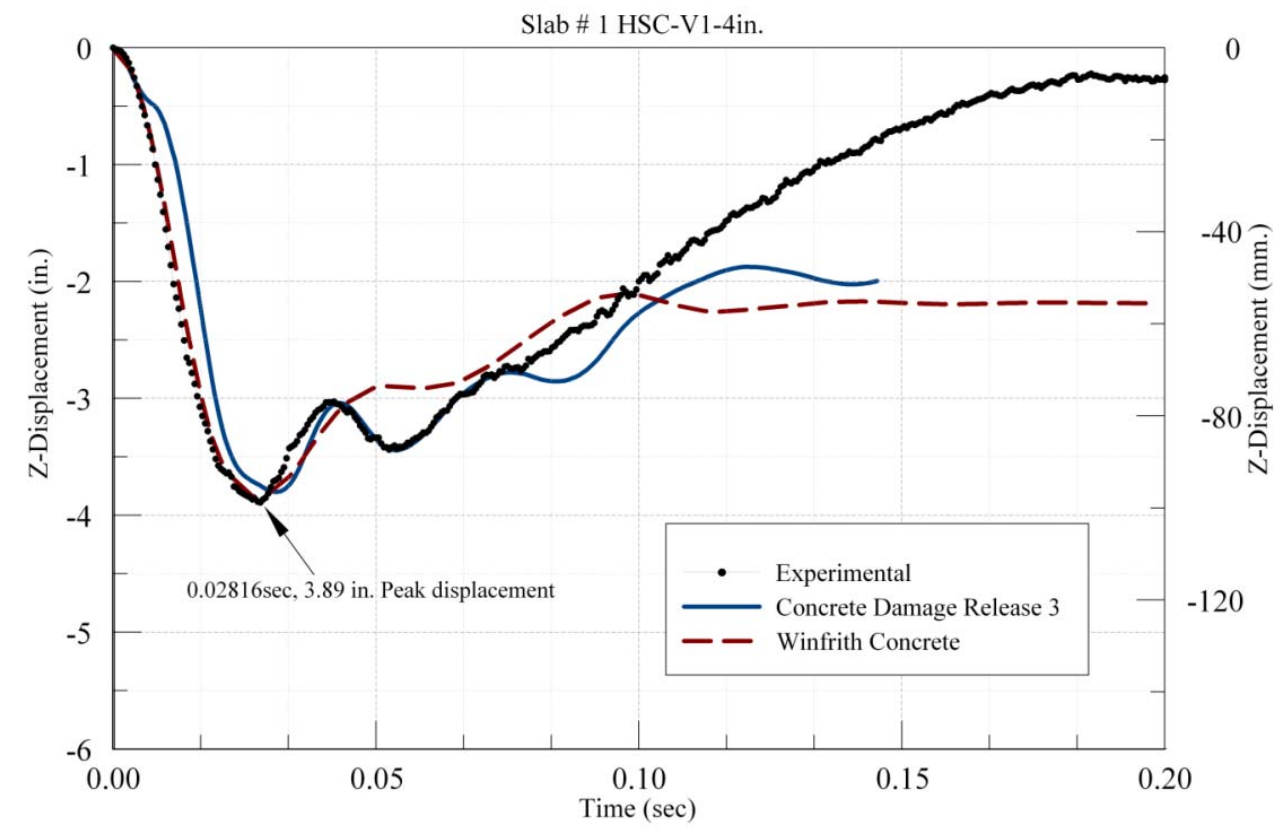

Figure 6-3: Deflection Comparison between Concrete Damage Model Release 3 and Winfrith Concrete for 1 in. $(25.4 \mathrm{~mm}$.) mesh model with Experimental Deflection for Slab\#1 - HSC-V1-4in. 


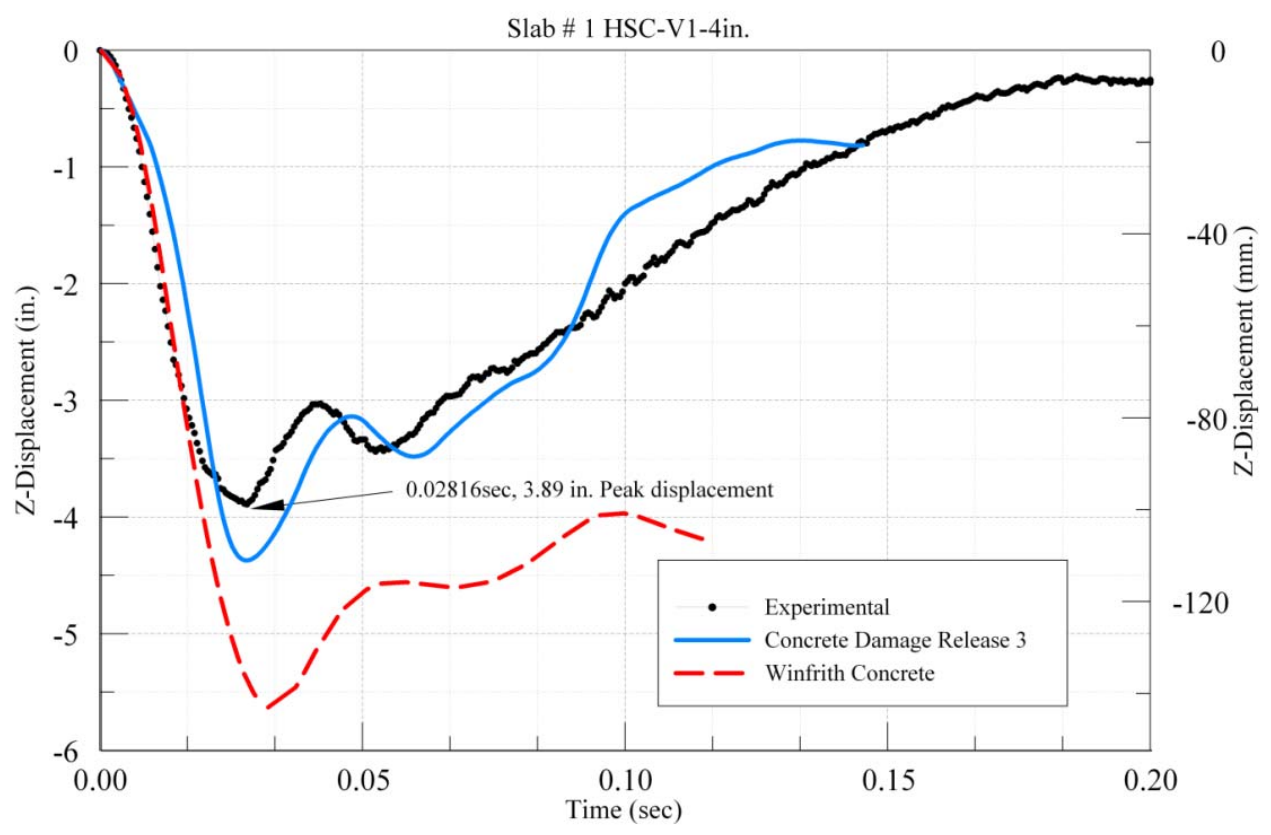

Figure 6-4: Deflection Comparison between Concrete Damage Model Release 3 and Winfrith Concrete for 1/2 in. (12.7 mm.) mesh model with Experimental Deflection for Slab\#1 - HSC-V1-4in.

\subsection{Mesh Size Effect for Slab \# 3 (HSC-V2-4in.)}

The deflection results obtained from numerical simulations for slab \# 3 which is a HSC-V2-4in. is compared in this section for two different mesh sizes. This slab experienced a peak pressure of $49.28 \mathrm{psi}(0.34 \mathrm{MPa})$ and an impulse of $997.62 \mathrm{psi}-\mathrm{msec}(6.878 \mathrm{MPa}-$ msec) in the blast experiment. The blast pressures recorded for this slab are summarized in Appendix A. The average deflection obtained from the experiment was 4.53 in (115.06 mm.) recorded at 33.9 milliseconds. 


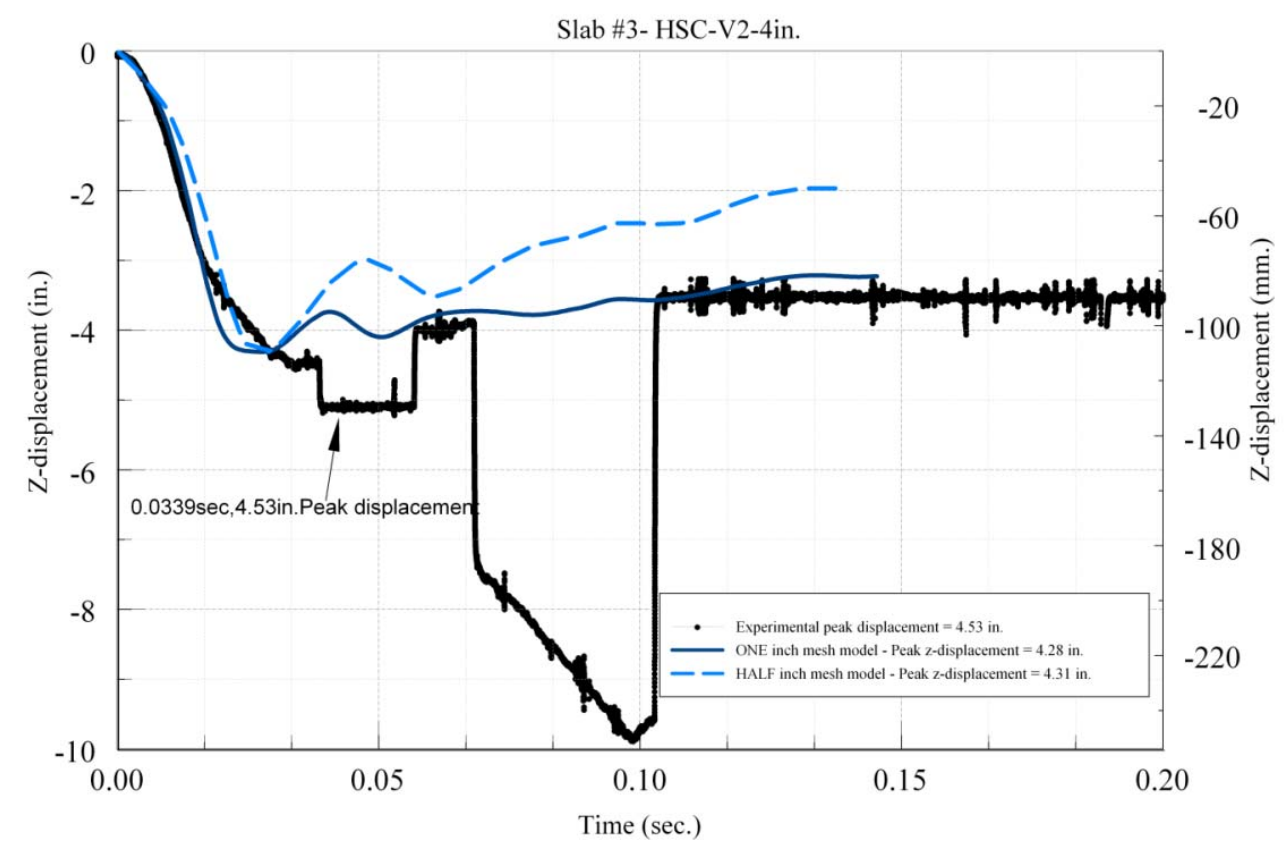

Figure 6-5: Deflection Comparison between 1 in. (25.4 mm.) and 1/2 in. (12.7 mm.) mesh sizes for Concrete Damage Model Release 3 and Experimental Deflection for Slab\#3 HSC-V2-4in.

The deflection results obtained from LS-DYNA® concrete models with two mesh sizes for CDMR3 are compared with the experimental deflections in Figure 6-5. The peak deflections obtained from the CDMR3 with 1 in. $(25.4 \mathrm{~mm}$.$) mesh was 4.28$ in (108.7 mm.) recorded at 30.5 milliseconds while for $1 / 2$ in. (12.7 mm.) mesh model it was 4.31 in. (109.47 mm.) recorded at 27.5 milliseconds. The deflections obtained from the models for CDMR3 with 1 in. $(25.4 \mathrm{~mm})$ mesh size showed a 5\% decrease while with the $1 / 2$ in. (12.7 mm.) model showed a 5\% decrease when compared to the experimental values. 


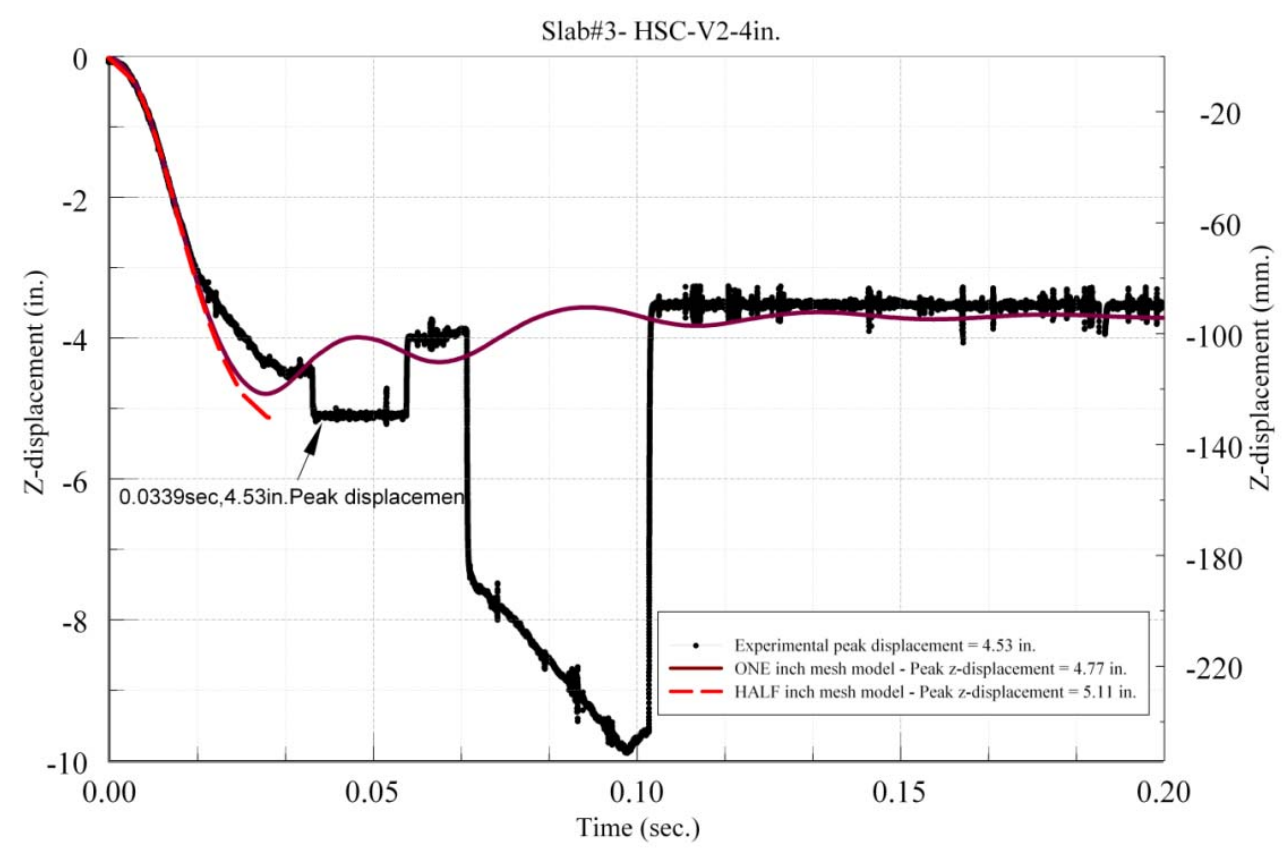

Figure 6-6: Deflection Comparison between 1 in. (25.4 mm.) and 1/2 in. (12.7 mm.) mesh sizes for Winfrith Concrete Model and Experimental Deflection for Slab\#3 - HSC-V2-4in.

The deflection results obtained from LS-DYNA ${ }^{\circledR}$ concrete models with two mesh sizes for WCM are compared with the experimental deflections in Figure 6-4. The peak deflections obtained from the WCM with 1 in. $(25.4 \mathrm{~mm}$.) mesh was 4.77in $(121.16 \mathrm{~mm}$.) recorded at 30 milliseconds while for $1 / 2$ in. (12.7 mm.) mesh model it was $5.11 \mathrm{in.} \mathrm{(129.79}$ mm.) recorded at 31.5 milliseconds. The deflections obtained from the models for WCM with 1 in. $(25.4 \mathrm{~mm})$ mesh size showed a 5\% increase while the deflections obtained from the $1 / 2$ in. (12.7 mm.) model showed a $12 \%$ increase when compared to the experimental values.

From Figure 6-5 and Figure 6-6 it can be noted that varying the mesh size from 1 in. (25.4 mm.) to $1 / 2$ in. $(12.7 \mathrm{~mm}$.) increased the deflection by 0.34 in. $(8.64 \mathrm{~mm}$.) for the WCM and by 0.03 in. $(0.76 \mathrm{~mm}$.) for CDMR3 respectively. The 1 in. mesh $(25.4 \mathrm{~mm})$ can 
be useful to predict the deflection accurately in both the models in comparison with the experimental deflection.

\subsection{Material Model Effect for Slab \# 3 (HSC-V2-4in.)}

Figure 6-7 and Figure 6-8 compare the deflections between two material models for two mesh sizes. From Figure 6-7 for the 1 in. $(25.4 \mathrm{~mm})$ mesh model the WCM predicted the deflection 0.24 in. $(6.09 \mathrm{~mm}$.) more while the CDMR3 predicted the deflection $0.25 \mathrm{in}$. (6.35 mm.) less than the experimental deflection. From Figure $6-8$ for the $1 / 2 \mathrm{in.}(12.7 \mathrm{~mm})$ mesh model the CDMR3 predicted the deflection $0.22 \mathrm{in.}(5.58 \mathrm{~mm}$.) less while the WCM predicted the deflection 0.58 in. (14.73 mm.) more respectively than the experimental value. The CDMR3 predicted the response better in both mesh size categories.

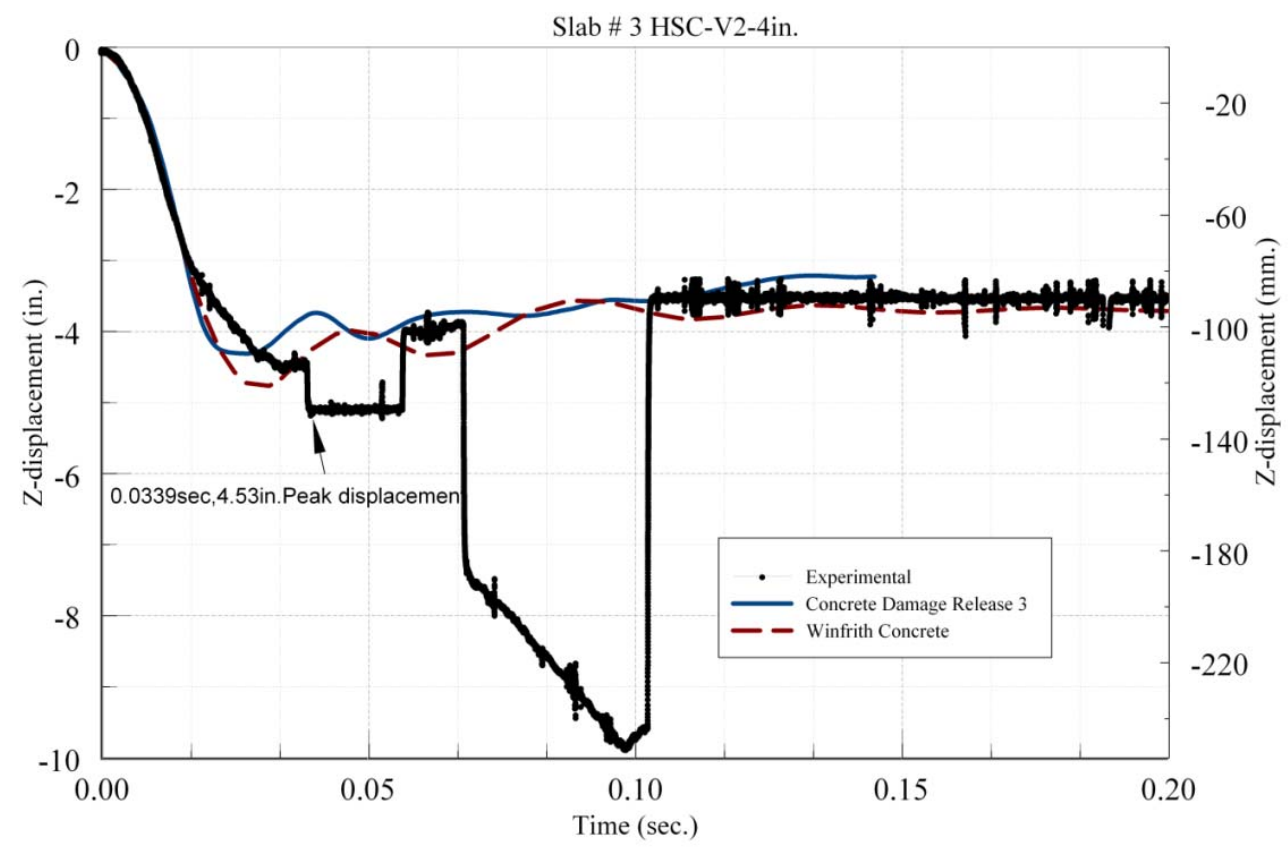

Figure 6-7: Deflection Comparison between Concrete Damage Model Release 3 and Winfrith Concrete for 1 in. $(25.4 \mathrm{~mm}$.) mesh model with Experimental Deflection for Slab\#3 - HSC-V2-4in. 


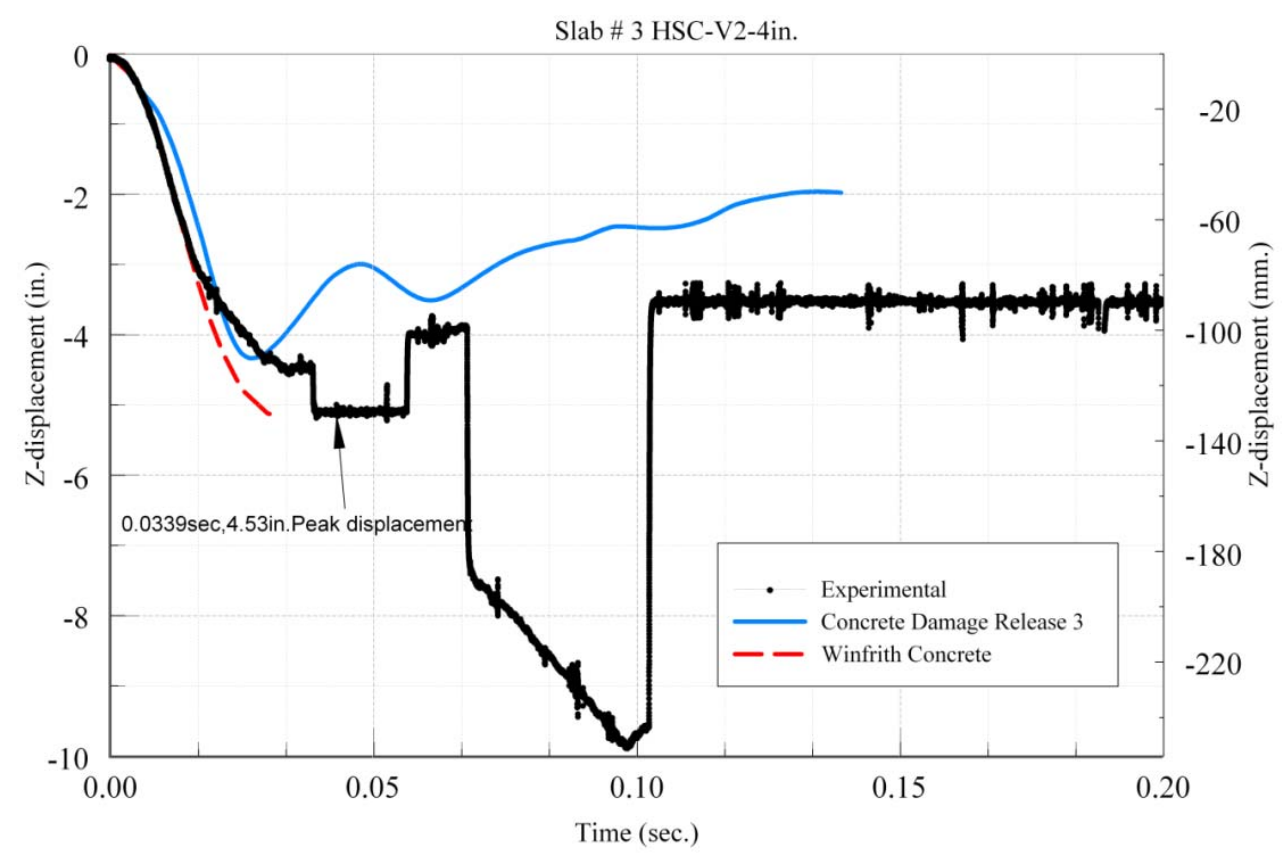

Figure 6-8: Deflection Comparison between Concrete Damage Model Release 3 and Winfrith Concrete for 1/2 in. (12.7 mm.) mesh model with Experimental Deflection for Slab\#3 - HSC-V2-4in.

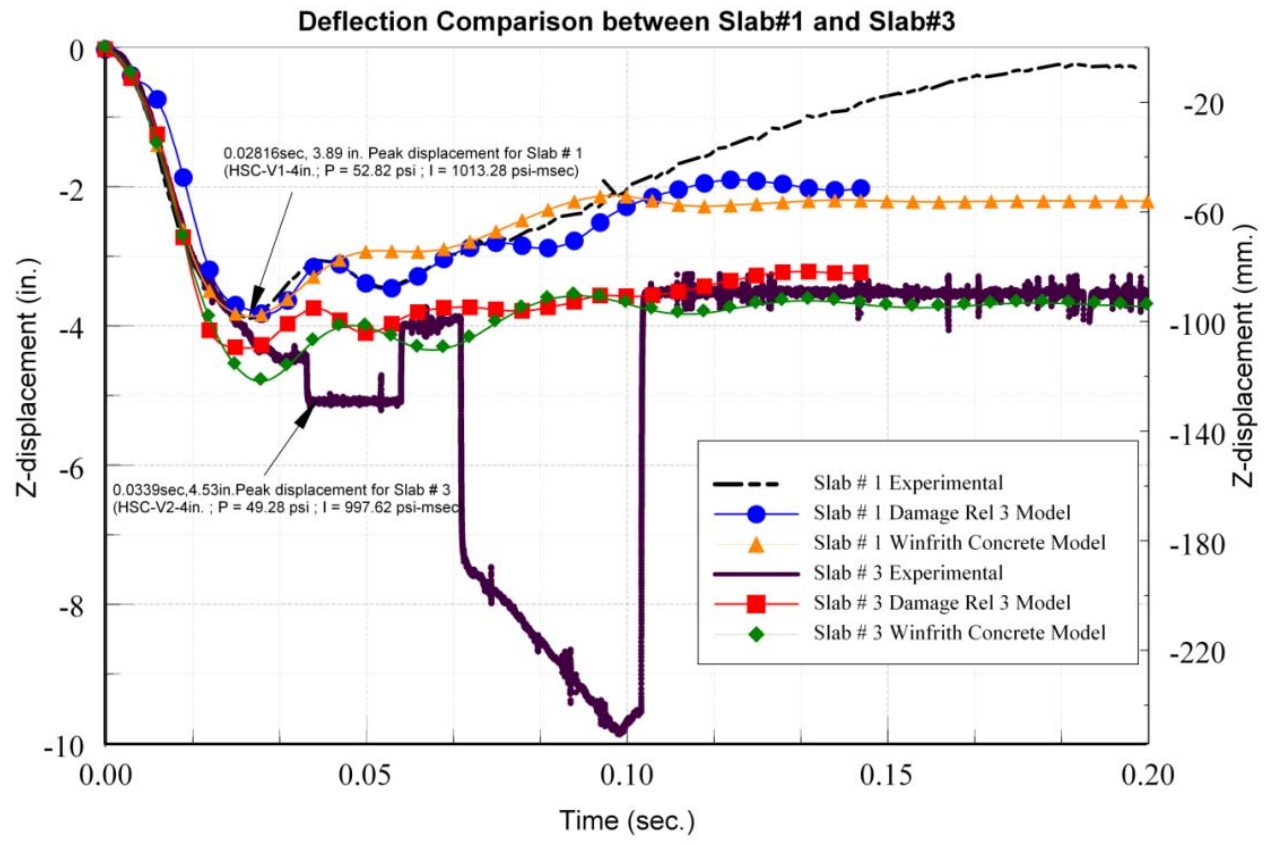

Figure 6-9: Deflection Comparison between Concrete Damage Model Release 3 and Winfrith Concrete for 1 in. $(25.4 \mathrm{~mm}$.) mesh model with Experimental Deflection for Slab\#1 - HSC-V1-4in and Slab\#3 - HSC-V2-4in. 
Figure 6-9 compares the two slabs i.e. Slab\#1-HSC-V1-4in. and Slab\#3-HSC-V24in. for both the experimental and numerical analysis results. The numerical analysis results presented here are using the $1 \mathrm{in} .(25.4 \mathrm{~mm}$.) mesh model as this mesh size yielded good results as compared to other mesh sizes in both the concrete material models used. These slabs were subjected to similar pressures of $52.82 \mathrm{psi}(0.36 \mathrm{MPa})$ and $49.28 \mathrm{psi}(0.34 \mathrm{MPa})$ respectively and an impulse of 1013.28 psi-msec (6.98 MPa-msec) and 997.6 psi-msec (6.878 $\mathrm{MPa}-\mathrm{msec})$ respectively during the experimental program.

As seen in the plot the peak deflections for the two slabs occured within a very small timeframe ranging between 27.5 milliseconds and 33.9 milliseconds. The experimental peak deflections recorded for the two slabs are 3.89 in. (98.81 mm.) and 4.53 in. (115.06 mm.) respectively. For both of these slabs when modeled using the two concrete material models gave a good prediction of the deflection as observed from the peak and residual displacements as noted in Table 6-1 and 6-2. The CDMR3 Model predicted the deflection response very closely to the experiment even in the post peak region. Although the peak values deviates more from the experimental peak deflection as compared to the WCM. The WCM predicted the peak deflections more closely but the post-peak deflection response is not very accurate. The two slabs under consideration here could withstand higher pressure and impulse when designed using high-strength material. The numerical analysis also shows a stable response with lesser rebound of the slab in the post-peak deflection-time history. 


\subsection{Mesh Size Effect for Slab \# 5 (HSC-V3-4in.)}

The deflection results obtained from numerical simulations for slab \# 5 which is a HSC-V3-4in. is compared for two different mesh sizes. This slab experienced a peak pressure of $42.04 \mathrm{psi}(0.28 \mathrm{MPa})$ and an impulse of $773.95 \mathrm{psi}-\mathrm{msec}(5.34 \mathrm{MPa}-\mathrm{msec})$ in the blast experiment. The blast pressures recorded for this slab are summarized in Appendix A. The average deflection obtained from the experiment was 2.46 in $(62.48 \mathrm{~mm}$.) recorded at 19.94 milliseconds.

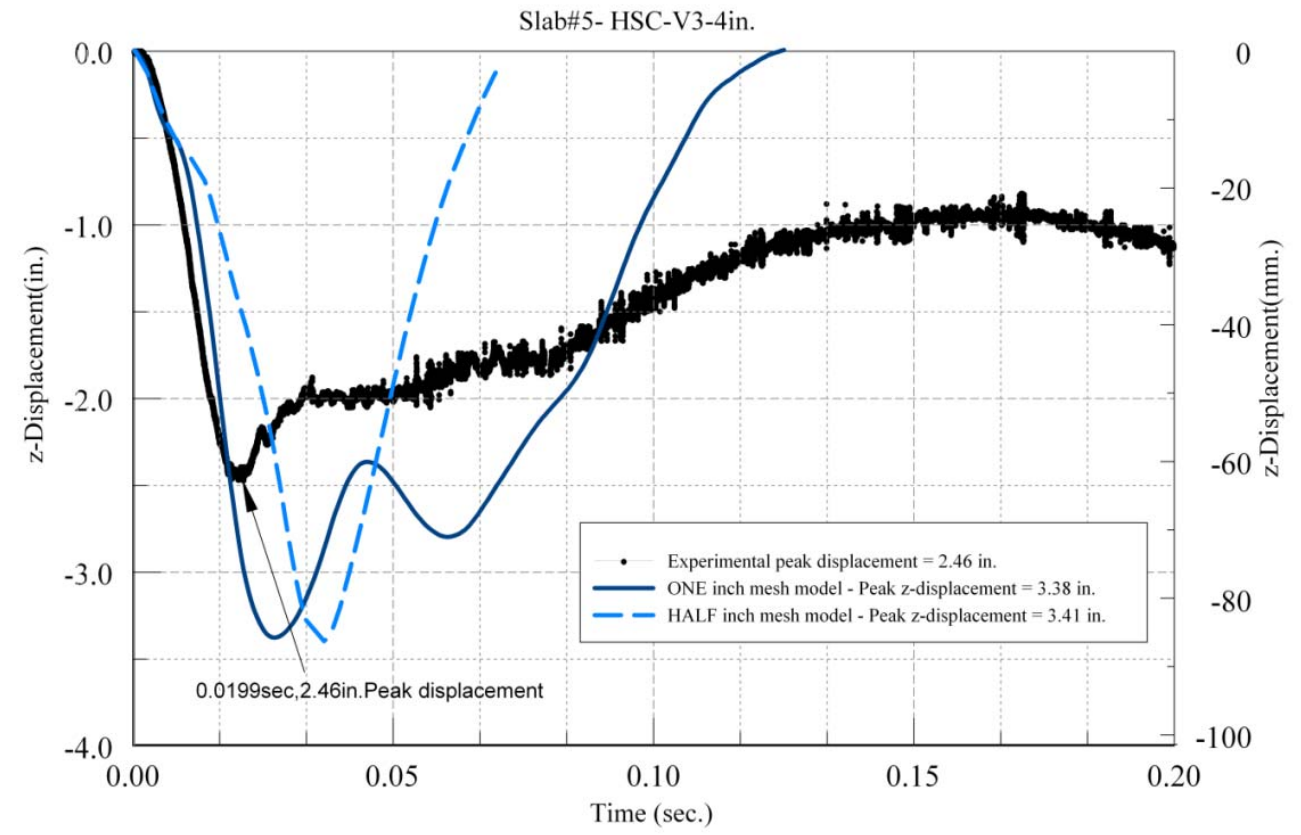

Figure 6-10 : Deflection Comparison between 1 in. $(25.4 \mathrm{~mm}$.) and 1/2 in. (12.7 mm.) mesh sizes for Concrete Damage Model Release 3 and Experimental Deflection for Slab\#5 - HSC-V3-4in.

The deflection results obtained from LS-DYNA® concrete models with two mesh sizes for CDMR3 are compared with the experimental deflections in Figure 6-10. The peak deflections obtained from the CDMR3 with 1 in. (25.4 mm.) mesh was 3.38 in. (85.85 mm.) recorded at 27 milliseconds while for $1 / 2 \mathrm{in.} \mathrm{(12.7} \mathrm{mm.)} \mathrm{mesh} \mathrm{model} \mathrm{it} \mathrm{was} 3.41 \mathrm{in}$. (86.61 $\mathrm{mm}$.) recorded at 36 milliseconds. The deflection obtained from the models with 1 in. (25.4 
$\mathrm{mm}$ ) mesh size were higher when compared to the experiments as the CDMR3 showed a $37 \%$ increase while the deflection obtained from the $1 / 2 \mathrm{in}$. $(12.7 \mathrm{~mm}$.) model are higher by $38 \%$ when compared to the experimental values.

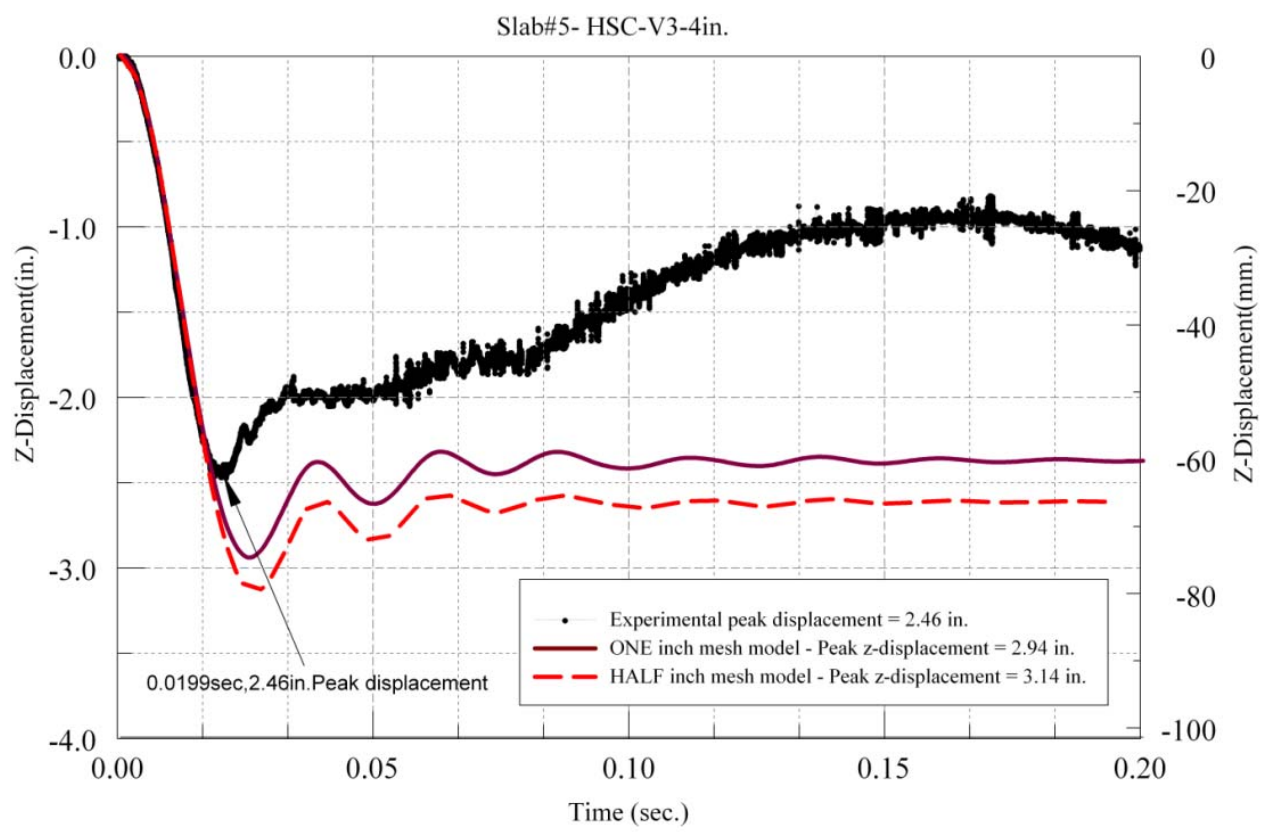

Figure 6-11: Deflection Comparison between 1 in. $(25.4 \mathrm{~mm}$.) and 1/2 in. (12.7 mm.) mesh sizes for Winfrith Concrete Model and Experimental Deflection for Slab\#5 - HSC-V3-4in.

The deflection results obtained from LS-DYNA ${ }^{\circledR}$ concrete models with two mesh sizes for WCM are compared with the experimental deflections in Figure 6-11. The peak deflections obtained from the WCM with 1 in. $(25.4 \mathrm{~mm}$.) mesh was 2.94 in. (74.67 mm.) recorded at 25 milliseconds while for $1 / 2$ in. (12.7 mm.) mesh model it was 3.14 in. (129.79 $\mathrm{mm}$.) recorded at 26.5 milliseconds. The deflections obtained from the models with $1 \mathrm{in}$. (25.4 mm) mesh size when compared to the experiments for the WCM showed a $19 \%$ increase while the deflections obtained from the $1 / 2 \mathrm{in}$. $(12.7 \mathrm{~mm}$.) model are higher by $27 \%$ when compared to the experiment. 
From Figure 6-10 and Figure 6-11 it can be noted that varying the mesh size from 1 in. $(25.4 \mathrm{~mm}$.) to $1 / 2 \mathrm{in}$. $(12.7 \mathrm{~mm}$.) increased the deflection by $0.2 \mathrm{in.}(5.08 \mathrm{~mm}$.) for the WCM and by 0.03 in. $(0.76 \mathrm{~mm}$.) for CDMR3 respectively. The 1 in. mesh $(25.4 \mathrm{~mm})$ can be useful to predict the deflection accurately in both the models in comparison with the experimental deflection.

\subsection{Material Model Effect for Slab \# 5 (HSC-V3-4in.)}

Figure 6-12 and Figure 6-13 compare the deflections between two material models for two mesh sizes. From Figure 6-12 for the 1 in. $(25.4 \mathrm{~mm})$ mesh model the WCM predicted the deflection 0.48 in. $(12.19 \mathrm{~mm}$.) more while the CDMR3 predicted the deflection which was $0.92 \mathrm{in}$. (23.36 mm.) more than the experimental values respectively. From Figure 6-13 for the 1/2 in. $(12.7 \mathrm{~mm})$ mesh model the WCM predicted the deflection 0.68 in. $(17.27 \mathrm{~mm}$.) more while the CDMR3 predicted the deflection which was $0.95 \mathrm{in}$. (24.13 mm.) more than the experimental values. The Winfrith Concrete Model gave a better prediction of the response in both mesh size categories. 


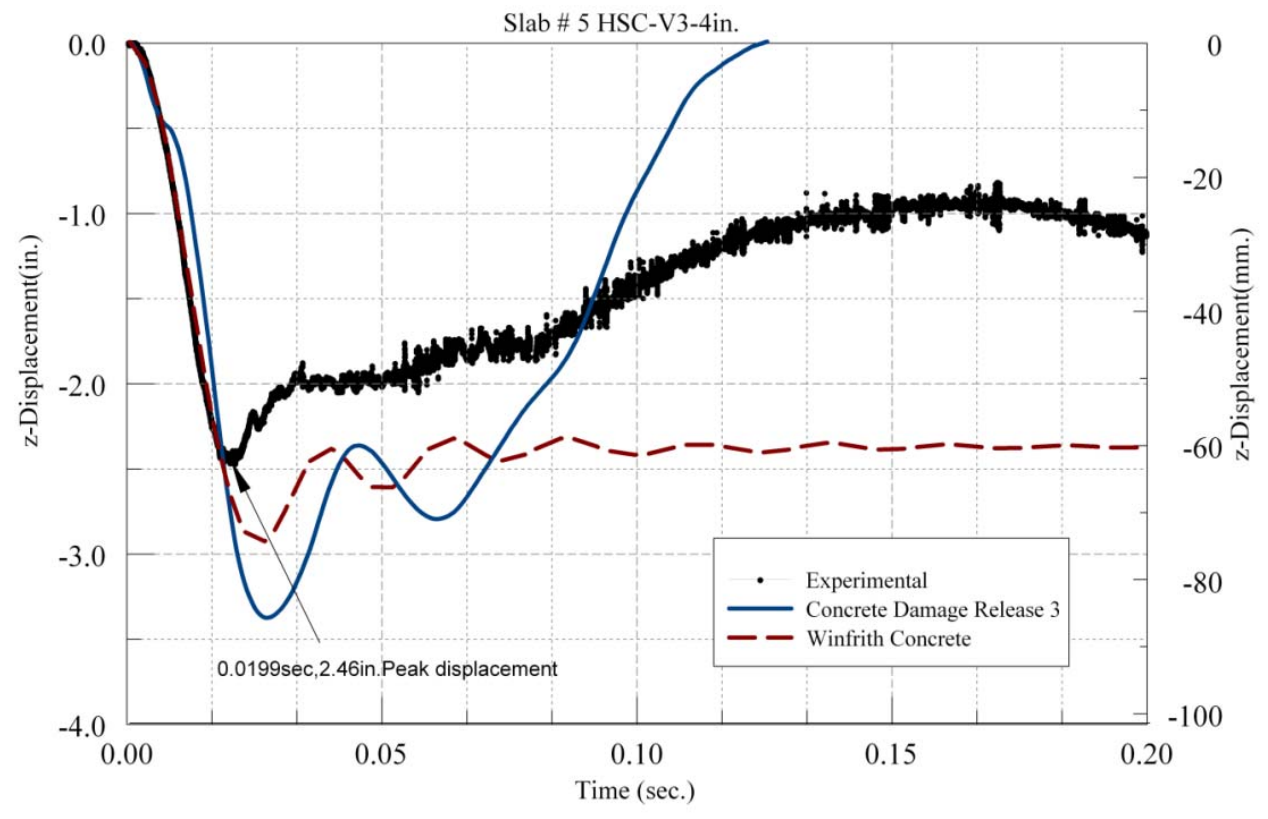

Figure 6-12: Deflection Comparison between Concrete Damage Model Release 3 and Winfrith Concrete for 1 in. (25.4 mm.) mesh model with Experimental Deflection for Slab\#5 - HSC-V3-4in.

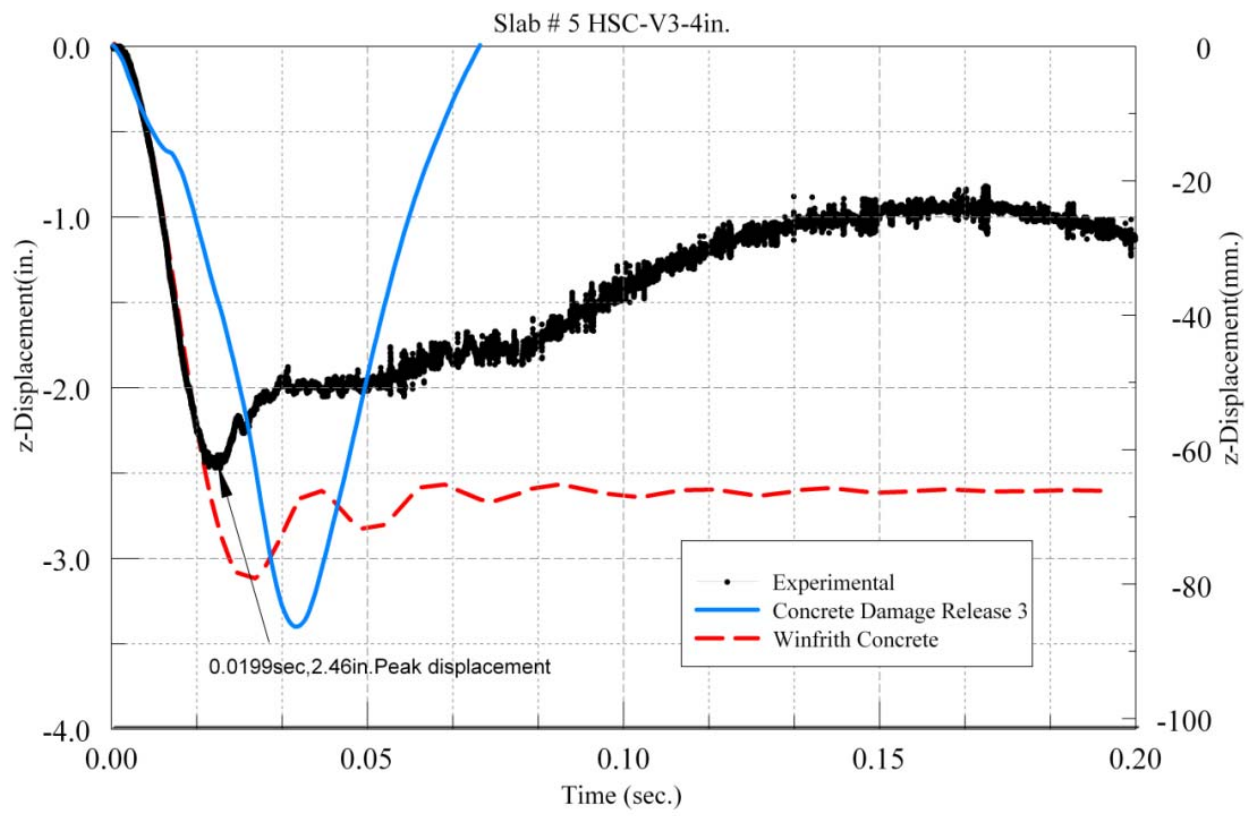

Figure 6-13: Deflection Comparison between Concrete Damage Model Release 3 and Winfrith Concrete for 1/2 in. (12.7 mm.) mesh model with Experimental Deflection for Slab\#5 - HSC-V3-4in. 


\subsection{Mesh Size Effect for Slab \# 7 (HSC-V4-8in.)}

The deflection results obtained from numerical simulations for slab \# 7 which is a HSC-V4-8in. is compared for two different mesh sizes. This slab experienced a peak pressure of $44.42 \mathrm{psi}(0.306 \mathrm{MPa})$ and an impulse of 753.56 psi-msec $(5.19 \mathrm{MPa}-\mathrm{msec})$ in the blast experiment. The blast pressures recorded for this slab are summarized in Appendix A. The average deflection obtained from the experiment was 7.2 in. (182.88 mm.) recorded at 38.73 milliseconds.

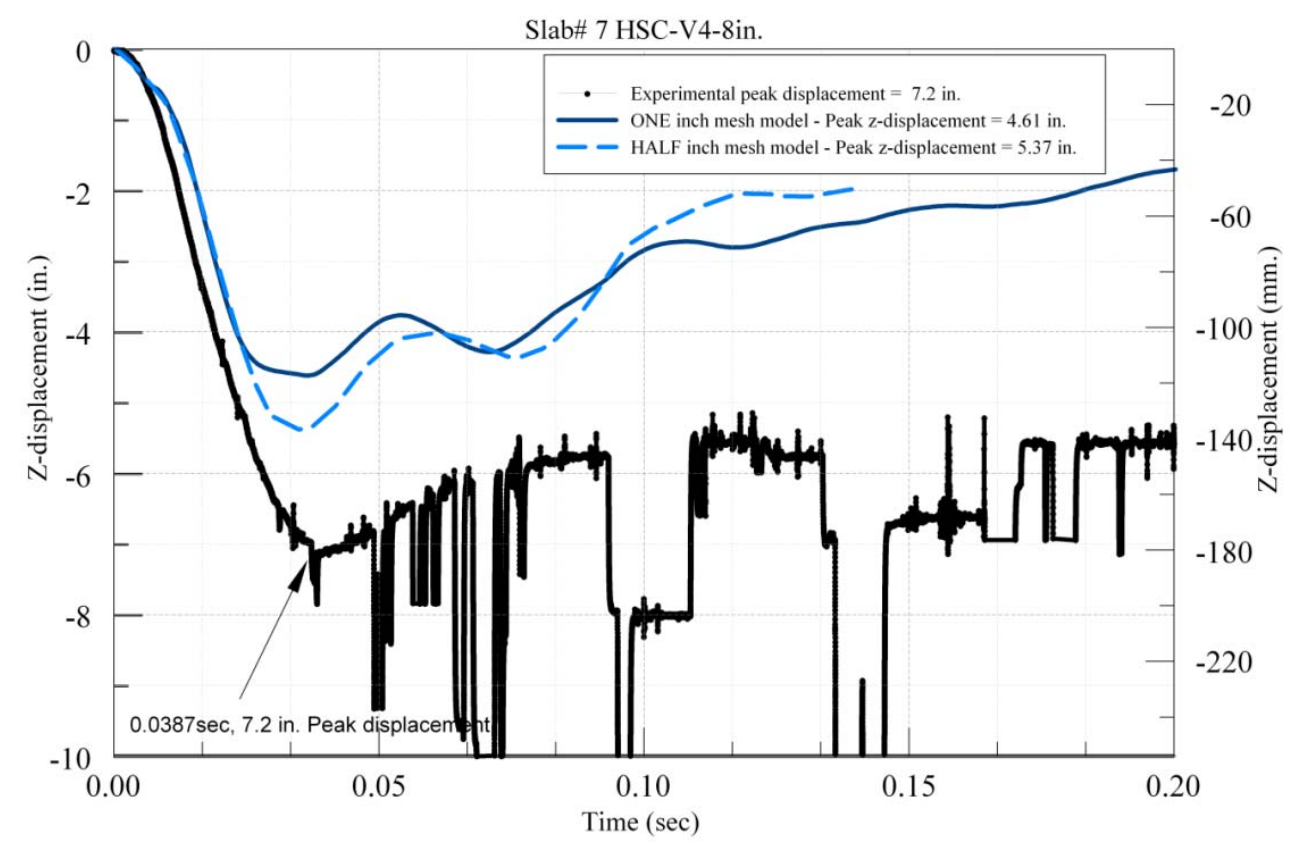

Figure 6-14: Deflection Comparison between 1 in. $(25.4 \mathrm{~mm}$.$) and 1/2 in. (12.7 \mathrm{~mm}$.) for mesh sizes for Concrete Damage Model Release 3 and Experimental Deflection for Slab\#7 - HSC-V48in.

The deflection results obtained from LS-DYNA® concrete models with two mesh sizes for CDMR3 are compared with the experimental deflections in Figure 6-14. The peak deflections obtained from the CDMR3 with 1 in. (25.4 mm.) mesh was 4.61 in. (117.09 mm.) recorded at 36 milliseconds while for $1 / 2$ in. (12.7 mm.) mesh model it was 5.37 in. (136.39 mm.) recorded at 35 milliseconds. The deflections obtained from the models with 1 
in. $(25.4 \mathrm{~mm})$ mesh size were lower when compared to the experiments as the CDMR3 showed a $36 \%$ decrease while the deflections obtained from the $1 / 2$ in. $(12.7 \mathrm{~mm}$.) model are lower by $25 \%$ when compared to the experiment.

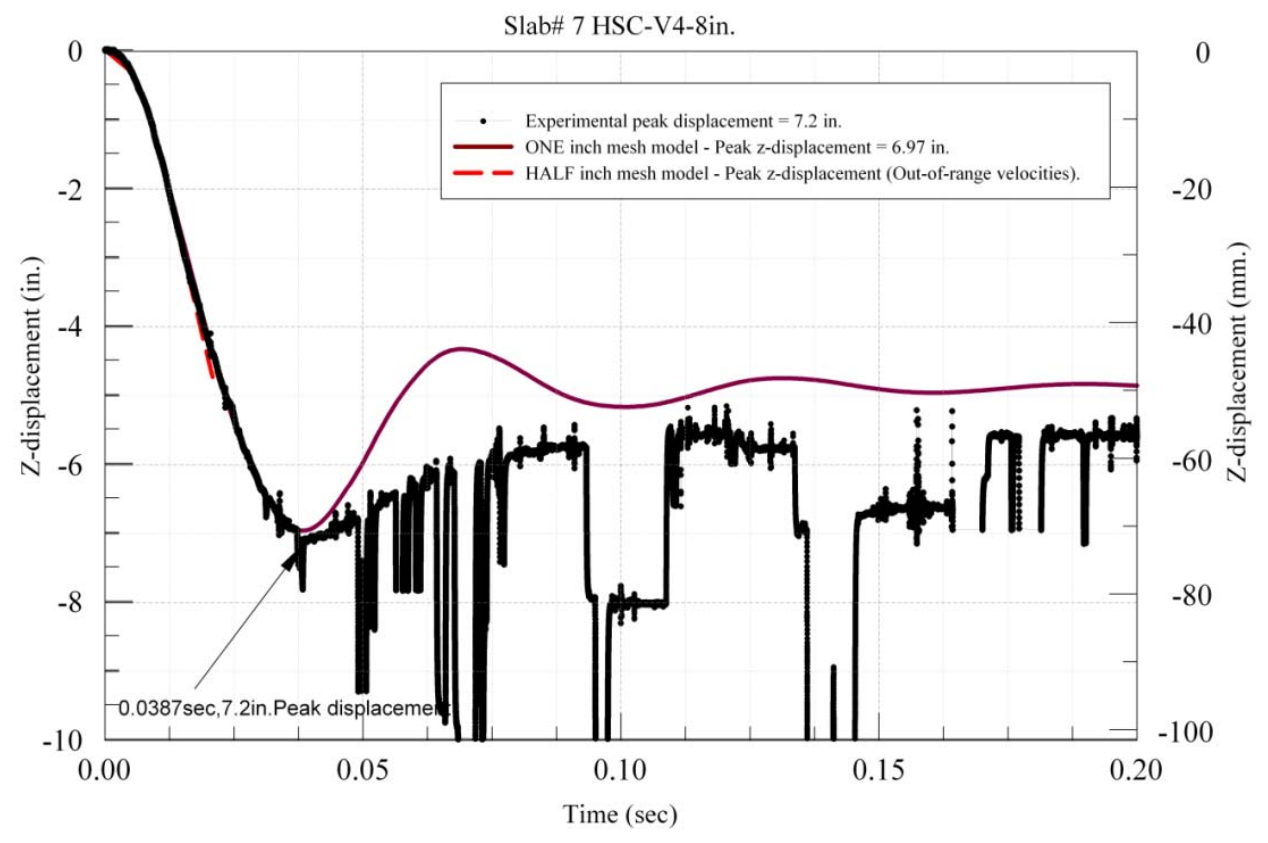

Figure 6-15: Deflection Comparison between 1 in. $(25.4 \mathrm{~mm}$.) and 1/2 in. (12.7 mm.) mesh sizes for Winfrith Concrete Model and Experimental Deflection for Slab\#7 - HSC-V4-8in.

The deflection results obtained from LS-DYNA ${ }^{\circledR}$ concrete models with two mesh sizes for WCM are compared with the experimental deflections in Figure 6-15. The peak deflections obtained from the WCM with 1 in. $(25.4 \mathrm{~mm}$.) mesh was $6.97 \mathrm{in.}(177.04 \mathrm{~mm}$.) recorded at 38.5 milliseconds while for $1 / 2 \mathrm{in}$. (12.7 mm.) mesh model the simulation terminated at 26.5 milliseconds before reaching the peak deflection as some of the elements reached velocities which were out-of-range. The deflections obtained from the models for WCM with 1 in. $(25.4 \mathrm{~mm})$ mesh size showed a $3 \%$ decrease while the deflections obtained from the $1 / 2$ in. $(12.7 \mathrm{~mm}$.) model could not be compared to the experiment as the program terminated before it reached the peak deflection. 
From Figure 6-14 and Figure 6-15 it can be noted that varying the mesh size from 1 in. $(25.4 \mathrm{~mm}$.) to $1 / 2 \mathrm{in}$. $(12.7 \mathrm{~mm}$.) increased the deflection by $0.76 \mathrm{in.}(19.3 \mathrm{~mm}$.) for the CDMR3. The 1 in. mesh $(25.4 \mathrm{~mm})$ model with Winfrith Concrete has shown considerably accurate prediction of the deflection-time history from the experiment. Thus the $1 \mathrm{in.} \mathrm{mesh}$ $(25.4 \mathrm{~mm})$ model can be useful to predict the deflection accurately in both the models in comparison with the experimental deflection.

\subsection{Material Model Effect for Slab \# 7 (HSC-V4-8in.)}

Figure 6-16 and Figure 6-17 compare the deflections between two material models for two mesh sizes. From Figure 6-16 for the 1 in. $(25.4 \mathrm{~mm})$ mesh model with the WCM predicted the deflection 0.23 in. $(5.84 \mathrm{~mm}$.) less while the CDMR3 predicted the deflection 2.59 in. $(65.78 \mathrm{~mm}$.) less than the experimental values respectively. From Figure 6-17 for the $1 / 2$ in. $(12.7 \mathrm{~mm})$ mesh model the CDMR3 predicted the deflection 1.83 in. (46.48 $\mathrm{mm}$.) less than the experimental deflection while the WCM predicted the deflection $0.38 \mathrm{in}$. (9.65 mm.) more than the experiment at 22 milliseconds after which the program terminated. The CDMR3 predicted the response lower in both mesh size category while the WCM predicted the response better in this case. 


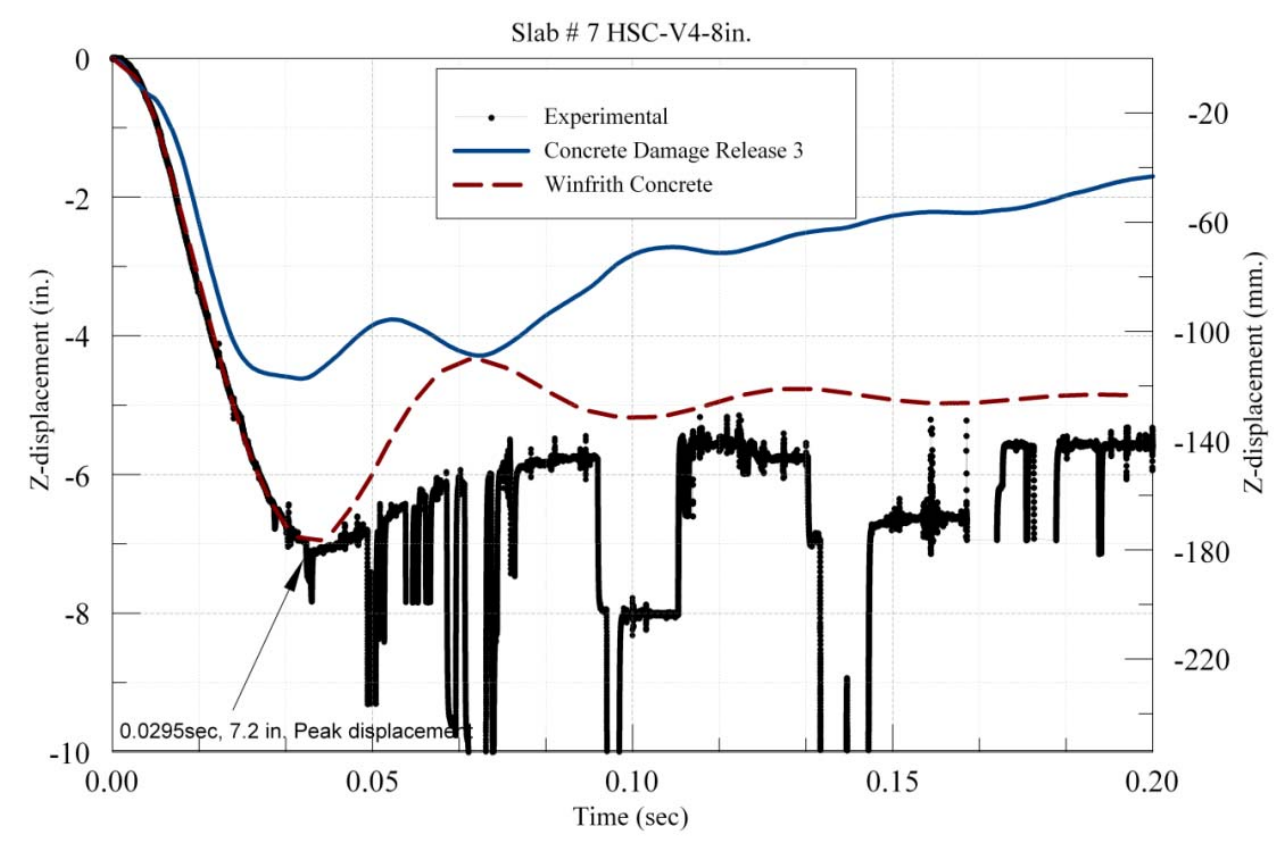

Figure 6-16: Deflection Comparison between Concrete Damage Model Release 3 and Winfrith Concrete for 1 in. $(25.4 \mathrm{~mm}$.) mesh model with Experimental Deflection for Slab\#7 - HSC-V4-8in.

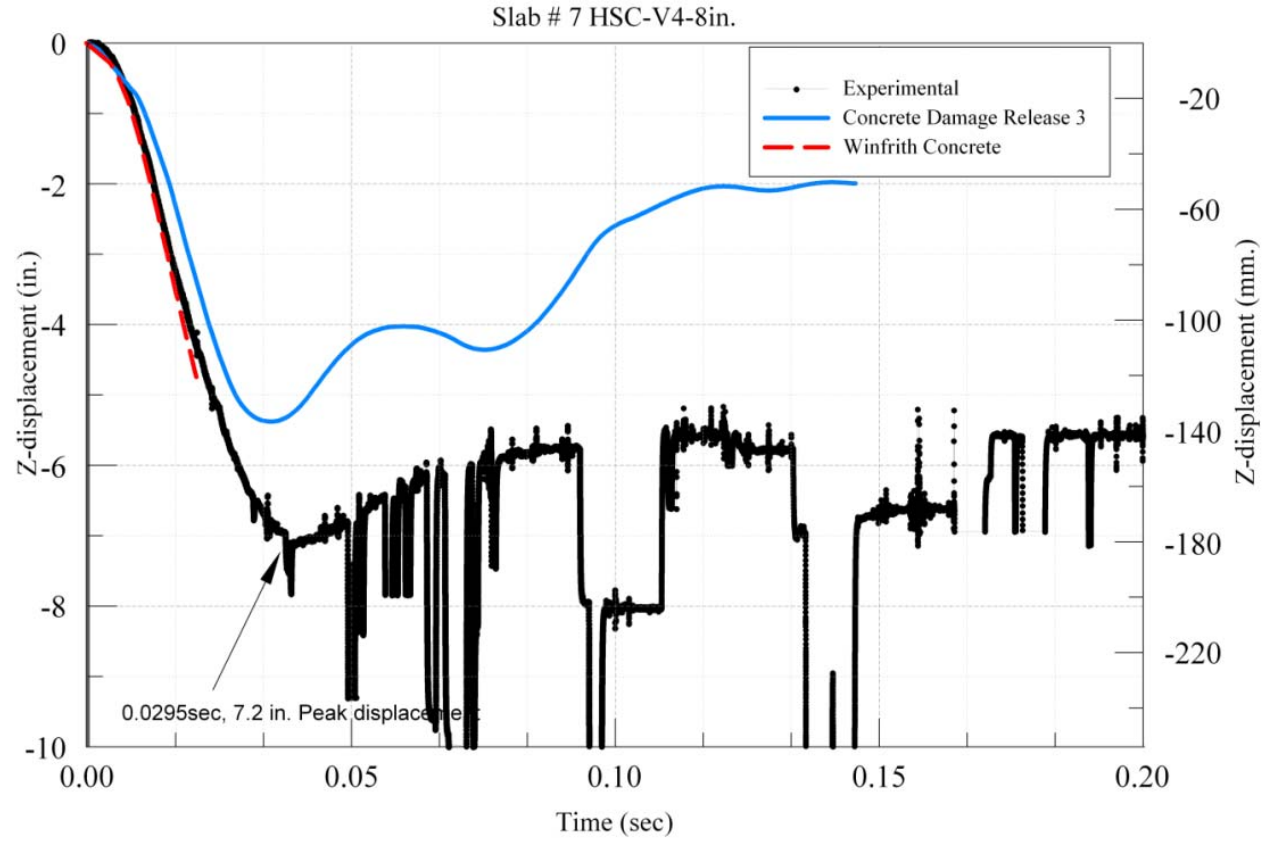

Figure 6-17: Deflection Comparison between Concrete Damage Model Release 3 and Winfrith Concrete for 1/2 in. (12.7 mm.) mesh model with Experimental Deflection Slab\#7 - HSC-V4-8in. 


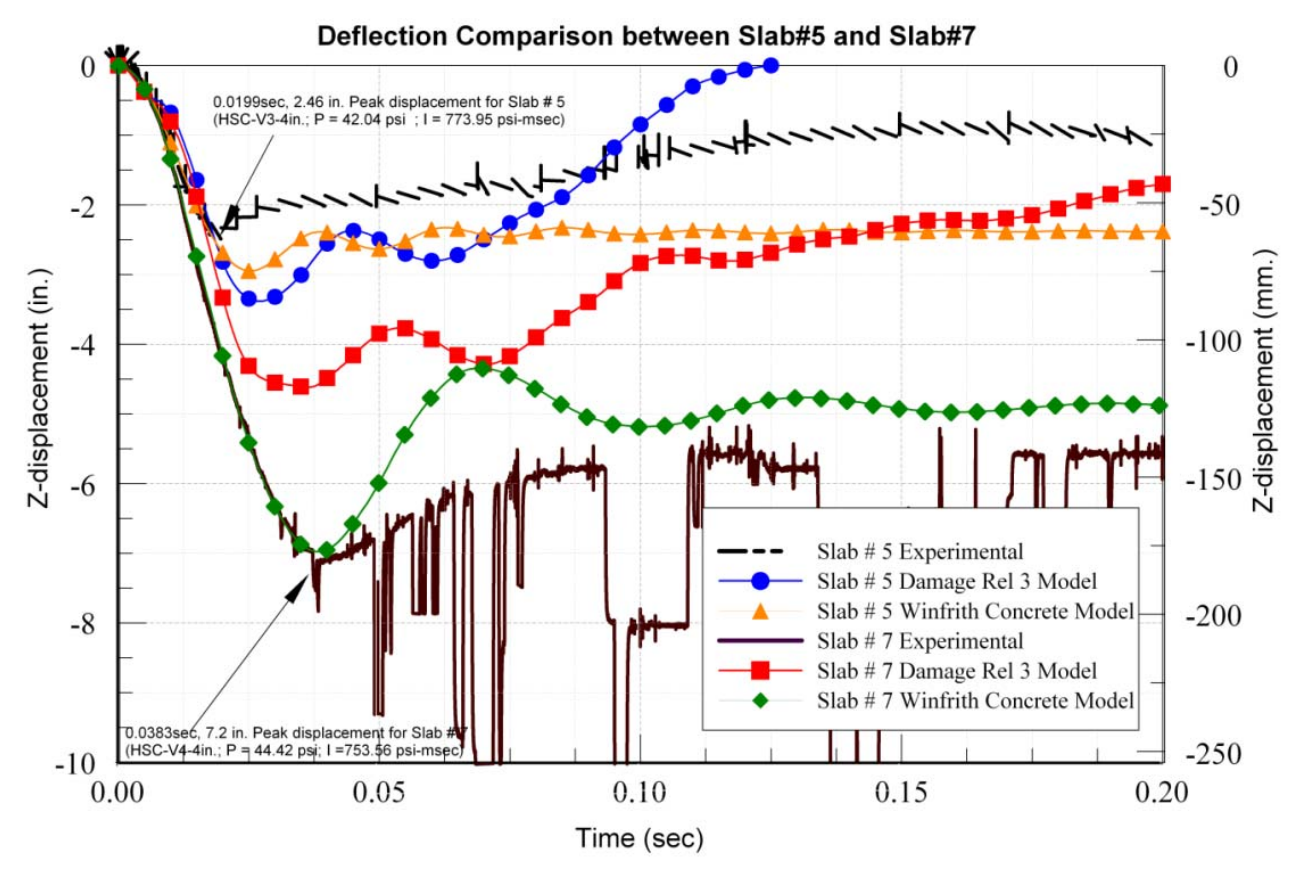

Figure 6-18: Deflection Comparison between Concrete Damage Model Release 3 and Winfrith Concrete for 1 in. $(25.4 \mathrm{~mm}$.) mesh model with Experimental Deflection for Slab\#5 - HSC-V3-4in. and Slab\#7 - HSC-V4-8in.

Figure 6-18 compares the two slabs i.e. Slab\#5 - HSC-V3-4in and Slab\#7 - HSCV4-8in. having the high-strength combination of concrete and steel with 4 in. and 8 in. steel spacing respectively for both the experimental and numerical analysis results. The numerical analysis results presented here are using the $1 \mathrm{in} .(25.4 \mathrm{~mm}$.) mesh model as this mesh size yielded good results as compared to other mesh sizes in both the concrete material models used. These slabs were subjected to similar pressures of 42.04 psi ( 0.28 $\mathrm{MPa})$ and $44.42 \mathrm{psi}(0.306 \mathrm{MPa})$ respectively and an impulse of 773.95 psi-msec (5.34 MPa-msec) and 753.56 psi-msec (5.19 MPa-msec) respectively during the experimental program.

The experimental peak deflections recorded for the two slabs are 2.46 in. (62.48 $\mathrm{mm}$.$) and 7.2 \mathrm{in.}(182.88 \mathrm{~mm}$.) respectively. The two different reinforcement ratios in the 
two slab types is the reason for such a large difference in the observed deflection. For both of these slabs when modeled using the WCM gave a good prediction of the deflection as observed from the peak and residual displacements as noted in Table 6-1 and 6-2. The CDMR3 predicted the deflection response not very close to the experiment even in the post peak region. The WCM predicted the peak deflections more closely but the post-peak deflection response is not very accurate.

The slabs under consideration here are reinforced with \#3 bars spaced at 4in. c/c (101.6 mm.) in the longitudinal direction (reinforcement ratio $=0.68 \%$ ) and with $\# 3$ bars spaced at 8 in. c/c $(203.2 \mathrm{~mm}$.) in the longitudinal direction (reinforcement ratio $=0.46 \%)$ respectively. The slab with higher reinforcement ratio produced lesser deflection.

\subsection{Mesh Size Effect for Slab \# 9 (HSC-V5-8in.)}

The deflection results obtained from numerical simulations for slab \# 9 which is a HSC-V5-8in. is compared for two different mesh sizes. This slab experienced a peak pressure of $34.01 \mathrm{psi}(0.23 \mathrm{MPa})$ and an impulse of $511.77 \mathrm{psi}-\mathrm{msec}(3.52 \mathrm{MPa}-\mathrm{msec})$ in the blast experiment. The blast pressures recorded for this slab are summarized in Appendix A. The average deflection obtained from the experiment was 3.4 in. $(86.36 \mathrm{~mm}$.) recorded at 33.4 milliseconds. 


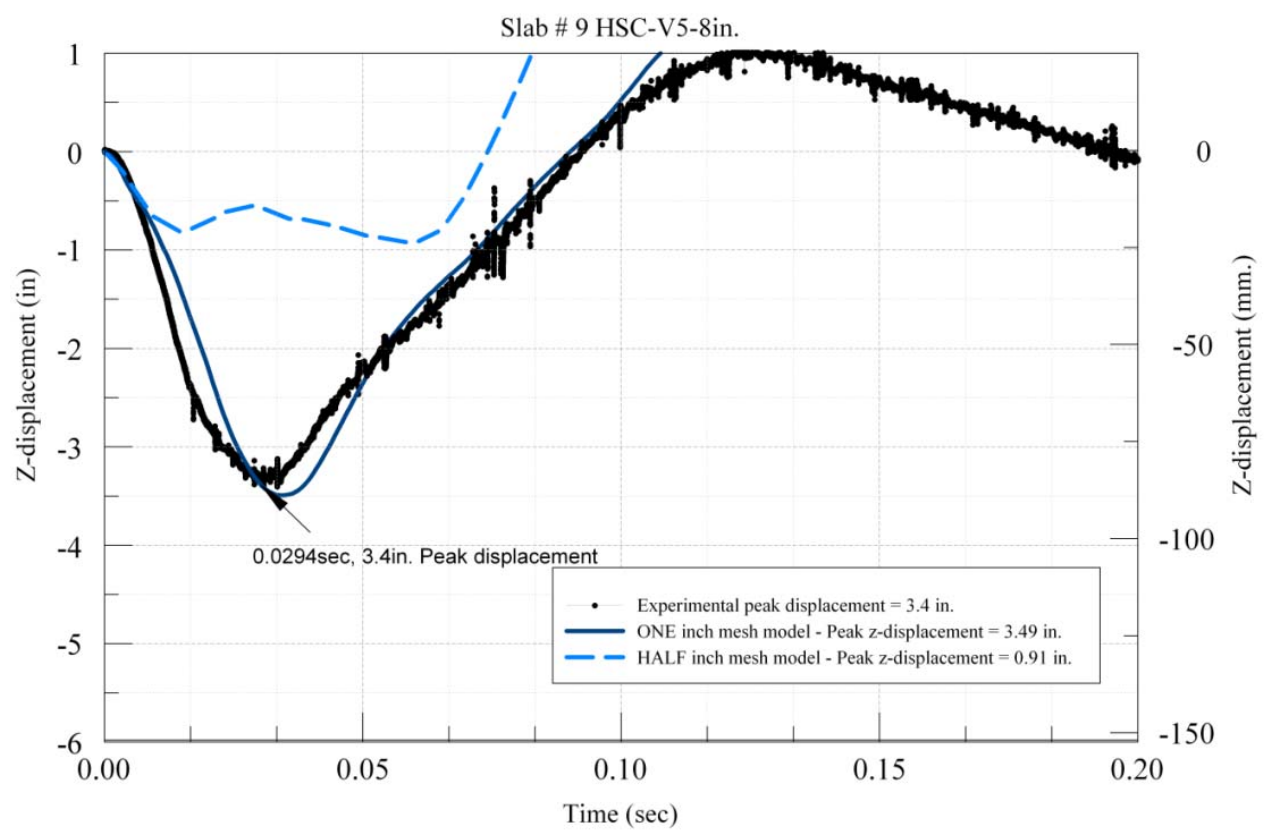

Figure 6-19: Deflection Comparison between 1 in. (25.4 mm.) and 1/2 in. (12.7 mm.) mesh sizes for Concrete Damage Model Release 3 and Experimental Deflection for Slab\#9 HSC-V5-8in.

The deflection results obtained from LS-DYNA® concrete models with two mesh sizes for CDMR3 are compared with the experimental deflections in Figure 6-19. The peak deflections obtained from the CDMR3 with 1 in. (25.4 mm.) mesh was 3.49 in. (88.646 mm.) recorded at 34.5 milliseconds while for $1 / 2$ in. $(12.7 \mathrm{~mm}$.) mesh model it was $0.91 \mathrm{in}$. (23.11 mm.) recorded at 59 milliseconds. The deflections obtained from the models with 1 in. $(25.4 \mathrm{~mm})$ mesh size showed a $2.5 \%$ increase while the deflections obtained from the $1 / 2$ in. (12.7 mm.) model showed a decrease by $73 \%$ when compared to the experimental values. This must be the case because the analysis terminated with an error due to occurrence of negative volume in certain elements. 


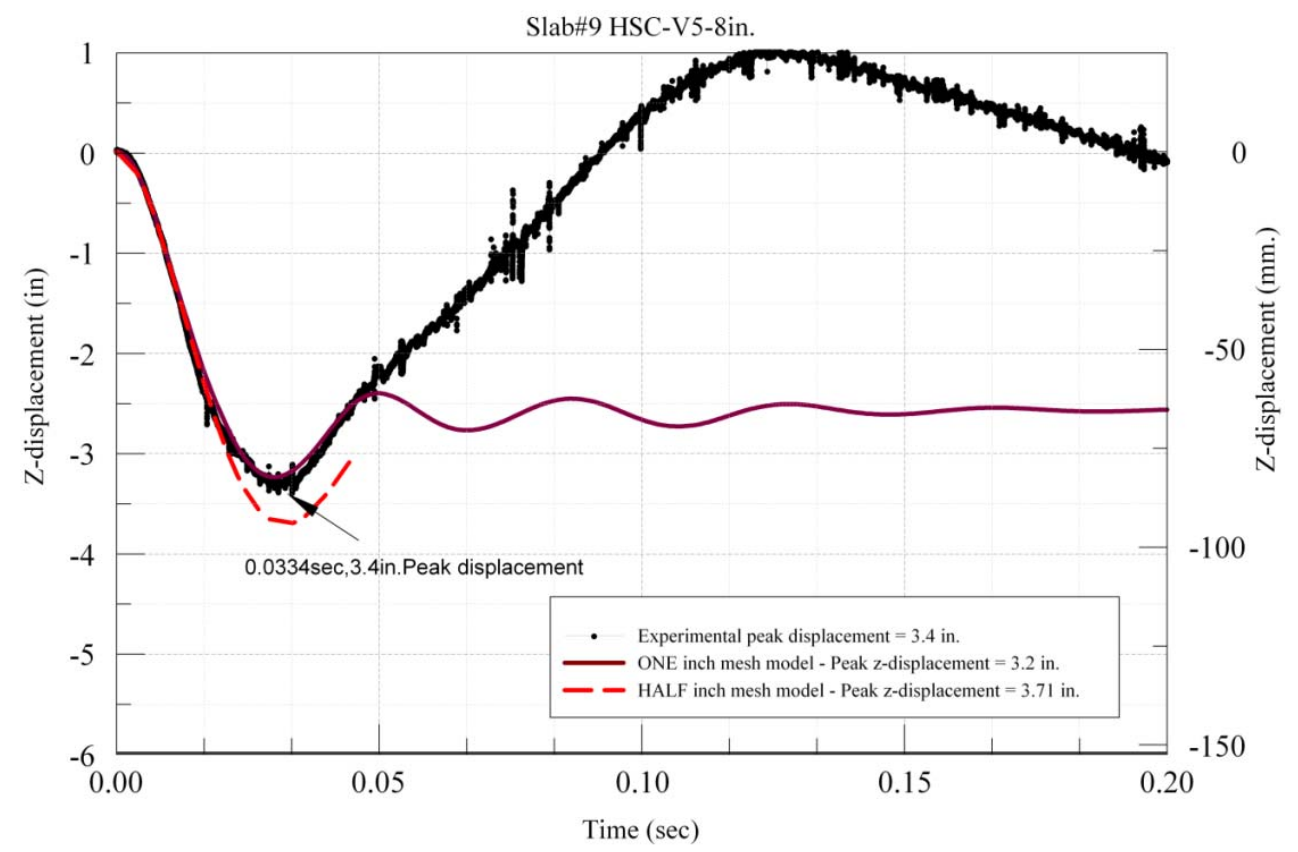

Figure 6-20: Deflection Comparison between 1 in. $(25.4 \mathrm{~mm}$.) and 1/2 in. (12.7 mm.) for mesh sizes Winfrith Concrete Model and Experimental Deflection for Slab\#9 - HSC-V58in.

The deflection results obtained from LS-DYNA® concrete models with two mesh sizes for WCM are compared with the experimental deflections in Figure 6-20. The peak deflections obtained from the WCM with 1 in. (25.4 mm.) mesh was $3.84 \mathrm{in}$. (97.54 mm.) recorded at 27.5 milliseconds while for $1 / 2 \mathrm{in}$. (12.7 $\mathrm{mm}$.) mesh model it was $3.72 \mathrm{in}$. (94.48 mm.) recorded at 32 milliseconds. The deflections obtained from the models with 1 in. $(25.4 \mathrm{~mm})$ mesh size showed a $4 \%$ decrease while the deflections obtained from the $1 / 2$ in. $(12.7 \mathrm{~mm}$.) model showed an increase by $9 \%$ when compared to the experimental values.

From Figure 6-19 and Figure 6-20 it can be noted that varying the mesh size from 1 in. $(25.4 \mathrm{~mm}$.) to $1 / 2 \mathrm{in.}(12.7 \mathrm{~mm}$.) increased the deflection by $0.46 \mathrm{in}$. $(11.68 \mathrm{~mm}$.) for the Winfrith Concrete Model. The 1 in. mesh $(25.4 \mathrm{~mm})$ can be useful to predict the deflection accurately in both the models in comparison with the experimental deflection. 


\subsection{Material Model Effect for Slab \# 9 (HSC-V5-8in.)}

Figure 6-21 and Figure 6-22 compare the deflections between two material models for two mesh sizes. From Figure 6-21 for the 1 in. $(25.4 \mathrm{~mm})$ mesh model the WCM predicted the deflection 0.15 in. $(3.81 \mathrm{~mm}$.) less while the CDMR3 predicted the deflection 0.09 in. (2.28 mm.) more than the experimental values. From Figure $6-22$ for the $1 / 2$ in. $(12.7 \mathrm{~mm})$ mesh model the WCM predicted the deflection $0.31 \mathrm{in} .(7.87 \mathrm{~mm}$.) more while the CDMR3 predicted the deflection 2.49 in. (63.24 mm.) less than the experimental values. Here, the Winfrith Concrete Model predicted the response better in both mesh size category.

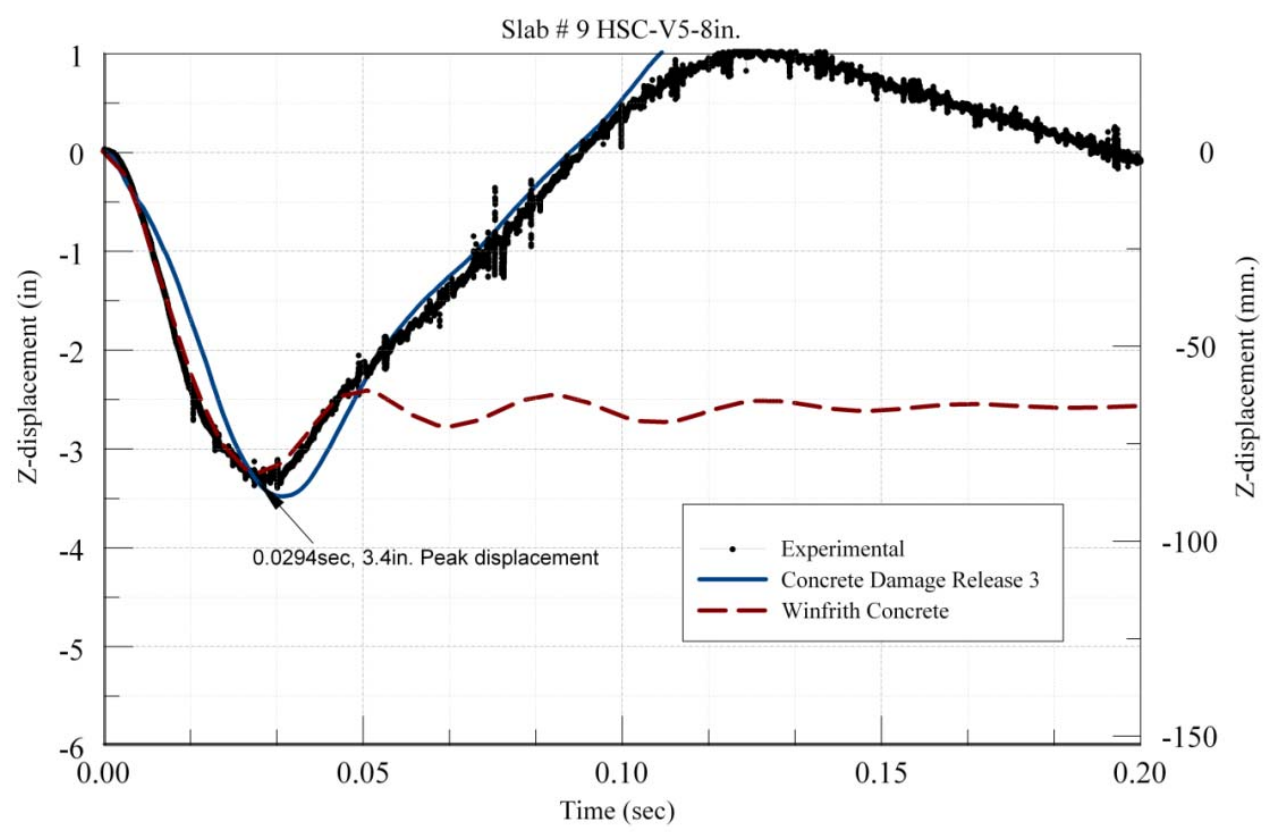

Figure 6-21: Deflection Comparison between Concrete Damage Model Release 3 and Winfrith Concrete for 1 in. (25.4 mm.) mesh model with Experimental Deflection for Slab\#9 - HSC-V5-8in. 


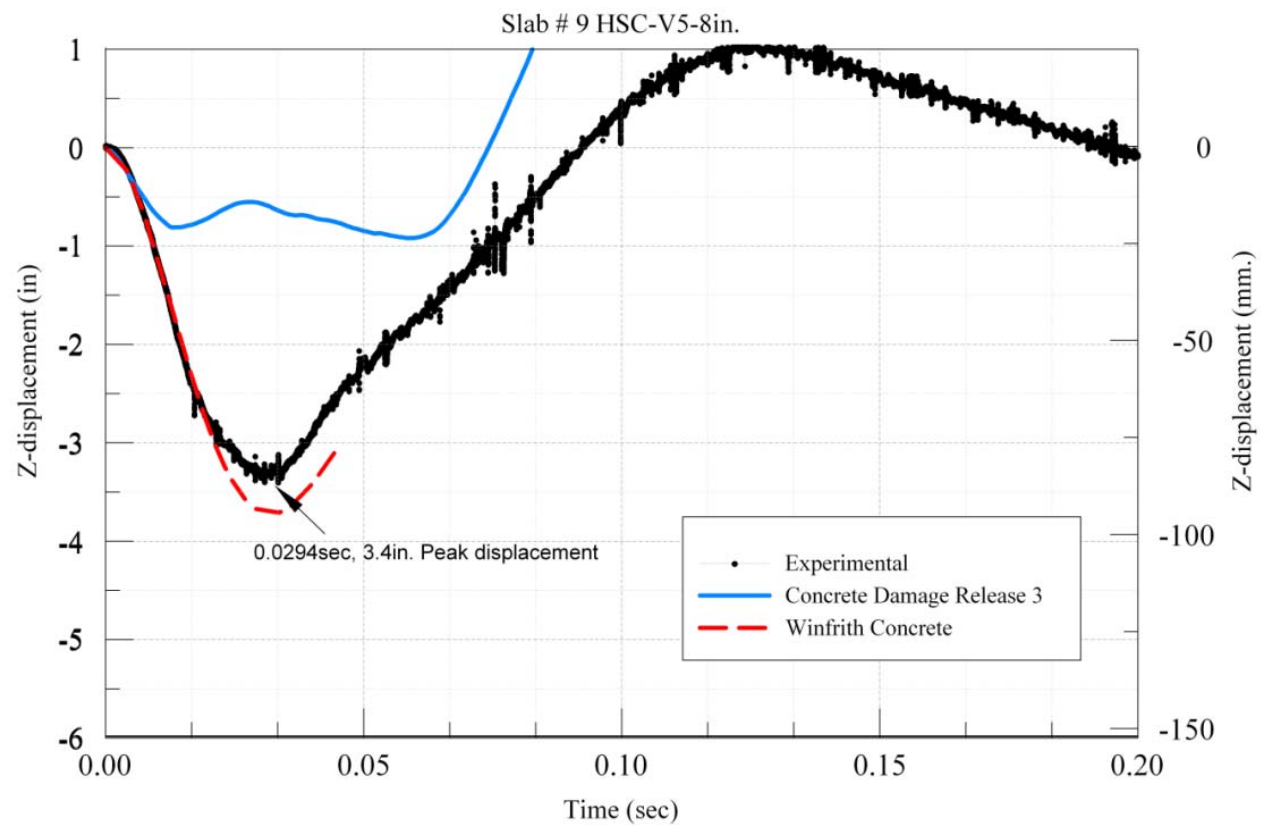

Figure 6-22: Deflection Comparison between Concrete Damage Model Release 3 and Winfrith Concrete for 1/2 in. (12.7 mm.) mesh model with Experimental Deflection Slab\#9 - HSC-V5-8in.

\subsection{Mesh Size Effect for Slab \# 11 (HSC-V6-8in.)}

The deflection results obtained from numerical simulations for slab \# 11 which is a HSC-V6-8in. is compared for two different mesh sizes. This slab experienced a peak pressure of $37.05 \mathrm{psi}(0.255 \mathrm{MPa})$ and an impulse of $576.07 \mathrm{psi}-\mathrm{msec}(3.97 \mathrm{MPa}-\mathrm{msec})$ in the blast experiment. The blast pressures recorded for this slab are summarized in Appendix A. The average deflection obtained from the experiment was $3.38 \mathrm{in}$. (85.85 mm.) recorded at 28.7 milliseconds. 


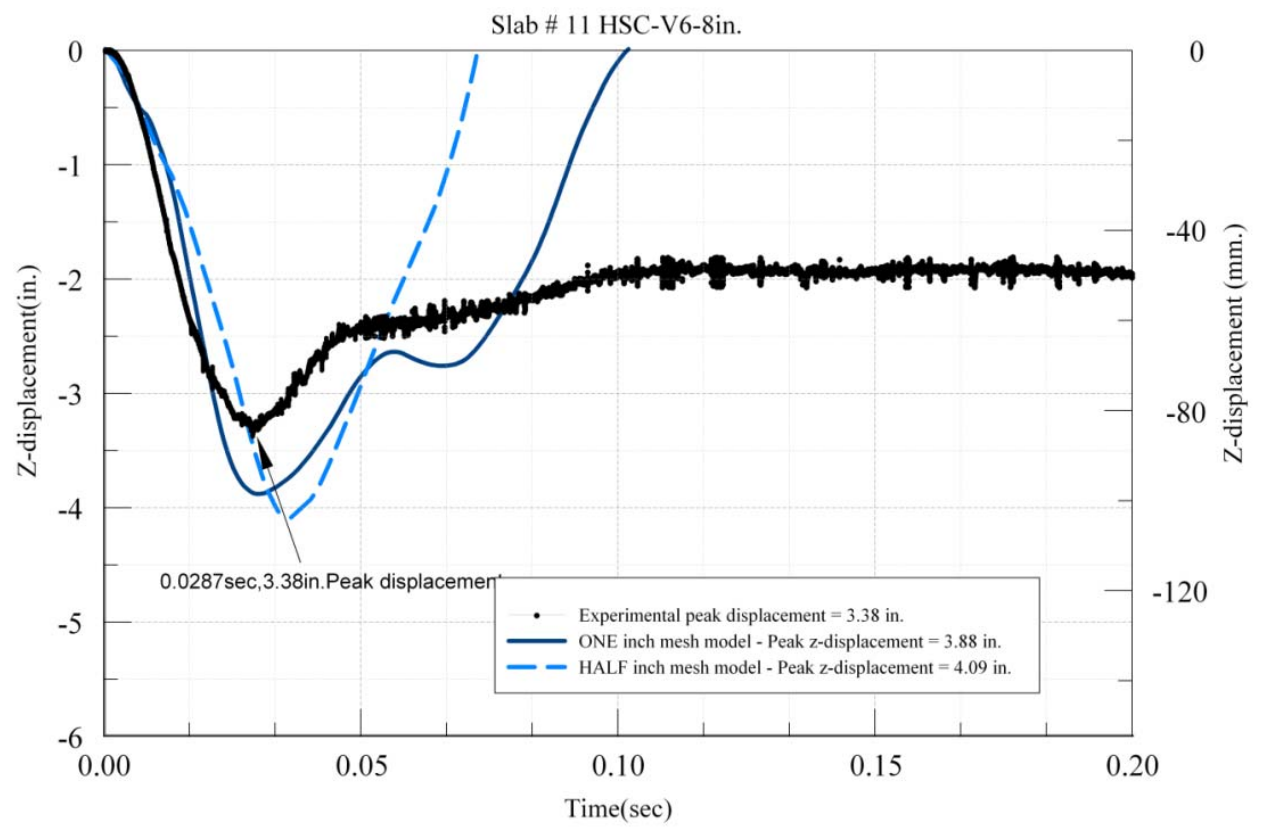

Figure 6-23: Deflection Comparison between 1 in. $(25.4 \mathrm{~mm}$.) and 1/2 in. $(12.7 \mathrm{~mm}$.) mesh sizes for Concrete Damage Model Release 3 and Experimental Deflection for Slab\#11- HSC-V6-8in.

The deflection results obtained from LS-DYNA® ${ }^{\circledR}$ concrete models with two mesh sizes for CDMR3 are compared with the experimental deflections in Figure 6-23. The peak deflections obtained from the CDMR3 with 1 in. (25.4 mm.) mesh was 3.88 in. (98.55 mm.) recorded at 29.5 milliseconds while for $1 / 2$ in. (12.7 mm.) mesh model it was 4.09 in. (103.88 mm.) recorded at 35.5 milliseconds. The deflections obtained from the models with 1 in. $(25.4 \mathrm{~mm})$ mesh size when compared to the experiments showed a $14 \%$ increase while the deflections obtained from the $1 / 2$ in. $(12.7 \mathrm{~mm}$.) model are higher by $21 \%$ when compared to the experiment. 


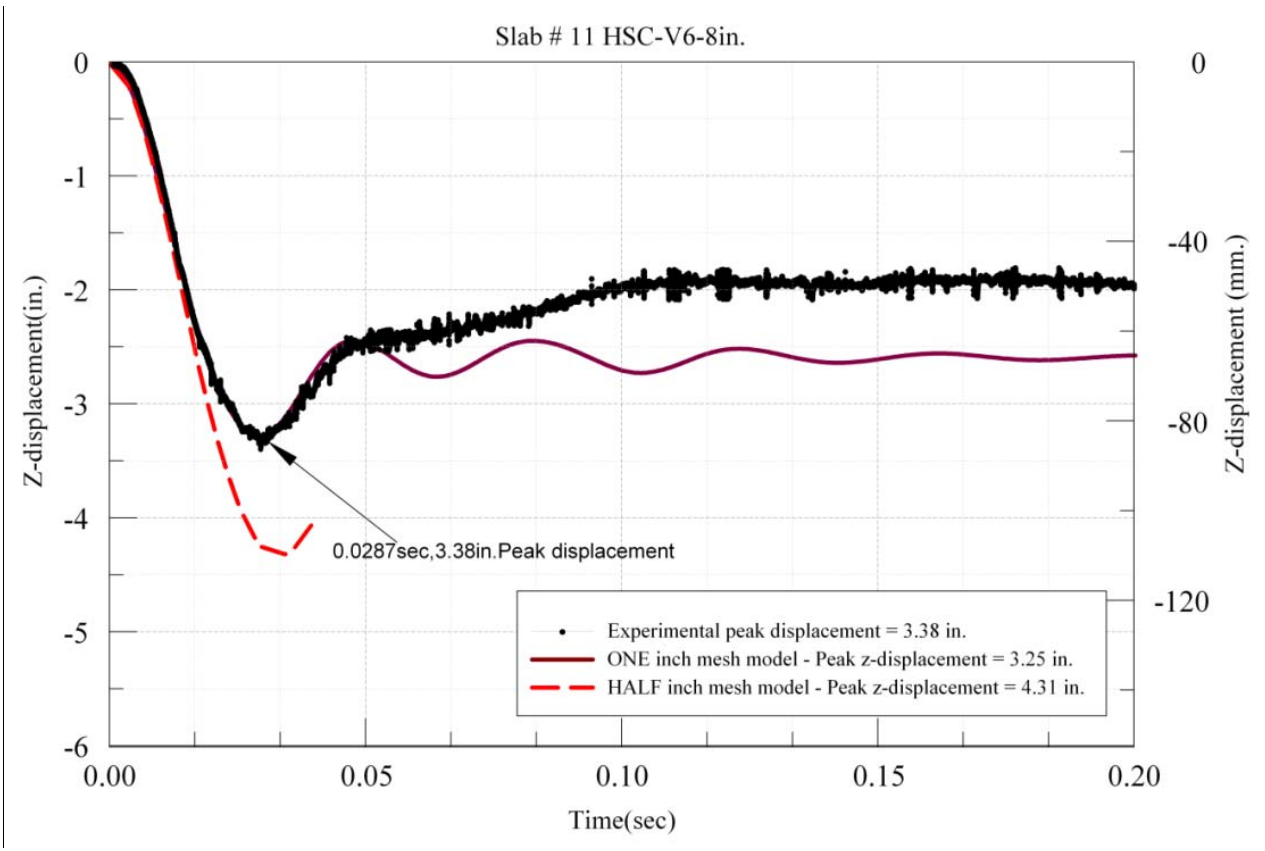

Figure 6-24: Deflection Comparison between 1 in. $(25.4 \mathrm{~mm}$.) and 1/2 in. (12.7 mm.) mesh sizes for Winfrith Concrete Model and Experimental Deflection for Slab\#11 - HSC-V6-8in.

The deflection results obtained from LS-DYNA® concrete models with two mesh

sizes for WCM is compared with the experimental deflections in Figure 6-24. The peak deflections obtained from the Winfrith Concrete model with 1 in. (25.4 mm.) mesh was 3.25 in. (82.55 mm.) recorded at 28.9 milliseconds while for $1 / 2$ in. (12.7 mm.) mesh model it was 4.31 in. (109.47 mm.) recorded at 32.5 milliseconds. The deflections obtained from the models with 1 in. $(25.4 \mathrm{~mm})$ mesh size when compared to the experiments showed a $4 \%$ decrease while the deflections obtained from the $1 / 2$ in. $(12.7 \mathrm{~mm}$.) model are higher by $27 \%$ when compared to the experiment.

From Figure 6-23 and Figure 6-24 it can be noted that varying the mesh size from 1 in. $(25.4 \mathrm{~mm}$.) to $1 / 2 \mathrm{in}$. (12.7 mm.) increased the deflection by $1.05 \mathrm{in}$. $(26.67 \mathrm{~mm}$.) for the WCM and by 0.12 in. (3.05 mm.) for CDMR3 respectively. The 1 in. mesh $(25.4 \mathrm{~mm})$ can be useful to predict the deflection accurately in both the models in comparison with the experimental deflection. 


\subsection{Material Model Effect for Slab \# 11 (HSC-V6-8in.)}

Figure 6-25 and Figure 6-26 compare the deflections between two material models for two mesh sizes. From Figure 6-25 for the 1 in. $(25.4 \mathrm{~mm})$ mesh model the WCM predicted the deflection 0.13 in. $(3.3 \mathrm{~mm}$.) less while the CDMR3 predicted the deflection $1 / 2$ in. $(12.7 \mathrm{~mm}$.$) more than the experiment. From Figure 6-26$ for the $1 / 2$ in. $(12.7 \mathrm{~mm})$ mesh model the CDMR3 predicted the deflection 0.71 in. $(18.03 \mathrm{~mm}$.) more while the WCM predicted the deflection 0.92 in. $(23.37 \mathrm{~mm}$.) more than the experimental values respectively. Both the concrete models predict the response higher than the experiment for the $1 / 2$ in. (12.7 mm.) category.

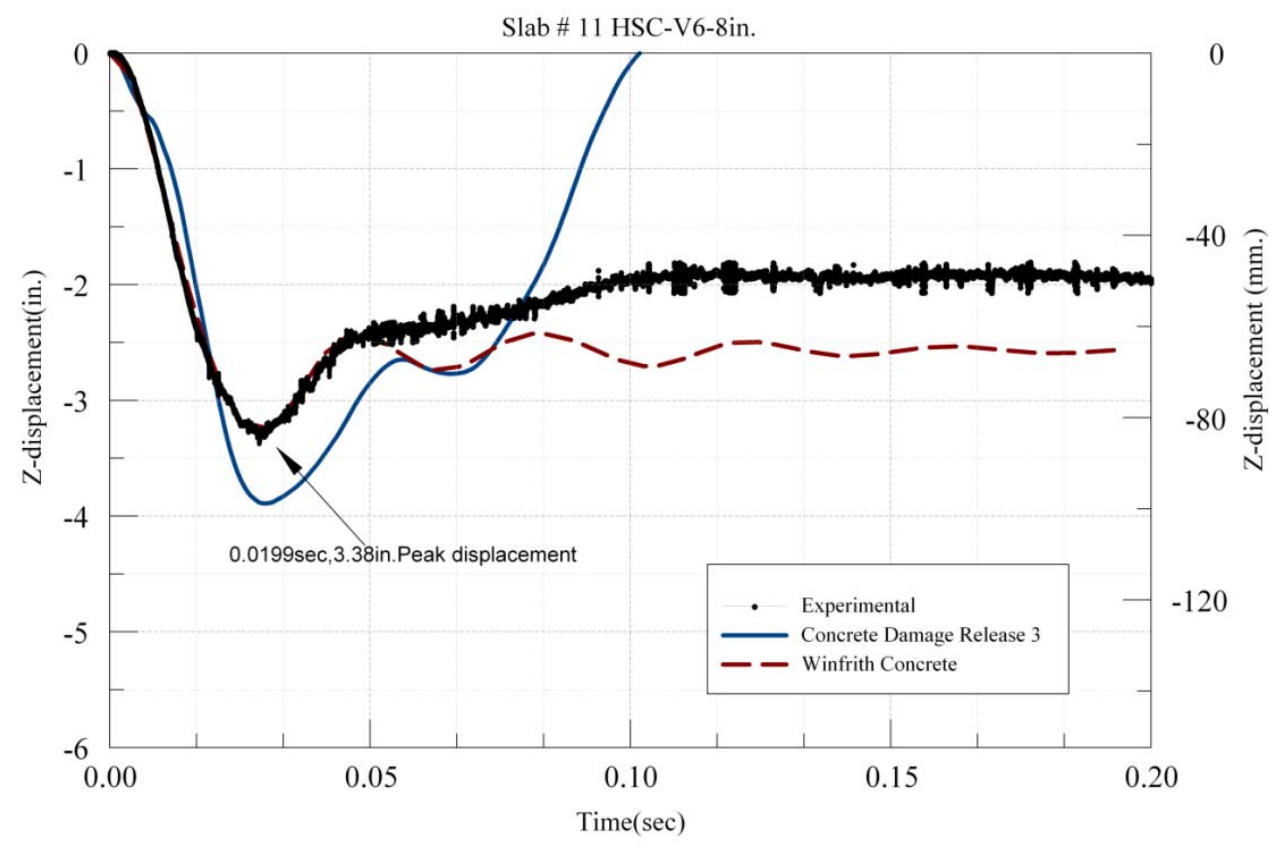

Figure 6-25: Deflection Comparison between Concrete Damage Model Release 3 and Winfrith Concrete for 1 in. (25.4 mm.) mesh model with Experimental Deflection for Slab\#11 - HSC-V6-8in. 


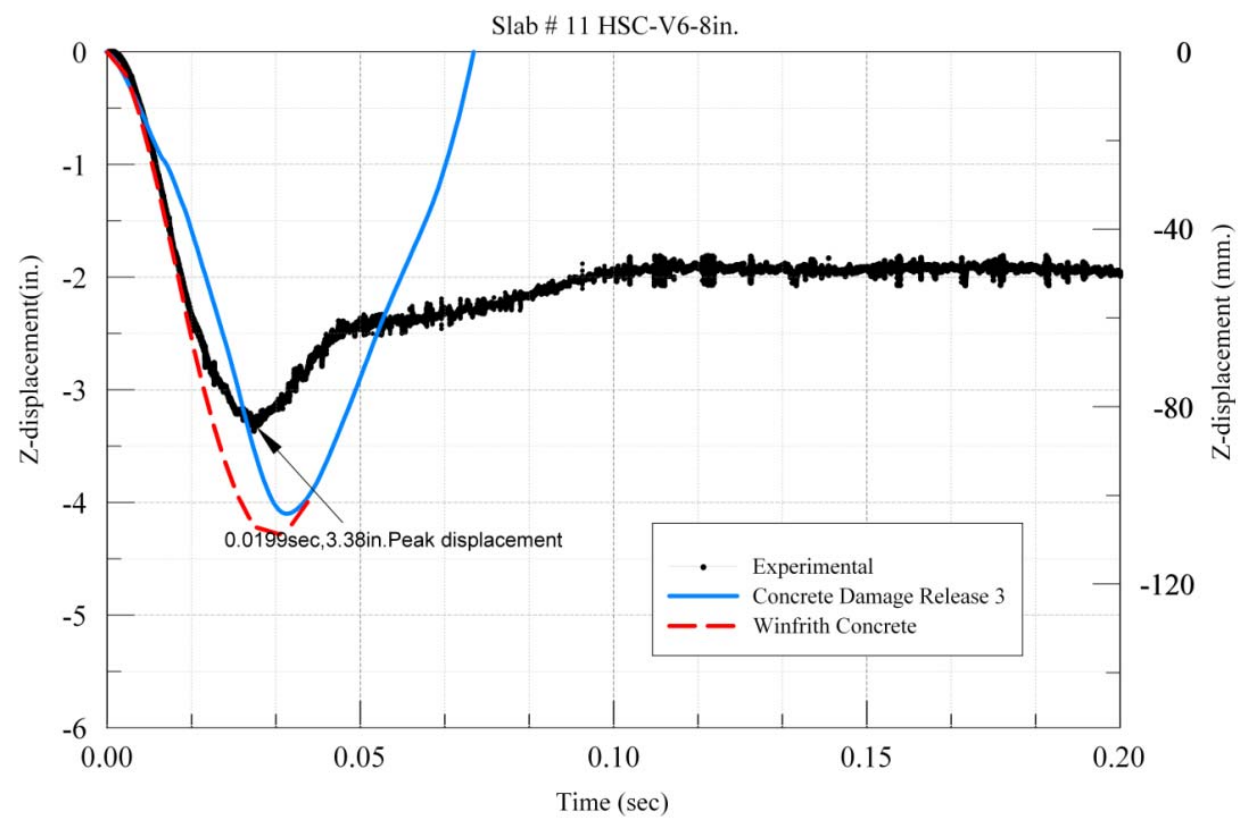

Figure 6-26: Deflection Comparison between Concrete Damage Model Release 3 and Winfrith Concrete for $1 / 2$ in. (12.7 mm.) mesh model with Experimental Deflection Slab\#11 - HSC-V6-8in.

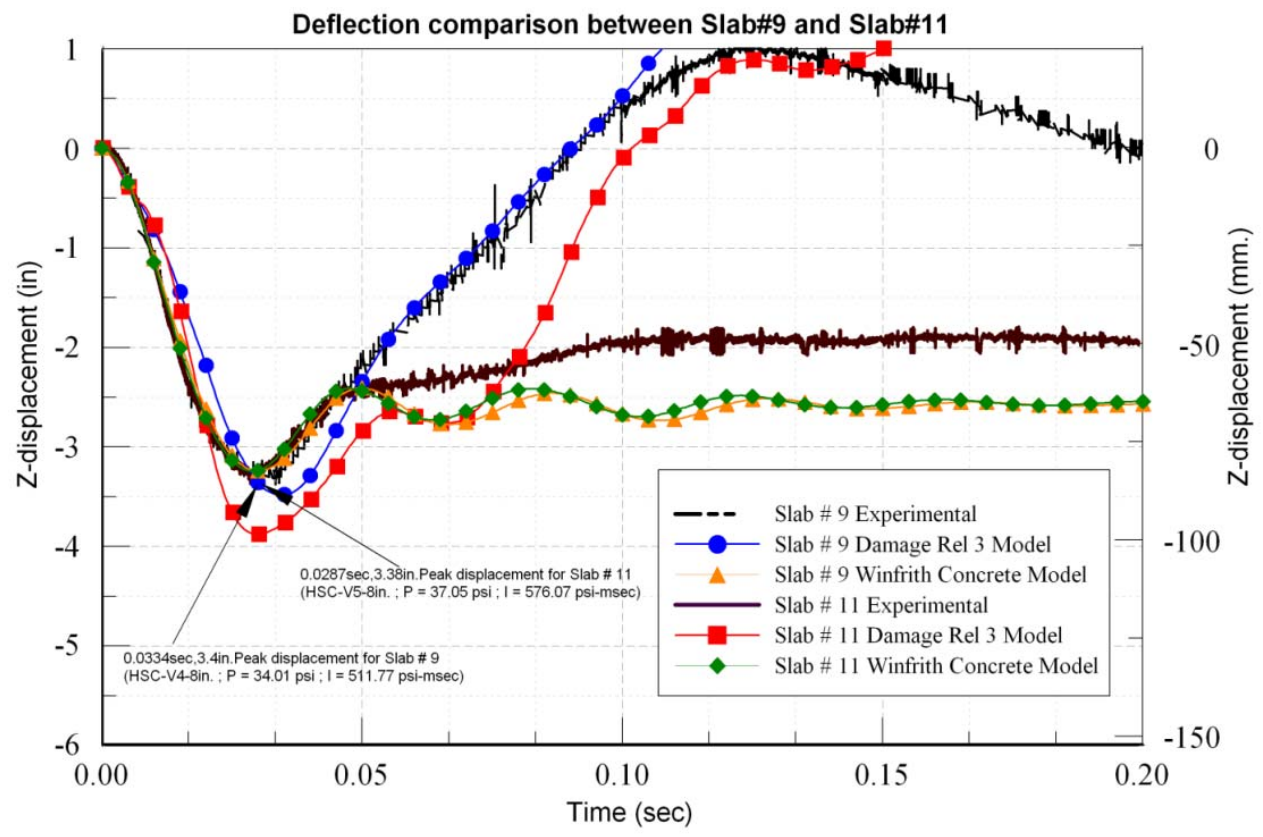

Figure 6-27: Deflection Comparison between Concrete Damage Model Release 3 and Winfrith Concrete for 1 in. (25.4 mm.) mesh model with Experimental Deflection for Slab\#9 - HSC-V5-8in and Slab\#11 - HSC-V6-8in. 
Figure 6-27 compares the two slabs i.e. Slab\#9 - HSC-V5-8in and Slab\#11 - HSCV6-8in. having the high-strength combination of concrete and steel with 8 in. steel spacing for both the experimental and numerical analysis results. The numerical analysis results presented here are using the 1 in. $(25.4 \mathrm{~mm}$.) mesh model as this mesh size yielded good results as compared to other mesh sizes in both the concrete material models used. These slabs were subjected to similar pressures of $34.01 \mathrm{psi}(0.23 \mathrm{MPa})$ and $37.05 \mathrm{psi}(0.255$ $\mathrm{MPa}$ ) respectively and an impulse of 511.77 psi-msec (3.52 MPa-msec) and 576.07 psimsec (3.97 $\mathrm{MPa}-\mathrm{msec})$ respectively during the experimental program.

As seen in the plot the peak deflections for the two slabs occured within a very small timeframe ranging between 28.7 milliseconds and 33.4 milliseconds. The experimental peak deflections recorded for the two slabs are 3.4 in. $(86.36 \mathrm{~mm}$.$) and 3.38 \mathrm{in.}(85.85 \mathrm{~mm}$. respectively. For both of these slabs when modeled using the two concrete material models gave a good prediction of the deflection as observed from the peak and residual displacements as noted in Table 6-1 and 6-2. The Concrete Damage Release 3 Model predicted the deflection response very close to the experiment even in the post peak region. Although the peak values deviates more from the experimental peak deflection as compared to the Winfrith Concrete Model. The Winfrith Concrete Model predicted the peak deflections more closely but the post-peak deflection response is not very accurate.

The slabs under consideration here are reinforced with \#3 bars spaced at $8 \mathrm{in}$. c/c (203.2 mm.) in the longitudinal direction (reinforcement ratio $=0.46 \%$ ). The numerical analysis using the Winfrith Concrete Model shows a stable response with lesser rebound of the slab in the post-peak deflection-time history. 


\subsubsection{Normal Strength Concrete with Normal Strength Steel Slabs (RSC-R)}

The second set of slabs studied here are the ones having combination of normal strength concrete reinforced with normal strength steel (RSC-R). The deflection-time histories for each of the 6 slabs are represented in this section. The comparison is made between two mesh sizes i.e. 1 " and 0.5 " for each of the two material models as shown in Table 6-7 and Table 6-8.

Table 6-7: Percentage comparison of deflections with the experimental value for normal strength slabs.

\begin{tabular}{|c|c|c|c|c|c|c|}
\hline \multirow[t]{3}{*}{$\begin{array}{l}\text { Slab } \\
\text { No. }\end{array}$} & \multirow[t]{3}{*}{ Description } & \multirow[t]{3}{*}{$\begin{array}{c}\text { Pressure (psi)/Impulse } \\
\text { (psi-msec) }\end{array}$} & \multicolumn{4}{|c|}{$\begin{array}{l}\text { Percentage Change in Deflections in the } \\
\text { Numerical Model from Experimental } \\
\text { Deflection values. }\end{array}$} \\
\hline & & & \multicolumn{2}{|c|}{1 in.mesh } & \multicolumn{2}{|c|}{0.5 in. mesh } \\
\hline & & & Winfrith & $\begin{array}{l}\text { Damage } \\
\text { Release } 3\end{array}$ & Winfrith & $\begin{array}{l}\text { Damage } \\
\text { Release } 3\end{array}$ \\
\hline 2 & RSC-R1-4in. & $53.1 / 976.71$ & $\downarrow 23 \%$ & $\uparrow 10 \%$ & $\downarrow 14 \%$ & $\uparrow 32 \%$ \\
\hline 4 & RSC-R2-4in. & $52.39 / 1000.38$ & $\downarrow 26.5 \%$ & $0 \%$ & $\downarrow 16 \%$ & $\uparrow 28 \%$ \\
\hline 6 & RSC-R3-4in. & $44.2 / 785.35$ & $\downarrow 33 \%$ & $\uparrow 9 \%$ & $\downarrow 22.7 \%$ & $* *$ \\
\hline 8 & RSC-R4-8in. & $33.4 / 494.39$ & $\downarrow 17 \%$ & $\uparrow 8 \%$ & $\downarrow 24.5 \%$ & $\uparrow 37 \%$ \\
\hline 10 & RSC-R5-8in. & $34.78 / 549.5$ & $\downarrow 8 \%$ & $\uparrow 10 \%$ & $\downarrow 18 \%$ & $\uparrow 36 \%$ \\
\hline 12 & RSC-R6-8in. & $33.74 / 509.01$ & $\downarrow 5 \%$ & $\uparrow 7 \%$ & $\downarrow 13 \%$ & $\uparrow 64 \%$ \\
\hline
\end{tabular}

Table 6-8: Percentage change in deflection when the mesh size was reduced from 1 in. $(25.4 \mathrm{~mm}$.$) to 1 / 2$ in. $(12.7 \mathrm{~mm}$.) for normal strength slabs.

\begin{tabular}{llcc}
\hline Slab No. & Description & \multicolumn{2}{c}{ Deflections } \\
\hline & & Winfrith & $\begin{array}{l}\text { Damage } \\
\text { Release 3 }\end{array}$ \\
\hline Slab 2 & RSC-R1-4in. & $\uparrow 11 \%$ & $\uparrow 20 \%$ \\
\hline Slab 4 & RSC-R2-4in. & $\uparrow 14 \%$ & $\uparrow 28 \%$ \\
Slab 6 & RSC-R3-4in. & $\uparrow 15 \%$ & $* *$ \\
Slab 8 & RSC-R4-8in. & $\downarrow 23 \%$ & $\uparrow 27 \%$ \\
Slab 10 & RSC-R5-8in. & $\downarrow 17 \%$ & $\uparrow 23 \%$ \\
Slab 12 & RSC-R6-8in. & $\downarrow 11 \%$ & $\uparrow 52 \%$ \\
\hline
\end{tabular}




\subsection{Mesh Size Effect for Slab \# 2 (RSC-R1-4in.)}

The deflection results obtained from numerical simulations for slab \# 2 which is a RSC-R1-4in. is compared for two different mesh sizes. This slab experienced a peak pressure of $53.1 \mathrm{psi}(0.366 \mathrm{MPa})$ and an impulse of 976.17 psi-msec $(6.73 \mathrm{MPa}-\mathrm{msec})$ in the blast experiment. The blast pressures recorded for this slab are summarized in Appendix A. The average deflection obtained from the experiment was 4.29 in $(108.96 \mathrm{~mm}$.) recorded at 29.94 milliseconds.

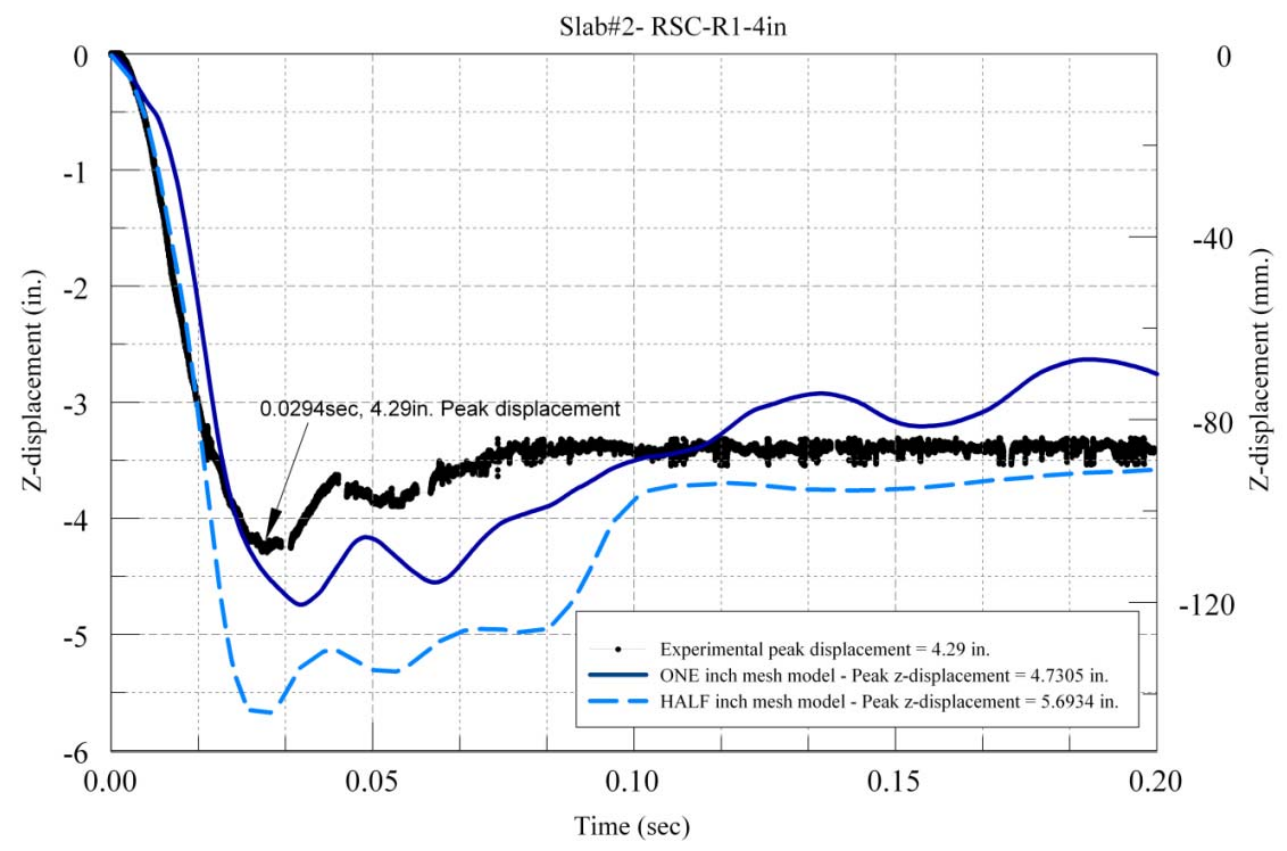

Figure 6-28: Deflection Comparison between 1 in. $(25.4 \mathrm{~mm}$.) and 1/2 in. (12.7 mm.) mesh sizes for Concrete Damage Model Release 3 and Experimental Deflection for Slab\#2 RSC-R1-4in.

The deflection results obtained from LS-DYNA® concrete models with two mesh sizes for CDMR3 are compared with the experimental deflections in Figure 6-28. The peak deflections obtained from the CDMR3 with 1 in. (25.4 mm.) mesh was 4.73 in. (120.14 $\mathrm{mm}$.) recorded at 36.5 milliseconds while for $1 / 2 \mathrm{in.}(12.7 \mathrm{~mm}$.) mesh model it was $5.69 \mathrm{in}$. 
(144.53 mm.) recorded at 28.5 milliseconds. The deflections obtained from the models for CDMR3 with 1 in. $(25.4 \mathrm{~mm})$ mesh size showed a $10 \%$ increase when compared to the experiments. The deflections obtained from the $1 / 2$ in. $(12.7 \mathrm{~mm}$.) model are higher by $32 \%$ when compared to the experiment.

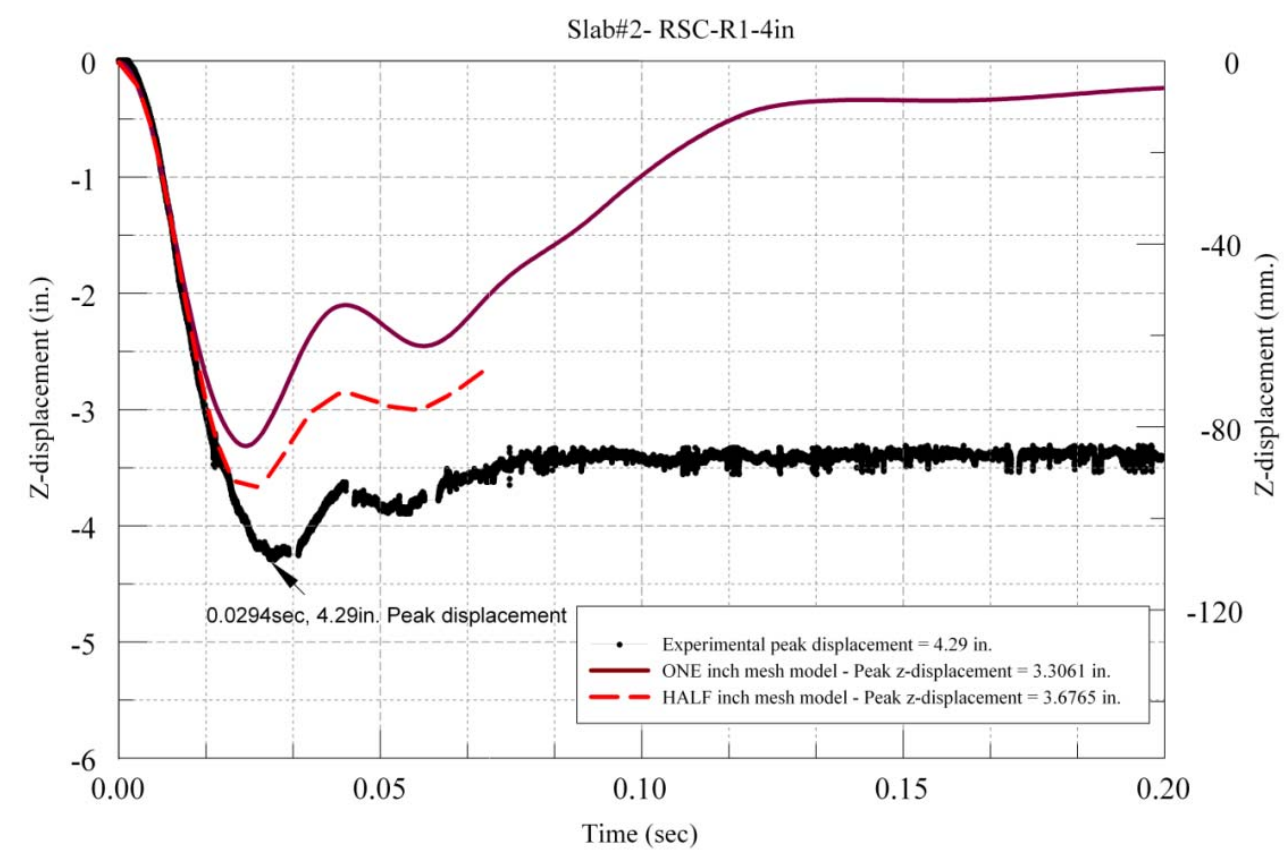

Figure 6-29: Deflection Comparison between 1 in. ( $25.4 \mathrm{~mm}$.) and 1/2 in. (12.7 mm.) mesh sizes for Winfrith Concrete Model and Experimental Deflection for Slab\#2 - RSC-R1-4in.

The deflection results obtained from LS-DYNA ${ }^{\circledR}$ concrete models with two mesh sizes for WCM are compared with the experimental deflections in Figure 6-29. The peak deflections obtained from the Winfrith Concrete model with 1 in. $(25.4 \mathrm{~mm}$.) mesh was 3.3 in. (83.82 mm.) recorded at 24.5 milliseconds while for $1 / 2$ in. $(12.7 \mathrm{~mm}$.) mesh model it was 3.67 in. $(93.22 \mathrm{~mm}$.) recorded at 25 milliseconds. The deflections obtained from the models with 1 in. $(25.4 \mathrm{~mm})$ mesh size showed a $23 \%$ decrease while the deflections obtained from the $1 / 2$ in. (12.7 mm.) model showed a $14 \%$ decrease when compared to the experimental values respectively. 
From Figure 6-28 and Figure 6-29 it can be noted that varying the mesh size from 1 in. $(25.4 \mathrm{~mm}$.) to $1 / 2 \mathrm{in}$. $(12.7 \mathrm{~mm}$.) increased the deflection by $0.37 \mathrm{in} .(9.4 \mathrm{~mm}$.) for the WCM and by 0.96 in. $(24.38 \mathrm{~mm}$.) for CDMR3 respectively. The $1 \mathrm{in}$. mesh $(25.4 \mathrm{~mm})$ can be useful to predict the deflection accurately in both the models in comparison with the experimental deflection.

\subsection{Material Model Effect for Slab \# 2 (RSC-R1-4in.)}

Figure 6-30 and Figure 6-31 compare the deflections between two material models for two mesh sizes. From Figure 6-30 for the 1 in. $(25.4 \mathrm{~mm})$ mesh model the CDMR3 predicted the deflection 0.44 in. $(11.18 \mathrm{~mm}$.) more than the experimental deflection while the WCM predicted the deflection which was 0.99 in. $(2.28 \mathrm{~mm}$.) less than the experiment. From Figure 6-31 for the 1/2 in. $(12.7 \mathrm{~mm})$ mesh model the WCM predicted the deflection 0.62 in. $(25.15 \mathrm{~mm}$.) less than the experimental deflection while the CDMR3 predicted the deflection 1.4 in. $(35.56 \mathrm{~mm}$.) more than the experiment. The Winfrith Concrete Model predicted the response better in both mesh size category. 


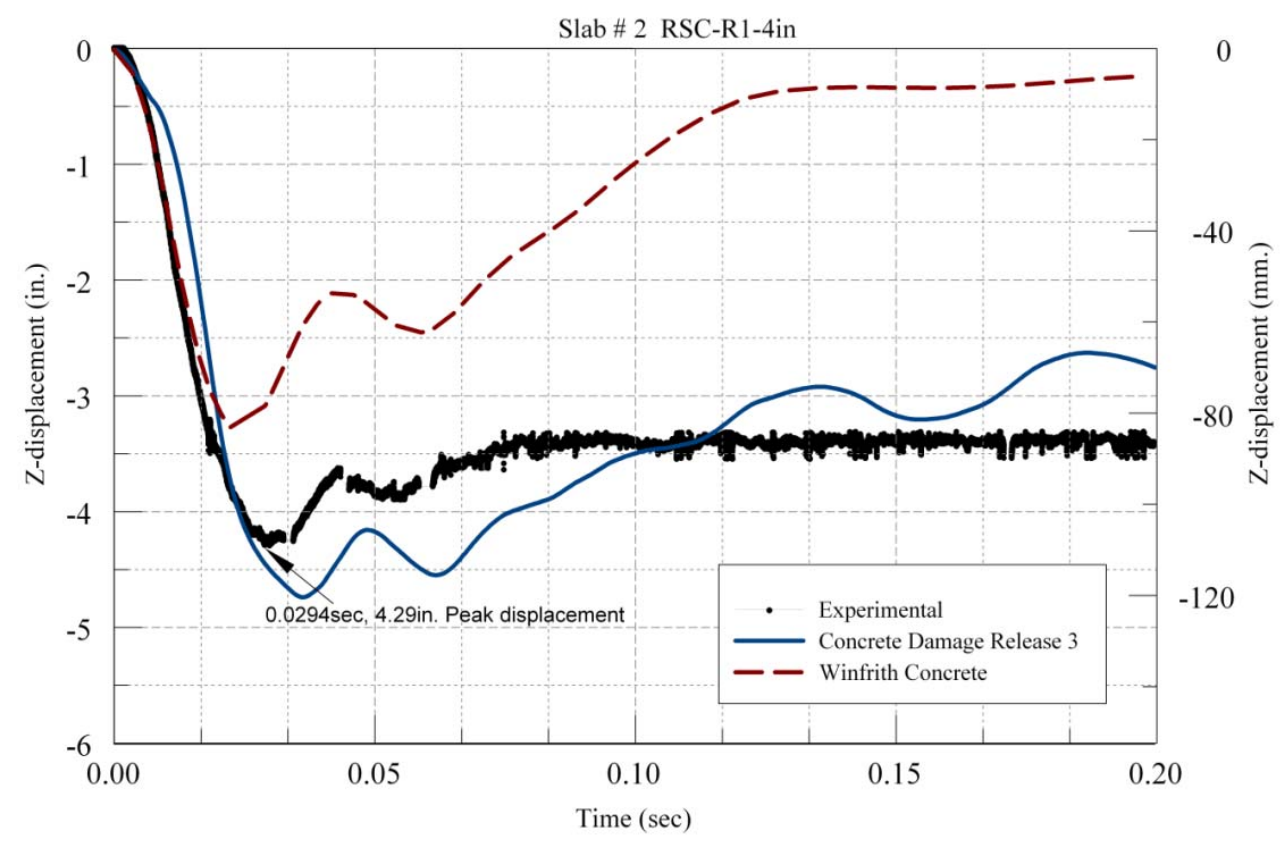

Figure 6-30: Deflection Comparison between Concrete Damage Model Release 3 and Winfrith Concrete for 1 in. (25.4 mm.) mesh model with Experimental Deflection for Slab\#2 - RSC-R1-4in.

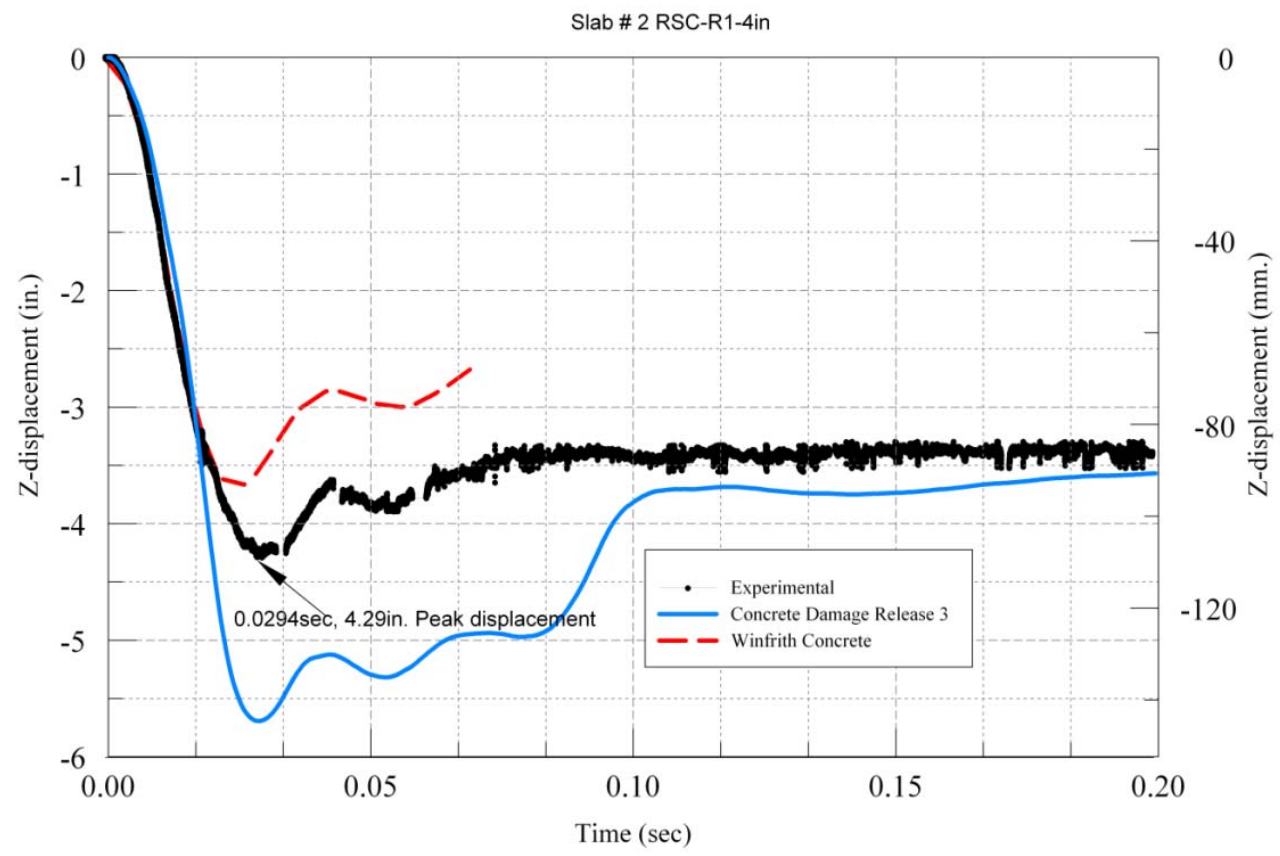

Figure 6-31: Deflection Comparison between Concrete Damage Model Release 3 and Winfrith Concrete for 1/2 in. (12.7 mm.) mesh model with Experimental Deflection Slab\#2- RSC-R1-4in. 


\subsection{Mesh Size Effect for Slab \# 4 (RSC-R2-4in.)}

The deflection results obtained from numerical simulations for slab \# 4 which is a RSC-R2-4in. is compared for two different mesh sizes. This slab experienced a peak pressure of $52.39 \mathrm{psi}(0.361 \mathrm{MPa})$ and an impulse of $1000.38 \mathrm{psi}-\mathrm{msec}(6.89 \mathrm{MPa}-\mathrm{msec})$ in the blast experiment. The blast pressures recorded for this slab are summarized in Appendix A. The average deflection obtained from the experiment was $4.45 \mathrm{in}$. (113.03 mm.) recorded at 32.73 milliseconds.

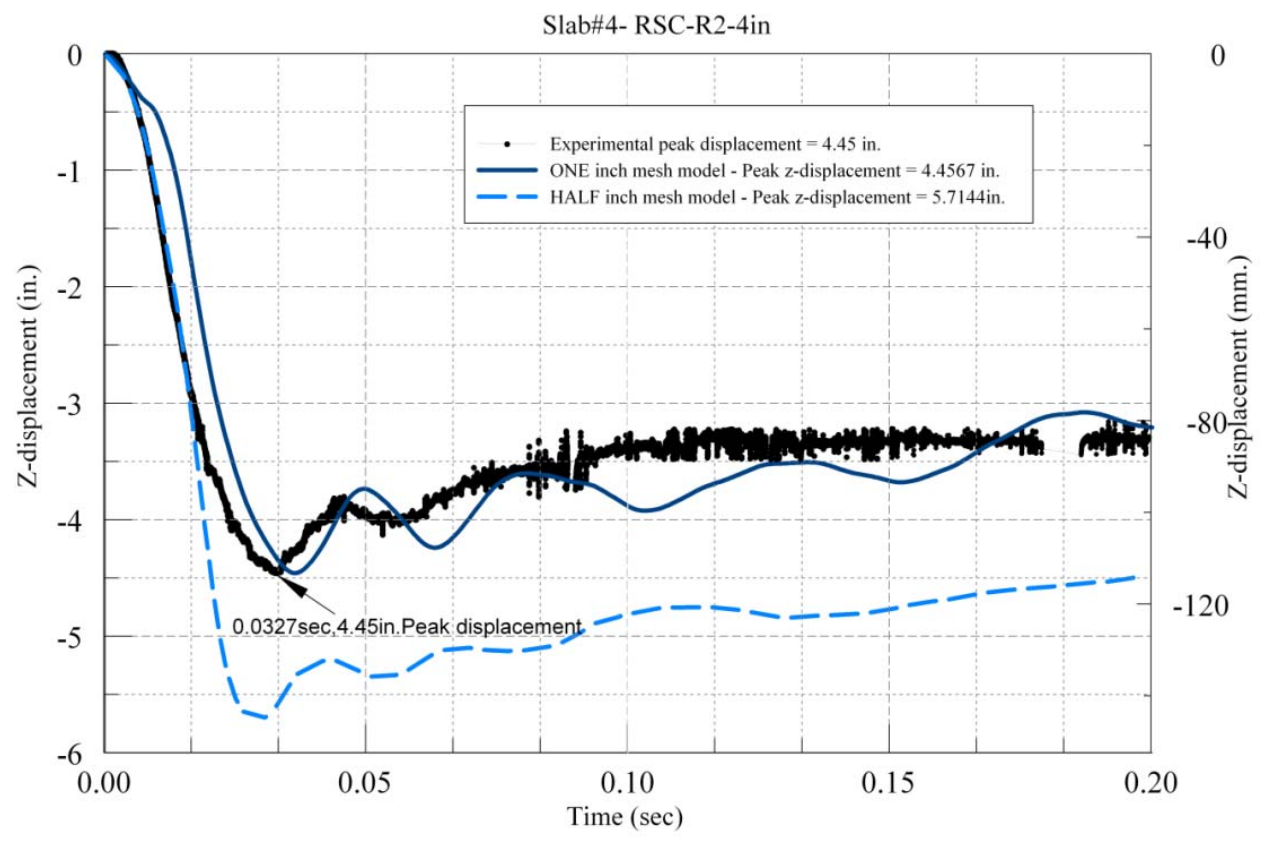

Figure 6-32: Deflection Comparison between 1 in. $(25.4 \mathrm{~mm}$.) and $1 / 2$ in. $(12.7 \mathrm{~mm}$.) mesh sizes for Concrete Damage Model Release 3 and Experimental Deflection for Slab\#4 RSC-R2-4in.

The deflection results obtained from LS-DYNA® concrete models with two mesh sizes for CDMR3 are compared with the experimental deflections in Figure 6-32. The peak deflections obtained from the CDMR3 with 1 in. (25.4 mm.) mesh was 4.45 in. (113.03 mm.) recorded at 36.5 milliseconds while for $1 / 2$ in. $(12.7 \mathrm{~mm}$.) mesh model it was $5.71 \mathrm{in}$. (145.03 mm.) recorded at 28.99 milliseconds. The deflections obtained from the models 
with 1 in. $(25.4 \mathrm{~mm})$ mesh size showed no change when compared to the experiments. The deflections obtained from the $1 / 2$ in. $(12.7 \mathrm{~mm}$.) model are higher by $28 \%$ when compared to the experiment.

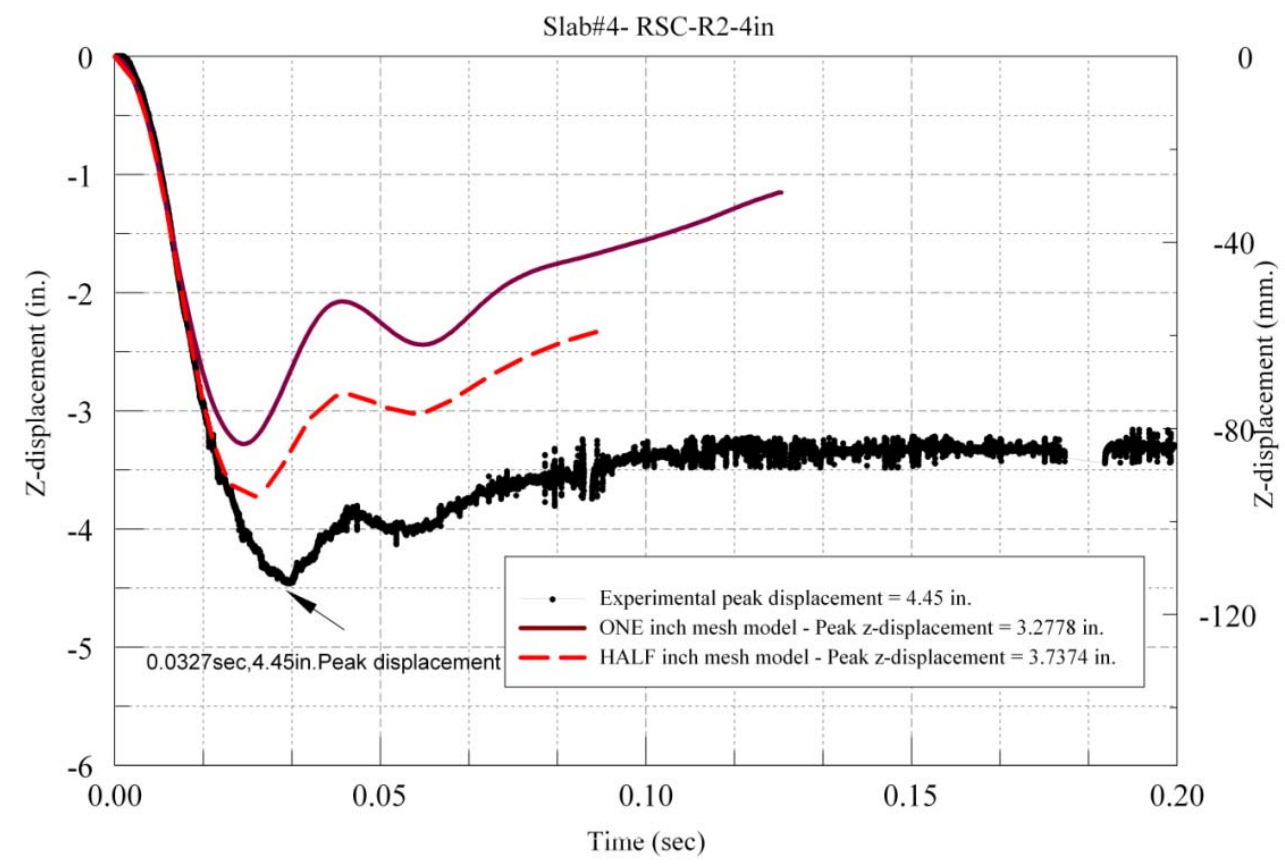

Figure 6-33: Deflection Comparison between 1 in. $(25.4 \mathrm{~mm}$.) and 1/2 in. (12.7 mm.) mesh sizes for Winfrith Concrete Model and Experimental Deflection for Slab\#4 - RSC-R2-4in.

The deflection results obtained from LS-DYNA ${ }^{\circledR}$ concrete models with two mesh sizes for WCM are compared with the experimental deflections in Figure 6-33. The peak deflections obtained from the WCM with 1 in. $(25.4 \mathrm{~mm}$.) mesh was $3.28 \mathrm{in.}(83.31 \mathrm{~mm}$.) recorded at 24.5 milliseconds while for $1 / 2 \mathrm{in}$. (12.7 mm.) mesh model it was $3.73 \mathrm{in}$. (94.74 mm.) recorded at 25.5 milliseconds. The deflections obtained from the models with 1 in. $(25.4 \mathrm{~mm})$ mesh size showed a $26.5 \%$ decrease while the deflections obtained from the $1 / 2$ in. (12.7 mm.) model decreased by $16 \%$ when compared to the experiment.

From Figure 6-32 and Figure 6-33 it can be noted that varying the mesh size from 1 in. $(25.4 \mathrm{~mm}$.) to $1 / 2 \mathrm{in}$. $(12.7 \mathrm{~mm}$.) increased the deflection by $0.46 \mathrm{in}$. $(11.68 \mathrm{~mm}$.) for the 
WCM and by 1.26 in. (32 mm.) for CDMR3 respectively. The 1 in. mesh $(25.4 \mathrm{~mm})$ can be useful to predict the deflection accurately with the CDMR3 in comparison with the experimental deflection.

\subsection{Material Model Effect for Slab \# 4 (RSC-R2-4in.)}

Figure 6-34 and Figure 6-35 compare the deflections between two material models for two mesh sizes. From Figure 6-34 for the 1 in. $(25.4 \mathrm{~mm})$ mesh model the CDMR3 predicted the deflection same as the experimental deflection. The Winfrith Concrete Model predicted the deflection which was 1.14 in. $(29.9 \mathrm{~mm}$.) less than the experiment. From Figure $6-35$ for the $1 / 2$ in. $(12.7 \mathrm{~mm})$ mesh model the WCM predicted the deflection 0.72 in. (18.29 mm.) less than the experimental deflection while the CDMR3 predicted the deflection 1.26 in. $(32 \mathrm{~mm}$.) more than the experiment. The Concrete Damage Model Release 3 predicted the response better in both mesh size category. 


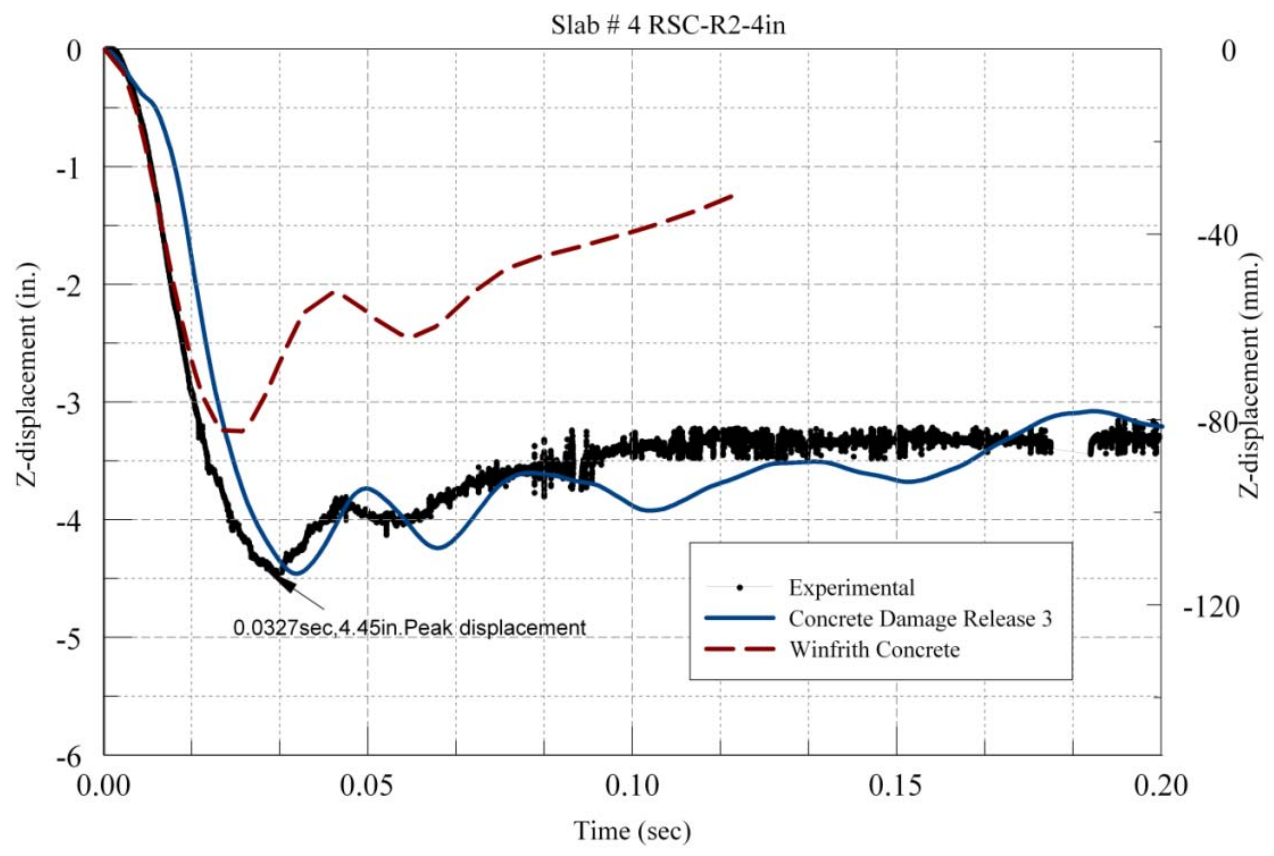

Figure 6-34: Deflection Comparison between Concrete Damage Model Release 3 and Winfrith Concrete for 1 in. $(25.4 \mathrm{~mm}$.) mesh model with Experimental Deflection for Slab\#4 - RSC-R2-4in.

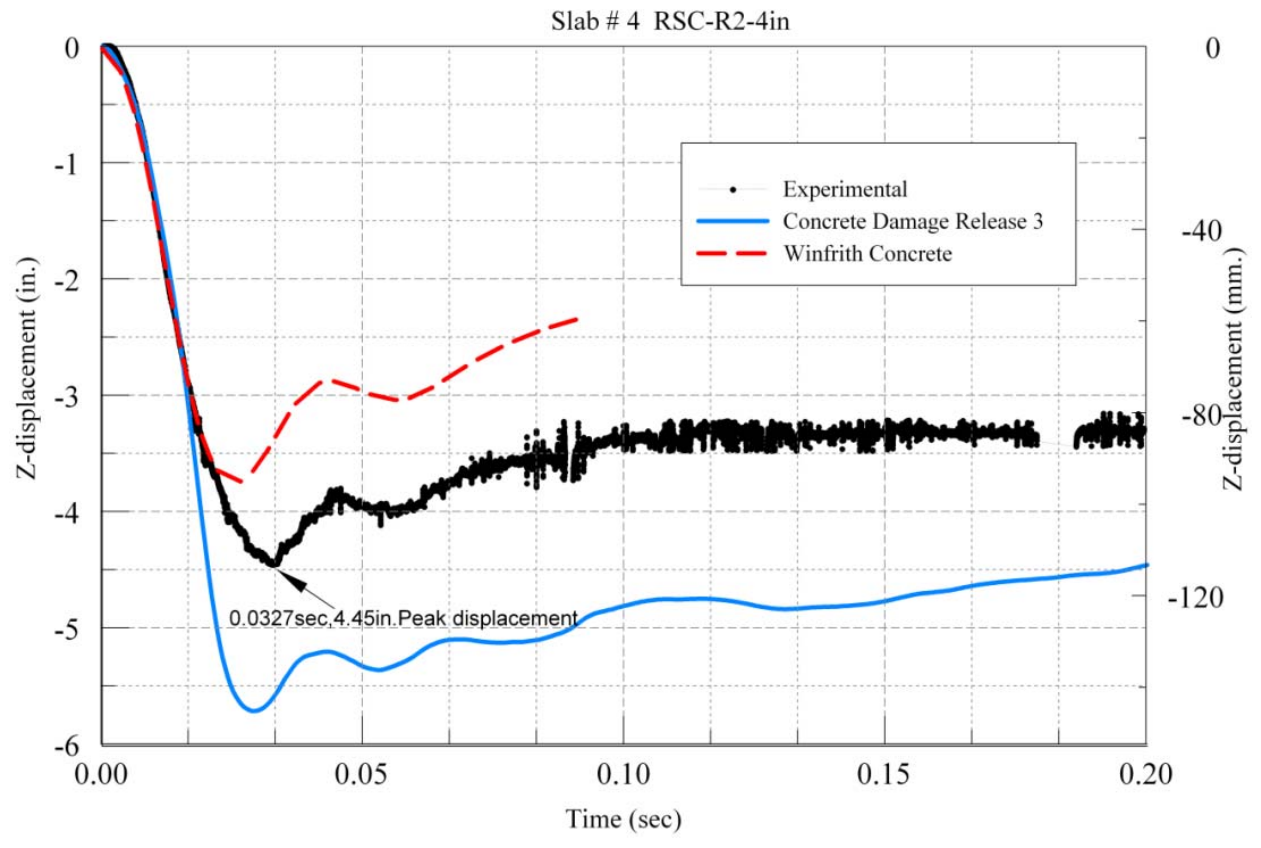

Figure 6-35: Deflection Comparison between Concrete Damage Model Release 3 and Winfrith Concrete for 1/2 in. (12.7 mm.) mesh model with Experimental Deflection Slab\#4- RSC-R2-4in. 


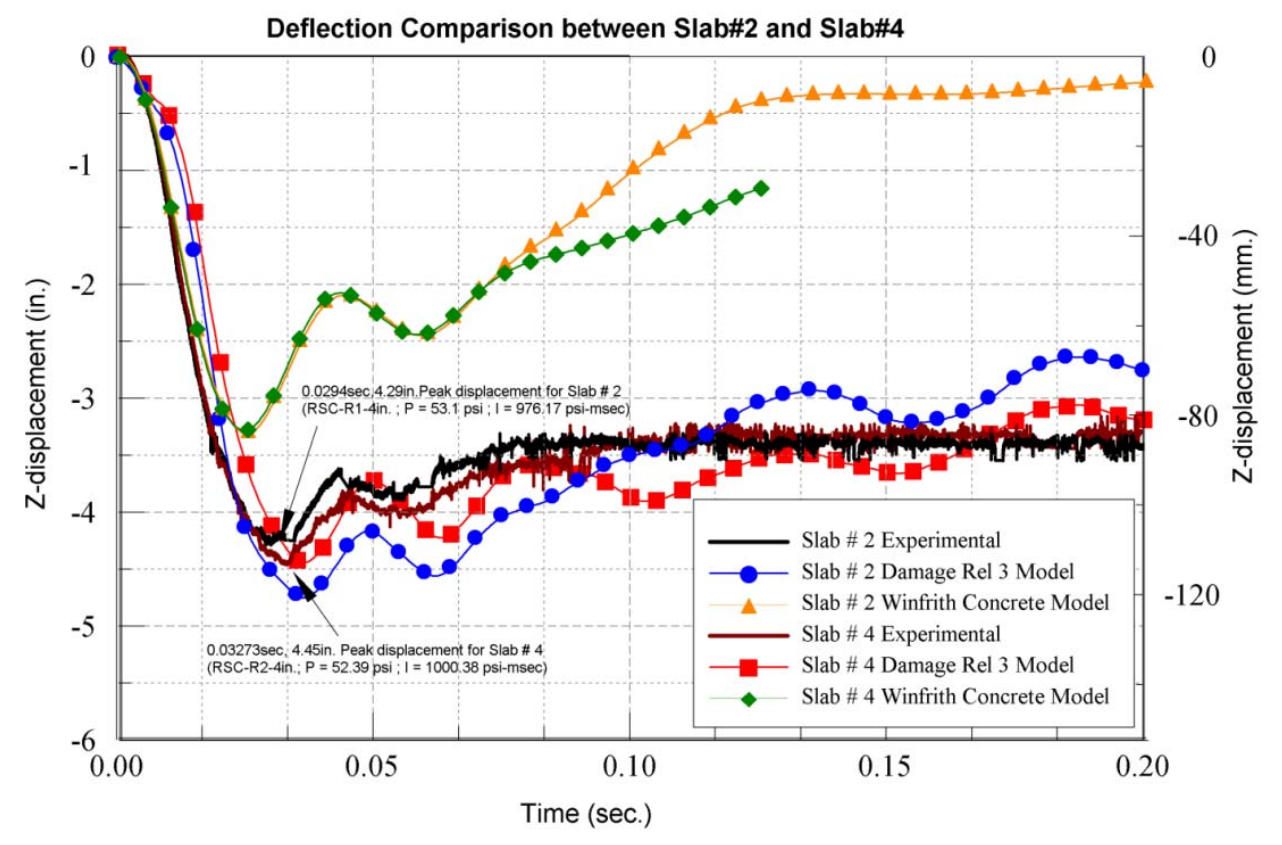

Figure 6-36: Deflection Comparison between Concrete Damage Model Release 3 and Winfrith Concrete for 1 in. $(25.4 \mathrm{~mm}$.) mesh model with Experimental Deflection for Slab\#2 - RSC-R1-4in. and Slab\#4 - RSC-R2-4in.

Figure 6-36 compares the two slabs i.e. Slab\#2 - RSC-R1-4in. and Slab\#4 - RSCR2-4in. having the normal-strength combination of concrete and steel with 4 in. steel spacing for both the experimental and numerical analysis results. The numerical analysis results presented here are using the $1 \mathrm{in.}(25.4 \mathrm{~mm}$.) mesh model as this mesh size yielded good results as compared to other mesh sizes in both the concrete material models used. These slabs were subjected to similar pressures of $53.1 \mathrm{psi}(0.366 \mathrm{MPa})$ and $52.39 \mathrm{psi}$ (0.361 MPa) respectively and an impulse of 976.17 psi-msec (6.73 MPa-msec) and 1000.38 psi-msec (6.89 MPa-msec) respectively during the experimental program. As seen in the plot the peak deflections for the two slabs occured within a very small timeframe ranging between 29.94 milliseconds and 34.73 milliseconds. The experimental peak deflections recorded for the two slabs are 4.29 in. $(108.96 \mathrm{~mm}$.$) and 4.45 \mathrm{in} .(113.03 \mathrm{~mm}$.) 
respectively. For both of these slabs when modeled using the CDMR3 gave a good prediction of the deflection as observed from the peak and residual displacements as noted in Table 6-3 and Table 6-4. The CDMR3 predicted the deflection response very closely to the experiment $\mathrm{n}$ in the peak as well as post-peak region. The peak values deviates more from the experimental peak deflection as compared to the response of WCM.

These slabs having RSC-R-4in. (reinforcement ratio $=0.68 \%$ ) could withstand higher pressure and impulse even when designed using normal-strength material. The numerical analysis also shows a stable response with lesser rebound of the slab in the postpeak deflection-time history for the CDMR3. The response for the Winfrith Concrete Model in the normal strength category is however not very accurate for the 1 in. model. A finer mesh is required to be used when modeling with the Winfrith Concrete Model.

\subsection{Mesh Size Effect for Slab \# 6 (RSC-R3-4in.)}

The deflection results obtained from numerical simulations for slab \# 6 which is a RSC-R3-4in. is compared in this section for two different mesh sizes. This slab experienced a peak pressure of $44.2 \mathrm{psi}(0.305 \mathrm{MPa})$ and an impulse of $785.35 \mathrm{psi}-\mathrm{msec}(5.42 \mathrm{MPa}-$ msec) in the blast experiment. The blast pressures recorded for this slab are summarized in Appendix A. The average deflection obtained from the experiment was 3.17 in. (113.03 mm.) recorded at 23.36 milliseconds. 


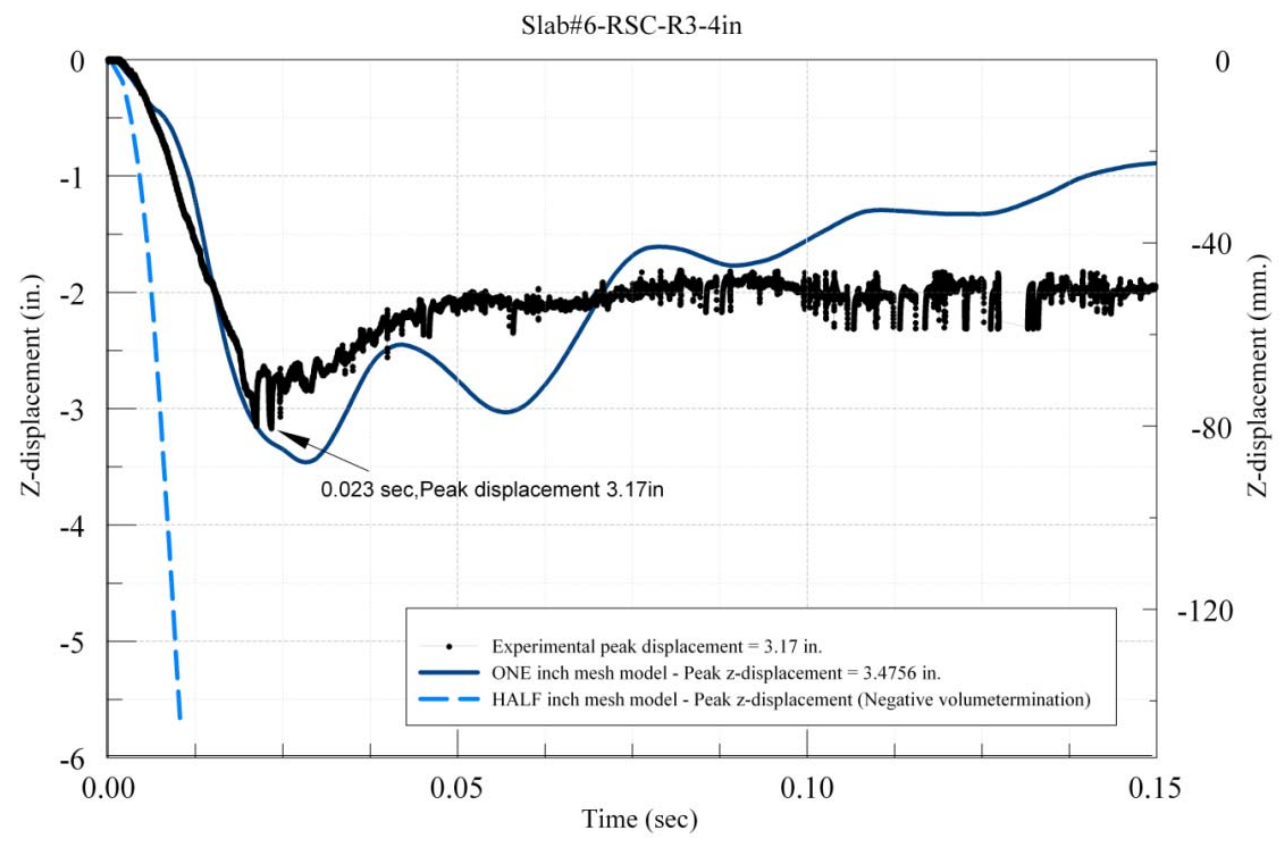

Figure 6-37: Deflection Comparison between 1 in. $(25.4 \mathrm{~mm}$.) and 1/2 in. (12.7 mm.) for mesh sizes Concrete Damage Model Release 3 and Experimental Deflection for Slab\#6 RSC-R3-4in.

The deflection results obtained from LS-DYNA ${ }^{\circledR}$ concrete models with two mesh sizes for CDMR3 are compared with the experimental deflections in Figure 6-37. The peak deflections obtained from the CDMR3 with 1 in. $(25.4 \mathrm{~mm}$.) mesh was $3.47 \mathrm{in.}$ ( $88.14 \mathrm{~mm}$.) recorded at 37.5 milliseconds while for $1 / 2 \mathrm{in}$. (12.7 mm.) mesh model the simulation stopped because negative volume developed in some elements . The deflections obtained from the models with 1 in. $(25.4 \mathrm{~mm})$ mesh size showed a $9 \%$ increase when compared to the experiments while the deflections obtained from the $1 / 2 \mathrm{in}$. $(12.7 \mathrm{~mm}$.) model could not be compared to the experiment as the analysis terminated due to generation of negative volume in the elements. 


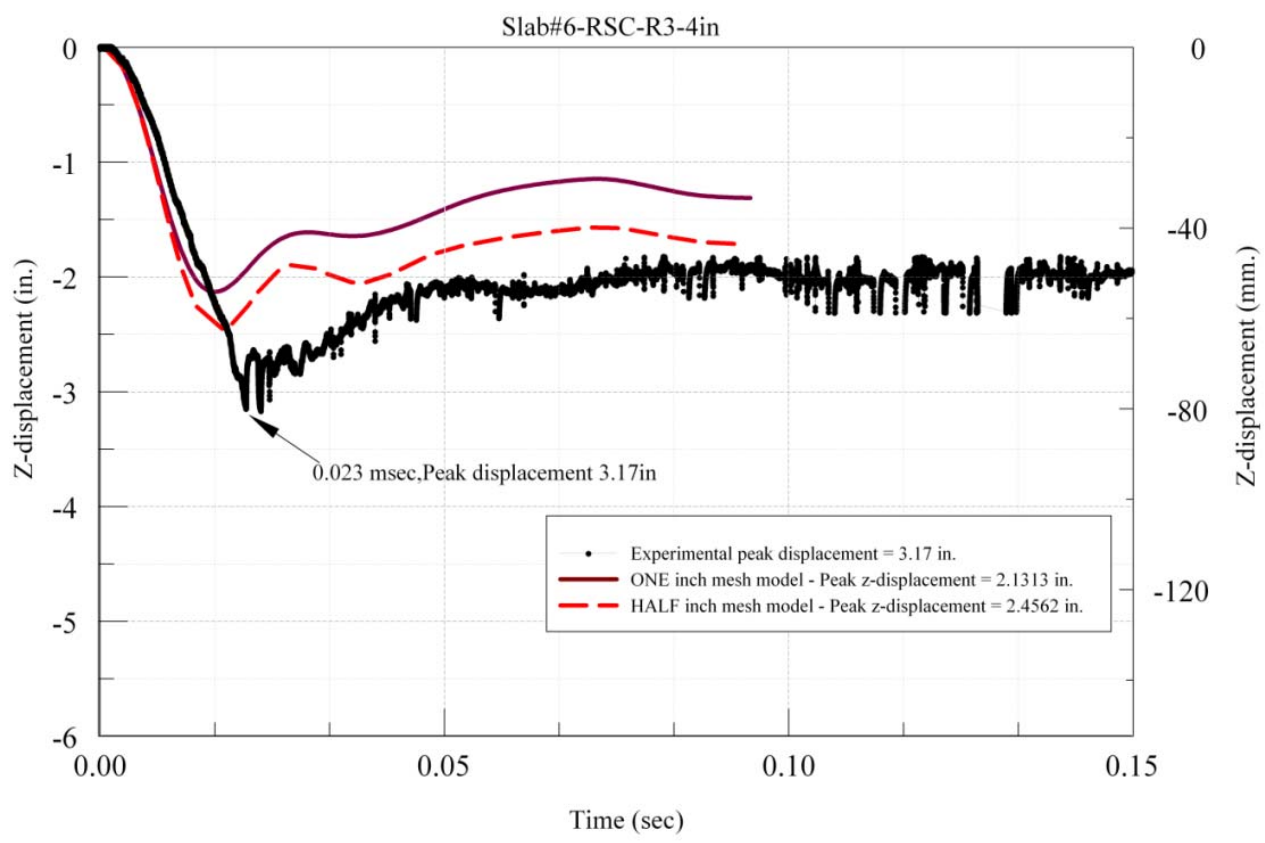

Figure 6-38: Deflection Comparison between 1 in. $(25.4 \mathrm{~mm}$.) and 1/2 in. $(12.7 \mathrm{~mm}$.) mesh sizes for Winfrith Concrete Model and Experimental Deflection for Slab\#6 - RSC-R3-4in.

The deflection results obtained from LS-DYNA® concrete models with two mesh sizes for WCM are compared with the experimental deflections in Figure 6-38. The peak deflections obtained from the WCM with 1 in. $(25.4 \mathrm{~mm}$.) mesh was $2.13 \mathrm{in.}(54.1 \mathrm{~mm}$.) recorded at 21.5 milliseconds while for $1 / 2 \mathrm{in}$. (12.7 mm.) mesh model it was $2.45 \mathrm{in}$. (62.23 mm.) recorded at 22.5 milliseconds. The deflections obtained from the models with 1 in. $(25.4 \mathrm{~mm})$ mesh size showed a $33 \%$ decrease when compared to the experimental while the deflections obtained from the $1 / 2$ in. ( $12.7 \mathrm{~mm}$.) model decreased by $22.7 \%$ when compared to the experiment.

From Figure 6-37 and Figure 6-38 it can be noted that varying the mesh size from 1 in. $(25.4 \mathrm{~mm}$.) to $1 / 2$ in. $(12.7 \mathrm{~mm}$.) increased the deflection by 0.32 in. $(8.13 \mathrm{~mm}$.) for the WCM. The 1 in. mesh $(25.4 \mathrm{~mm})$ can be useful to predict the deflection accurately in both the models in comparison with the experimental deflection. 


\subsection{Material Model Effect for Slab \# 6 (RSC-R3-4in.)}

Figure 6-39 and Figure 6-40 compare the deflections between two material models for two mesh sizes. From Figure 6-39 for the 1 in. $(25.4 \mathrm{~mm})$ mesh model the CDMR3 predicted the deflection $0.3 \mathrm{in}$. $(7.62 \mathrm{~mm}$.) more than the experimental deflection while the WCM predicted the deflection 1.04 in. $(26.42 \mathrm{~mm}$.) less than the experiment. From Figure 6-40 for the $1 / 2$ in. $(12.7 \mathrm{~mm})$ mesh model the WCM predicted the deflection $0.72 \mathrm{in.}$ (18.3 mm.) less than the experimental deflection while the CDMR3 predicted the deflection much higher than the experiment as the analysis ended in the error. The Winfrith Concrete Model predicted the response better in both mesh size category.

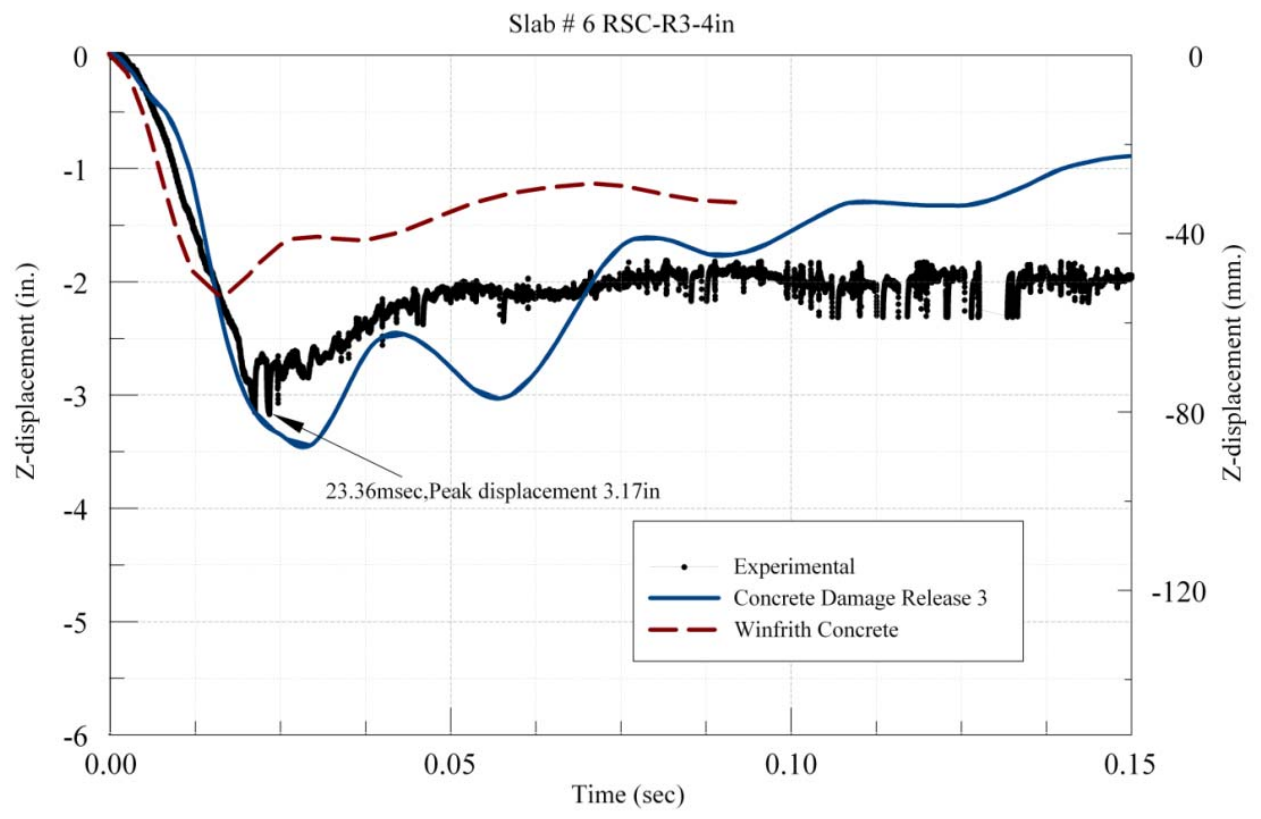

Figure 6-39: Deflection Comparison between Concrete Damage Model Release 3 and Winfrith Concrete for 1 in. (25.4 mm.) mesh model with Experimental Deflection for Slab\#6 - RSC-R3-4in. 


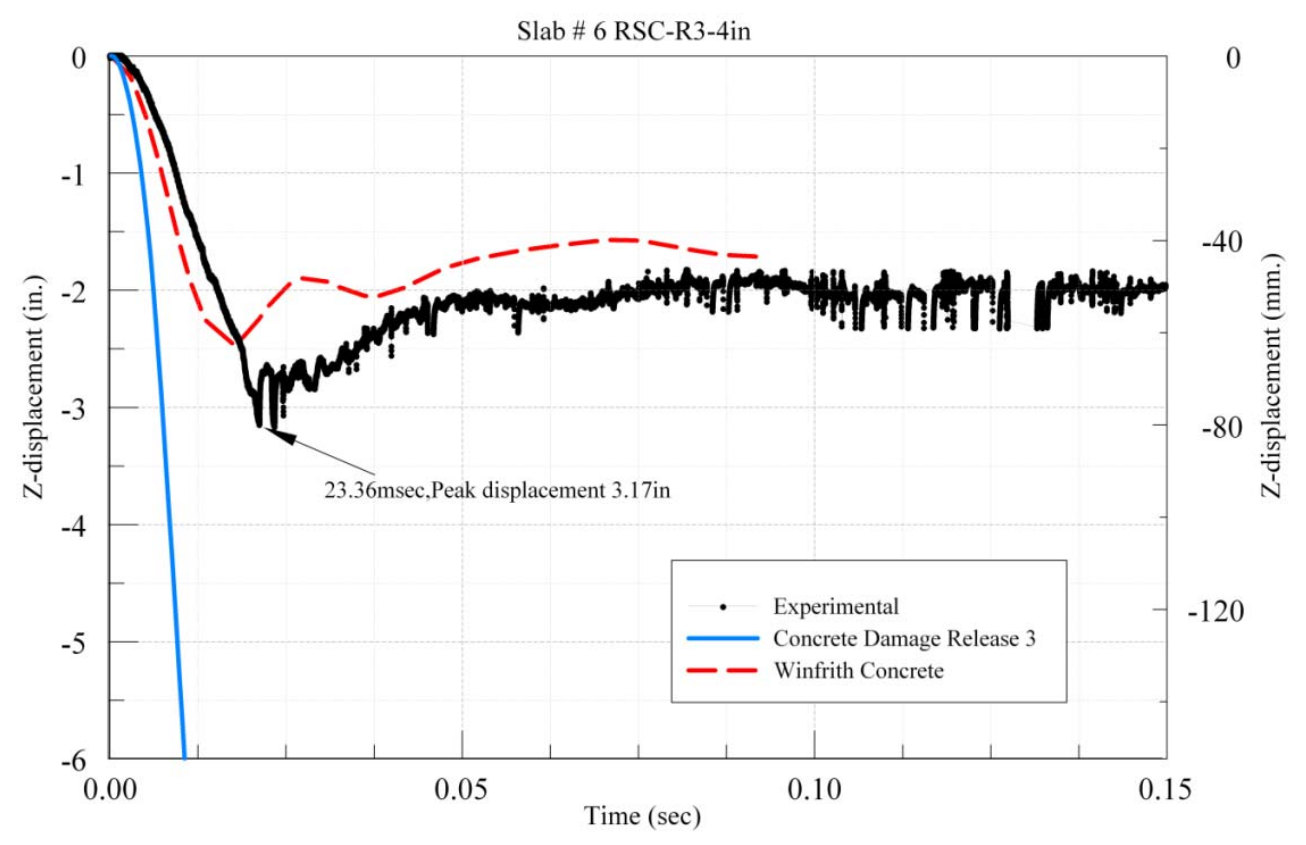

Figure 6-40: Deflection Comparison between Concrete Damage Model Release 3 and Winfrith Concrete for 1/2 in. (12.7 mm.) mesh model with Experimental Deflection Slab\#6-RSC-R3-4in.

\subsection{Mesh Size Effect for Slab \# 8 (RSC-R4-8in.)}

The deflection results obtained from numerical simulations for slab \# 8 which is a RSC-R4-8in. is compared in this section for two different mesh sizes. This slab experienced a peak pressure of $33.4 \mathrm{psi}(0.23 \mathrm{MPa})$ and an impulse of $494.39 \mathrm{psi}-\mathrm{msec}$ (3.41 MPa-msec) in the blast experiment. The blast pressures recorded for this slab are summarized in Appendix A. The average deflection obtained from the experiment was 3.38 in. (85.85 mm.) recorded at 28.74 milliseconds. 


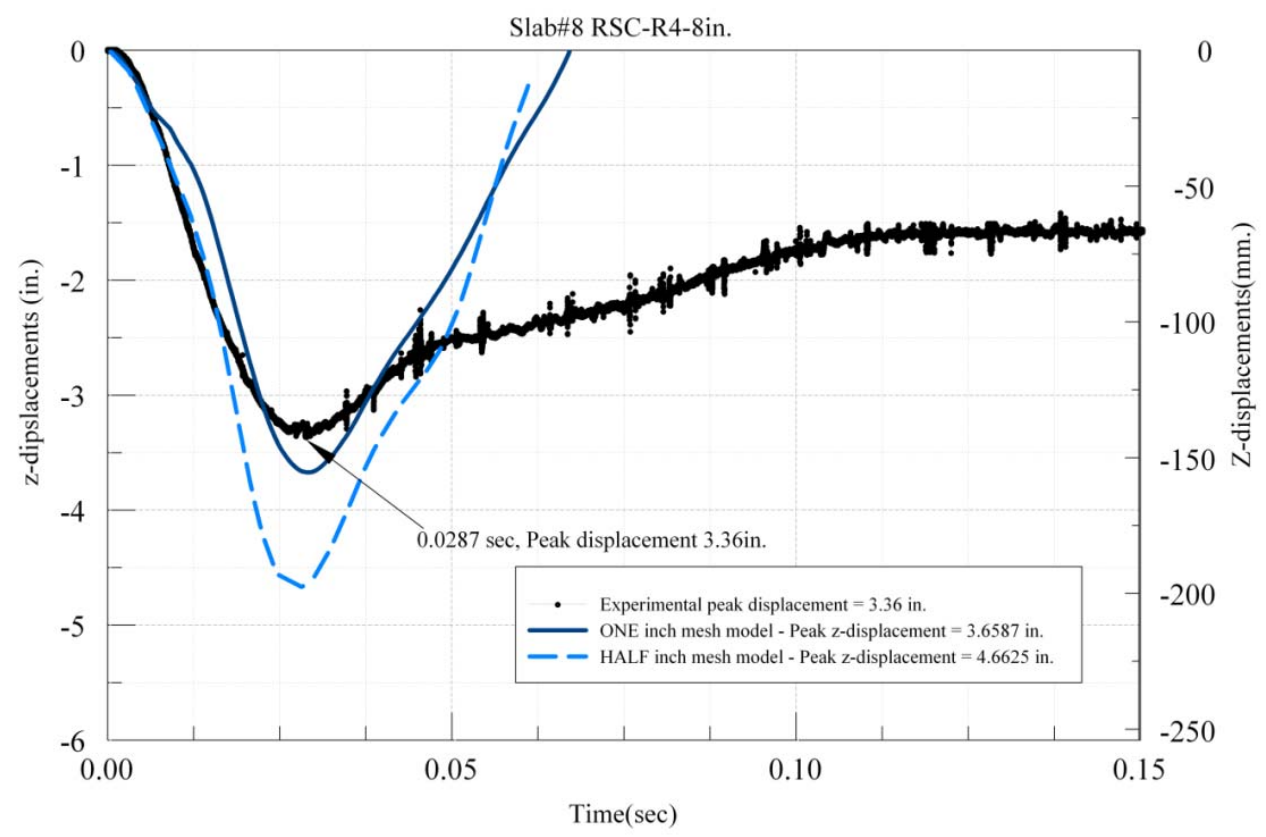

Figure 6-41: Deflection Comparison between 1 in. $(25.4 \mathrm{~mm}$.) and 1/2 in. (12.7 mm.) mesh sizes for Concrete Damage Model Release 3 and Experimental Deflection for Slab\#8 RSC-R4-8in.

The deflection results obtained from LS-DYNA ${ }^{\circledR}$ concrete models with two mesh sizes for CDMR3 are compared with the experimental deflections in Figure 6-41. The peak deflections obtained from the CDMR3 with 1 in. (25.4 mm.) mesh was 3.66 in. (92.96 mm.) recorded at 38.5 milliseconds while for $1 / 2 \mathrm{in.}(12.7 \mathrm{~mm}$.) mesh model it was $4.66 \mathrm{in}$. $(118.36 \mathrm{~mm}$.) recorded at 36 milliseconds. The deflections obtained from the models with 1 in. $(25.4 \mathrm{~mm})$ mesh size showed an $8 \%$ increase when compared to the experiments while the deflections obtained from the $1 / 2$ in. $(12.7 \mathrm{~mm}$.) model are higher by $37 \%$ when compared to the experiment. 


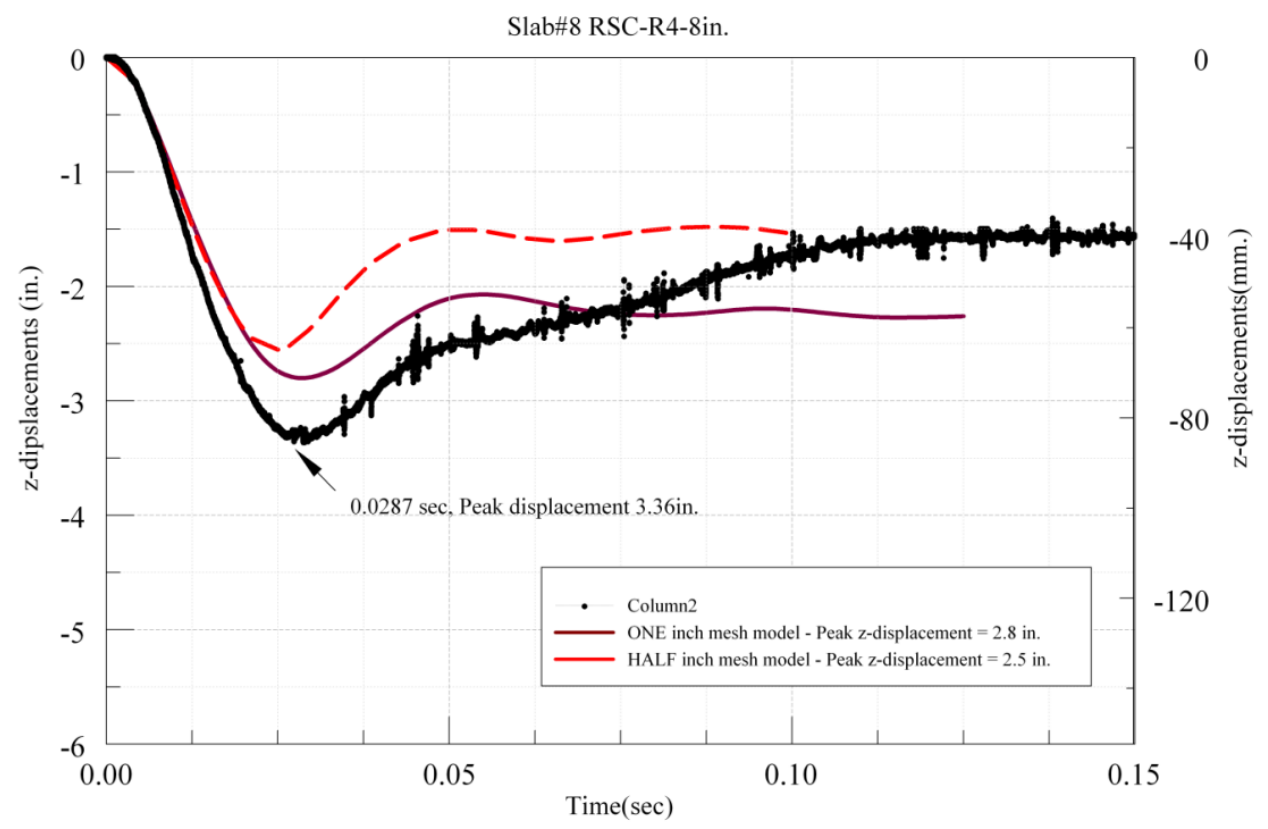

Figure 6-42 : Deflection Comparison between 1 in. (25.4 mm.) and 1/2 in. (12.7 mm.) mesh sizes for Winfrith Concrete Model and Experimental Deflection for Slab\#8 - RSCR4-8in.

The deflection results obtained from LS-DYNA® ${ }^{\circledR}$ concrete models with 1 in. $(25.4$ mm.) and 1/2 in. (12.7 mm.) mesh sizes for WCM are compared with the experimental deflections in Figure 6-42. The peak deflections obtained from the WCM with 1 in. (25.4 mm.) mesh was 2.8 in. (71.12 mm.) recorded at 28.5 milliseconds while for $1 / 2$ in. (12.7 mm.) mesh model it was 2.5 in. $(63.5 \mathrm{~mm}$.) recorded at 24.5 milliseconds. The deflections obtained from the models with 1 in. $(25.4 \mathrm{~mm})$ mesh size showed a $17 \%$ decrease when compared to the experiments. The deflections obtained from the $1 / 2 \mathrm{in}$. $(12.7 \mathrm{~mm}$.) model are lower by $24.5 \%$ when compared to the experiment.

From Figure 6-41 and Figure 6-42 it can be noted that varying the mesh size from 1 in. $(25.4 \mathrm{~mm}$.$) to 1 / 2 \mathrm{in} .(12.7 \mathrm{~mm}$.) decreased the deflection by $0.25 \mathrm{in} .(6.35 \mathrm{~mm}$. $)$ for the WCM and increased by $1.01 \mathrm{in.}(25.65 \mathrm{~mm}$.) for CDMR3 respectively. The $1 \mathrm{in}$. mesh (25.4 
$\mathrm{mm}$ ) can be useful to predict the deflection accurately in both the models in comparison with the experimental deflection.

\subsection{Material Model Effect for Slab \# 8 (RSC-R4-8in.)}

Figure 6-43 and Figure 6-44 compare the deflections between two material models for two mesh sizes. From Figure 6-43 for the 1 in. $(25.4 \mathrm{~mm})$ mesh model the CDMR3 predicted the deflection 0.27 in. $(6.86 \mathrm{~mm}$.) more than the experimental deflection while the WCM predicted the deflection 0.58 in. $(14.73 \mathrm{~mm}$.) less than the experiment. From Figure 6-44 for the $1 / 2$ in. $(12.7 \mathrm{~mm})$ mesh model the WCM predicted the deflection $0.83 \mathrm{in}$. (20.99 mm.) less than the experimental deflection while the CDMR3 predicted the deflection 1.28 in. $(32.51 \mathrm{~mm}$.) more than the experiment. The WCM predicted the response better in both mesh size category.

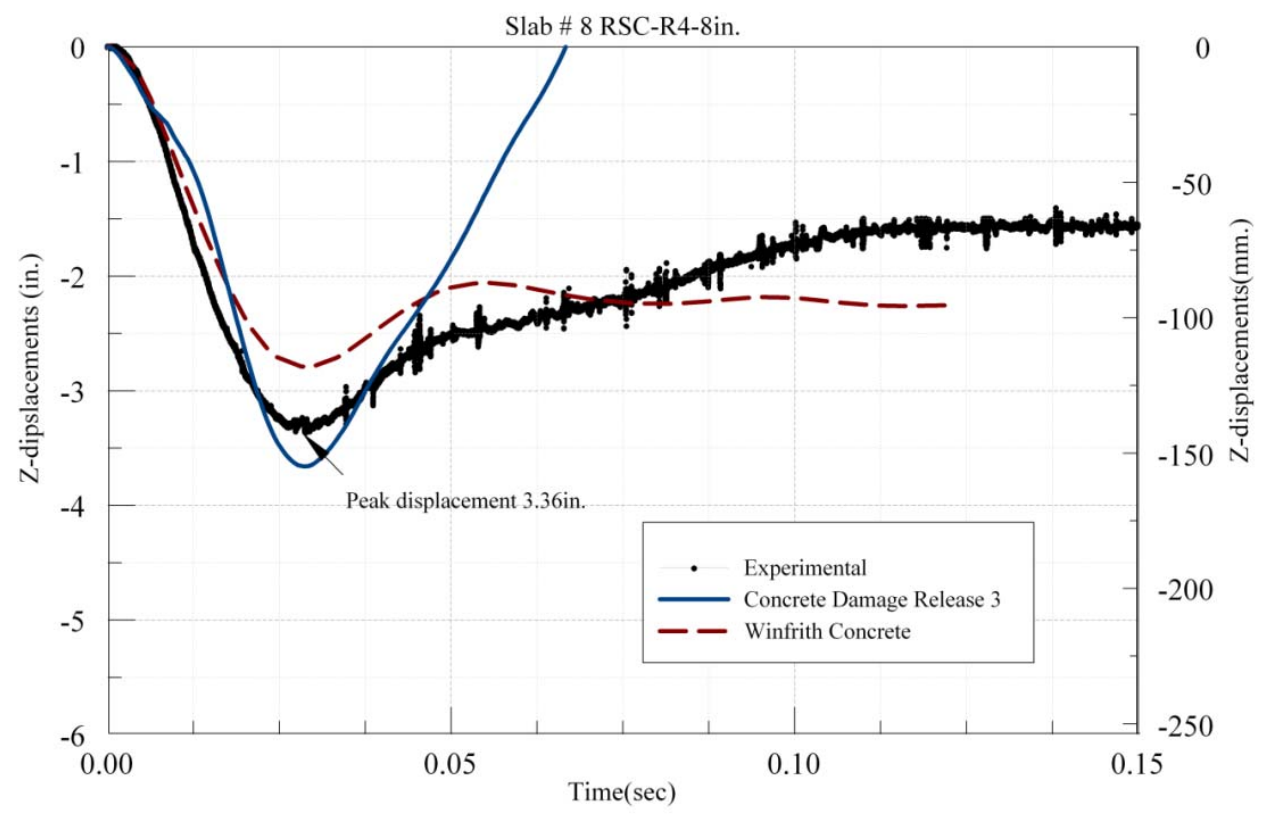

Figure 6-43: Deflection Comparison between Concrete Damage Model Release 3 and Winfrith Concrete for 1 in. $(25.4 \mathrm{~mm}$.) mesh model with Experimental Deflection for Slab\#8 - RSC-R4-8in. 


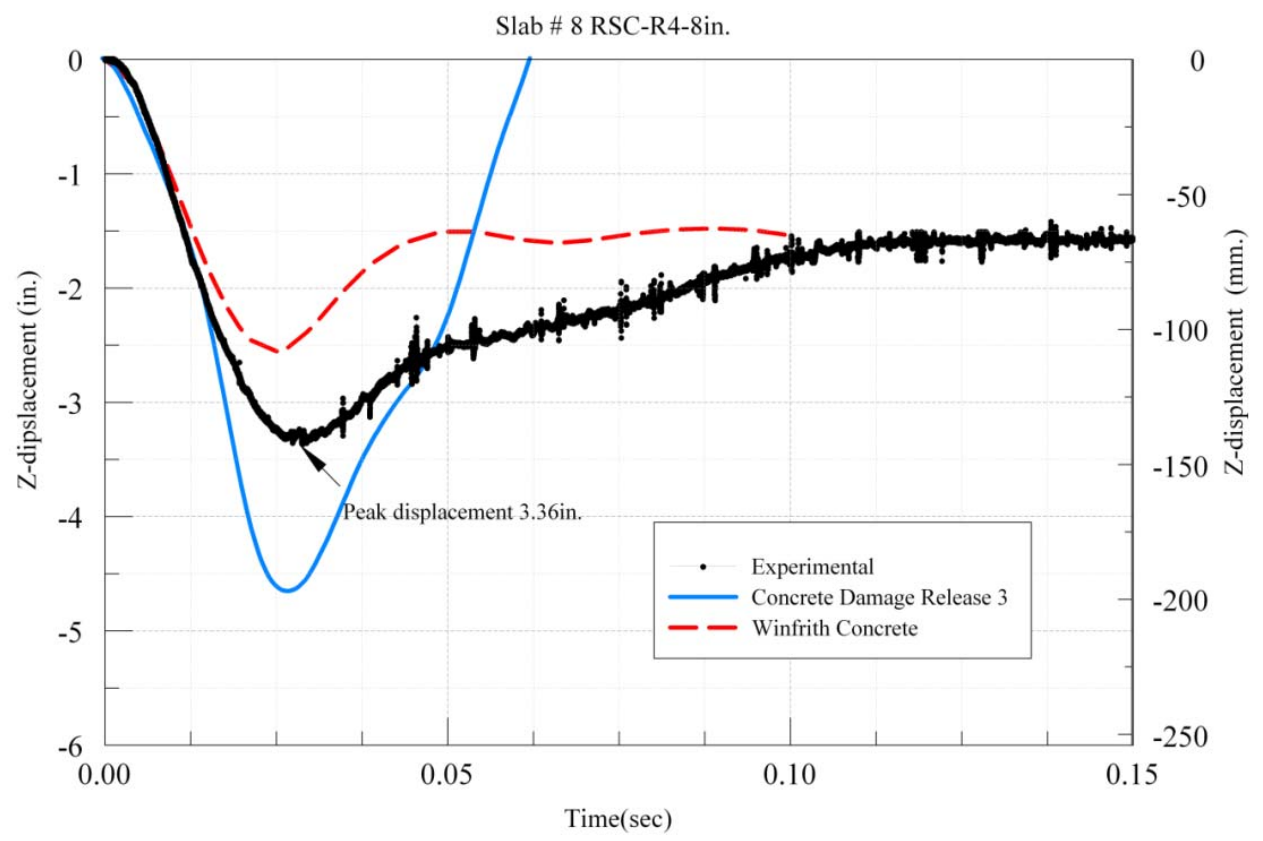

Figure 6-44: Deflection Comparison between Concrete Damage Model Release 3 and Winfrith Concrete for 1/2 in. (12.7 mm.) mesh model with Experimental Deflection for Slab\#8 - RSC-R4-8in.

\subsection{Mesh Size Effect for Slab \# 10 (RSC-R5-8in.)}

The deflection results obtained from numerical simulations for slab \# 10 which is a RSC-R5-8in. is compared in this section for two different mesh sizes. This slab experienced a peak pressure of $34.78 \mathrm{psi}(0.24 \mathrm{MPa})$ and an impulse of $549.5 \mathrm{psi}-\mathrm{msec}$ (3.78 $\mathrm{MPa}-\mathrm{msec})$ in the blast experiment. The blast pressures recorded for this slab are summarized in Appendix A. The average deflection obtained from the experiment was 3.6 in. (91.44 mm.) recorded at 30.3 milliseconds. 


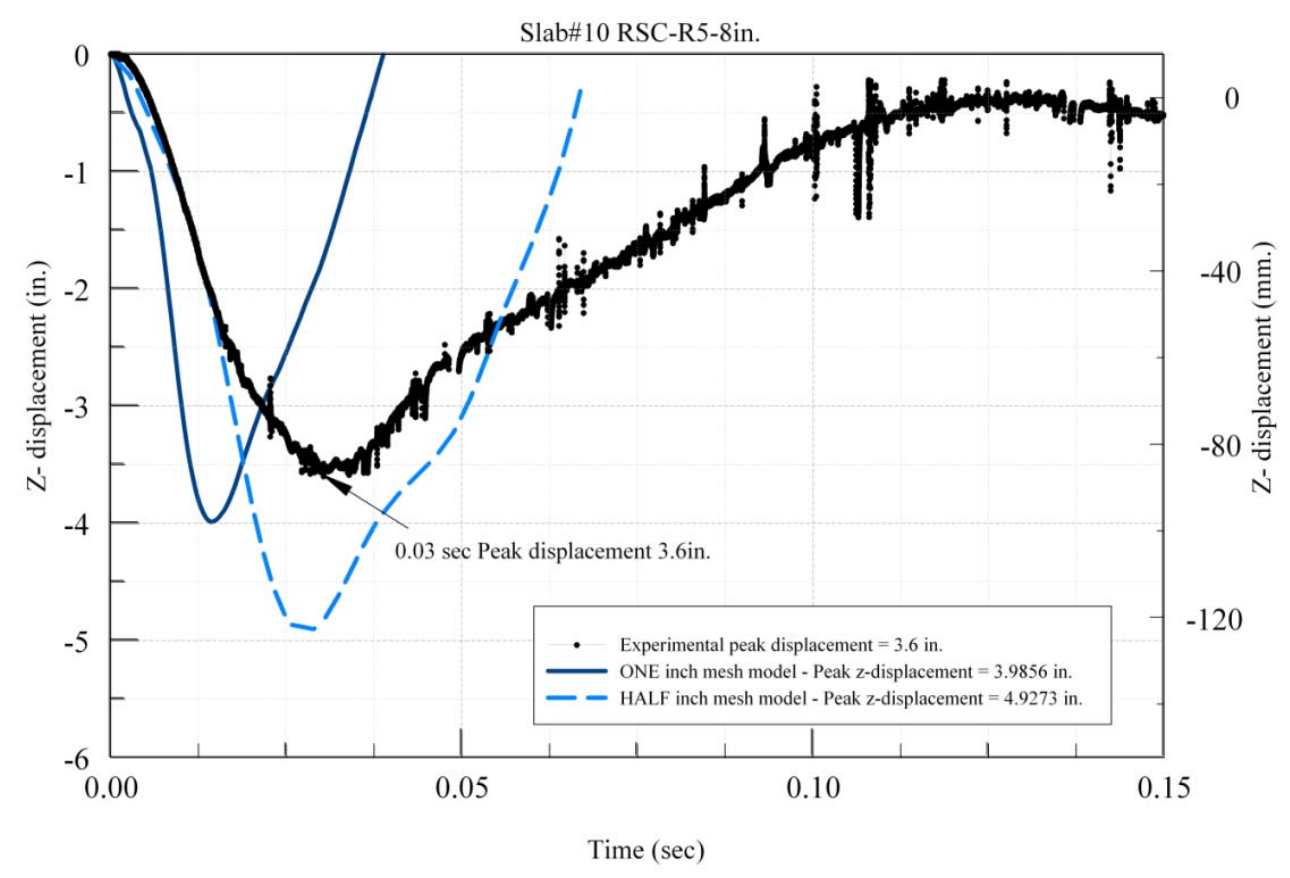

Figure 6-45: Deflection Comparison between 1 in. (25.4 mm.) and 1/2 in. (12.7 mm.) mesh sizes for Concrete Damage Model Release 3 and Experimental Deflection for Slab\#10 RSC-R5-8in.

The deflection results obtained from LS-DYNA® concrete models with two mesh sizes for CDMR3 are compared with the experimental deflections in Figure 6-45. The peak deflections obtained from the CDMR3 with 1 in. (25.4 mm.) mesh was 3.98 in. (101.09 $\mathrm{mm}$.) recorded at 18.0 milliseconds while for $1 / 2 \mathrm{in}$. $(12.7 \mathrm{~mm}$.) mesh model it was $4.93 \mathrm{in}$. (125.22 mm.) recorded at 27.0 milliseconds. The deflections obtained from the models with 1 in. $(25.4 \mathrm{~mm})$ mesh size showed a $10 \%$ increase when compared to the experiments while the deflections obtained from the $1 / 2$ in. $(12.7 \mathrm{~mm}$.) model are higher by $36 \%$ when compared to the experiment. 


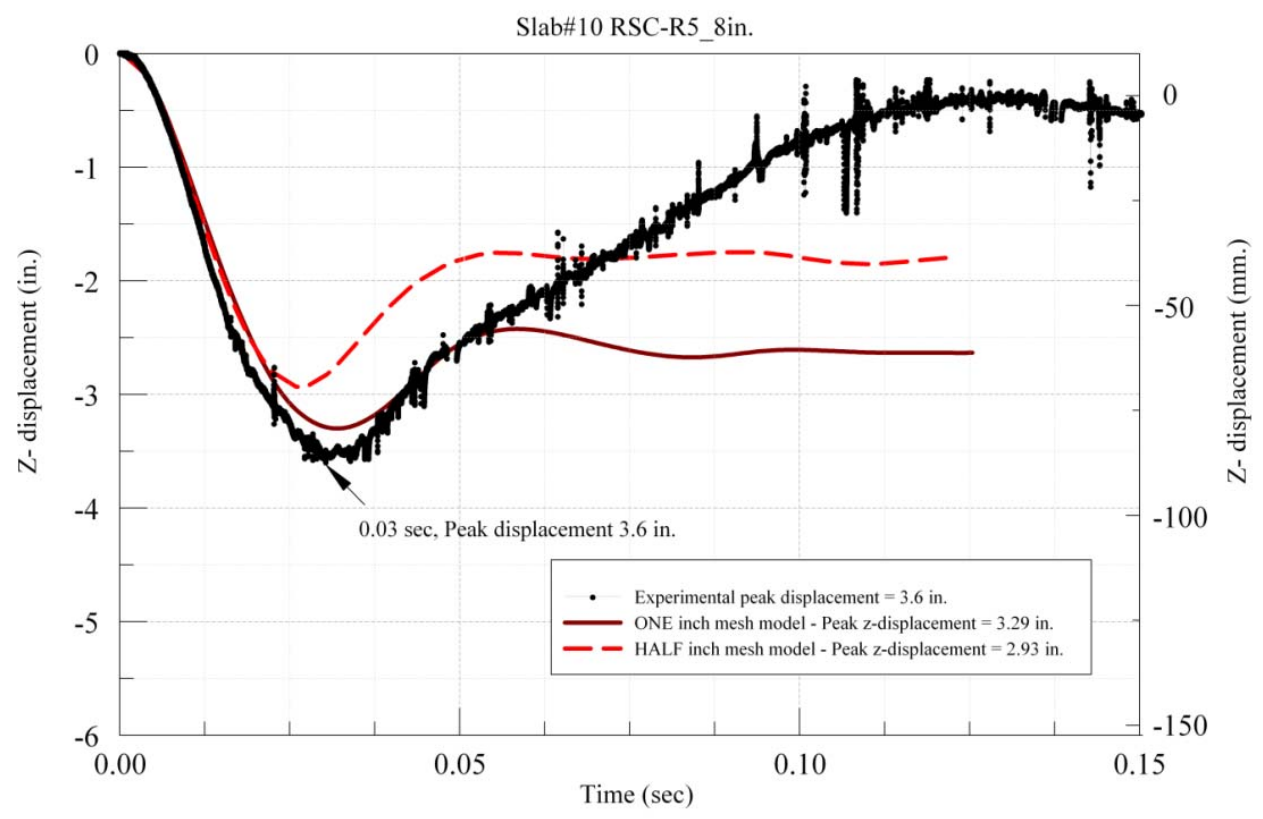

Figure 6-46: Deflection Comparison between 1 in. (25.4 mm.) and 1/2 in. (12.7 mm.) mesh sizes for Winfrith Concrete Model and Experimental Deflection for Slab\#10 - RSC-R5-8in.

The deflection results obtained from LS-DYNA® concrete models with two mesh sizes for WCM are compared with the experimental deflections in Figure 6-46. The peak deflections obtained from the Winfrith Concrete model with 1 in. $(25.4 \mathrm{~mm}$.) mesh was 3.29 in. $(83.57 \mathrm{~mm}$.) recorded at 31.5 milliseconds while for $1 / 2 \mathrm{in.}(12.7 \mathrm{~mm}$.) mesh model it was 2.93 in. $(63.5 \mathrm{~mm}$.) recorded at 26 milliseconds. The deflections obtained from the models with 1 in. $(25.4 \mathrm{~mm})$ mesh size showed an $8 \%$ decrease when compared to the experiments while the deflections obtained from the $1 / 2$ in. $(12.7 \mathrm{~mm}$.) model are lower by $18 \%$ when compared to the experiment.

From Figure 6-45 and Figure 6-46 it can be noted that varying the mesh size from 1 in. $(25.4 \mathrm{~mm}$.$) to 1 / 2 \mathrm{in} .(12.7 \mathrm{~mm}$.) decreased the deflection by $0.97 \mathrm{in}$. $(24.64 \mathrm{~mm}$.) for the WCM and by 0.94 in. (23.88 mm.) for CDMR3 respectively. The $1 \mathrm{in.} \mathrm{mesh}(25.4 \mathrm{~mm})$ can be useful to predict the deflection accurately in both the models in comparison with the experimental deflection. 


\subsection{Material Model Effect for Slab \# 10 (RSC-R5-8in.)}

Figure 6-47 and Figure 6-48 compare the deflections between two material models for two mesh sizes. From Figure $6-47$ for the 1 in. $(25.4 \mathrm{~mm})$ mesh model the WCM predicted the deflection 0.31 in. $(7.87 \mathrm{~mm}$.) less than the experimental deflection CDMR3 predicted the deflection 0.38 in. $(9.65 \mathrm{~mm}$.) more than the experimental values. From Figure $6-48$ for the $1 / 2$ in. $(12.7 \mathrm{~mm})$ mesh model the WCM predicted the deflection 0.67 in. (17.02 mm.) less than the experimental deflection while the CDMR3 predicted the deflection 1.32 in. (33.53 mm.) more than the experiment. The Winfrith Concrete Model predicted the response better in both mesh size category.

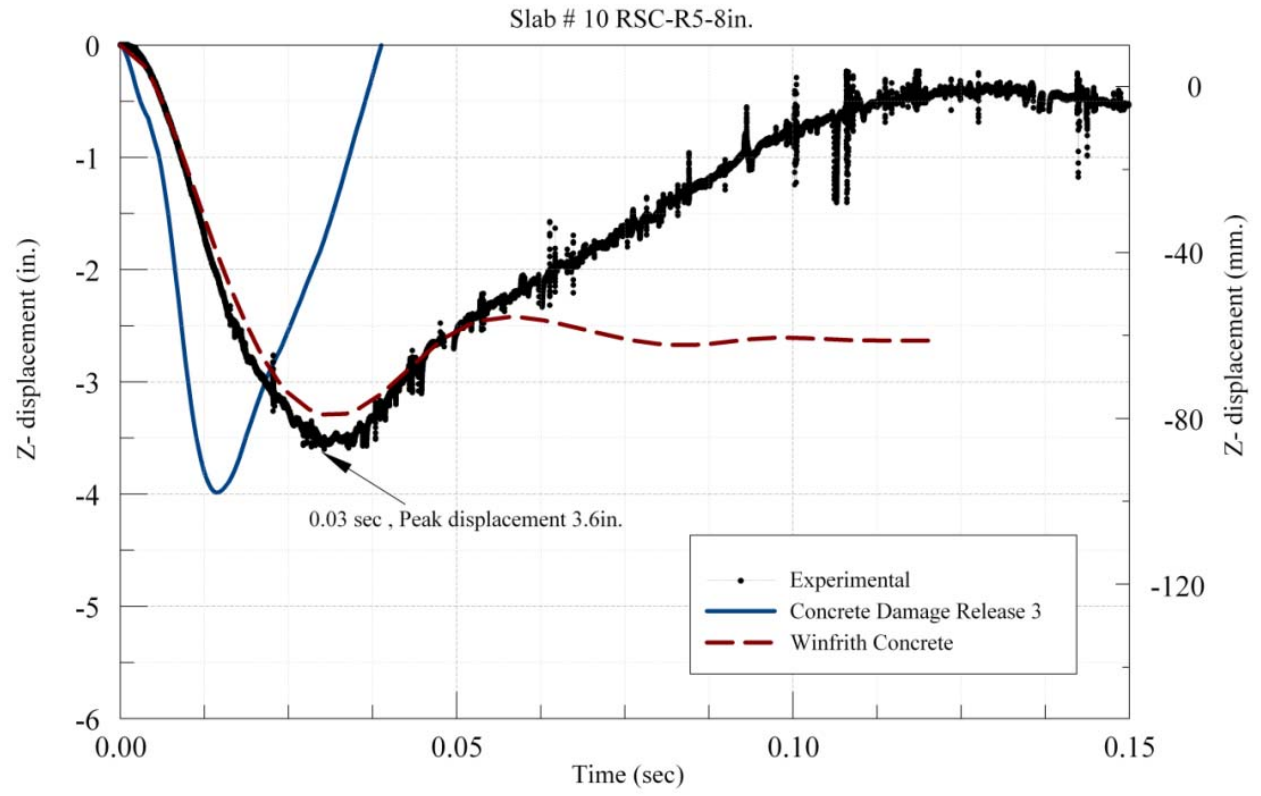

Figure 6-47: Deflection Comparison between Concrete Damage Model Release 3 and Winfrith Concrete for 1 in. (25.4 mm.) mesh model with Experimental Deflection for Slab\#10 - RSC-R5-8in. 


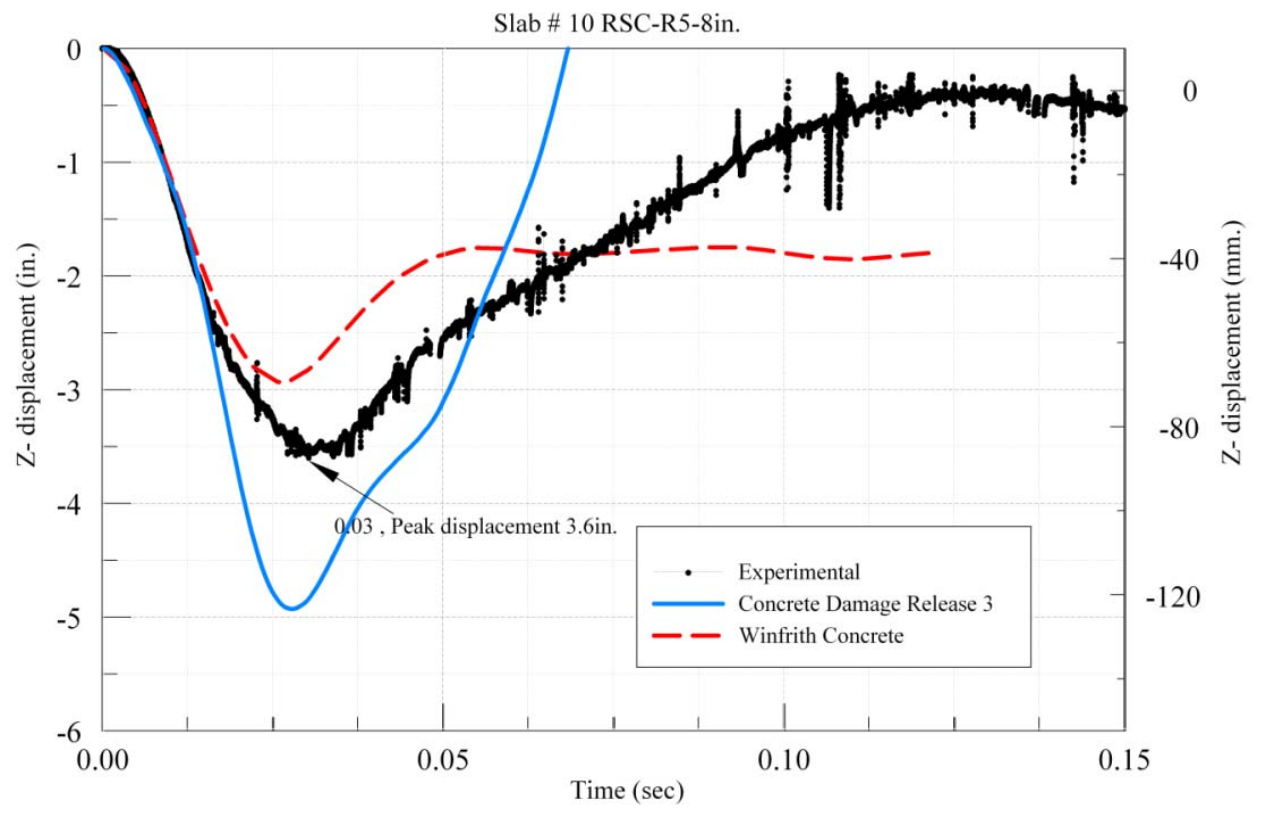

Figure 6-48: Deflection Comparison between Concrete Damage Model Release 3 and Winfrith Concrete for 1/2 in. (12.7 mm.) mesh model with Experimental Deflection for Slab\#10 - RSC-R5-8in.

\subsection{Mesh Size Effect for Slab \# 12 (RSC-R6-8in.)}

The deflection results obtained from numerical simulations for slab \# 12 which is a RSC-R6-8in. is compared for two different mesh sizes. This slab experienced a peak pressure of $33.74 \mathrm{psi}(0.23 \mathrm{MPa})$ and an impulse of $509.01 \mathrm{psi}-\mathrm{msec}(3.51 \mathrm{MPa}-\mathrm{msec})$ in the blast experiment. The blast pressures recorded for this slab are summarized in Appendix A. The average deflection obtained from the experiment was $3.17 \mathrm{in}$. (80.52 mm.) recorded at 23.36 milliseconds. 


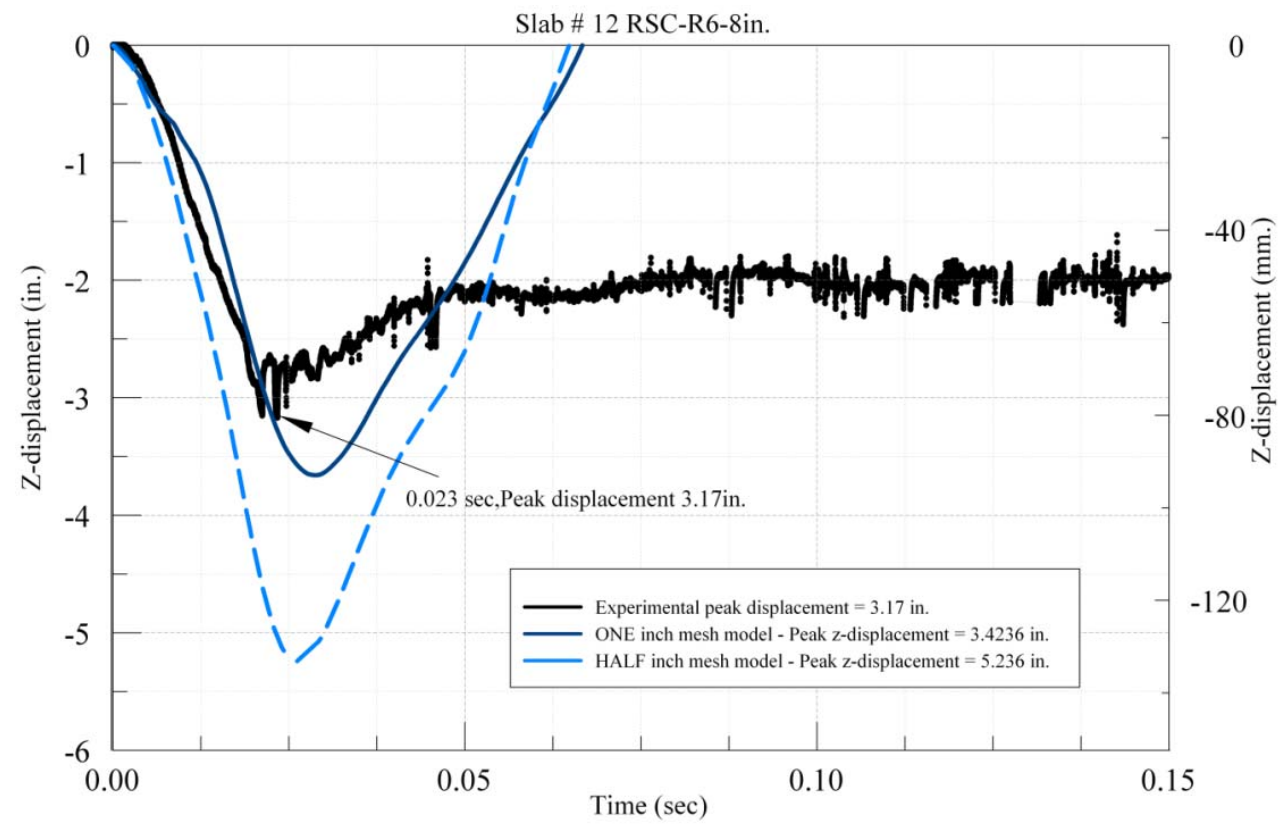

Figure 6-49 : Deflection Comparison between 1 in. $(25.4 \mathrm{~mm}$.) and 1/2 in. (12.7 mm.) mesh sizes for Concrete Damage Model Release 3 and Experimental Deflection for Slab\#12 - RSC-R6-8in.

The deflection results obtained from LS-DYNA ${ }^{\circledR}$ concrete models with two mesh sizes for CDMR3 are compared with the experimental deflections in Figure 6-49The peak deflections obtained from the CDMR3 with 1 in. $(25.4 \mathrm{~mm}$.) mesh was $3.43 \mathrm{in.}(87.122$ $\mathrm{mm}$.) recorded at 38.5 milliseconds while for $1 / 2 \mathrm{in.}(12.7 \mathrm{~mm}$.) mesh model it was $5.23 \mathrm{in}$. (132.84 mm.) recorded at 37.0 milliseconds. The deflections obtained from the models with 1 in. $(25.4 \mathrm{~mm})$ mesh size showed a $7 \%$ increase when compared to the experiments while the deflections obtained from the $1 / 2$ in. $(12.7 \mathrm{~mm}$.) model are higher by $64 \%$ when compared to the experimental values. 


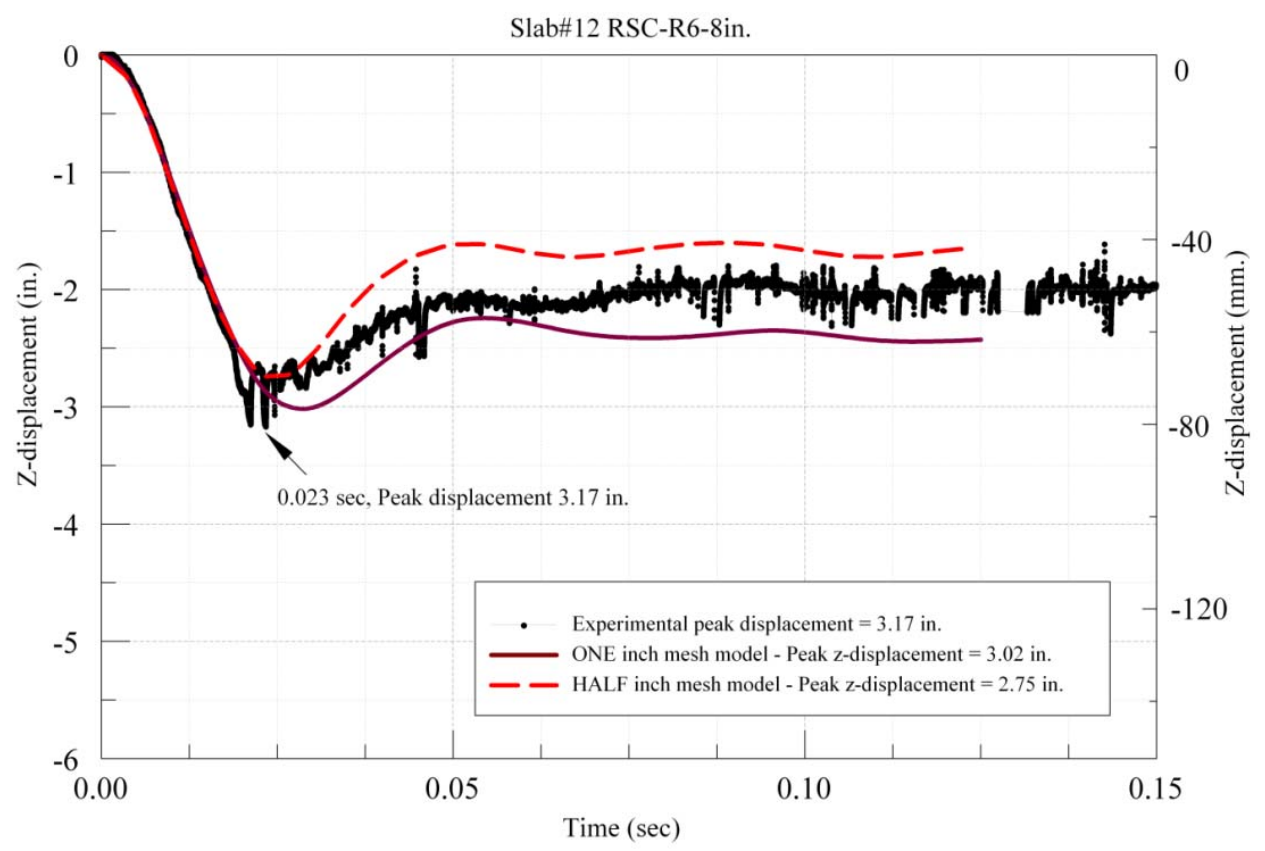

Figure 6-50: Deflection Comparison between 1 in. $(25.4 \mathrm{~mm}$.) and 1/2 in. (12.7 mm.) mesh sizes for Winfrith Concrete Model and Experimental Deflection for Slab\#12 - RSC-R6-8in.

The deflection results obtained from LS-DYNA ${ }^{\circledR}$ concrete models with two mesh sizes for WCM are compared with the experimental deflections in Figure 6-50. The peak deflections obtained from the WCM with 1 in. $(25.4 \mathrm{~mm}$.) mesh was $3.02 \mathrm{in.}(76.71 \mathrm{~mm}$.) recorded at 28.5 milliseconds while for $1 / 2 \mathrm{in.} \mathrm{(12.7} \mathrm{mm.)} \mathrm{mesh} \mathrm{model} \mathrm{it} \mathrm{was} 2.74 \mathrm{in}$. (63.5 $\mathrm{mm}$.) recorded at 24.5 milliseconds. The deflections obtained from the models with $1 \mathrm{in}$. $(25.4 \mathrm{~mm})$ mesh size showed a $5 \%$ decrease when compared to the while the deflections obtained from the $1 / 2$ in. $(12.7 \mathrm{~mm}$.) model are lower by $13 \%$ when compared to the experimental values.

From Figure 6-49 and Figure 6-50 it can be noted that varying the mesh size from 1 in. $(25.4 \mathrm{~mm}$.) to $1 / 2 \mathrm{in}$. $(12.7 \mathrm{~mm}$.) decreased the deflection by $0.26 \mathrm{in} .(6.6 \mathrm{~mm}$.) for the Winfrith Concrete Model and increased by 1.81 in. (45.97 mm.) for Concrete Damage 
Model Release 3 respectively. The 1 in. mesh $(25.4 \mathrm{~mm})$ can be useful to predict the deflection accurately in both the models in comparison with the experimental deflection.

\subsection{Material Model Effect for Slab \# 12 (RSC-R6-8in.)}

Figure 6-51 and Figure 6-52 compare the deflections between two material models for two mesh sizes. From Figure 6-51 for the 1 in. $(25.4 \mathrm{~mm})$ mesh model the WCM predicted the deflection 0.16 in. $(4.06 \mathrm{~mm}$.) less than the experimental deflection while the CDMR3 predicted the deflection 0.25 in. $(6.35 \mathrm{~mm}$.) more than the experiment. From Figure 6-52 for the 1/2 in. $(12.7 \mathrm{~mm})$ mesh model the WCM predicted the deflection 0.42 in. (10.67 mm.) less than the experimental deflection while the CDMR3 predicted the deflection 2.03 in. $(51.56 \mathrm{~mm}$.) more than the experiment. The Winfrith Concrete Model predicted the response better in both mesh size category.

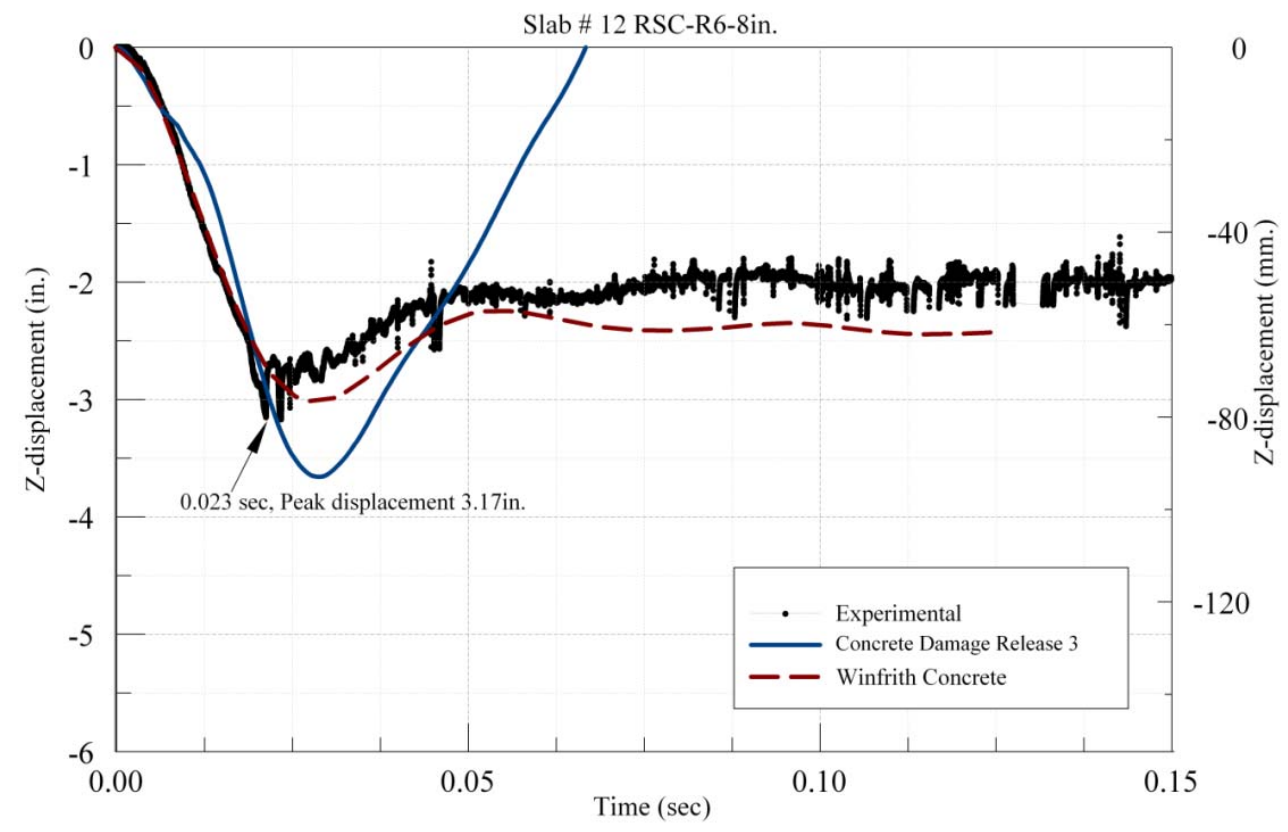

Figure 6-51: Deflection Comparison between Concrete Damage Model Release 3 and Winfrith Concrete for 1 in. (25.4 mm.) mesh model with Experimental Deflection for Slab\#12 - RSC-R6-8in. 


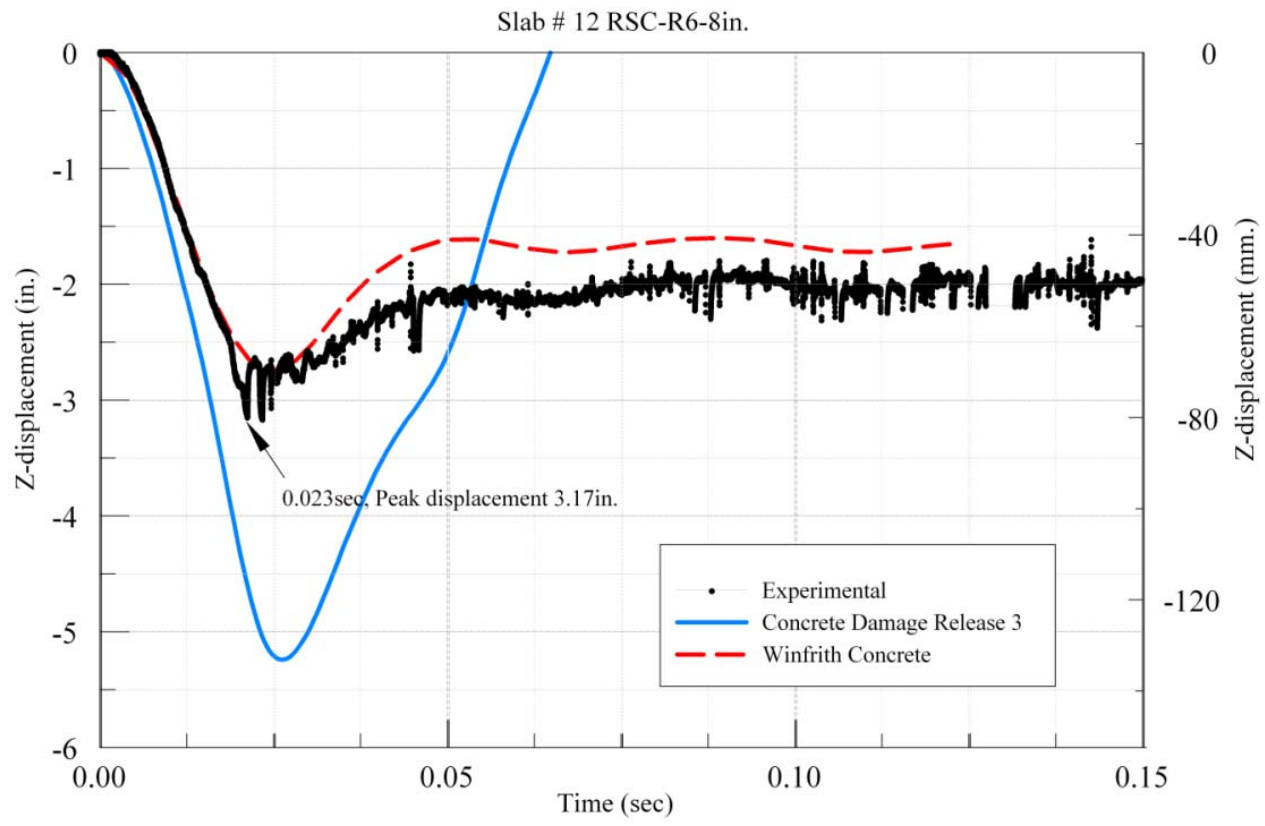

Figure 6-52: Deflection Comparison between Concrete Damage Model Release 3 and Winfrith Concrete for 1/2 in. (12.7 mm.) mesh model with Experimental Deflection for Slab\#12 - RSC-R6-8in.

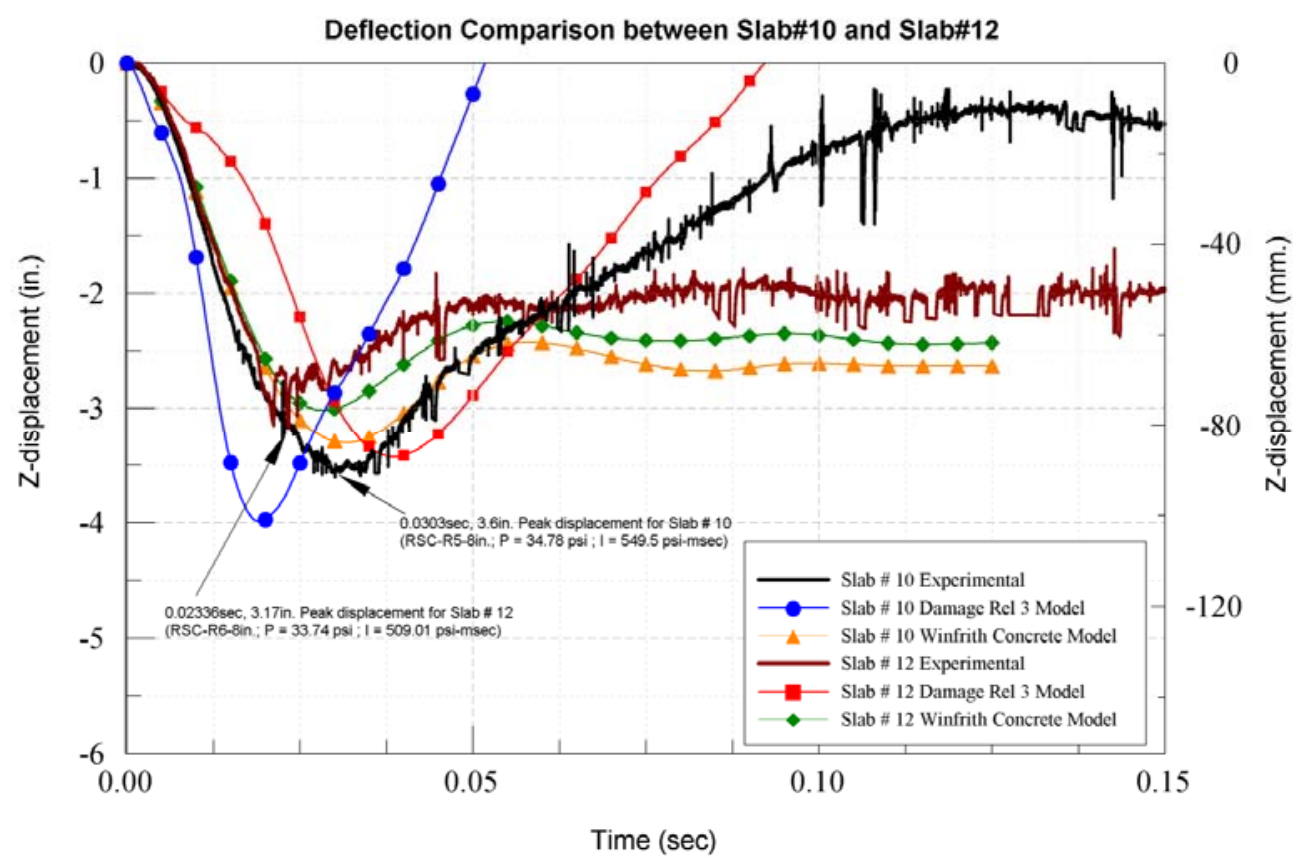

Figure 6-53: Deflection Comparison between Concrete Damage Model Release 3 and Winfrith Concrete for 1 in. (25.4 mm.) mesh model with Experimental Deflection for Slab\#10 - RSC-R5-8in. and Slab\#12 - RSC-R6-8in. 
Figure 6-53 compares the two slabs i.e. Slab\#10 - RSC-R5-8in. and Slab\#12 - RSCR6-8in. having the high-strength combination of concrete and steel with 8 in. steel spacing for both the experimental and numerical analysis results. The numerical analysis results presented here are using the 1 in. $(25.4 \mathrm{~mm}$.) mesh model as this mesh size yielded good results as compared to other mesh sizes in both the concrete material models used. These slabs were subjected to similar pressures of $34.78 \mathrm{psi}(0.24 \mathrm{MPa})$ and $33.74 \mathrm{psi}(0.23 \mathrm{MPa})$ respectively and an impulse of $549.5 \mathrm{psi}-\mathrm{msec}$ (3.78 MPa-msec) and $509.01 \mathrm{psi}-\mathrm{msec}$ (3.51 MPa-msec) respectively during the experimental program.

As seen in the plot the peak deflections for the two slabs occured within a very small timeframe ranging between 23.36 milliseconds and 30.3 milliseconds. The experimental peak deflections recorded for the two slabs are 3.6 in. $(91.44 \mathrm{~mm}$.$) and 3.17 \mathrm{in} .(80.52 \mathrm{~mm}$. respectively. For both of these slabs when modeled using the two concrete material models gave a good prediction of the deflection as observed from the peak and residual displacements as noted in Table 6-3 and Table 6-4. The WCM predicted the deflection response very close to the experiment but the post-peak deflection response deviates more from the experimental post-peak deflection. The CDMR3 predicted the peak deflections higher than the experiment also the post-peak deflection response is not very accurate as the slab rebounds completely. 


\subsection{Comparison Criterion 2; Crack Propagation Study}

The crack patterns observed in the numerical simulation are compared with the crack patterns developed on the slab as observed in the experiment. Two concrete material models namely, the WCM and the CDMR3 are considered for comparison. The slab model used for studying the crack patterns is the $0.25 \mathrm{in} .(6.35 \mathrm{~mm})$ mesh model for both 4 in. and 8 in. type slabs. The 0.25 in. mesh model was used because the finer mesh can predict finer cracks as they are formed.

\subsubsection{High Strength Concrete with High Strength Steel Slabs (HSC-V-4 in.)}

In this section the High Strength Slabs with \#3 bars spaced at 4 in. c/c $(101.6 \mathrm{~mm}$.) in the longitudinal direction (reinforcement ratio $=0.68 \%$ ) are considered for comparison based on damage crack patterns developed on the slab. The damage crack patterns captured on the slab after the experiment and numerical analysis are represented in Figure 6-54, Figure 6-55 and Figure 6-56 for this type of slab. Since this type of slab has the combination of high strength materials combined with higher reinforcement ratio the crack patterns observed on the slab are very narrow.

The damage patterns observed on the CDMR3 are represented in Part (a) of these figures. The lateral damage crack patterns are seen as contours of the max. principal strain as well as erosion of elements in the cracked area. The propagation of crack from the center of the slab to the periphery can be observed on the slab models as the simulation progresses. The LS-DYNA model displays all of the cracks that generate in the model including narrow cracks which cannot be easily distinguished in the results. The damage patterns observed on the WCM are represented in Part (c) of these figures. The narrow cracks could be neglected by setting the minimum crack width as 0.0002 in. $(0.0051 \mathrm{~mm}$.). 
6.2.1.1 Damage Crack Patterns for Slab \# 1 (HSC-V1-4in.)

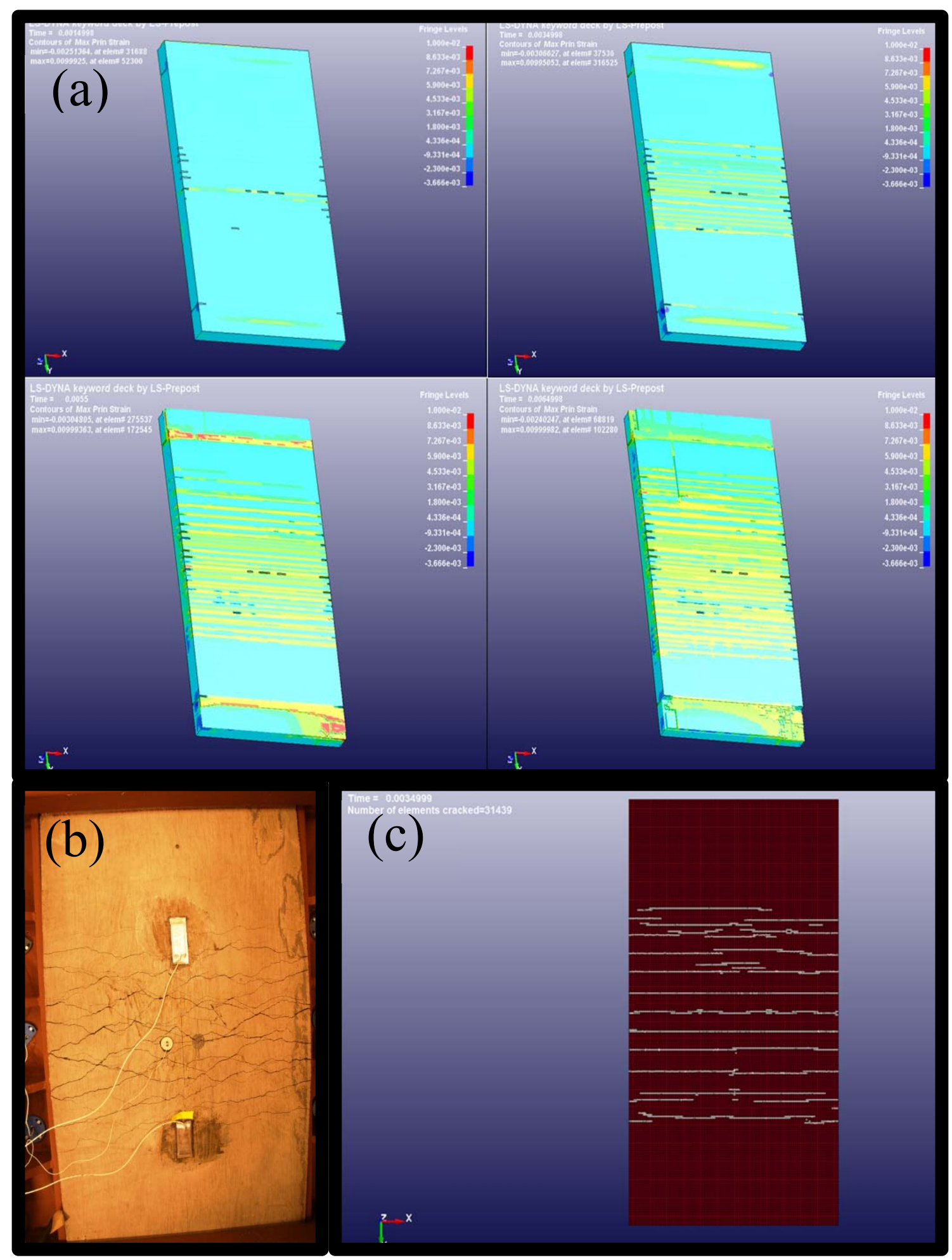

Figure 6-54: Damage crack patters for Slab \# 1 from (a) Concrete Damage Rel3 Model, (b) Experiment and (c) Winfrith Concrete Model 
6.2.1.2 Damage Crack Patterns for Slab \# 3 (HSC-V2-4in.)

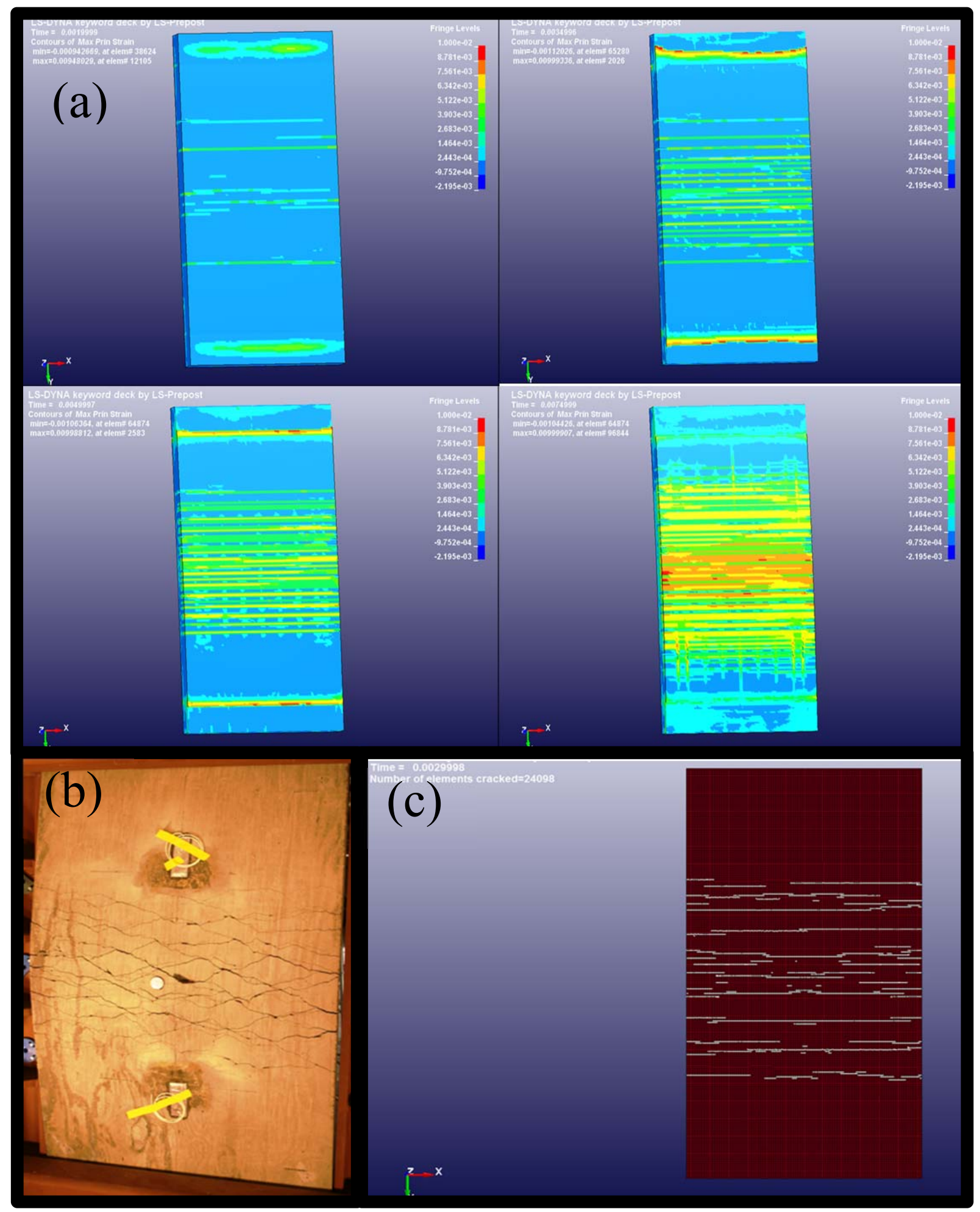

Figure 6-55: Damage crack patters for Slab \# 3 from (a) Concrete Damage Rel3 Model, (b) Experiment and (c) Winfrith Concrete Model 
6.2.1.3 Damage Crack Patterns for Slab \# 5 (HSC-V3-4in.)

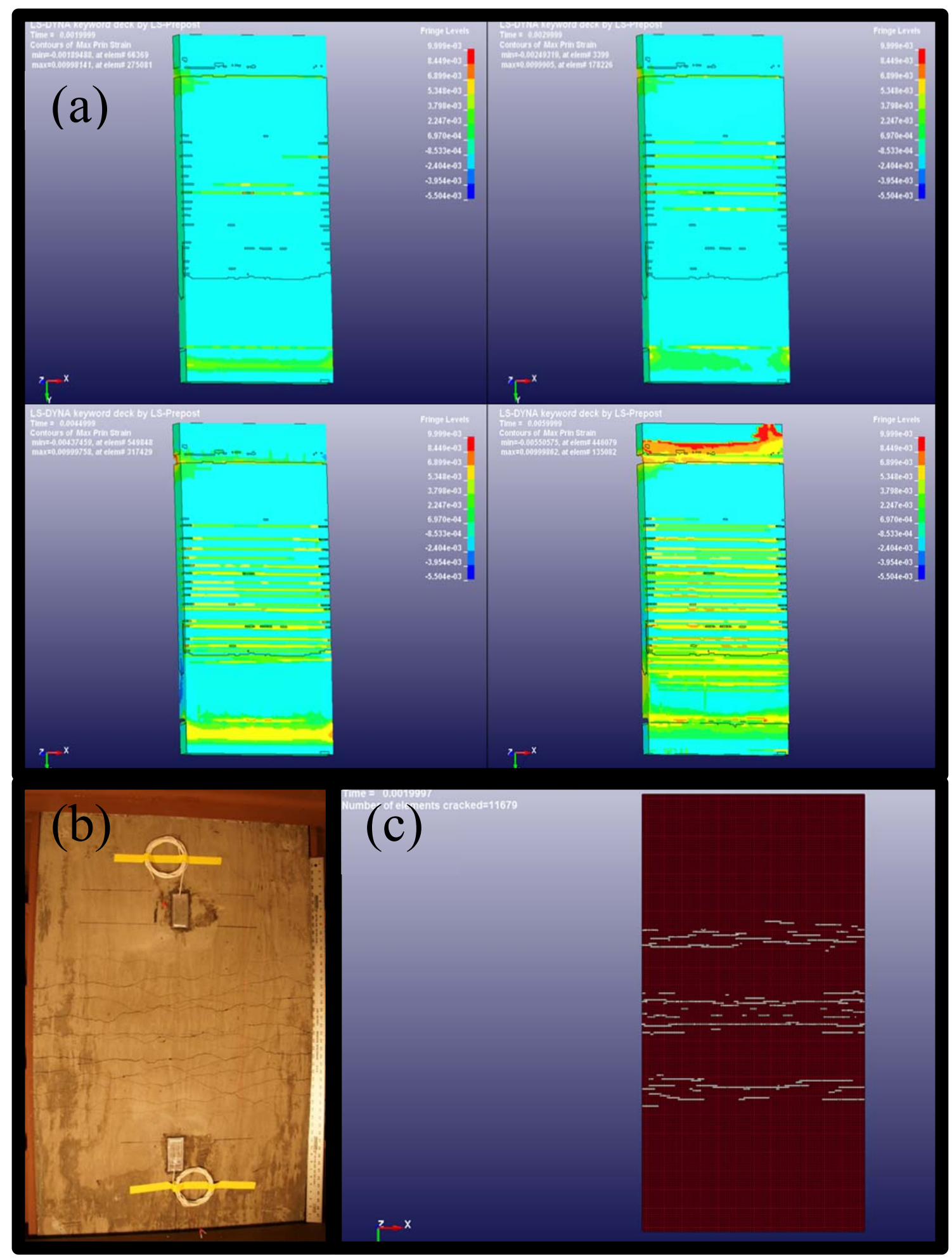

Figure 6-56: Damage crack patters for Slab \# 5 from (a) Concrete Damage Rel3 Model, (b) Experiment and (c) Winfrith Concrete Model 


\subsubsection{High Strength Concrete with High Strength Steel Slabs (HSC-V-8 in.)}

In this section the High Strength Slabs with \#3 bars spaced at $8 \mathrm{in} . \mathrm{c} / \mathrm{c}$ in the longitudinal direction (reinforcement ratio $=0.46 \%$ ) are considered for comparison based on damage crack patterns developed on the slab. The damage crack patterns captured on the slab after the experiment and numerical analysis are represented in Figure 6-57, Figure 6-58 and Figure 6-59 for this type of slab. Since this type of slab has the combination of high strength materials combined with lower reinforcement ratio the crack patterns observed on the slab are much wider.

The damage patterns observed on the CDMR3 are represented in Part (a) of these figures. The LS-DYNA model displays all of the cracks that generate in the model including narrow cracks which cannot be easily distinguished in the results. However, the wide cracks that are generated in these slabs are very well predicted in the numerical model as the elements in this region have been eroded. The damage patterns observed on the WCM are represented in Part (c) of these figures. Slab \# 7 experienced a higher pressure and impulse in this category and thus shows wider cracks in the center of the slabs which are also predicted well in the CDMR3 slab model. Slab \# 9 and Slab \# 11 experienced pressure and impulse much lower than Slab \# 7 and thus the damage observed is comparatively less in both experimental and also the numerical slab models. 
6.2.2.1 Damage Crack Patterns for Slab \# 7 (HSC-V4-8in.) v

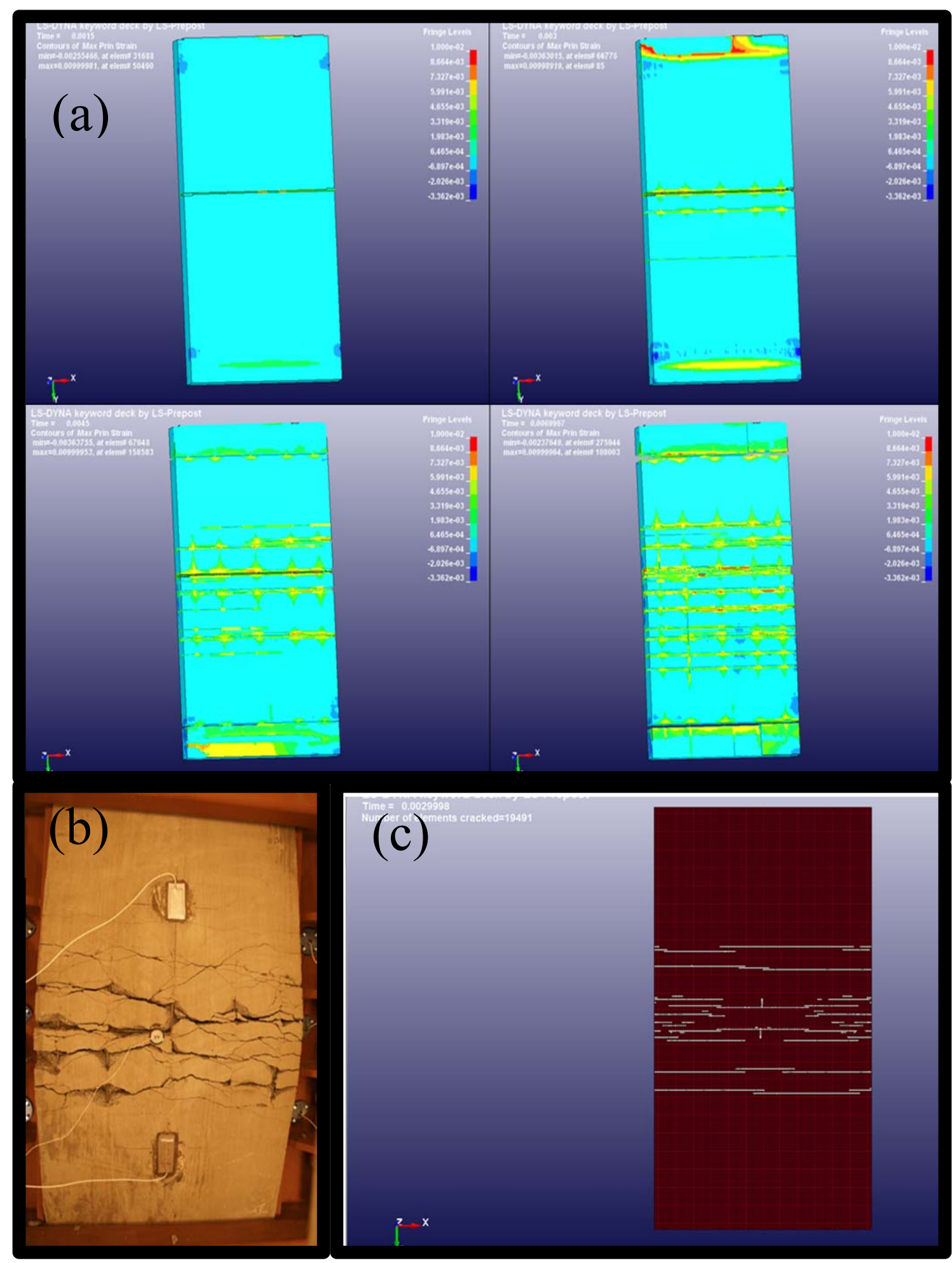

Figure 6-57: Damage crack patters for Slab \# 7 from (a) Concrete Damage Rel3 Model, (b) Experiment and (c) Winfrith Concrete Model 


\subsubsection{Damage Crack Patterns for Slab \# 9 (HSC-V5-8in.)}

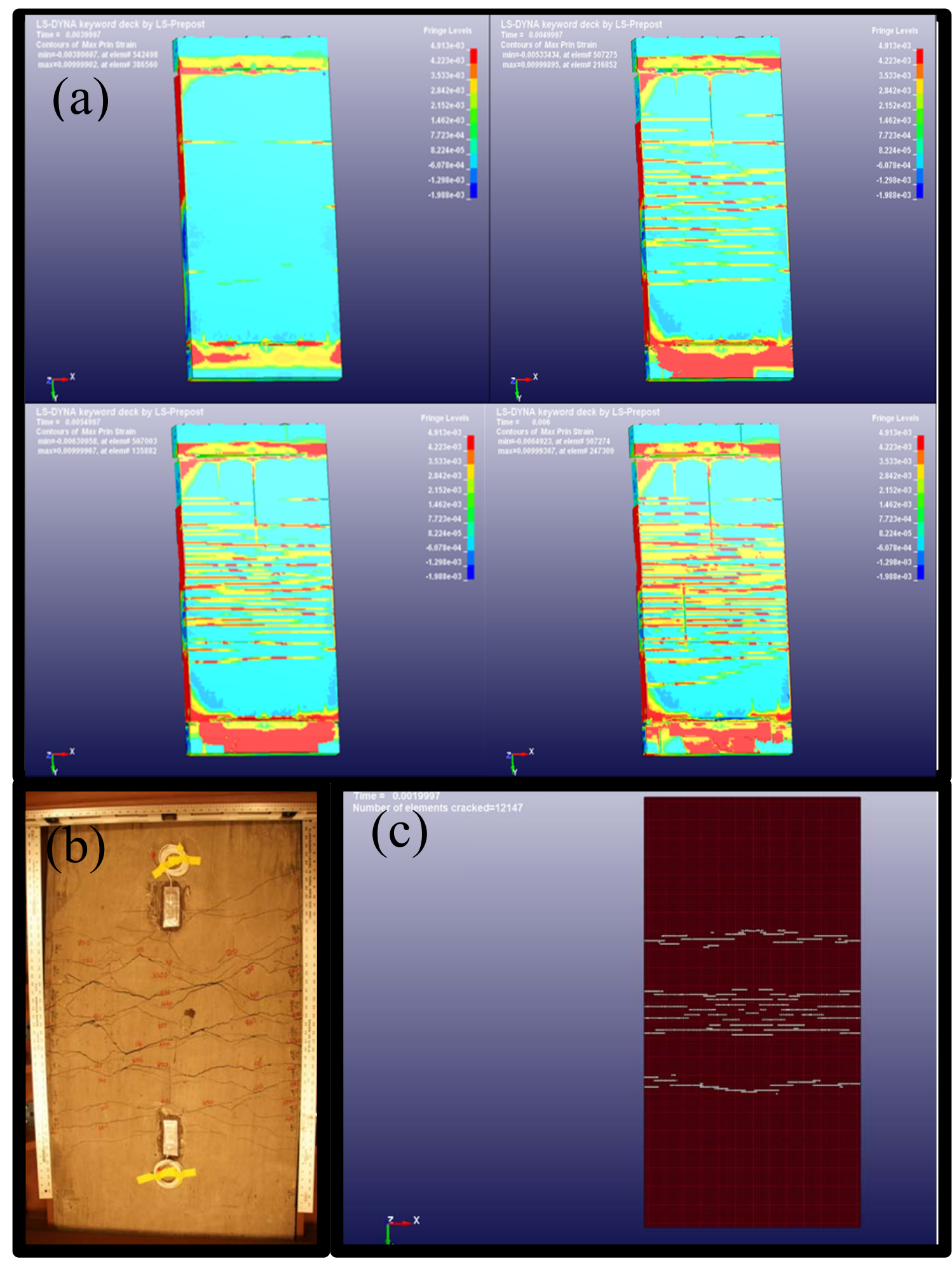

Figure 6-58: Damage crack patters for Slab \# 9 from (a) Concrete Damage Rel3 Model, (b) Experiment and (c) Winfrith Concrete Model 
6.2.2.3 Damage Crack Patterns for Slab \# 11 (HSC-V6-8in.)

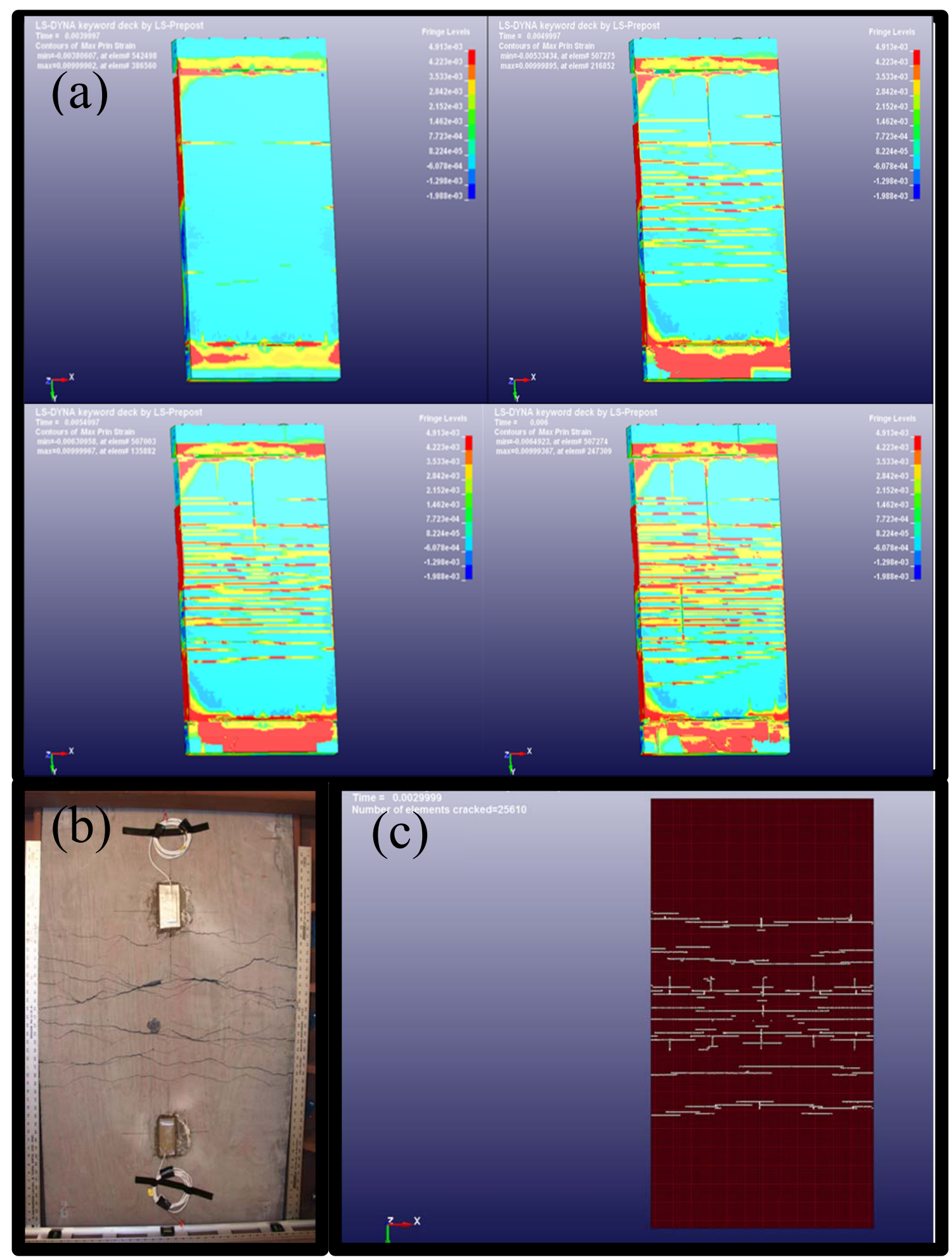

Figure 6-59: Damage crack patters for Slab \# 11 from (a) Concrete Damage Rel3 Model, (b) Experiment and (c) Winfrith Concrete Model 


\subsubsection{Normal Strength Concrete with Normal Strength Steel Slabs (RSC-R- 4in.)}

In this section the Normal Strength Steel Slabs with \#3 bars spaced at 4in. c/c (101.6 $\mathrm{mm}$.) in the longitudinal direction (reinforcement ratio $=0.68 \%$ ) are considered for comparison based on damage crack patterns developed on the slab. The damage crack patterns captured on the slab after the experiment and numerical analysis are represented in Figure 6-60, Figure 6-61 and Figure 6-62 for this type of slab. Since this type of slab has the combination of normal strength materials combined with higher reinforcement ratio the crack patterns observed on the slab are narrow.

The damage patterns observed on the CDMR3 are represented in Part (a) of these figures. The lateral damage crack patterns are seen as contours of the max. principal strain as well as erosion of elements in the cracked area. The propagation of crack from the center of the slab to the periphery can be observed on the slab models as the simulation progresses. The LS-DYNA model displays all of the cracks that generate in the model including narrow cracks which cannot be easily distinguished in the results. The damage patterns observed on the WCM are represented in Part (c) of these figures. The narrow cracks could be neglected by setting the minimum crack width as 0.0002 in. (0.0051 mm.). 
6.2.3.1 Damage Crack Patterns for Slab \# 2 (RSC-R1-4in.)

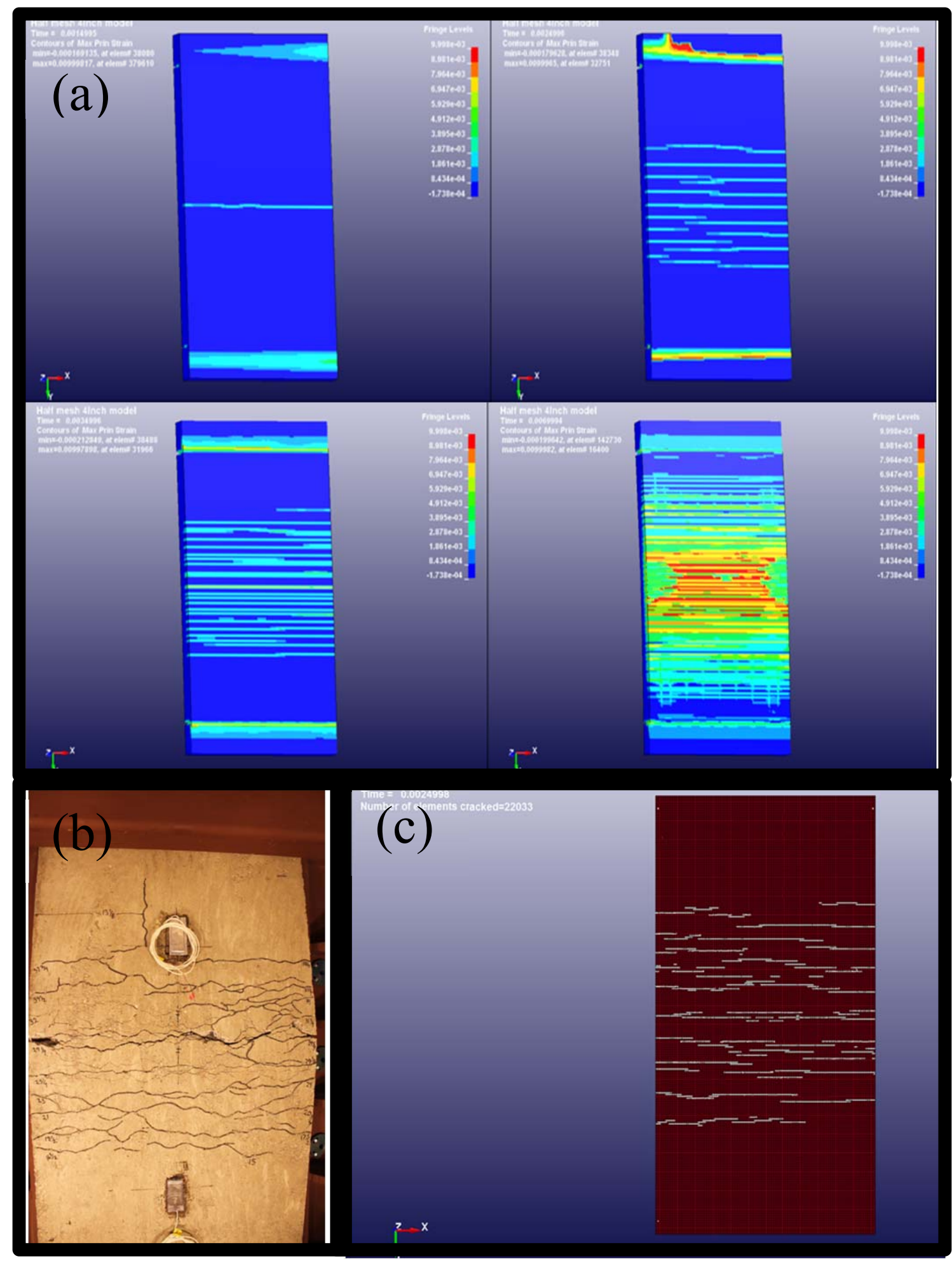

Figure 6-60: Damage crack patters for Slab \# 2 from (a) Concrete Damage Rel3 Model, (b) Experiment and (c) Winfrith Concrete Model 
6.2.3.2 Damage Crack Patterns for Slab \# 4 (RSC-R2-4in.)

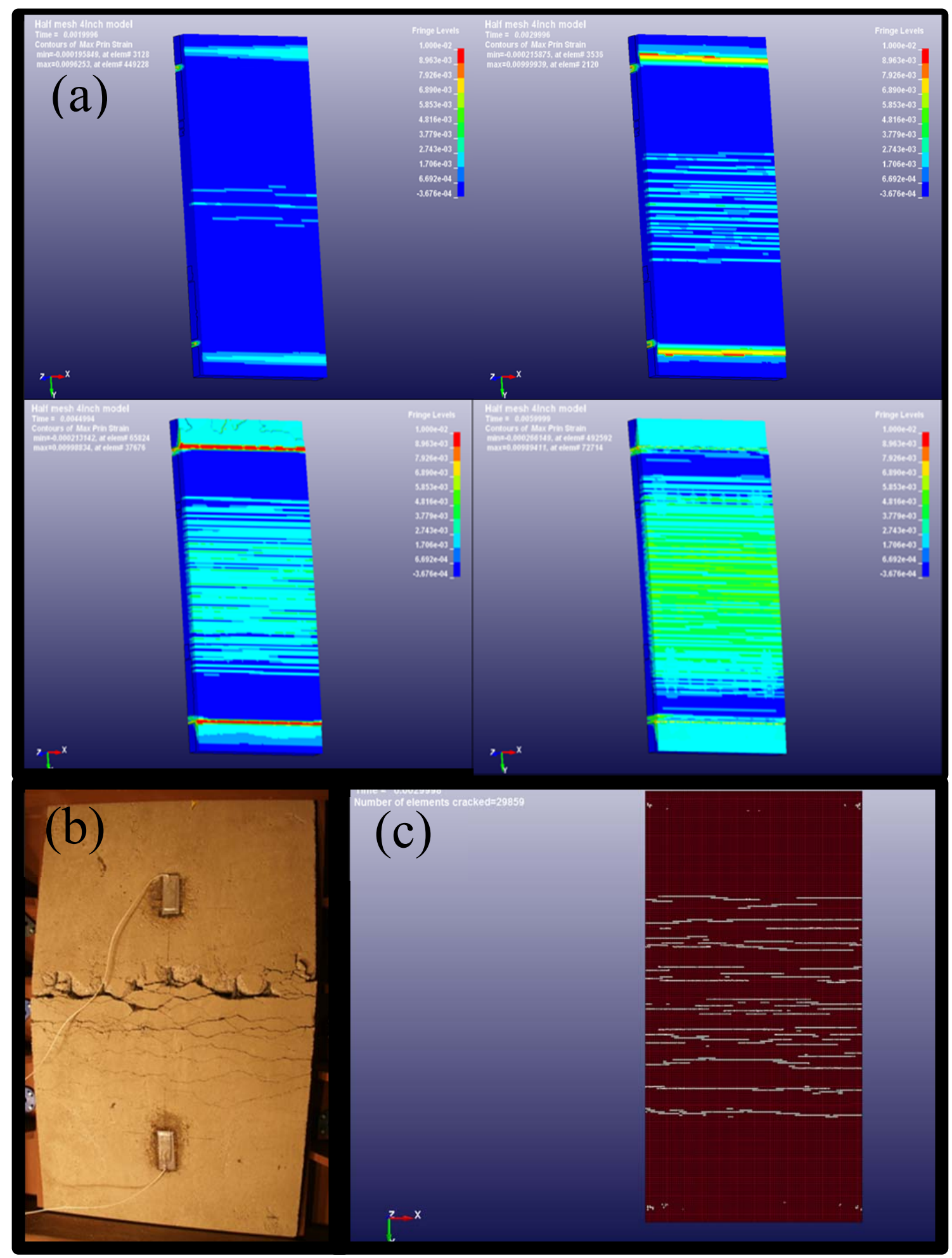

Figure 6-61: Damage crack patters for Slab \# 4 from (a) Concrete Damage Rel3 Model, (b) Experiment and (c) Winfrith Concrete Model 
6.2.3.3 Damage Crack Patterns for Slab \# 6 (RSC-R3-4in.)

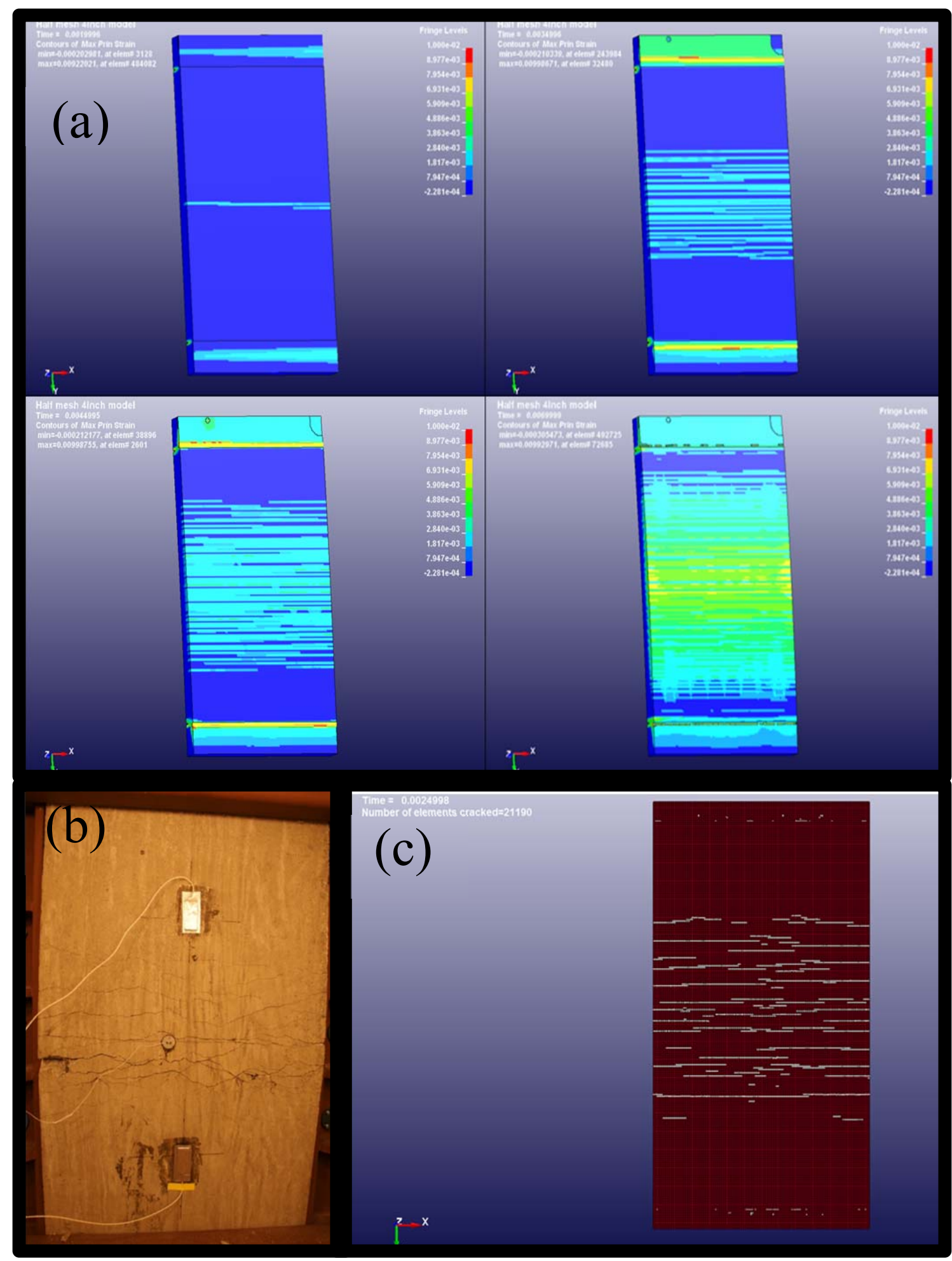

Figure 6-62: Damage crack patters for Slab \# 6 from (a) Concrete Damage Rel3 Model, (b) Experiment and (c) Winfrith Concrete Model 


\subsubsection{Normal Strength Concrete with Normal Strength Steel Slabs (RSC-R- 8in.)}

In this section the High Strength Slabs with \#3 bars spaced at 8in. c/c in the longitudinal direction (reinforcement ratio $=0.46 \%$ ) are considered for comparison based on damage crack patterns developed on the slab. The damage crack patterns captured on the slab after the experiment and numerical analysis are represented in Figure 6-63, Figure 6-64 and Figure 6-65 for this type of slab.

The damage patterns observed on the CDMR3 are represented in Part (a) of these figures. The LS-DYNA model displays all of the cracks that generate in the model including narrow cracks which cannot be easily distinguished in the results. However, the wide cracks that are generated in these slabs are very well predicted in the numerical model as the elements in this region have been eroded. The damage patterns observed on the WCM are represented in Part (c) of these figures.

The Normal Strength Concrete with Normal Strength Steel Slabs with with \#3 bars spaced at $8 \mathrm{in} . \mathrm{c} / \mathrm{c}$ in the longitudinal direction (reinforcement ratio $=0.46 \%$ ) has the weakest combination with regards to the material strength and the reinforcement ratio but these slabs experienced lower pressures and impulse and hence do not show a high visible damage. 
6.2.4.1 Damage Crack Patterns for Slab \# 8 (RSC-R4-8in.)

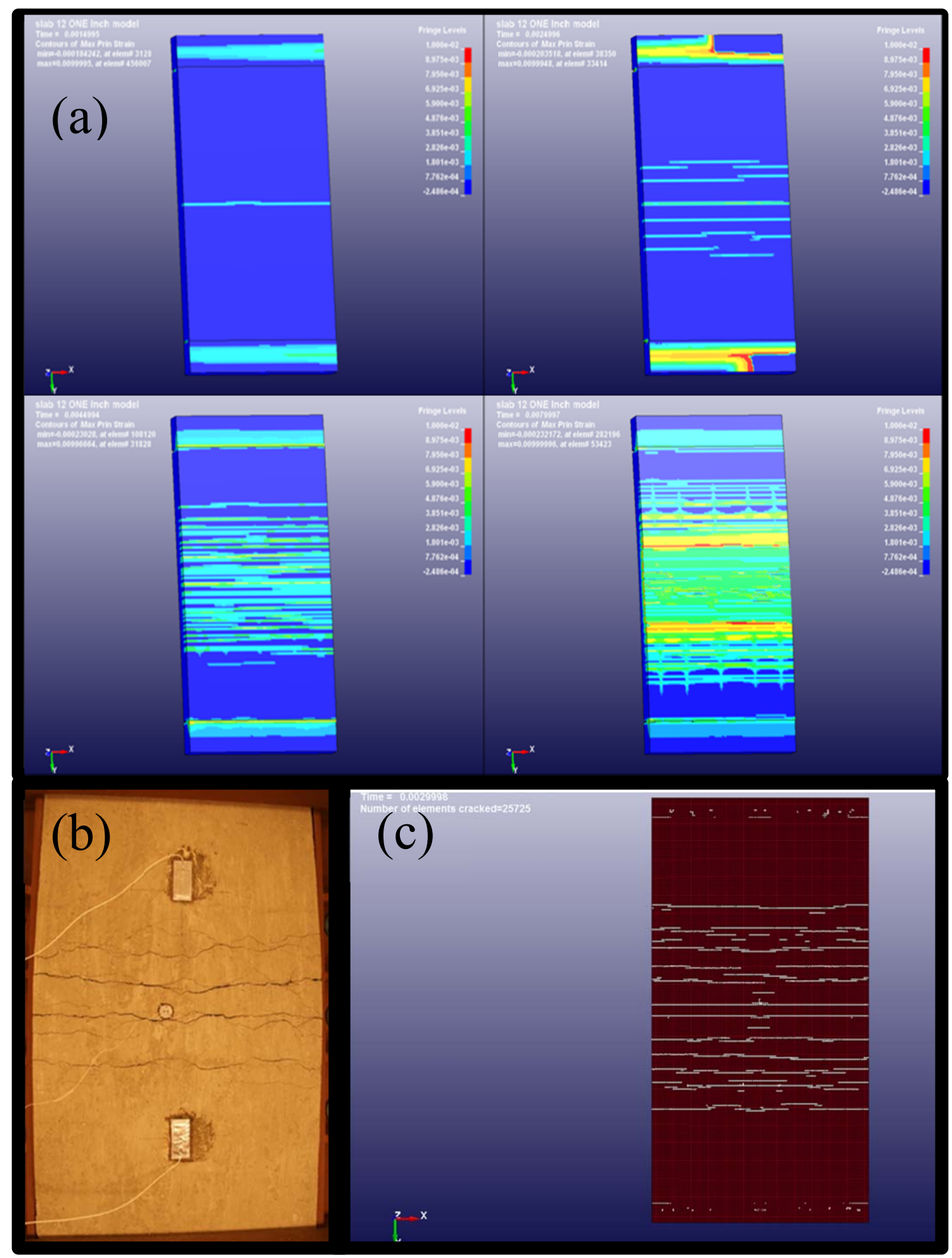

Figure 6-63: Damage crack patters for Slab \# 8 from (a) Concrete Damage Rel3 Model, (b) Experiment and (c) Winfrith Concrete Model 


\subsubsection{Damage Crack Patterns for Slab \# 10 (RSC-R5-8in.)}

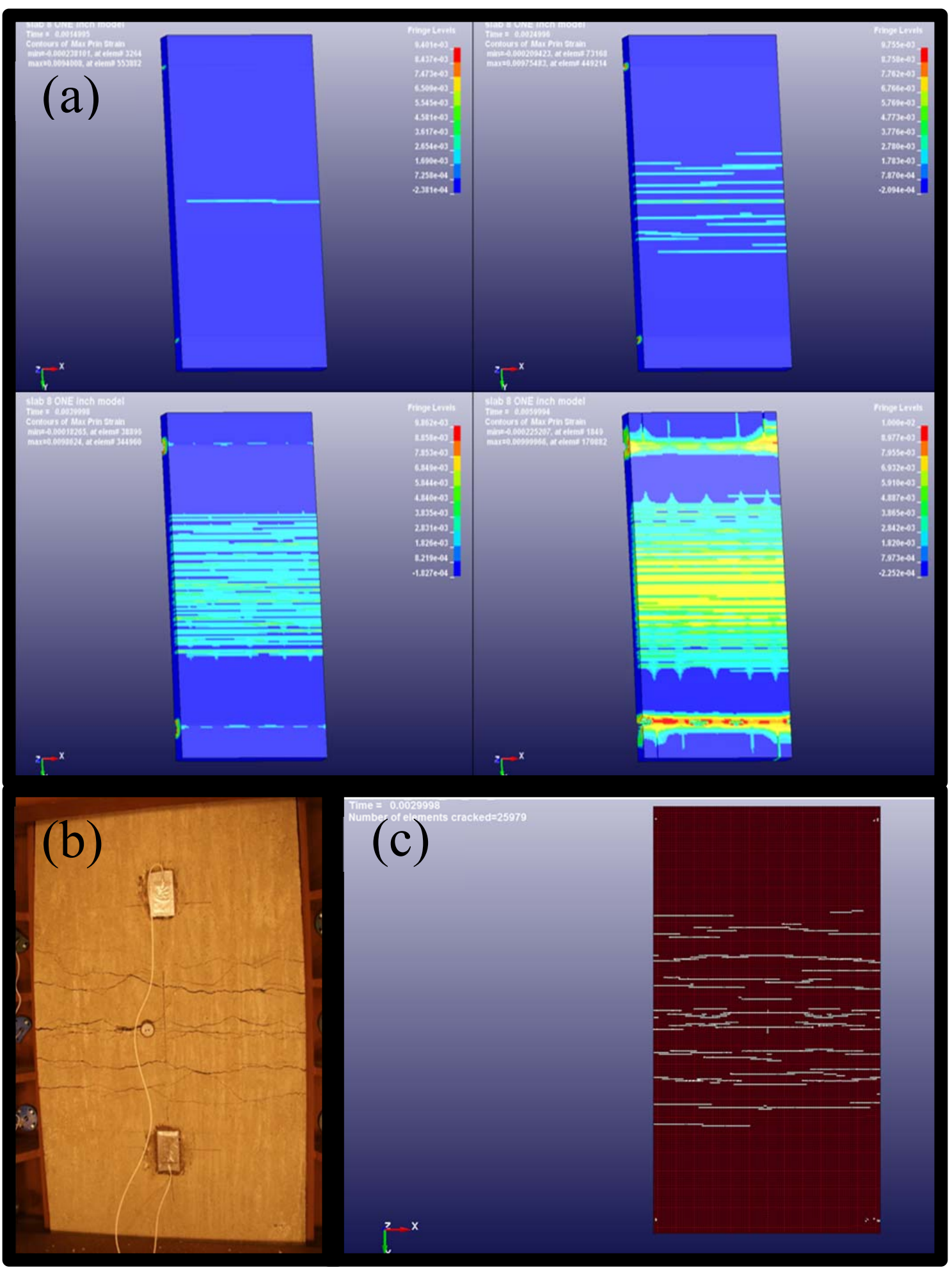

Figure 6-64: Damage crack patters for Slab \# 10 from (a) Concrete Damage Rel3 Model, (b) Experiment and (c) Winfrith Concrete Model 


\subsubsection{Damage Crack Patterns for Slab \# 12 (RSC-R6-8in.)}

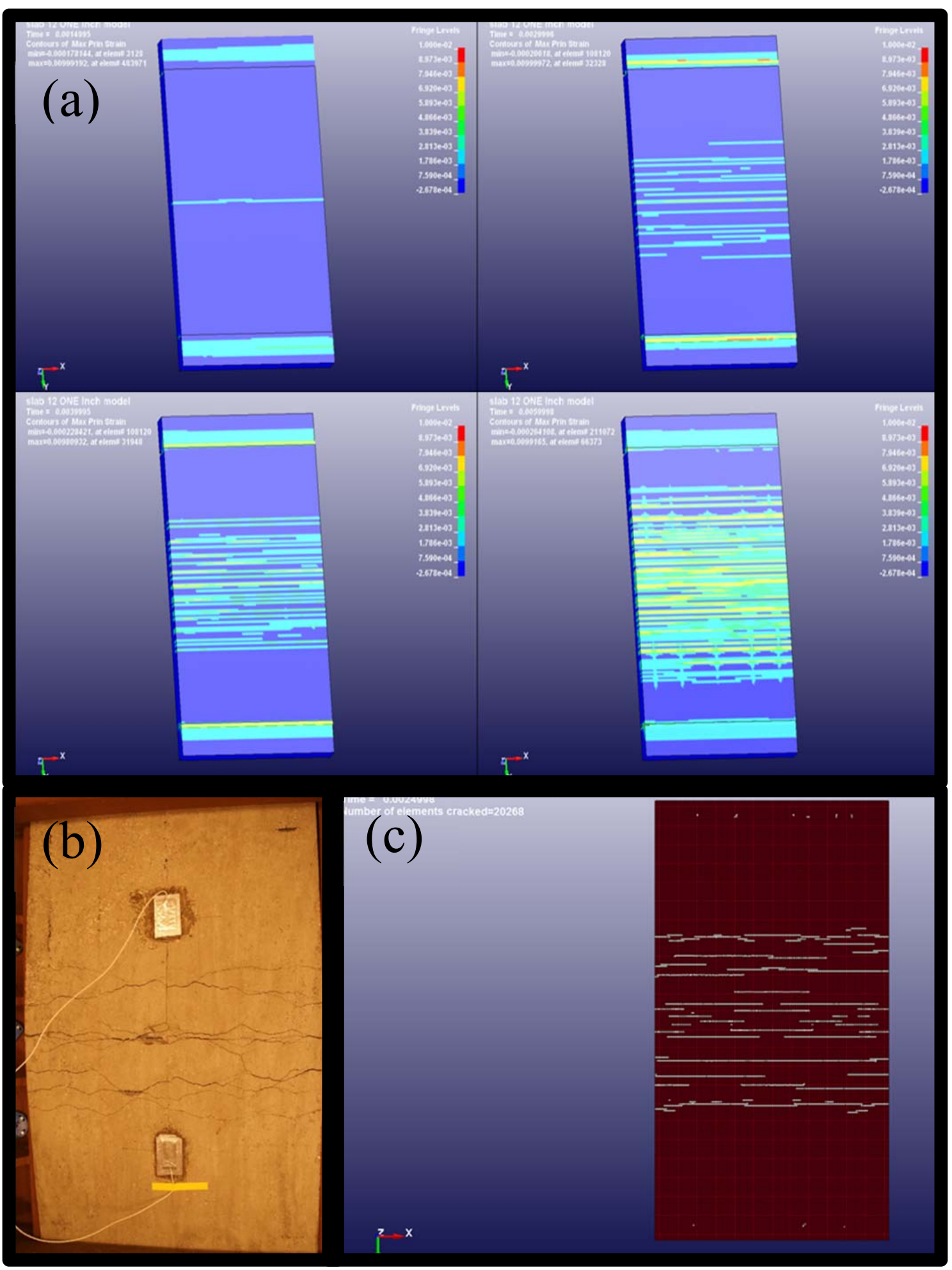

Figure 6-65: Damage crack patters for Slab \# 12 from (a) Concrete Damage Rel3 Model, (b) Experiment and (c) Winfrith Concrete Model 


\section{CHAPTER 7}

\section{DISCUSSION OF RESULTS}

The numerical analysis results for the set of $12 \mathrm{RC}$ slabs on comparison with the experimental data provide an understanding on the behavior of the RC slabs when subjected to blast loading. The two combinations of slabs namely, high-strength concrete with highstrength steel (HSC-V) and normal-strength concrete with normal-strength steel (RSC-R) have been discussed in detail here for the deflection and damage response shown by both numerical analysis and experimental investigation which lead to achieving the primary objective of experimental validation of the numerical analysis.

7.1 High-Strength Concrete - Comparison of Model with 1 in. (25.4 mm.) Mesh to $1 / 2$ in.

$$
\text { (12.7 mm.) Mesh Model. }
$$

The percentage change in peak slab deflection when mesh size was reduced from 1 in. $(25.4 \mathrm{~mm}$.) to $1 / 2$ in. $(12.7 \mathrm{~mm}$.) has been shown in Table 6-6 in Chapter 6. It was observed that a finer mesh of $1 / 2$ in. $(12.7 \mathrm{~mm}$.) substantially increased the deflection in both the concrete models namely the Winfrith Concrete Model and the Concrete Damage Model Release 3. However, the increase in deflection is comparatively more for the Winfrith Concrete Model with a percentage increase of $46 \%$ in slabs having 4 in. spaced steel while a

percentage increase of $32 \%$ in slabs having 8 in. spaced steel. However, the 1 in. (25.4 mm.) mesh model produces the deflection near the experimental values as compared to the $1 / 2$ in. (12.7 mm.) mesh model. 


\subsection{High Strength Concrete - Comparison of Winfrith Concrete Model with Concrete}

\section{Damage Release 3.}

The two concrete models used for modeling concrete behavior namely the Winfrith Concrete Model with Concrete Damage Release 3 have performed well in predicting peak and residual deflections in the high-strength concrete category with the $1 \mathrm{in} .(25.4 \mathrm{~mm}$.) mesh model. The deflection response for the two models is compared with the experiments in Table 6-5. The Winfrith Concrete Model has predicted the deflection closer to the experiment as compared to the Concrete Damage Model Release 3 in both the peak and residual deflection region of the deflection time-history. When the Winfrith Concrete Model is used for slabs having 4 in. (101.6 mm.) spaced steel the peak deflection is $1.5 \%$ less than the experimental deflection and the residual deflection is $10 \%$ more than the experimental deflection. Similarly, when the Winfrith Concrete Model is used for slabs having 8 in. (203.2 mm.) spaced steel the peak deflection is $3 \%$ less than the experimental deflection the residual deflection is $12 \%$ less than the experimental deflection.

7.3 Normal Strength Concrete - Comparison of model with 1 in. $(25.4 \mathrm{~mm}$.) mesh to $1 / 2$ in. (12.7 mm.) mesh model.

The percentage change in peak slab deflection when mesh size was reduced from 1 in. $(25.4 \mathrm{~mm}$.) to $1 / 2 \mathrm{in}$. $(12.7 \mathrm{~mm}$.) has been shown in Table 6-8 in Chapter 6. It was observed that a finer mesh of $1 / 2$ in. $(12.7 \mathrm{~mm}$.) substantially increased the deflection in the Concrete Damage Model Release 3 for both the models having 4 in. $(101.6 \mathrm{~mm}$.) and 8 in. (203.3 mm.) spaced steel. The Winfrith Concrete Model has shown an increase in deflection of $11 \%$ to $15 \%$ on reduction of mesh size from $1 \mathrm{in} .(25.4 \mathrm{~mm}$.) to $1 / 2 \mathrm{in}$. $(12.7 \mathrm{~mm}$.) for the 
model having steel spaced at 4 in. (101.6 mm.). But, the model having steel spaced at 8 in. (203.2 mm.) has a reduction in deflection up to $23 \%$ when the mesh size is reduced to $1 / 2$ in.

\subsection{Normal Strength Concrete - Comparison of Winfrith Concrete Model with Concrete}

\section{Damage Release 3.}

In the normal strength category out of the two concrete models the Concrete Damage Model Release 3 has performed better than the Winfrith Concrete Model in predicting the peak-deflection for both slabs having 4 in. (101.6 mm.) and 8 in. (203.2 mm.) spaced steel. However the post-peak response for the Concrete Damage Model Release 3 is not as good as that of Winfrith Concrete Model in terms of its residual deflection. The Winfrith Concrete Model predicts the response 33\% lower than the experimental value in the peak-deflection region but the post-peak deflection response is closer to the experimental deflection response.

\subsection{Comparison of High Strength Material with Normal Strength Material.}

The performance of high-strength slabs when compared to the normal-strength slabs having 4 in. (101.6 mm.) longitudinally spaced steel doesn't show a distinct reduction in the peak deflection due to use of high strength material. The reinforcement ratio of $0.68 \%$ makes the effect of strength negligible as can be observed from the deflection values presented in Table 6-1 and Table 6-2. Both types of slabs in the $0.68 \%$ reinforcement ratio category have experienced pressures in the range of 49.28 psi. to 53.1 psi. and have produced deflection in the range of 3.89 in. to 4.53 in. Thus, on increasing the concrete 
strength the deflection reduced by $9 \%$ in the experimental analysis. While in the numerical analysis for Winfrith Concrete Model the deflection increased by 16\% while for Concrete Damage Release 3 the deflection reduced by $19 \%$.

The performance of high-strength slabs when compared to the normal-strength slabs having 8 in. (203.2 mm.) longitudinally spaced steel also doesn't show a distinct reduction in the peak deflection due to use of high strength material. These types of slabs have been subjected to pressures in the range of 511.77 psi. to 576.07 psi. for the high-strength and in the range of 509.01 psi. to 549.5 psi. for normal strength slabs. The deflection obtained from the slab consisting of high-strength material was less by $5 \%$ than the deflection obtained from the slab consisting of normal-strength material. Thus the effect of using higher-strength material is only reasonable when higher pressures and impulses are acting on the slab.

7.6 Comparison of Slabs with 4 in. (101.6 mm.) c/c Longitudinal Steel to 8 in. (203.2 mm.) c/c Longitudinal Steel.

Comparison of slabs with 4 in. (101.6 mm.) c/c longitudinal steel to 8 in. (203.2 mm.) c/c longitudinal steel can be made at two levels based on the two strengths of materials used. For high-strength slabs the deflection increased by $190 \%$ when the reinforcement ratio was reduced from from $0.68 \%$ to $0.46 \%$. This is also true for normalstrength slabs where the deflection increased by $6 \%$ when the reinforcement ratio was reduced from from $0.68 \%$ to $0.46 \%$. The use of higher reinforcement ratio has improved the response of the slab when combined with high-strength materials. 
7.7 Comparison for validation of numerical analysis by studying damage response

Through visual observation it is seen that the damage patterns as recorded in the experiment have been predicted well by Concrete Damage Model Release 3 and Winfrith Concrete Model. The Winfrith Concrete Model used a $1 / 4$ in. $(6.35 \mathrm{~mm}$.) mesh model to generate the visual crack patterns. The narrow cracks were neglected by setting a minimum crack width and thus a clear damage pattern was generated which was good for comparison with the experimental damage recorded in the photographs. The Concrete Damage Model Release 3 which used an erosion criterion also needed 1/4 in. (6.35 mm.) mesh model to generate the visual crack patterns. The maximum principal strain in the material which was represented using different color contours gave information regarding crack generation and propagation. But as the simulation progressed the contours were not distinctly visible and hence only the initial response of the slab could be considered for comparison. The cracks produced during the initial phase of the simulation by the Concrete Damage Model Release 3 with the erosion material model have provided a good match to the crack produced during the experiment.

The analyses of the results obtained during the comparison of numerical analysis with experimental investigation have been summarized and conclusions and recommendations for future work are presented in the next chapter. 


\section{CHAPTER 8}

\section{CONCLUSIONS AND FUTURE WORK}

This chapter gives the conclusions based on the numerical analysis done on the 12 single-mat reinforced concrete slabs subjected to blast loading and their comparison with the results obtained from the experimental investigation in order to validate the material models namely, Winfrith Concrete Model and Concrete Damage Model Release 3. This chapter also includes the scope of future studies using the observations and results of this study.

1. In the high-strength material slabs (HSC-V) and normal-strength material slabs (RSC-R) on reducing the mesh sizes from 1 in. $(25.4 \mathrm{~mm}$.) to $1 / 2 \mathrm{in.}(12.7 \mathrm{~mm}$.) the deflection increases by up to 1.1 to 1.5 times for both Winfrith Concrete Model and Concrete Damage Model Release 3 in slabs having longitudinal reinforcement spaced at 4 in. (101.6 mm.) c/c.

2. In both high-strength material slabs (HSC-V) and normal-strength material slabs (RSC-R) modeled using Winfrith Concrete Model and Concrete Damage Model Release 3 the 1 in. $(25.4 \mathrm{~mm}$.) mesh model has predicted peak deflections closer to the experimental values and has utilized less number of CPU hours.

3. Winfrith Concrete Model has predicted deflection closer to the experimental deflection in high-strength slabs in both peak-deflection and post-peak deflection regions.

4. For Concrete Damage Model Release 3 laboratory test data for concrete can be utilized to give input parameters by combining them with generated parameters. 
5. In the high-strength material slabs (HSC-V) and normal-strength material slabs (RSC-R) having longitudinal reinforcement ratio of $0.68 \%$ (4in. c/c spaced longitudinal steel gives reinforcement ratio $=0.68 \%$ ) when subjected to similar pressure and impulse values the deflection observed is not affected by reduction in strength of concrete and steel in both experimental and numerical analysis.

6. On reduction of the reinforcement ratio from $0.68 \%$ to $0.46 \%$ the slab deflection increased by twice the amount.

7. The capability of Winfrith Concrete Model to generate the crack patterns with a $1 / 4$ in. $(6.53 \mathrm{~mm}$.) mesh model can be used to perform detailed crack analysis by comparing the cracks developed in the numerical model with experimental crack data.

8. The Concrete Damage Model Release 3 also required the $1 / 4$ in. $(6.53 \mathrm{~mm}$.) mesh model to generate the crack patterns developed on the slab. However it was not suitable in making comparison with the experimental results because of erosion of elements from the slab model.

9. The Winfrith Concrete Model provides better prediction of slab response to blast loading for both high-strength and normal-strength slabs, for two-different slabs reinforcement ratios based on the comparison of peak deflections in numerical model with the experimental results . 


\subsection{Future Scope of Work}

The future work that can be performed based on the conclusions obtained from this study are suggested in the following.

1. There is scope of improvement in using modified parameters in the Concrete Damage Model Release 3 to predict the response more close to experiment for normalstrength concrete.

2. Use of hourglass control needs to be studied in order to develop relation between its parameters and the strength of concrete used.

3. Pressure-impulse diagrams can be developed based on the experimental data available for single-mat slabs. 
Summary of Peak Pressures and Impulse for twelve RC slabs recorded at six

locations on each slab:

\begin{tabular}{|c|c|c|c|c|c|c|c|c|c|c|c|}
\hline Slab\#1 & $\begin{array}{l}\mathrm{P}+ \\
\text { (psi) }\end{array}$ & $\begin{array}{c}1+ \\
\text { (psi-msec) }\end{array}$ & Slab\#2 & $\begin{array}{l}\mathrm{P}+ \\
\text { (psi) }\end{array}$ & $\begin{array}{c}+ \\
\text { (psi-msec) }\end{array}$ & Slab\#3 & $\begin{array}{l}\mathrm{P}+ \\
\text { (psi) }\end{array}$ & $\begin{array}{c}+ \\
\text { (psi-msec) }\end{array}$ & Slab\#4 & $\begin{array}{l}\mathrm{P}+ \\
\text { (psi) }\end{array}$ & $\begin{array}{c}+ \\
\text { (psi-msec) }\end{array}$ \\
\hline $\mathrm{P} 1$ & 48.97 & 994.16 & $\mathrm{P} 1$ & 5255 & 97156 & $\mathrm{P} 1$ & 47.43 & 973.95 & P1 & 48.25 & 986.22 \\
\hline P2 & 54.72 & 114259 & $\mathrm{P} 2$ & 56.73 & 1089.44 & P2 & 5274 & 1140.11 & $\mathrm{P} 2$ & 54 & 1073.28 \\
\hline P3 & 5239 & 998.72 & P3 & 5172 & 97204 & P3 & 48.68 & 984.34 & P3 & 50.49 & 988.37 \\
\hline P4 & 53.1 & 966.49 & P4 & 53.3 & 889.41 & P4 & 48.55 & 923 & P4 & 55.83 & 1014.28 \\
\hline P5 & 53.48 & 978.36 & P5 & 5187 & 974.37 & P5 & 48.45 & 97128 & P5 & 521 & 974.33 \\
\hline P6 & 53.04 & 996.94 & P6 & 53.67 & 985.68 & P6 & 50.74 & 101177 & P6 & 5165 & 993.69 \\
\hline PD & 53.2 & 986.16 & PD & 49.98 & 967.83 & PD & 47.6 & 976.78 & PD & 49.58 & 99268 \\
\hline $\mathrm{PE}$ & 53.65 & 10428 & PE & 55 & 959 & PE & 50.02 & 999.73 & PE & 57.2 & 980.16 \\
\hline Sum & 42255 & 8106.22 & Sum & 424.82 & 7809.33 & Sum & 394.21 & 7980.96 & Sum & 419.1 & 8003.01 \\
\hline \multirow[t]{2}{*}{ Ang } & 5282 & 1013.28 & Ang & 53.10 & 976.17 & Ang & 49.28 & 997.62 & Ang & 5239 & 1000.38 \\
\hline & \begin{tabular}{|l|} 
Deflection \\
(in)
\end{tabular} & & & \begin{tabular}{|c|} 
Deflection \\
(in)
\end{tabular} & & & \begin{tabular}{|c|} 
Deflection \\
(in)
\end{tabular} & & & \begin{tabular}{|c|} 
Deflection \\
(in)
\end{tabular} & \\
\hline L1 & 3.89 & & L1 & 4.29 & & L1 & 4.53 & & L1 & 4.45 & \\
\hline \multirow[t]{2}{*}{ A1 } & 3.97 & & A1 & 5.37 & & \begin{tabular}{|l}
$\mathrm{A} 1$ \\
\end{tabular} & 4.69 & & A1 & NG & \\
\hline & Strain & & & Strain & & & Strain & & & Strain & \\
\hline S1 & & & S1 & & & S1 & & & S1 & & \\
\hline $\mathrm{S2}$ & & & S2 & & & S2 & & & S2 & & \\
\hline \multirow[b]{2}{*}{ Slab $\# 5$} & & & & & & & & & & & \\
\hline & $\begin{array}{l}\mathrm{P}+ \\
\text { (psi) }\end{array}$ & $\begin{array}{c}1+ \\
\text { (psi-msec) }\end{array}$ & Slab\#6 & $\begin{array}{l}\mathrm{P}+ \\
\text { (psi) }\end{array}$ & $\begin{array}{c}+ \\
\text { (psi-msec) }\end{array}$ & Slab\#7 & $\begin{array}{l}\mathrm{P}+ \\
\text { (psi) }\end{array}$ & $\begin{array}{c}+ \\
\text { (psi-msec) }\end{array}$ & Slab\#8 & $\begin{array}{l}\mathrm{P}+ \\
\text { (psi) }\end{array}$ & \begin{tabular}{c|}
+ \\
(psi-msec)
\end{tabular} \\
\hline $\mathrm{P} 1$ & 424 & 756.33 & $\mathrm{P} 1$ & 43.97 & 778.53 & $\mathrm{P} 1$ & 4189 & 755.87 & $\mathrm{P} 1$ & 3238 & 493.5 \\
\hline $\mathrm{P} 2$ & 44.62 & 805.45 & $\mathrm{P} 2$ & 43.63 & 789.51 & $\mathrm{P} 2$ & 45.87 & 743.29 & $\mathrm{P} 2$ & 3291 & 53202 \\
\hline P3 & 421 & 754.03 & P3 & 44.57 & 77282 & P3 & 44.92 & 757.07 & P3 & 35 & 494.99 \\
\hline P4 & 43.19 & 806.8 & P4 & 45.65 & 800.56 & P4 & 50.61 & 766.41 & P4 & 34.41 & 40128 \\
\hline P5 & 4105 & 744.67 & P5 & 43.19 & 77171 & P5 & 46.83 & 744.18 & P5 & 33.9 & 488.51 \\
\hline P6 & 4147 & 778.9 & P6 & 44.84 & 799.05 & P6 & 4218 & 753.33 & P6 & 34.32 & 534.79 \\
\hline PD & 39.81 & 758.61 & $\overline{P D}$ & 44.46 & 773.35 & PD & 40.22 & 749.39 & $\mathrm{PD}$ & 3173 & 498.04 \\
\hline $\mathrm{PE}$ & 4167 & 786.8 & PE & 43.28 & 797.28 & PE & 4287 & 76135 & $\mathrm{PE}$ & 3257 & 51195 \\
\hline Sum & 336.31 & 619159 & Sum & 353.59 & 628281 & Sum & 355.39 & 6030.89 & Sum & 267.22 & 3955.08 \\
\hline \multirow[t]{2}{*}{ Ang } & 4204 & 773.95 & Ang & 44.20 & 785.35 & Avg & 44.42 & 753.86 & Ang & 33.40 & 494.39 \\
\hline & \begin{tabular}{|c|} 
Deflection \\
(in)
\end{tabular} & & & \begin{tabular}{|c|} 
Deflection \\
(in)
\end{tabular} & & & \begin{tabular}{|c|} 
Deflection \\
(in)
\end{tabular} & & & \begin{tabular}{|c|} 
Deflection \\
(in)
\end{tabular} & \\
\hline L1 & 246 & & L1 & 3.17 & & L1 & 7.2 & & ப1 & 3.36 & \\
\hline \multirow[t]{2}{*}{ A1 } & NG & & A1 & NA & & A1 & \multicolumn{2}{|c|}{$5.44,7.28,8.61$} & A1 & 3.38 & \\
\hline & Strain & & & Strain & & & Strain & & & Strain & \\
\hline S1 & & & S1 & & & S1 & & & S1 & & \\
\hline S2 & & & $\mathrm{S} 2$ & & & $\$ 2$ & & & S2 & & \\
\hline \multirow[b]{2}{*}{ Slab\#9 } & $\mathrm{P}+$ & $1+$ & & $\mathrm{P}+$ & $\sqrt{1+}$ & \multirow[b]{2}{*}{ Slab\#11 } & $\mathrm{P}+$ & $1+$ & \multirow[b]{2}{*}{ Slab\#12 } & $\mathrm{P}+$ & $1+$ \\
\hline & (psi) & (psi-msec) & Slab\#10 & (psi) & (psi-msec) & & (psi) & (psi-msec) & & (psi) & (psi-msec) \\
\hline $\mathrm{P} 1$ & 3265 & 490.44 & $\mathrm{P} 1$ & 34.94 & 518.32 & $\mathrm{P} 1$ & 37.91 & 565.13 & $\mathrm{P} 1$ & 34.17 & 484.64 \\
\hline P2 & 35.09 & 553.94 & P2 & 36.43 & 549.86 & P2 & 37.18 & 57136 & P2 & 33.4 & 400.48 \\
\hline P3 & 36.25 & 49239 & P3 & 37 & 519.8 & P3 & 37.19 & 578.71 & P3 & 36.91 & 485.62 \\
\hline P4 & 35.69 & 535.85 & P4 & 34.94 & 58235 & $\mathrm{P} 4$ & 37.45 & 586.54 & P4 & 326 & 59256 \\
\hline P5 & 3234 & 488.46 & P5 & 33.4 & 51101 & P5 & 37.47 & 569.86 & P5 & 33.43 & 499.28 \\
\hline P6 & 33.69 & 515.66 & P6 & 33.94 & 615.82 & P6 & 37.76 & 58216 & P6 & 3224 & 558.79 \\
\hline PD & 33.81 & 50171 & PD & 33.24 & 529.24 & PD & 35.79 & 57133 & PD & 3273 & 519.73 \\
\hline $\mathrm{PE}$ & 3257 & 515.72 & PE & 34.37 & 569.58 & PE & 35.65 & 583.47 & PE & 34.4 & 531 \\
\hline Sum & 27209 & 4094.17 & Sum & 278.26 & 4395.98 & Sum & 296.4 & 4608.56 & Sum & 269.88 & 40721 \\
\hline \multirow[t]{2}{*}{ Ang } & 34.01 & 51177 & Ang & 34.78 & 549.50 & Ang & 37.05 & 576.07 & Ang & 33.74 & 509.01 \\
\hline & Deflection & & & Deflection & & & Deflection & & & Deflection & \\
\hline L1 & (In) & & $\square$ & (in) & & & $\frac{(\text { in) }}{3.38}$ & & & (in) & \\
\hline \multirow[t]{2}{*}{ A1 } & \multicolumn{2}{|c|}{$178,3.57$} & \begin{tabular}{|l} 
A1 \\
\end{tabular} & 3.75 & & \begin{tabular}{|l} 
A1 \\
\end{tabular} & 3.96 & & \begin{tabular}{|l|} 
A1 \\
.
\end{tabular} & \multicolumn{2}{|c|}{212,285} \\
\hline & Strain & & & Strain & & & Strain & & & Strain & \\
\hline S1 & & & S1 & & & S1 & & & S1 & & \\
\hline $\mathrm{S} 2$ & & & $\mathrm{~S} 2$ & & & s2 & & & S2 & & \\
\hline
\end{tabular}




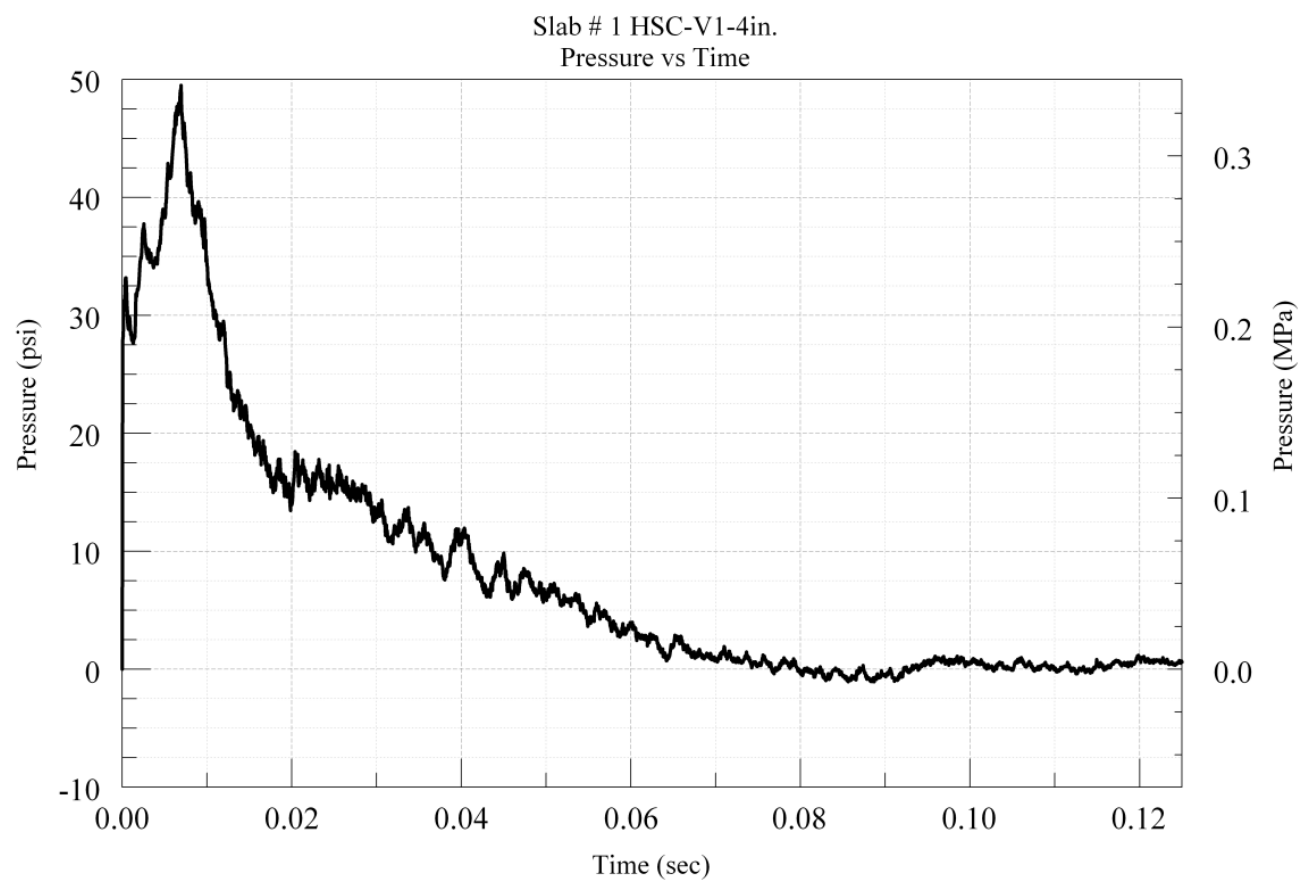

Figure B-1 : Average Pressure-time History for Slab \# 1.

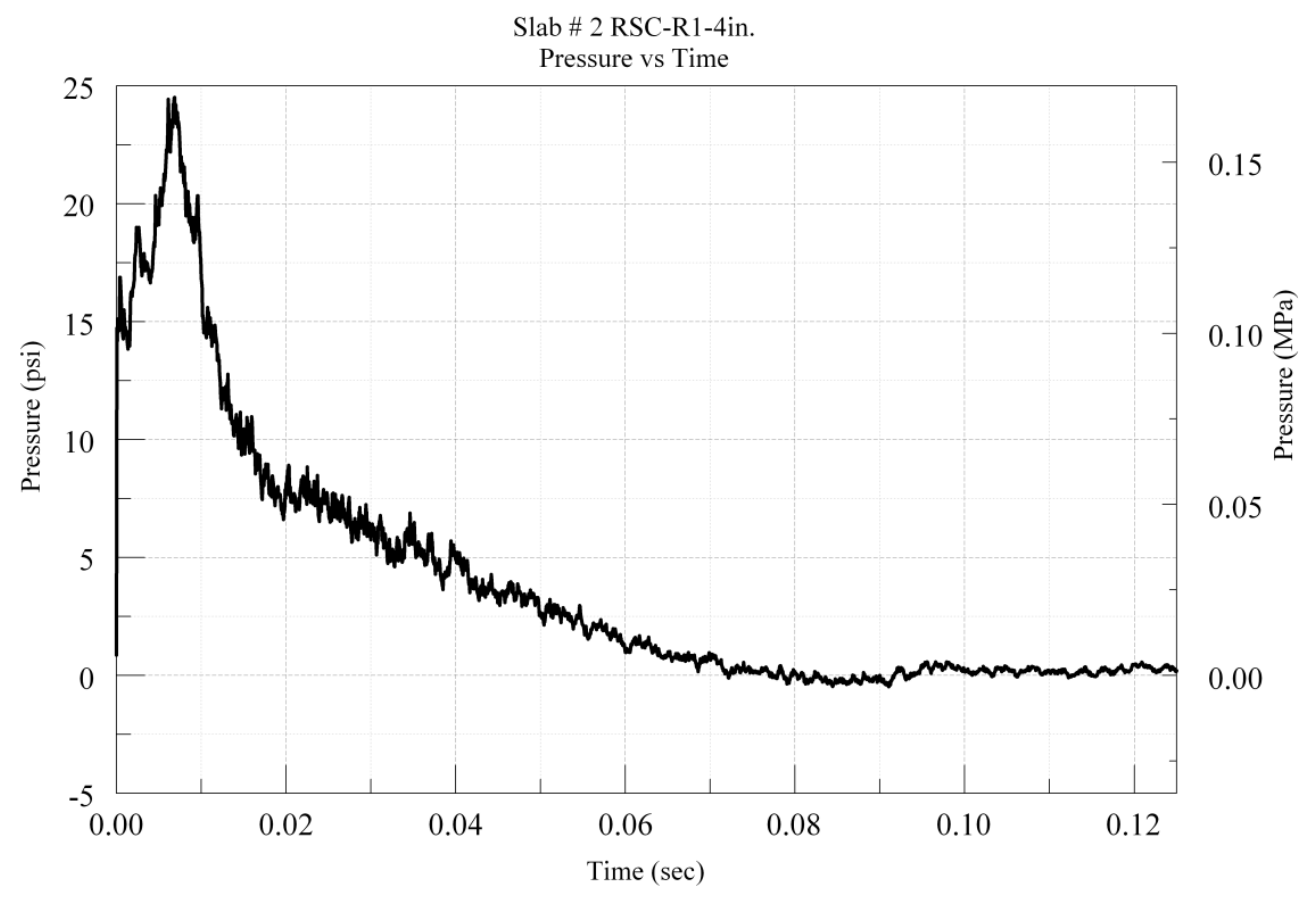

Figure B-2: Average Pressure-time History for Slab \# 2. 


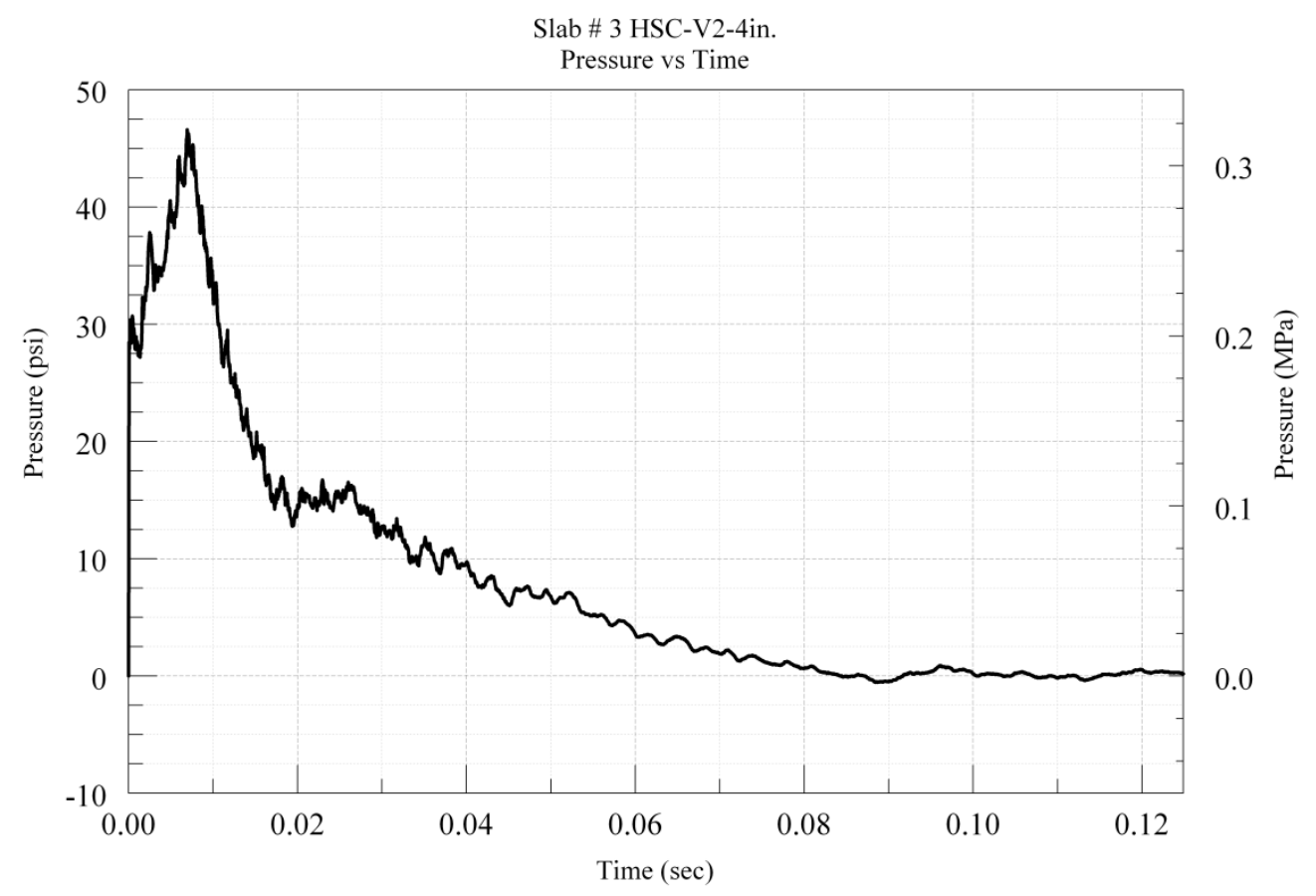

Figure B-3: Average Pressure-time History for Slab \# 3.

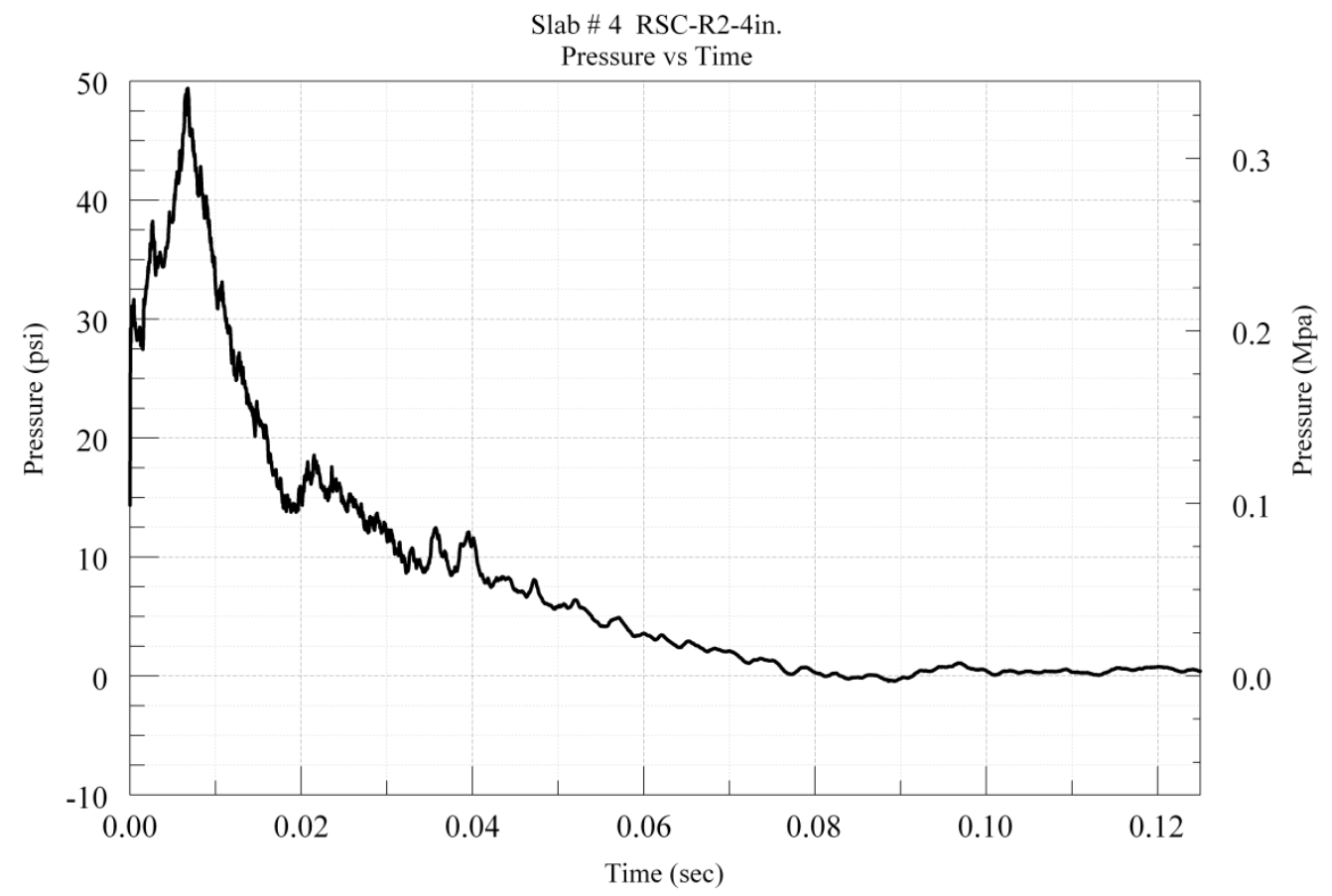

Figure B-4: Average Pressure-time History for Slab \# 4. 


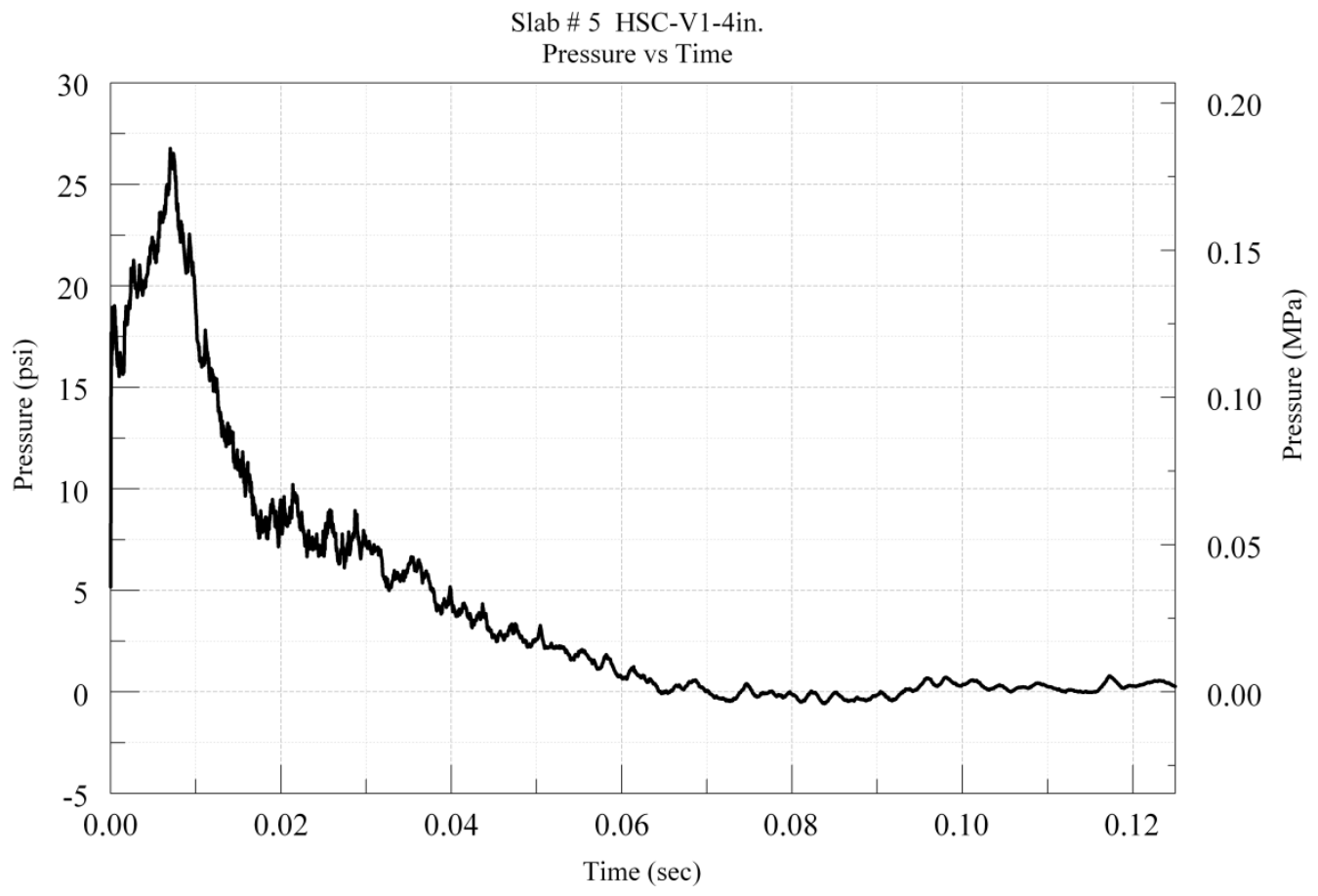

Figure B-5: Average Pressure-time History for Slab \# 5.

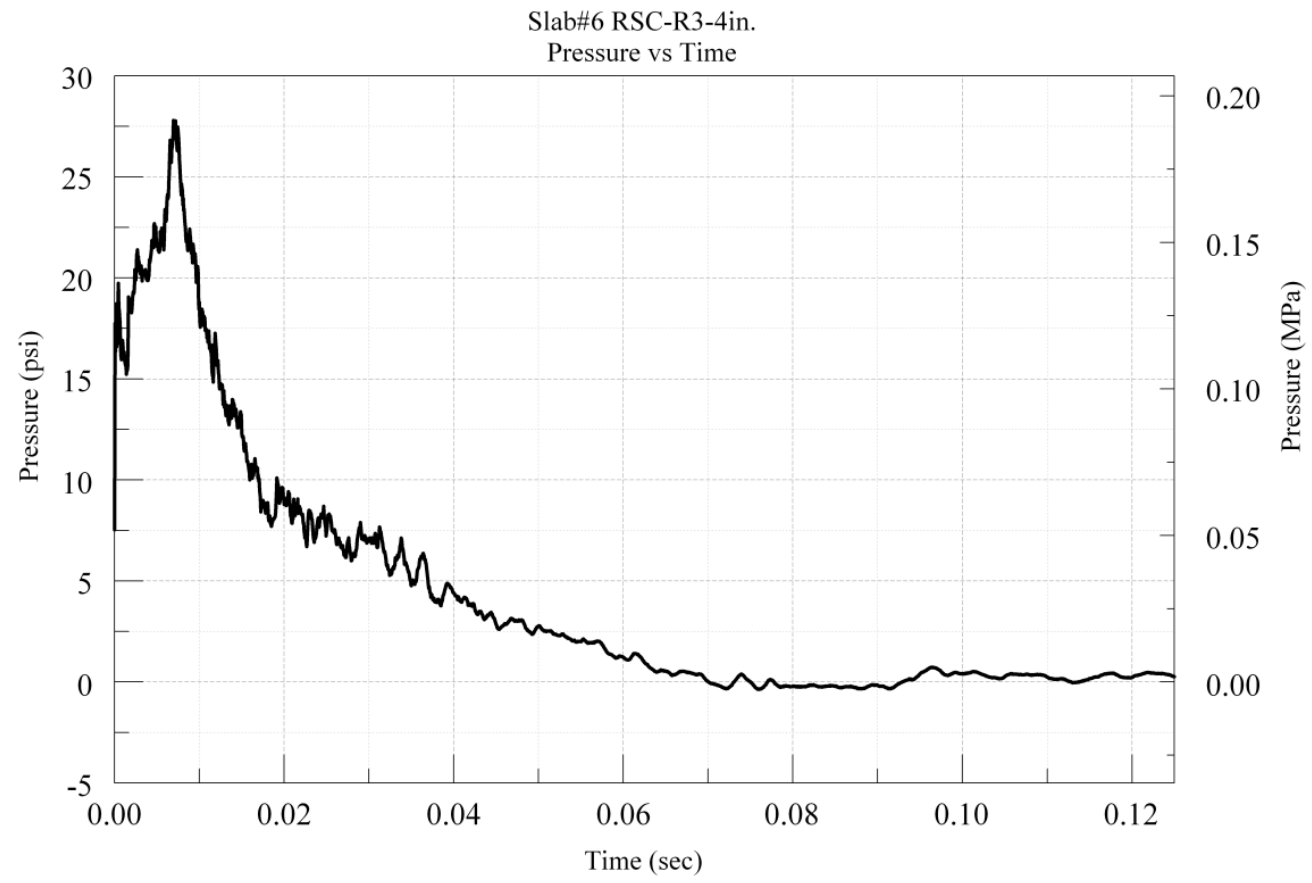

Figure B-6: Average Pressure-time History for Slab \# 6. 


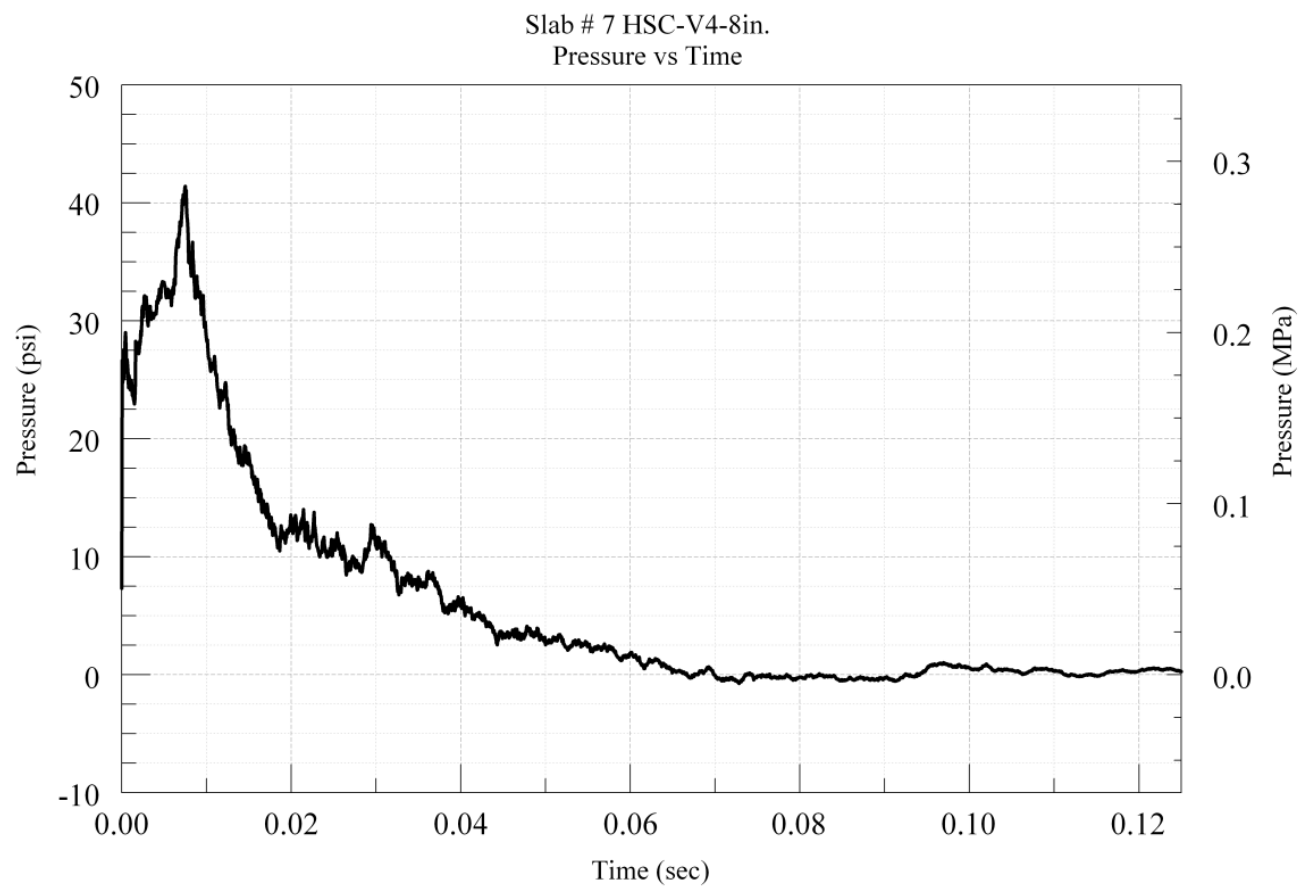

Figure B-7: Average Pressure-time History for Slab \# 7.

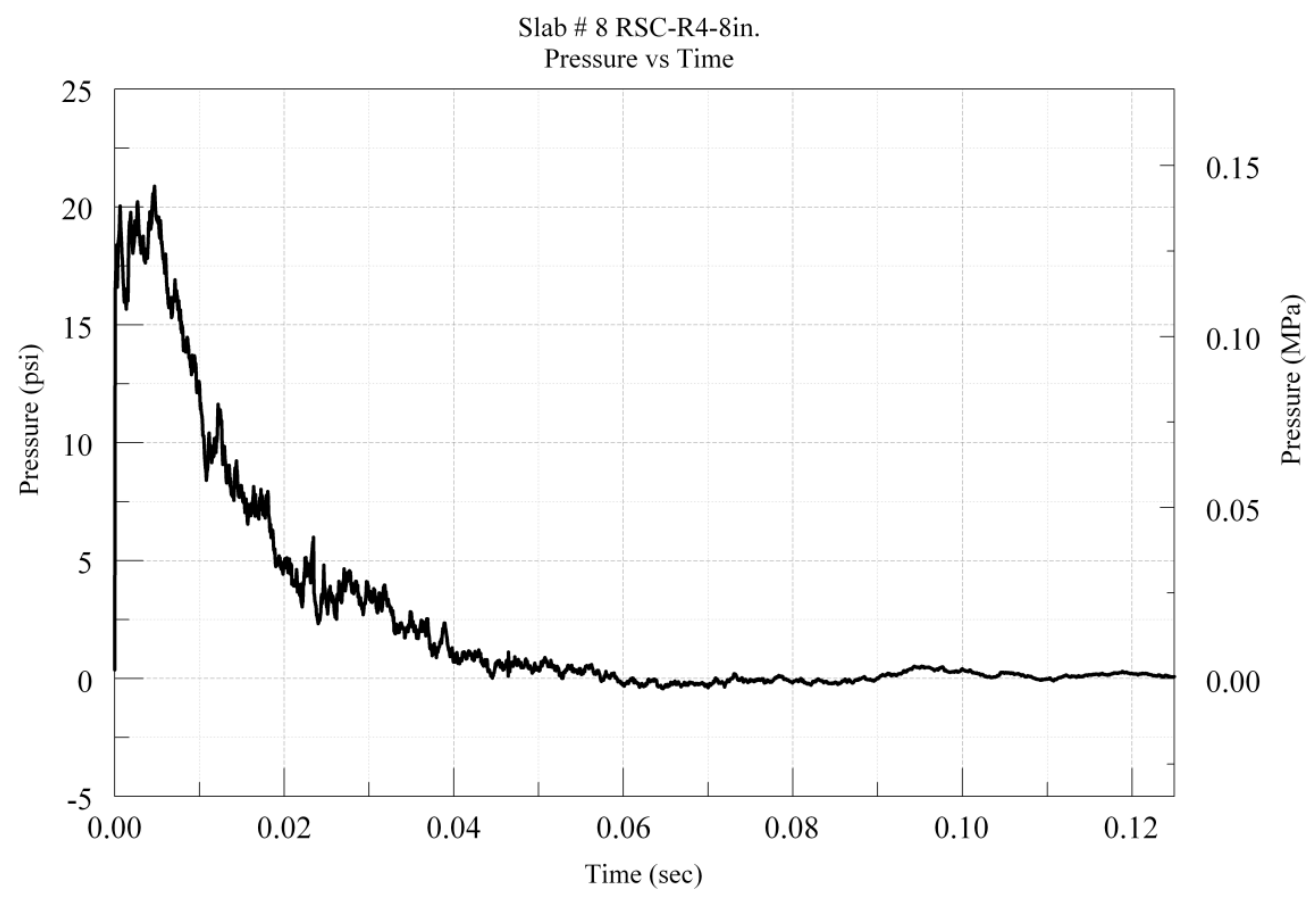

Figure B-8: Average Pressure-time History for Slab \# 8. 


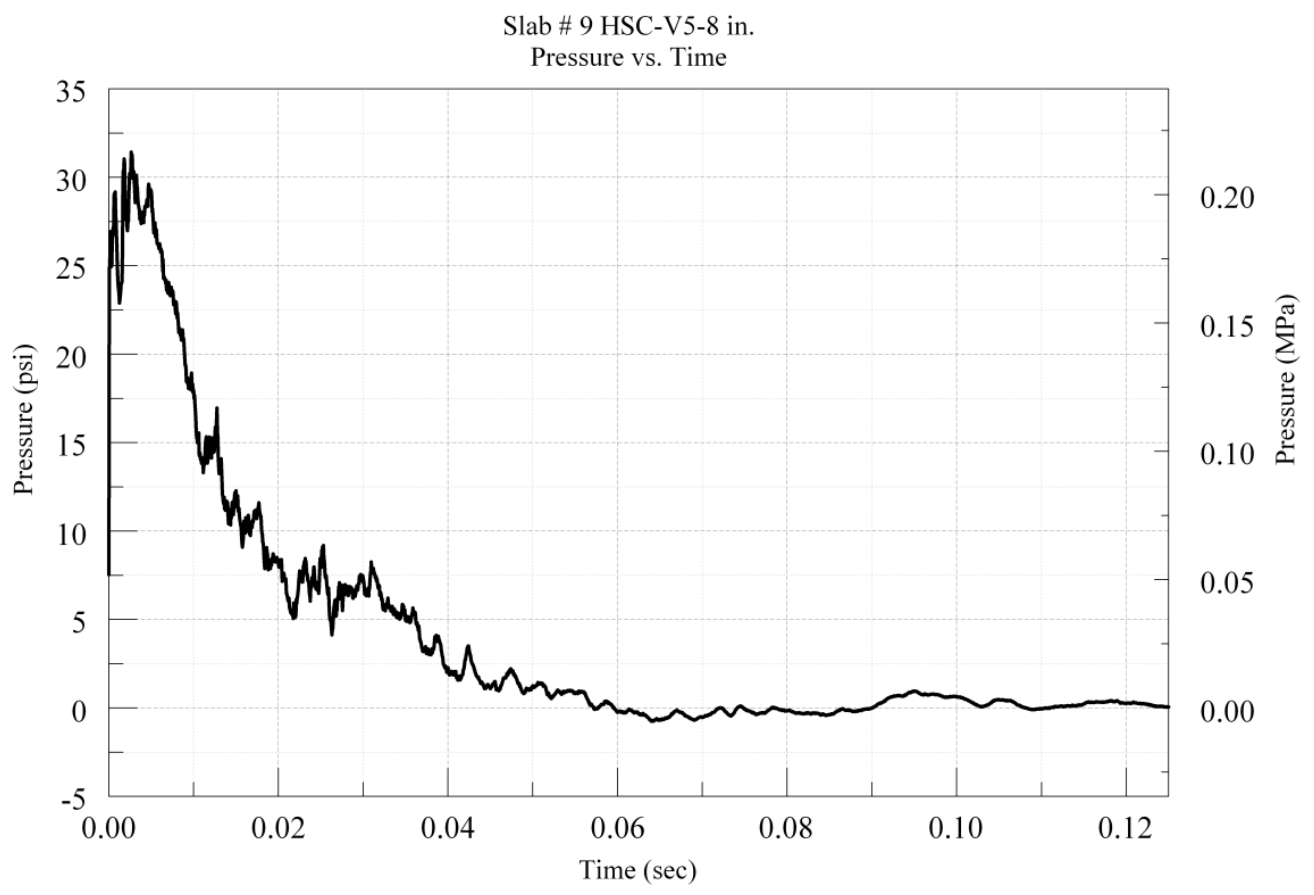

Figure B-9: Average Pressure-time History for Slab \# 9.

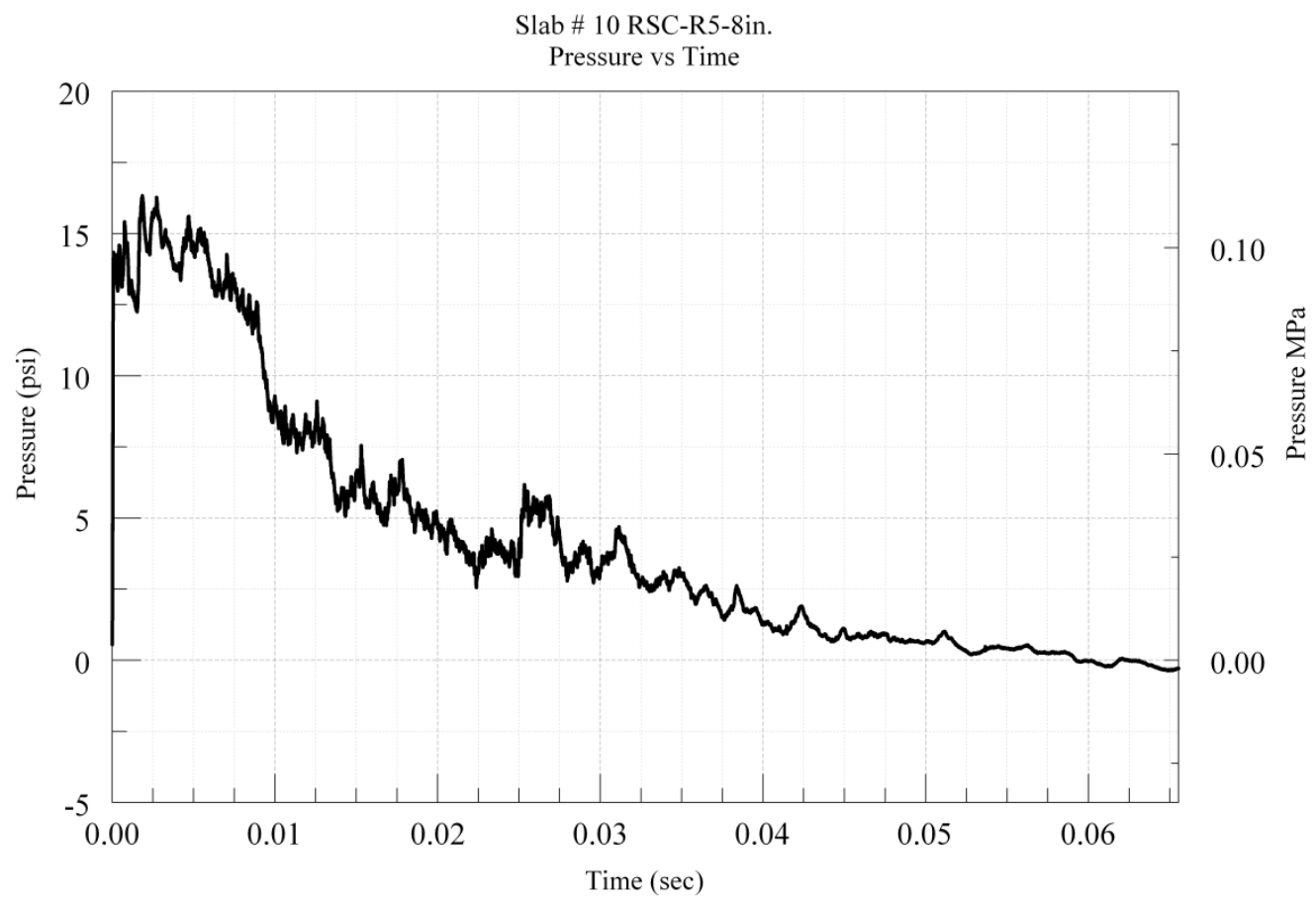

Figure B-10: Average Pressure-time History for Slab \# 10. 


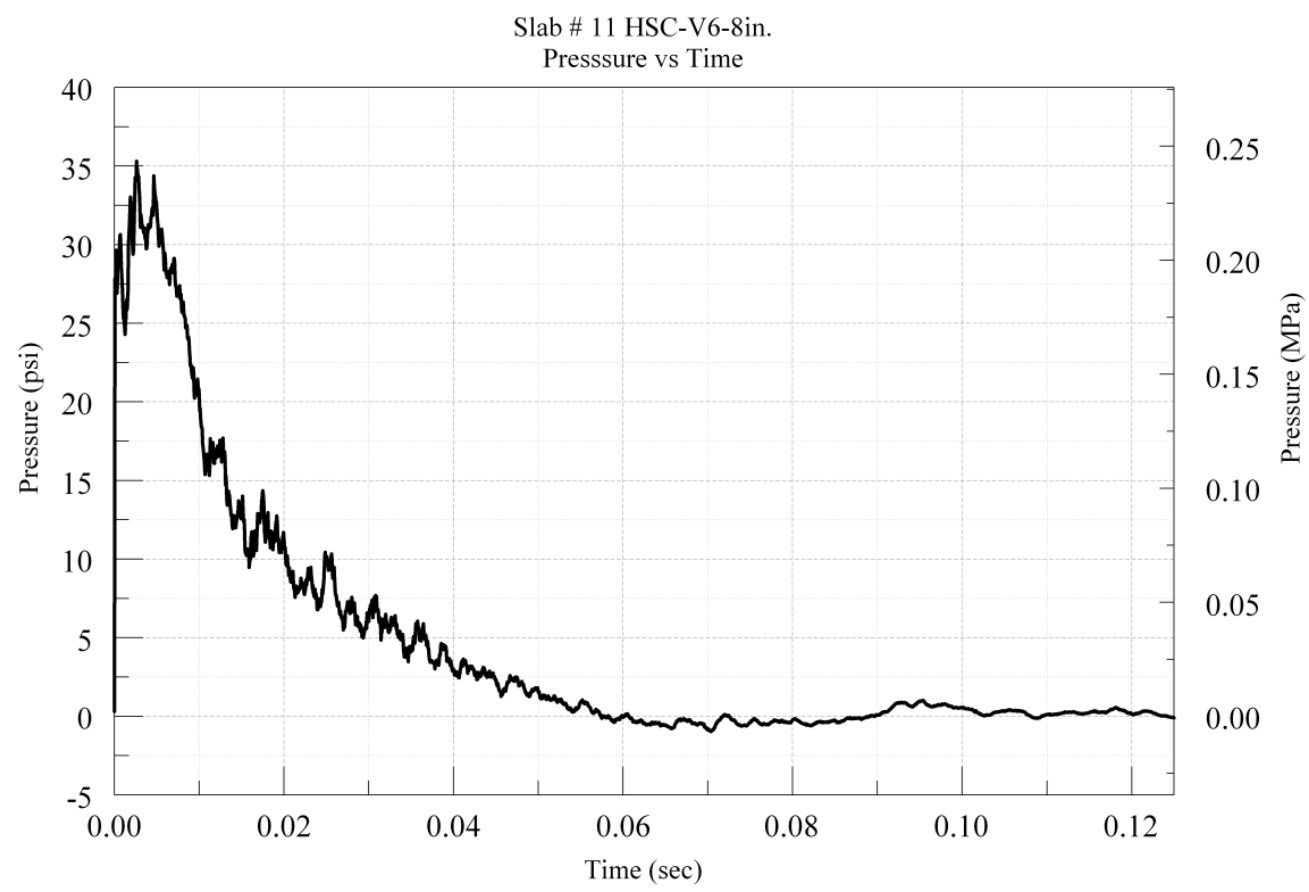

Figure B-11: Average Pressure-time History for Slab \# 11.

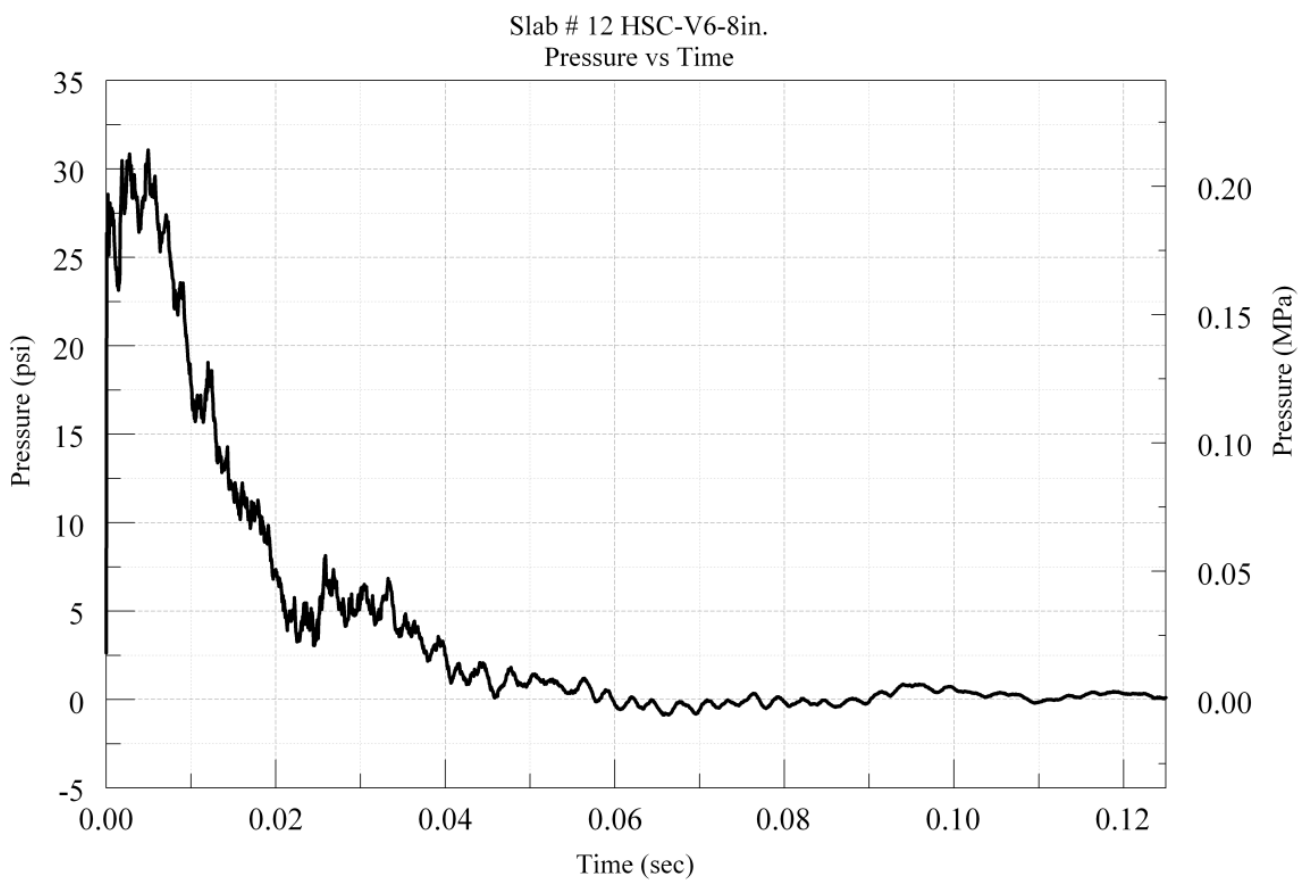

Figure B-12: Average Pressure-time History for Slab \# 12. 


\section{APPENDIX C - SUMMARY TABLES}

Table C-1: Input Parameters for Winfrith Concrete Model

\begin{tabular}{|c|c|c|c|}
\hline Variable & Description & $\begin{array}{l}\text { Input value for } \\
\text { High strength } \\
\text { concrete }\end{array}$ & $\begin{array}{l}\text { Input value for } \\
\text { Normal strength } \\
\text { concrete }\end{array}$ \\
\hline RO & Mass Density & $2.246 \mathrm{E}-04 \mathrm{lb}-\mathrm{s} / \mathrm{in}^{3}$ & $2.246 \mathrm{E}-04 \mathrm{lb}-\mathrm{s} / \mathrm{in}^{3}$ \\
\hline TM & Initial Tangent Modulus of Concrete & $3.6 \mathrm{E}+06 \mathrm{psi}$ & $3.6 \mathrm{E}+06 \mathrm{psi}$ \\
\hline PR & Poisson's Ratio & 0.18 & 0.18 \\
\hline UCS & Uniaxial Compressive Strength & $11600 \mathrm{psi}$ & $5000 \mathrm{psi}$ \\
\hline UTS & Uniaxial Tensile Strength & $928 \mathrm{psi}$ & $460 \mathrm{psi}$ \\
\hline FE & Fracture Energy/Crack Width & 0.0002 & 0.0002 \\
\hline ASIZE & Aggregate Size (radius) & $0.125 \mathrm{in}$. & $0.125 \mathrm{in}$. \\
\hline $\mathbf{E}$ & Young's modulus of rebar & Default & Default \\
\hline YS & Yield stress of rebar & Default & Default \\
\hline EH & Hardening modulus of rebar & Default & Default \\
\hline UELONG & Ultimate elongation before rebar fails & Default & Default \\
\hline RATE & Rate effects & 1 & 1 \\
\hline CONM & $\begin{array}{l}\text { Factor to convert model mass units to } \\
\mathrm{Kg}\end{array}$ & -1 & -1 \\
\hline CONL & $\begin{array}{l}\text { Factors to convert model length units to } \\
\text { meters }\end{array}$ & 0.0254 & 0.0254 \\
\hline CONT & $\begin{array}{l}\text { Factors to convert model length units to } \\
\text { meters }\end{array}$ & 1 & 1 \\
\hline EPS1,.. & Volumetric Strain Values & Default & Default \\
\hline P1, P2,.. & $\begin{array}{l}\text { Pressures corresponding to volumetric } \\
\text { strain values }\end{array}$ & Default & Default \\
\hline
\end{tabular}


Table C-2: Input parameters for Concrete Damage Model Release 3

\begin{tabular}{|c|c|c|c|}
\hline Variable & Description & $\begin{array}{l}\text { Input value for } \\
\text { High strength } \\
\text { concrete }\end{array}$ & $\begin{array}{l}\text { Input value for } \\
\text { Normal strength } \\
\text { concrete }\end{array}$ \\
\hline RHO & Mass Density & $2.24 \mathrm{E}-04 \mathrm{lb}-\mathrm{s} / \mathrm{in}^{3}$ & $2.24 \mathrm{E}-04 \mathrm{lb}-\mathrm{s} / \mathrm{in}^{3}$ \\
\hline PR & Poisson's Ratio & 0.18 & 0.18 \\
\hline FT & Uniaxial Tensile Strength & 928 psi & 462psi \\
\hline A0/-fc' & Uniaxial Compressive Strength & 4700 & 3200 \\
\hline A1 & Maximum shear surface parameter & 0.55 & 0.60 \\
\hline $\mathbf{A} 2$ & Maximum shear failure parameter & 0.0000082 & 0.00000152 \\
\hline B1 & Damage Scaling Parameter & 1.6 & 1.6 \\
\hline OMEGA & Fractional dilatancy & 0.5 & 0.5 \\
\hline A1F & Residual Failure Coefficient & 0.4417 & 0.4417 \\
\hline $\mathbf{S} \boldsymbol{\lambda}$ & Stretch factor & 100 & 100 \\
\hline NOUT & $\begin{array}{l}\text { Output selector for effective plastic } \\
\text { strain }\end{array}$ & 2 & 2 \\
\hline RSIZE & Unit Conversion factor for length & 1 & 1 \\
\hline UCF & Unit Conversion factor for stress & 1 & 1 \\
\hline LCRATE & Load Curve for strain rate effects & 0 & 0 \\
\hline LOCWID & Maximum aggregate diameter & 1 & 1 \\
\hline$\lambda 01-\lambda 13$ & Damage Functions & default & default \\
\hline B3 & $\begin{array}{l}\text { Damage scaling coefficient for tri- } \\
\text { axial tension }\end{array}$ & 1.15 & 1.15 \\
\hline AOY & Initial yield surface cohesion & 3460 & 1500 \\
\hline A1Y & Initial yield surface coefficient & 0.625 & 0.625 \\
\hline$\eta 01-\eta 13$ & Scale factor & default & default \\
\hline B2 & Tensile Damage scaling coefficient & 1.35 & 1.35 \\
\hline $\mathbf{A} 2 \mathbf{F}$ & Residual failure surface coefficient & 0.00000763 & 0.0000177 \\
\hline A2Y & Initial yield surface coefficient & 0.0000166 & 0.0000384 \\
\hline
\end{tabular}

Table C-3: Input Parameters for Plastic Kinematic Model for Steel Rebar

\begin{tabular}{llll}
\hline Variable & Description & $\begin{array}{l}\text { Input value for } \\
\text { High strength steel }\end{array}$ & $\begin{array}{l}\text { Input value for } \\
\text { Normal strength } \\
\text { steel }\end{array}$ \\
\hline RO & Mass Density & $7.30 \mathrm{E}-04 \mathrm{lb}-\mathrm{s} / \mathrm{in}^{3}$ & $7.30 \mathrm{E}-04 \mathrm{lb}-\mathrm{s} / \mathrm{in}^{3}$ \\
\hline E & Young's Modulus of Rebar & $2.90 \mathrm{E}+07 \mathrm{psi}$ & $2.90 \mathrm{E}+07 \mathrm{psi}$ \\
PR & Poisson's Ratio & $3.00 \mathrm{E}-01 \mathrm{psi}$ & $3.00 \mathrm{E}-01 \mathrm{psi}$ \\
SIGY & Yield strength of Rebar & $83000 \mathrm{psi}$ & $60000 \mathrm{psi}$ \\
ETAN & Tangent Modulus & Default & Default \\
BETA & Hardening Parameter & Default & Default \\
SRC & Strain Rate Parameter & Default & Default \\
SRP & Strain Rate Parameter & Default & Default \\
FS & Failure Strain for Eroding Elements & Default & Default \\
\hline
\end{tabular}




\section{APPENDIX D - LS-DYNA INPUT}

\begin{tabular}{|c|c|c|c|c|c|c|c|}
\hline \multicolumn{8}{|c|}{$\begin{array}{l}\text { \$\# LS-DYNA Keyword file created by LS-PREPOST } 3.0-30 \text { May2010 } \\
\text { \$\# Created on Jul-25-2012 (11:21:13) } \\
\text { "KEYWORD }\end{array}$} \\
\hline *TITLE & & & & & & & \\
\hline \multicolumn{8}{|l|}{ \$\# title } \\
\hline \multicolumn{8}{|c|}{$\begin{array}{l}\text { LS-DYNA keyword deck by LS-Prepost } \\
\text { "CONTROL ACCURACY }\end{array}$} \\
\hline \multicolumn{8}{|c|}{$\$$ cleaned up (eliminated unused commands, parts) } \\
\hline \multicolumn{5}{|c|}{$\begin{array}{l}\text { \$ cleaned up (eliminated unused commands, parts) } \\
\text { \$\# osu inn pidosu }\end{array}$} & & & \\
\hline 1 & 0 & 0 & & & & & \\
\hline \multicolumn{5}{|c|}{${ }^{*}$ CONTROL_ENERGY } & \\
\hline \multicolumn{8}{|c|}{ \$\# hgen rwen } \\
\hline 2 & 2 & 2 & 2 & & & & \\
\hline \multicolumn{8}{|c|}{ *CONTROL_HOURGLASS } \\
\hline$\$$ & 0.0 & & & & & & \\
\hline \multicolumn{8}{|c|}{ inq } \\
\hline \multirow{2}{*}{\multicolumn{8}{|c|}{ *CONTROL TERMINATION }} \\
\hline & & & & & & & \\
\hline$\$ \#$ endtim & endeyc & dtmin & endeng & endmas & & & \\
\hline & 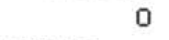 & 0.000 & 0.000 & 0.000 & & & \\
\hline \multicolumn{8}{|c|}{${ }^{*}$ CONTROL_TIMESTEP } \\
\hline$\overline{0} .0$ & 0.0 & 0 & 0.0 & 0.0 & & & \\
\hline$\$ \#$ dtinit & tssfac & isdo & tslimt & dt $2 m s$ & letm & erode & ms1st \\
\hline 0.000 & 0.600000 & 0 & 0.000 & 0.000 & 0 & 0 & 0 \\
\hline \$\# dt2msf & dt $2 \mathrm{mslc}$ & imscl 1 & & & & & \\
\hline 0.000 & 0 & 0 & & & & & \\
\hline \multicolumn{8}{|c|}{ "DATABASE_BNDOUT } \\
\hline$d \bar{t}$ & binary & leur & ioopt & & & & \\
\hline 0.001000 & 0 & 0 & 1 & & & & \\
\hline \multicolumn{8}{|c|}{ "DATABASE_GLSTAT } \\
\hline$d \bar{t}$ & binary & leur & ioopt & & & & \\
\hline & 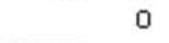 & 0 & 1 & & & & \\
\hline \multicolumn{8}{|c|}{ "DATABASE_MATSUM } \\
\hline$d \bar{t}$ & binary & leur & ioopt & & & & \\
\hline 0.001000 & 0 & 0 & 1 & & & & \\
\hline \multicolumn{8}{|c|}{ "DATABASE_BINARY_D3PLOT } \\
\hline$d \bar{t}$ & $\bar{l} c d t$ & beam & npltc & psetid & & & \\
\hline $5.0000 E-4$ & 0 & 0 & 0 & 0 & & & \\
\hline \multicolumn{8}{|l|}{$\$ \#$ ioopt } \\
\hline \multicolumn{8}{|l|}{0} \\
\hline \multicolumn{8}{|c|}{ "DATABASE_BINARY_D3 THDT } \\
\hline$d \bar{t}$ & $\bar{l} c d t$ & beam & npltc & psetid & & & \\
\hline 0.004000 & 0 & 0 & 0 & 0 & & & \\
\hline "DATABASE_F & XTENT_BINA & & & & & & \\
\hline \$\# neip $\bar{h}$ & nēips & $\operatorname{maxint}$ & strflg & sigflg & epsflg & rltflg & engflg \\
\hline 0 & 0 & 0 & 1 & 0 & 0 & 0 & 0 \\
\hline \$\# cmpflg & ieverp & beamip & deomp & shge & stssz & n3thdt & ialemat \\
\hline 0 & 0 & 1 & 0 & 0 & 0 & 0 & 0 \\
\hline \$\# nintsld & pkp_sen & $\operatorname{sclp}$ & unused & mssc 1 & therm & iniout & iniout \\
\hline 0 & 0 & 1.000000 & 0 & 0 & os & Ess & RESS \\
\hline
\end{tabular}

Figure D-1: Input and Output Control Parameters 


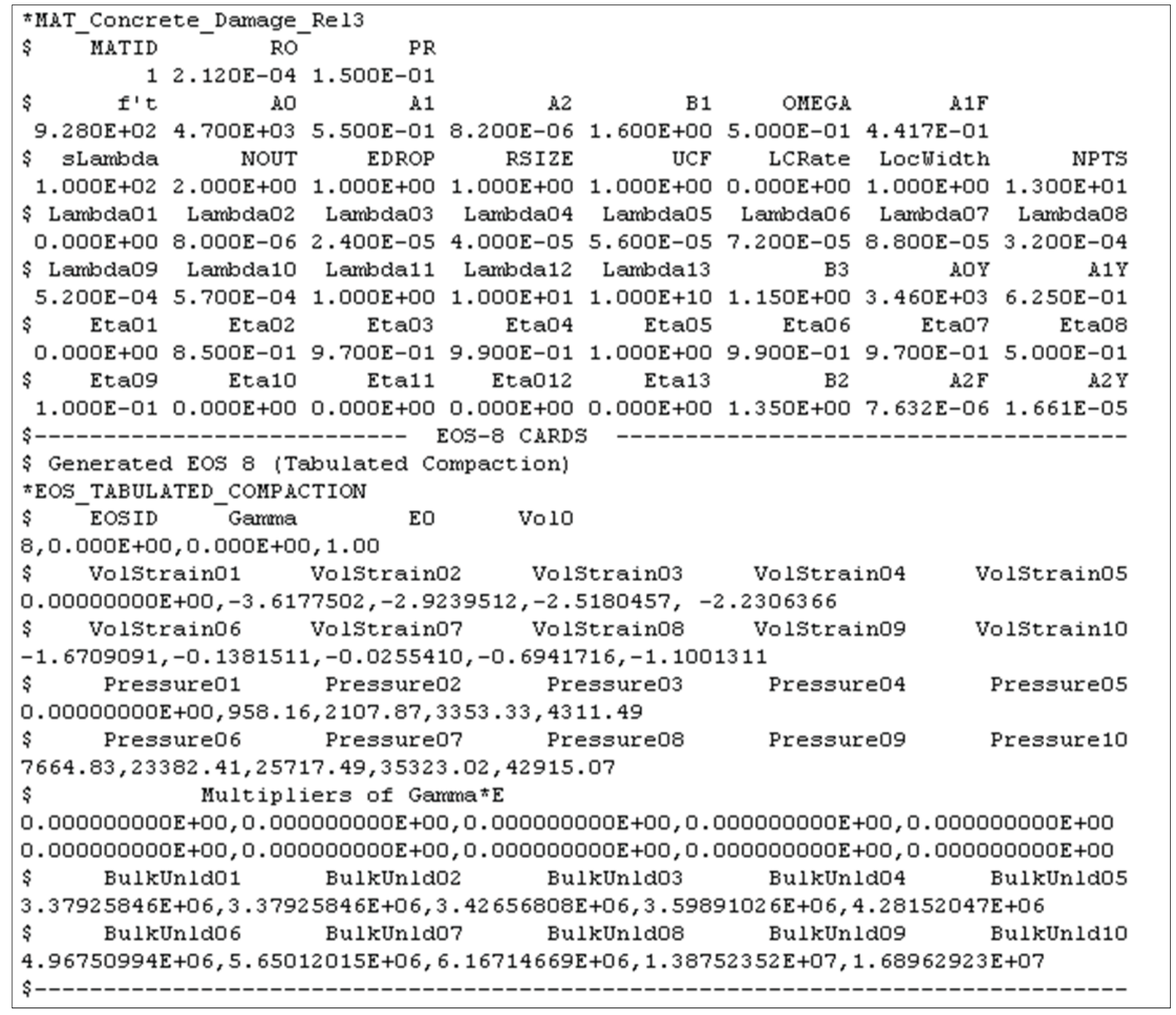

Figure D-2: Input Parameters for Concrete Damage Model Release 3 for HighStrength Concrete 


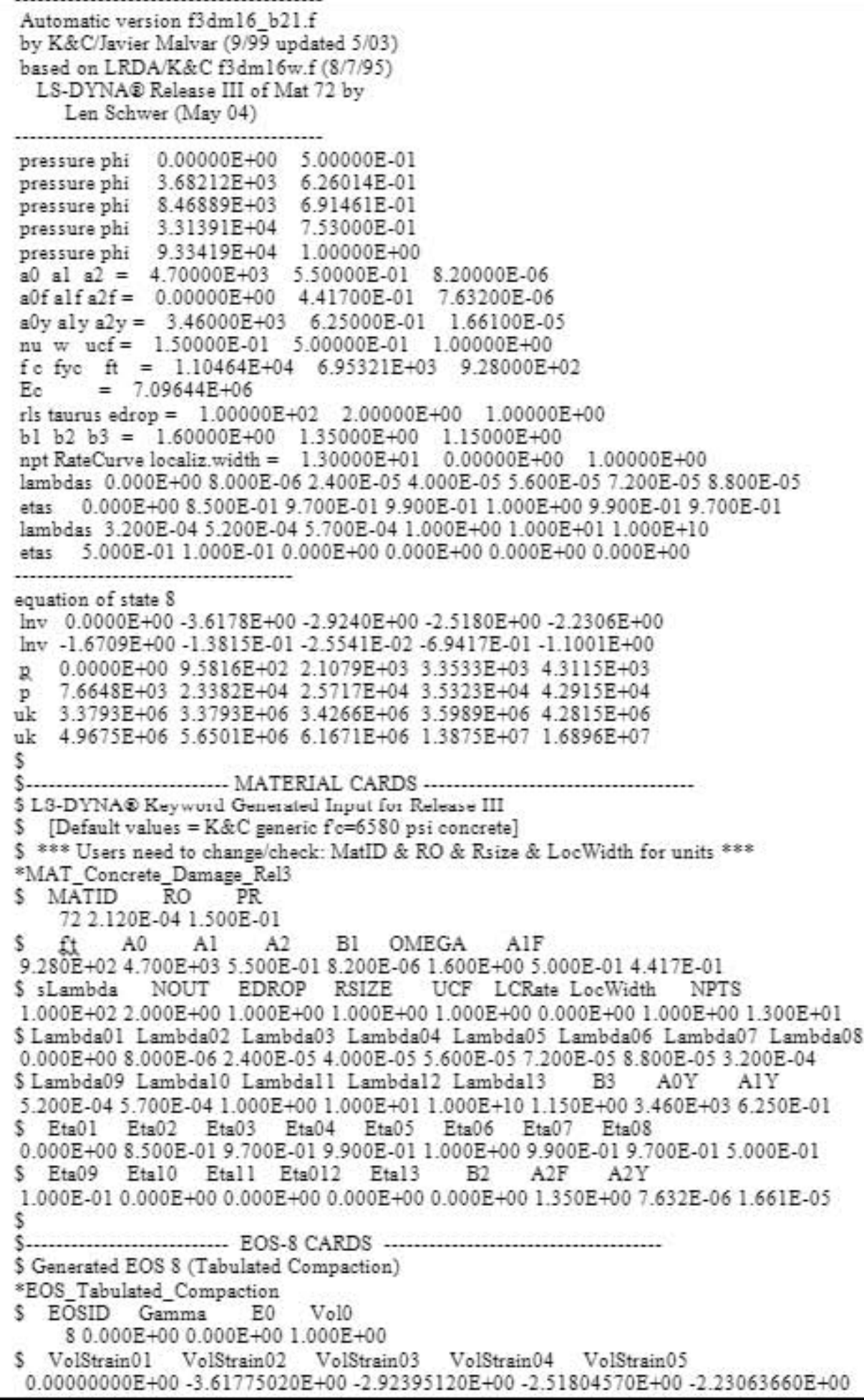

$\$$ VolStrain01 VolStrain02 VolStrain03 VolStrain04 VolStrain05 $0.00000000 \mathrm{E}+00-3.61775020 \mathrm{E}+00-2.92395120 \mathrm{E}+00-2.51804570 \mathrm{E}+00-2.23063660 \mathrm{E}+00$

Figure D-3: Input Parameters Generated by Concrete Damage Model Release 3 for High- Strength Concrete. 


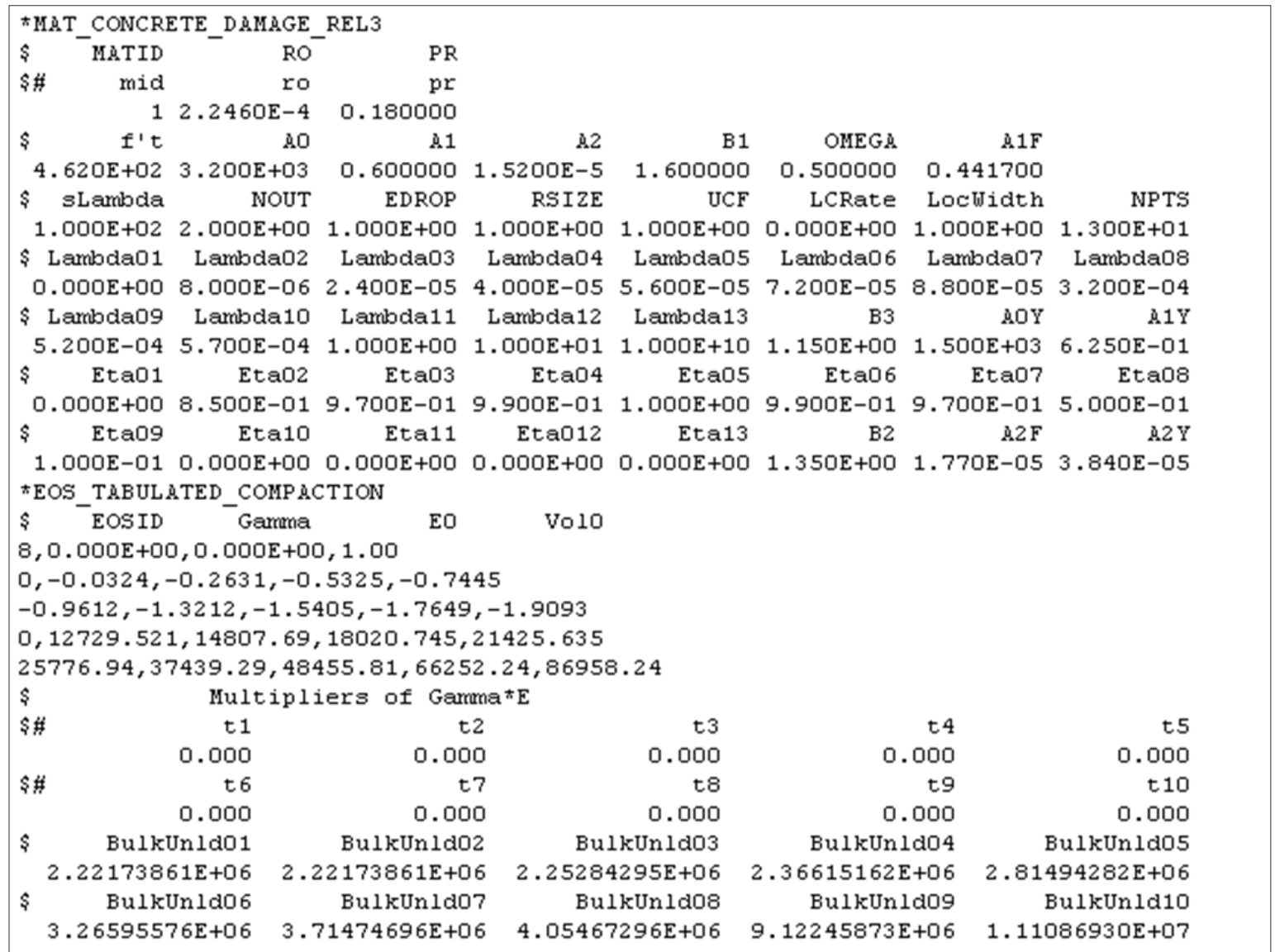

Figure D-4: Input Parameters for Concrete Damage Model Release 3for NormalStrength Concrete 
Automatic version fidm 16 b21.f

by K\&C/Javier Malvar (9/99 upcated 5/03)

based on LRDA K\&C f3dml6w f $(8 / 7 / 95)$

LS-DYNA Release III of Mat 72 by

Len Schwer (May 04)

pressure phi $\quad 0.00000 \mathrm{E}-00 \quad 5.00000 \mathrm{E}-01$

prasure phi $2.23333 \mathrm{E}-03 \quad 6.25716 \mathrm{E}-01$

prasqure phi $5.13667 \mathrm{E}-03 \quad 6.37453 \mathrm{E}-01$

preasure phi $2.01000 \mathrm{E}-04 \quad 7.53000 \mathrm{E}-01$

pressure phi $5.66150 \mathrm{E}-04 \quad 1.00000 \mathrm{E}-00$

aQ al a2 $=1.98052 \mathrm{E}-03 \quad 4.46300 \mathrm{E}-01 \quad 1.20597 \mathrm{E}-05$

a f alf $\mathrm{a} \mathrm{f}=0.00000 \mathrm{E}-00 \quad 4.41700 \mathrm{E}-01 \quad 1.76567 \mathrm{E}-05$

a0y aly a2y $=1.49544 \mathrm{E}-03 \quad 6.25000 \mathrm{E}-01 \quad 3.84328 \mathrm{E}-05$

phis ucf $=1.50000 \mathrm{E}-01 \quad 5.00000 \mathrm{E}-01 \quad 1.00000 \mathrm{E}-00$

$f C$ fyc $f$ t $=6.70000 \mathrm{E}-03 \quad 3.00522 \mathrm{E}-03 \quad 5.61531 \mathrm{E}-02$

$\mathrm{Ec} \quad=4.66565 \mathrm{E}-06$

If taurus edrop $=1.00000 \mathrm{E}+02 \quad 2.00000 \mathrm{E}-00 \quad 1.00000 \mathrm{E}-00$

$b_{1} b_{2} b_{3}=1.60000 \mathrm{E}-00 \quad 1.35000 \mathrm{E}-00 \quad 1.15000 \mathrm{E}-00$

Int. RateCurve localiz. width $=1.30000 \mathrm{E}-01 \quad 0.00000 \mathrm{E}-00 \quad 1.00000 \mathrm{E}-00$

lambdas, $0.000 \mathrm{E}-00 \quad 8.000 \mathrm{E}-062.400 \mathrm{E}-05$ 4.000E-05 5.600E-05 7.200E-05 8.800E-05

etai $0.000 \mathrm{E}-008.500 \mathrm{E}-019.700 \mathrm{E}-019.900 \mathrm{E}-011.000 \mathrm{E}-009.900 \mathrm{E}-019.700 \mathrm{E}-01$

lambdas.3.200E-04 5.200E-045.700E-04 1.000E-00 1.000E-01 1.000E-10

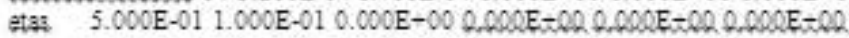

equation of state 8

Inv $0.0000 \mathrm{E}-00-1.5000 \mathrm{E}-03-4.3000 \mathrm{E}-03-1.0100 \mathrm{E}-02-3.0500 \mathrm{E}-02$

lnX $-5.1300 \mathrm{E}-02-7.2600 \mathrm{E}-02-9.4300 \mathrm{E}-02-1.7400 \mathrm{E}-01-2.0800 \mathrm{E}-01$

R. $0.0000 \mathrm{E}-00 \quad 3.3326 \mathrm{E}-03 \quad 7.2651 \mathrm{E}-03 \quad 1.1664 \mathrm{E}-04 \quad 2.2162 \mathrm{E}-04$

p $3.3426 \mathrm{E}-04 \quad 4.7423 \mathrm{E}-047.2551 \mathrm{E}-04 \quad 4.2357 \mathrm{E}-05 \quad 6.4786 \mathrm{E}-0.5$

th $2.2217 \mathrm{E}-06 \quad 2.2212 \mathrm{E}-0.062 .2528 \mathrm{E}-06 \quad 2.3662 \mathrm{E}-06 \quad 2.8149 \mathrm{E}-06$

15: $3.2660 \mathrm{E}-06 \quad 3.7147 \mathrm{E}-06 \quad+.0547 \mathrm{E}-06 \quad 9.1225 \mathrm{E}-06 \quad 1.1109 \mathrm{E}-07$

SOATERIAL CARDS

S LS-DYNA Keyword Generated Inyut for Release III

5 Default values $=\mathrm{K} \& \mathrm{C}$ generic $\mathrm{f} \mathrm{c}=6580 \mathrm{psi}$ concrete]

5. *4* Users nead to change check: MatID \& RO \& Raize \& LocWidth for units *4*

"MAT_Concrete_Damage_Rel3

5 MATID RO PR.

$722.120 \mathrm{E}-04$ 1.500E-01

5 ft $\mathrm{AO} A 1$ A2 BI OMEGA AIF

$5.615 \mathrm{E}-021.981 \mathrm{E}-03$ 4.463E-01 $1.206 \mathrm{E}-05$ 1.600E-00 5.000E-01 4.417E-01

S. sLambda NOUT EDRO? RSIZE UCF LCRate LocWidth NPTS

$1.000 \mathrm{E}-022.000 \mathrm{E}-00 \quad 1.000 \mathrm{E}-00$ L.000E-00. $1.000 \mathrm{E}-0.0 .000 \mathrm{E}-00 \quad 1.000 \mathrm{E}-001.300 \mathrm{E}-01$

\$ I ambda01 I ambda02 Lambda03 Lambda04 Lambda05 Lambda06 Lambda07 Lambda08

$0.000 \mathrm{E}-00$ 8.000E-06 2.400E-05 4.000E-05 5.600E-05 7.200E-05 8.800E-05 3.200E-04

5. Lambda09. I ambda10 Lambda11 Lambda12 Lambda13 B3 AOY A1Y

$5.200 \mathrm{E}-045.700 \mathrm{E}-04$ 1.000E-00 1.000E-01 1.000E-10 1.150E-00 1.495E-03.6.250E-01

$5 \mathrm{Eta01} \mathrm{Eta02}_{\mathrm{ta}} \mathrm{Eta03} \mathrm{Eta04} \mathrm{Eta05} \mathrm{Eta06}$ Eta07 Eta08

0.000E-00 8.500E-01 9.700E-0:9.900E-01 1.000E-00 9.900E-01 9.700E-01 5.000E-01

5 Eta09 Eta10 Etal1 Exa012 Eta13 B2 A2F A2Y

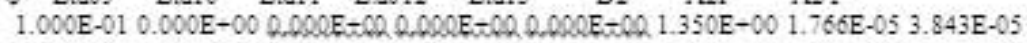

5 EOS-8 CARDS

5 Generated EOS 8 (Tabulated Compaction)

-EOS_Tabulated_Compaction

$\$$ EŌSID Gamma EO Volo $80.000 \mathrm{E}-00$ Q, $000 \mathrm{E}-00.1000 \mathrm{E}-00$

3. VolStrain01 VolStrain02 VolStrain03 VolStrain 04 VolStrain05

$0.00000000 \mathrm{E}-00-1.50000000 \mathrm{E}-03-4.30000000 \mathrm{E}-03-1.01000000 \mathrm{E}-02-3.05000000 \mathrm{E}-02$

S. VolStrain 06 VolStrain 07 Volstrain 08 VolStrain 09 Volstrainio

$-5.13000000 \mathrm{E}-02-7.26000000 \mathrm{E}-02-9.43000000 \mathrm{E}-02-1.74000000 \mathrm{E}-01-2.08000000 \mathrm{E}-01$

5 Pressure01 Pressure 02 Pressure 03 Pressure04 Pressure05

$0.00000000 \mathrm{E}-00.3 .33260791 \mathrm{E}-03 \quad 7.26508525 \mathrm{E}-03 \quad 1.16641277 \mathrm{E}-04 \quad 2.21618426 \mathrm{E}-04$

$\$$ Preasure06 Prassure07 Prasure08 Pressure09 Pressure10

$3.34260574 \mathrm{E}-04.4 .74230106 \mathrm{E}-047.25508743 \mathrm{E}-04 \quad 4.23574466 \mathrm{E}-05 \quad 6.47858979 \mathrm{E}-05$

5 Multipliers of Gamma*E

$.0000000000-00,0000000000 \mathrm{E}-00.000000000 \mathrm{E}-00$

$.000000000 \mathrm{E}-00.0000000000 \mathrm{E}-00.0000000000 \mathrm{E}-00$

5 Bulk:nid01 Bulk:nid02 Bulk:nid03 Bulk:Unld04 Bulk:Unld05

$2.22173861 \mathrm{E}-06,222173861 \mathrm{E}-0.6 \quad 2.25284295 \mathrm{E}-06 \quad 2.36615162 \mathrm{E}-06 \quad 2.81494282 \mathrm{E}-06$

Figure D-5: Input Parameters Generated by Concrete Damage Model Release 3 for High-Strength Concrete 


\begin{tabular}{|c|c|c|c|c|c|c|c|c|}
\hline $\begin{array}{l}* \mathrm{Mi} \\
\$ \$ \\
\$\end{array}$ & 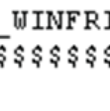 & $\begin{array}{l}\text { TH_CONCRE } \\
\$ \$ \$ \$ \$ \$ \$ \$ \$\end{array}$ & $\begin{array}{l}\text { TE } \\
\$ \$ \$ \$ \$ \$ \$ \$ \$ \$ \\
\text { Mater }\end{array}$ & $\begin{array}{l}\$ \$ \$ \$ \$ \$ \$ \$ \$ \\
\text { ial Defin }\end{array}$ & $\begin{array}{l}\text { \$\$\$\$\$ } \\
\text { ions }\end{array}$ & \$\$\$\$\$\$\$\$ & \$\$\$\$\$\$\$\$ & $\$ \$ \$ \$ \$ \$ \$ \$$ \\
\hline \multirow[t]{2}{*}{ \$\# } & mid & ro & $\mathrm{tm}$ & pr & ucs & uts & fe & asize \\
\hline & 1 & $2.2460 \mathrm{E}-4$ & $3.6000 \mathrm{E}+6$ & 0.180000 & 11600.00 & 700.00000 & $2.0000 E-4$ & 0.125000 \\
\hline \multirow[t]{2}{*}{ \$\# } & e & ys & eh & uelong & rate & conm & conl & cont \\
\hline & 0.000 & 0.000 & 0.000 & 0.000 & 1.000000 & -1.000000 & 0.025400 & 1.000000 \\
\hline \multirow[t]{2}{*}{ \$\# } & eps1 & eps2 & eps3 & eps4 & eps5 & eps 6 & eps7 & eps8 \\
\hline & 0.000 & 0.000 & 0.000 & 0.000 & 0.000 & 0.000 & 0.000 & 0.000 \\
\hline \multirow[t]{2}{*}{ \$\# } & p1 & p2 & p3 & p4 & p5 & p 6 & p7 & p8 \\
\hline & 0.000 & 0.000 & 0.000 & 0.000 & 0.000 & 0.000 & 0.000 & 0.000 \\
\hline
\end{tabular}

Figure D-6: Input Parameters for Winfrith Concrete Model for High-Strength Concrete

\begin{tabular}{|c|c|c|c|c|c|c|c|c|}
\hline \multicolumn{8}{|c|}{ *MAT UINFRITH CONCRETE } & 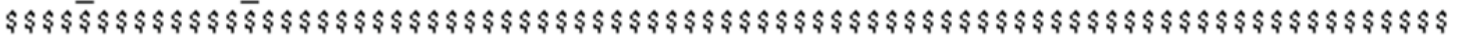 \\
\hline$\$$ & & & Mater & ial Defini & itions & & & \\
\hline \multirow[t]{2}{*}{ \$\# } & mid & ro & $\operatorname{trm}$ & pr & ucs & uts & fe & asize \\
\hline & 1 & $2.2460 \mathrm{E}-4$ & $3.6000 \mathrm{E}+6$ & 0.180000 & 5000.0000 & 462.00000 & $2.0000 \mathrm{E}-4$ & 0.125000 \\
\hline \multirow[t]{2}{*}{ \$\# } & e & ys & eh & uelong & rate & conm & conl & cont \\
\hline & 0.000 & 0.000 & 0.000 & 0.000 & 1.000000 & -1.000000 & 0.025400 & 1.000000 \\
\hline \multirow[t]{2}{*}{ \$\# } & eps1 & eps2 & eps3 & eps4 & eps5 & eps 6 & eps7 & eps8 \\
\hline & 0.000 & 0.000 & 0.000 & 0.000 & 0.000 & 0.000 & 0.000 & 0.000 \\
\hline \multirow[t]{2}{*}{ \$\# } & $\mathrm{p} 1$ & p2 & p3 & $\mathrm{p} 4$ & p5 & p 6 & p7 & p8 \\
\hline & 0.000 & 0.000 & 0.000 & 0.000 & 0.000 & 0.000 & 0.000 & 0.000 \\
\hline
\end{tabular}

Figure D-7: Input Parameters for Winfrith Concrete Model for Normal-Strength Concrete

\begin{tabular}{|c|c|c|c|c|c|c|c|}
\hline \multicolumn{8}{|c|}{ "MAT PLASTIC_KINEMATIC } \\
\hline$\$ \#$ & mid & ro & e & pr & sigy & etan & beta \\
\hline & 2 & $7.3000 E-4$ & $2.9000 \mathrm{E}+7$ & 0.300000 & 83000.000 & 0.000 & 0.000 \\
\hline \multirow[t]{2}{*}{$\$ \#$} & $\operatorname{src}$ & $\operatorname{srp}$ & fs & $\mathrm{vp}$ & & & \\
\hline & 0.000 & 0.000 & 0.000 & 0.000 & & & \\
\hline
\end{tabular}

Figure D-8: Input Parameters for Plastic-Kinematic Model for High-Strength Concrete

\begin{tabular}{|c|c|c|c|c|c|c|c|}
\hline \multicolumn{8}{|c|}{ "MAT_PLASTIC_KINEMATIC } \\
\hline \multirow[t]{2}{*}{$\$ \#$} & mid & ro & e & pr & sigy & etan & beta \\
\hline & 2 & $7.3000 \mathrm{E}-4$ & $2.9000 \mathrm{E}+7$ & 0.300000 & 60000.000 & $2.9000 \mathrm{E}+6$ & 0.000 \\
\hline \multirow[t]{2}{*}{ \$\# } & $\operatorname{src}$ & $\operatorname{srp}$ & fs & $\mathrm{vp}$ & & & \\
\hline & 0.000 & 0.000 & 0.000 & 0.000 & & & \\
\hline
\end{tabular}

Figure D-9: Input Parameters for Plastic-Kinematic Model for High-Strength Concrete 


\begin{tabular}{|c|c|c|c|c|c|c|c|c|}
\hline \multicolumn{9}{|c|}{ "CONSTRAINED_LAGRANGE_IN_SOLID } \\
\hline & 2 & 1 & 1 & 1 & 0 & 2 & 0 & 0 \\
\hline \multirow[t]{4}{*}{ \$ } & 2 & 1 & 1 & 1 & 0 & 4 & & \\
\hline & 0.000 & 0.000 & 0.000 & 0.000 & 0.000 & 0 & 0 & 0.000 \\
\hline & 0.000 & 0.000 & 0.000 & 0 & 0.000 & 0 & 0 & 0 \\
\hline & 0 & 0 & 0 & 0 & 0.000 & 0 & 0.000 & \\
\hline
\end{tabular}

Figure D-10: Input Parameters for Constrained Lagrange in Solid Formulation

\begin{tabular}{|rrrrrrrrr|}
\hline \multicolumn{2}{|c}{ "MAT_ADD_EROSION } & & & & & & \\
\$\# & mid & exc1 & mxpres & mneps & effeps & voleps & numfip & ncs \\
& 1 & 0.000 & 0.000 & 0.000 & 0.000 & 0.000 & 1.000000 & 1.000000 \\
\$\# mnpres & sigp1 & sigrm & mxeps & epssh & sigth & impulse & failtm \\
& 0.000 & 0.000 & 0.000 & 0.010000 & 0.000 & 0.000 & 0.000 & 0.000 \\
\hline
\end{tabular}

Figure D-11: Input Parameters for Mat Add Erosion Model 


\section{REFERENCES}

1. Mlakar Sr, P., et al., The Oklahoma City bombing: Analysis of blast damage to the Murrah Building. Journal of Performance of Constructed Facilities, 1998. 12: p. 113.

2. (DoD), D.o.D., Unified facilities criteria (UFC), DoD minimum antiterrorism standards for buildings. Department of Defense, UFC 4-010-01, 2007.

3. Committee, A.o.B.M.T., Protecting Buildings from Bomb Damage - Transfer of Blast-Effects Mitigation Technologies from Military to Civilian Applications. National Research Council, 1995.

4. LSDYNAV970, 971 Keyword manual Vol. 1 and Vol. 2, . Livermore Software Technology Corporation, Livermore, CA.

5. Crawford, J. and S. Lan, Design and Implementation of Protective Technologies for Improving Blast Resistance of Buildings, in Enhancing Building Security Seminar Proceedings. 2005: Singapore.

6. Hao, D.U.a.L., Zhongxian, Numerical Analysis of Dynamic Behavior of RC slabs Under Blast Loading. Transactions of Tianjin University, 2008. 15(1): p. 61-64.

7. Mosalam, K.M. and A.S. Mosallam, Nonlinear Transient Analysis of Reinforced Concrete Slabs Subjected to Blast Loading and Retrofitted with CFRP Composites. Composites Part B: Engineering, 2001. 32(8): p. 623-636.

8. $\quad$ Ågårdh, L., Finite element modeling of fibre reinforced concrete slabs subjected to blast load. Le Journal de Physique IV, 1997. 7(C3): p. 3-3.

9. Kuang, X., et al., Numerical Simulation for Responses of Reinforced Concrete Slabs under Blast Loads. Computational Structural Engineering Journal, 2009: p. 691-698.

10. El-Dakhakhni, W.W., W.F. Mekky, and S.H.C. Rezaei, Validity of SDOF Models for Analyzing Two-Way Reinforced Concrete Panels under Blast Loading. Journal of Performance of Constructed Facilities, 2010. 24(4): p. 311-325. 
11. Schwer, L. and L. Malvar, Simplified Concrete Modeling with MAT_CONCRETE_DAMAGE_REL3, in JRI LS-DYNA User Week. 2005: LSDYNA Anwenderforum, Bamberg.

12. Tanapornraweekit, G., et al. Modelling of a Reinforced Concrete Panel Subjected to Blast Load by Explicit Non-linear Finite Element Code. in Proceedings of the Earthquake Engineering 2007. Australia.

13. Zhou, X., et al., Numerical prediction of concrete slab response to blast loading. International Journal of Impact Engineering, 2008. 35(10): p. 1186-1200.

14. Broadhouse, B., The Winfrith Concrete Model in LS-DYNA3D. Report: SPD/D (95), Impact, Fire and Blast Department, Winfrith Technology Center, Dorset, UK, 1993: p. 339-344.

15. Gebbeken, N. and M. Ruppert, A new material model for concrete in high-dynamic hydrocode simulations. Archive of Applied Mechanics, 2000. 70(7): p. 463-478.

16. Low, H.Y. and H. Hao, Reliability analysis of reinforced concrete slabs under explosive loading. Journal of Structural Safety, 2001. 23(2): p. 157-178.

17. Hallquist, J.O., D.W. Stillman, and T.L. Lin, LS-DYNA3D users manual. LSTC Report, Livermore, CA, 1994. Vol. 1007.

18. Kadambi Vasudevan, A., Finite element analysis and experimental comparison of doubly reinforced concrete slabs subjected to blast loads. 2012, UNIVERSITY OF MISSOURI-KANSAS CITY.

19. LSDYNAV970, 971 Keyword manual Vol. 1 and Vol. 2, . Livermore Software Technology Corporation.

20. Hallquist, J.O., LS-DYNA theory manual. Livermore Software Technology Corporation, 2006. 3.

21. Kong, S., A. Remennikov, and B. Uy, Numerical simulation of the response of noncomposite steel-concrete-steel sandwich panels to impact loading. Australian Journal of Structural Engineering. 12(3): p. 211-224. 
22. Hibbitt, Karlsson, and Sorensen, ABAQUS theory manual. 1998: Hibbitt, Karlsson \& Sorensen.

23. Kosloff, D. and G.A. Frazier, Treatment of Hourglass Patterns in Low Order Finite Element Codes. International journal for numerical and analytical methods in geomechanics, 2005. Vol. 2(1): p. 57-72.

24. Wilkins, M.L., Use of artificial viscosity in multidimensional fluid dynamic calculations. Journal of Computational Physics, 1980. 36(3): p. 281-303.

25. Ottosen, N.S., A failure criterion for concrete. Journal of the Engineering Mechanics Division, 1977. 103(4): p. 527-535.

26. Schwer, L., The Winfrith Concrete Model: Beauty or Beast? Insights into the Winfrith Concrete Model. $8^{\text {th }}$ European LS-DYNA Users Conference, 2011.

27. Wittmann, F., et al., Fracture energy and strain softening of concrete as determined by means of compact tension specimens. Materials and structures, 1988. 21(1): p. 21-32.

28. Broadhouse, B. and G. Attwood, Finite element analysis of the impact response of reinforced concrete structures using dyna3d, in SMiRT-12, K. Kussmaul, Editor. 1993, Elsevier Science Publishers, B.V. p. 339-344.

29. Magallanes, J.M., et al. Recent Improvements to Release III of the $K \& C$ Concrete Model. in 11th International LS-DYNA Users Conference. 2010.

30. Malvar, L.J., et al., A Plasticity Concrete Material Model for DYNA3D. International Journal of Impact Engineering, 1997. 19(9-10): p. 847-873.

31. Hallquist, J.O., LS-DYNA theory manual. Livermore Software Technology Corporation, Livermore, CA, 2006. Vol. 3. 
Gunjan Ashok Shetye was born in Mumbai, in the state of Maharashtra, India on November 16, 1988. She joined University of Mumbai's Sardar Patel College of Engineering to pursue her Civil Engineering Studies. She was awarded the Bachelor of Engineering degree from University of Mumbai in May, 2010.

Gunjan joined University of Missouri - Kansas City (UMKC) in the fall term of 2010 to pursue her Master's degree in Civil Engineering. She started working as a Graduate Research and Teaching Assistant in Civil and Mechanical Engineering Department since Fall 2010. She pursued her research interests in the field of finite-element analysis of reinforced concrete slabs subjected to blast loading in the Computational Mechanics Laboratory (UMKC) with Dr. Ganesh Thiagarajan. She is currently pursuing practical training as a Structrual Engineer with Black and Veatch in Overland Park, Kansas.

Upon completion of her degree requirements, Gunjan plans to continue her career in field of Structural Engineering and to pursue research interests. 